GISELLE DE SOUZA LEITE PINTER

PADRÕES MORFOLÓGICOS DE TRONCO, RAÍZES E CASCA EXTERNA DE ÁRVORES EMERGENTES E DE DOSSEL DE FLORESTA OMBRÓFILA DENSA NO PARQUE ESTADUAL “CARLOS BOTELHO”, SP

São Paulo, SP - Brasil

2008 
GISELLE DE SOUZA LEITE PINTER

PADRÕES MORFOLÓGICOS DE TRONCO, RAÍZES E CASCA EXTERNA DE ÁRVORES EMERGENTES E DE DOSSEL DE FLORESTA OMBRÓFILA DENSA NO PARQUE ESTADUAL “CARLOS BOTELHO”, SP

Dissertação apresentada ao Instituto de Biociências da Universidade de São Paulo, para obtenção do título de Mestre em Ciências, na área de Botânica.

Orientador: Prof. Dr. PAULO TAKEO SANO

São Paulo, SP - Brasil

2008 
Ficha catalográfica

Pinter, Giselle de Souza Leite

Estudos de padrões morfológicos de tronco, raízes e casca externa de árvores emergentes e de dossel da floresta ombrófila densa no Parque Estadual "Carlos Botelho", SP

Dissertação (mestrado), Instituto de Biociências da Universidade de São Paulo. Departamento de Botânica.

1. floresta ombrófila densa. 2. parcelas permanentes. 3 . morfologia vegetal. I. Universidade de São Paulo. Instituto de Biociências. Departamento de Botânica.

\section{COMISSÃO JULGADORA}


Dedico àqueles que, ao olharem uma árvore, vêem algo além de sua espécie. 


\section{AGRADECIMENTOS}

Agradeço de todo o meu coração

A Deus, que existe em mim e em tudo e todos à minha volta.

Às árvores, que permitiram conhecê-las e me conhecer com uma profundidade positivamente assustadora.

Ao Prof. Dr. Paulo Sano, que acreditou no meu potencial, me orientando com respeito às minhas limitações e meu ritmo.

Ao Prof. Dr. Vinícius Castro Souza, que me orientou nos primeiros passos deste projeto.

Ao Renato Augusto Lima, que me apresentou à Parcela e pela enorme contribuição na identificação das árvores juntamente com Natália Macedo Ivanauskas.

Ao Herbert pela carinhosa disponibilidade em discutir sobre meu projeto dando valiosas sugestões.

Ao Leonardo por gentilmente presentear-me com seu talento nos esquemas das árvores enriquecendo este trabalho.

Aos colegas que me ajudaram na realização deste projeto e pela companhia nos herbários da ESALQ e USP.

À FAPESP, pelo apoio logístico que me permitiu uma melhor dedicação ao projeto.

Ao programa de Pós-Graduação em Botânica da USP, pela oportunidade de realização do mestrado.

À diretoria e aos funcionários do Parque Estadual "Carlos Botelho", pelo apoio, amizade e infra-estrutura oferecida.

À Alice e à Carla, pela nutrição no percurso espiritual.

Às minhas grandes amigas Val, Gláucia, Ana, Sílvia, Dani, Mirela, Cássia e Cris, pelas trocas e pelos presentes que me fortaleceram nesta caminhada.

À Rita e ao Khel, pela enorme amizade e calorosa acolhida em Piracicaba.

Aos meus irmãozinhos: Carol, Lets, Mogli, Redondo, Raoni, Cássio, Chacal, Érica e Marquinhos.

À família Pinter, que me acolheu de braços abertos em seu ninho.

A meus pais e irmãos, por serem tão importantes na construção do que sou desde o berço.

Ao meu marido, hoje e sempre. 
Pensar em Deus é desobedecer a Deus,

Porque Deus quis que o não conhecêssemos, Por isso se nos não mostrou...

Sejamos simples e calmos,

Como os regatos e as árvores,

E Deus amar-nos-á fazendo de nós

Belos como as árvores e os regatos,

E dar-nos-á verdor na sua primavera,

E um rio aonde ir ter quando acabemos! ...

Alberto Caeiro 


\section{SUMÁRIO}

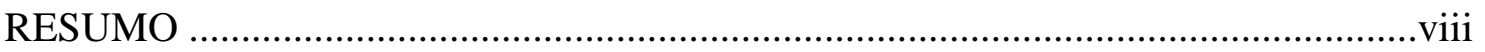

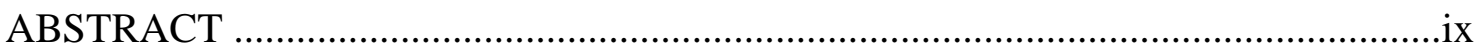

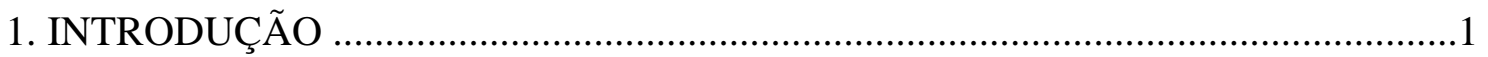

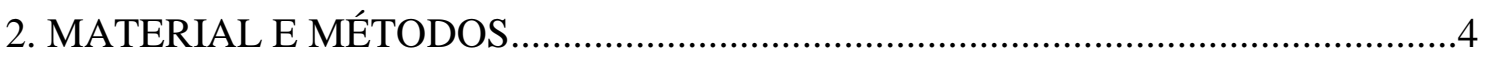

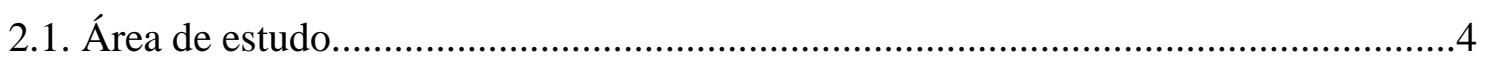

2.2. Instalação da Parcela Permanente.........................................................................

2.3. Levantamento das espécies................................................................................6

2.4. Caracteres observados..............................................................................6

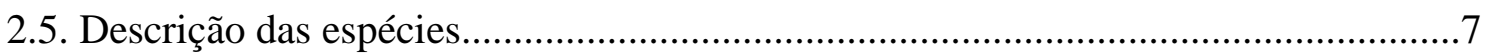

2.6. Produção do Guia Ilustrado de Identificação..............................................................

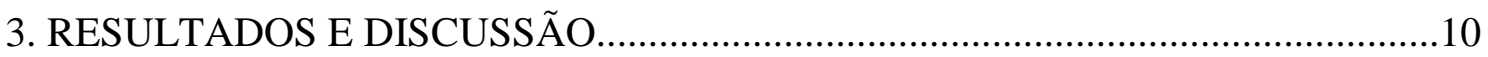

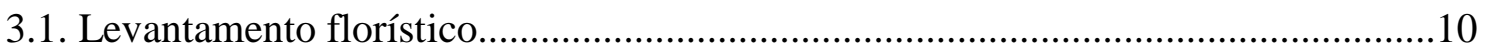

3.2. Analise dos padrões morfológicos...................................................................12

3.2.1. Tronco

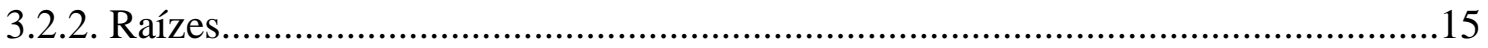

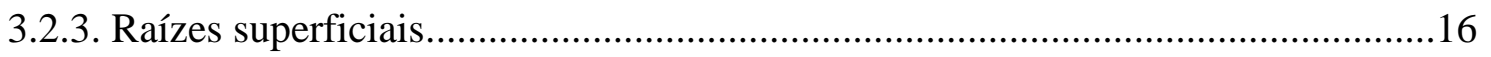

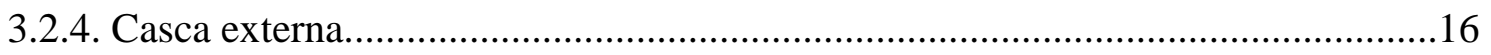

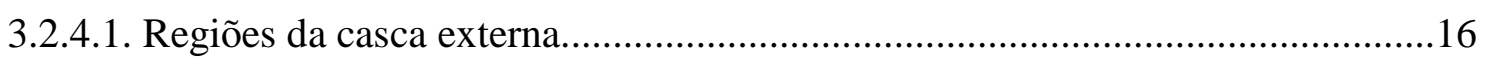

3.2.4.2. Caracteres observados na casca externa............................................................17

3.2.4.3. Estados dos caracteres observados na casca externa...........................................18

3.2.4.4. Padrões encontrados para a casca externa......................................................20

3.3 Chave de identificação para espécies emergentes e de dossel da Parcela

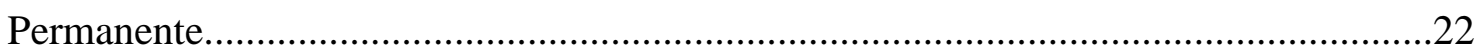

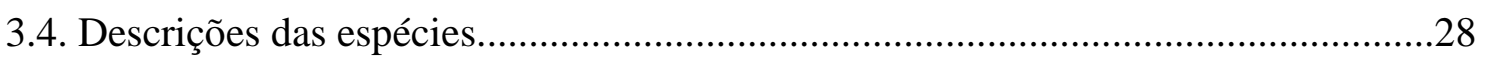

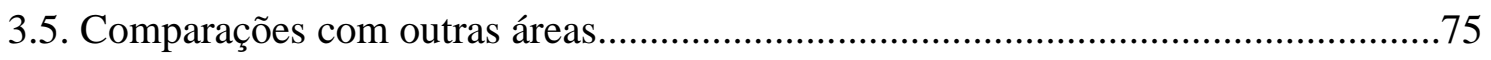

3.5.1. Tronco

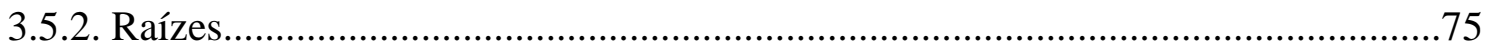

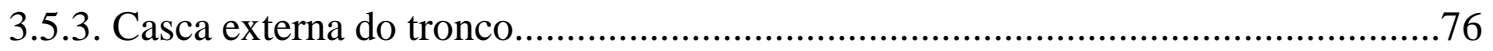

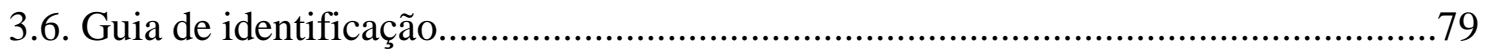

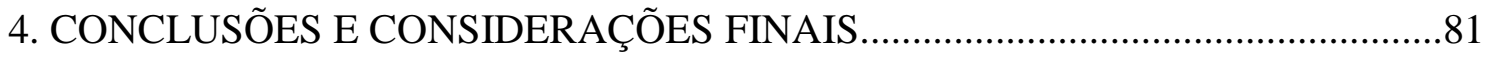

5. IMPRESSÕES FINAIS: Términos e novos começos.................................................83

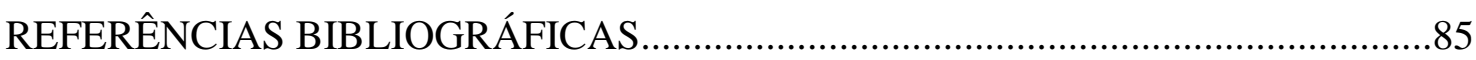




\section{PADRÕES MORFOLÓGICOS DE TRONCO, RAÍZES E CASCA EXTERNA DE ÁRVORES EMERGENTES E DE DOSSEL DE FLORESTA OMBRÓFILA DENSA NO PARQUE ESTADUAL “CARLOS BOTELHO”, SP}

\section{RESUMO}

Árvores emergentes e de dossel da Floresta Ombrófila Densa Sub-montana de uma Parcela Permanente (10,24ha) no Parque Estadual "Carlos Botelho", SP, foram estudadas e descritas morfologicamente considerando padrões de tronco, raízes e casca externa com a finalidade de auxiliar na identificação de campo. $\mathrm{O}$ critério de inclusão (DAP igual ou superior a $48 \mathrm{~cm}$ ) abrangeu 324 indivíduos de 64 espécies pertencentes a 36 famílias. São fornecidas descrições, ilustrações e chave de identificação para as espécies estudadas baseadas em características do tronco à altura do peito e da base; das raízes aparentes e rentes ao tronco; das raízes superficiais; e das texturas da casca externa nas regiões da árvore mencionadas. Considerando que não há uma terminologia padrão para descrição dos caracteres estudados, é proposta aqui uma nomenclatura, além de serem utilizados termos propostos por Torres et al. (1994) e Ribeiro et al. (1999), com adaptações para as variações observadas no local de estudo. O tronco foi diferenciado em cilíndrico ou acanalado, com base reta ou dilatada. As raízes variaram entre digitadas e sapopemas. Foram categorizados 13 padrões básicos de textura da casca externa: liso, áspero, sujo, rugoso, fissurado, fendido, lenticelado, reticulado, com placas, escamoso, laminado, variegado e com depressões. O uso de terminologia padronizada na descrição de características de tronco, raízes e casca permite sua aplicação e comparação com dados de estudos desenvolvidos em diferentes regiões, sendo importante ressaltar sua utilização aliada a outros caracteres da planta para uma identificação mais eficiente. 
MORPHOLOGIC PATTERNS OF TRUNK, ROOTS AND OUTER BARK OF

EMERGENT AND CANOPY TREES OF DENSE OMBROPHYLLOUS FOREST IN “CARLOS BOTELHO” STATE PARK, SP

\begin{abstract}
Emergent and canopy trees of lowmontane dense ombrophyllous forest in a permanent plot (10,24ha) in "Carlos Botelho" State Park, SP, were studied and morphologically described. Trunk, roots and outer bark patterns were considered in order to make field identification easier. A total of 324 trees, 64 species and 36 families were included $(\mathrm{DAP} \geq 48 \mathrm{~cm})$ and analyzed. We provide descriptions, figures and an identification key based on the following features: trunk at breast high; trunk base; apparent roots; superficial roots; and texture of outer bark. Since there is not a standard morphological nomenclature for these patterns, we propose a nomenclature here, besides using those terms proposed by Torres et al. (1994) and Ribeiro et al. (1999) with some adaptations. Trunk are named terete or angular, straight or with an expanded base. Roots are named digitated or buttressed. Thirteen basic patterns of outer bark texture were named: entire, rough, messy, rugose, fissured, cracked, lenticellate, reticulate, flaky, scaly, laminate, variegated and dippled. Using this terminology allows its application and comparison with data from different areas. They should be used with other features, reproductive and vegetative ones, in order to allow a correct identification.
\end{abstract}




\section{INTRODUÇÃO}

As principais formações florestais existentes no Estado de São Paulo são as Formações Pioneiras com Influência Marinha (Floresta de Restinga), a Floresta Ombrófila Densa (Floresta Atlântica de Encosta), a Floresta Estacional Semidecídua e a Savana Florestada (Cerradão). No intuito de ter à disposição dados sobre áreas que abordassem uma diversidade significativa de variáveis físicas e vegetacionais (solo, topografia, pluviosidade, composição florística, estrutura, etc.), para estudos ecológicos nas mais diversas áreas do conhecimento, o projeto temático "Diversidade, Dinâmica e Conservação em Florestas do Estado de São Paulo: 40ha de Parcelas Permanentes", vinculado ao Biota/FAPESP, alocou Parcelas Permanentes em quatro Unidades de Conservação que representam tais formações: Parque Estadual Ilha do Cardoso, Parque Estadual "Carlos Botelho", Estação Ecológica dos Caetetus e Estação Ecológica de Assis.

Mostrando quais espécies compõem determinada comunidade e como as várias formas de vida estão estruturadas pode-se compreender a relação de interdependência dos indivíduos e destes com o ambiente. Pagano \& Leitão-Filho (1987) destacam a importância de estudos florísticos e fitossociológicos para tentar explicar as variações existentes em áreas relativamente próximas, e quais fatores estariam condicionando tais mudanças.

Nas florestas tropicais, uma série de dificuldades é apresentada ao realizar estudos florísticos, como sua elevada riqueza, o não-florescimento de várias espécies durante o período de execução dos trabalhos de campo e o grande porte dos indivíduos. De Rosayro (1953) já apontava a importância do registro de características de campo para auxiliar na identificação das espécies por ser aplicável à maioria das condições de campo numa tentativa de superar tais dificuldades.

Acessar ramos de indivíduos de grande porte é uma difícil tarefa na Floresta Ombrófila Densa, onde o dossel ultrapassa os $15 \mathrm{~m}$. A tesoura de alta poda (podão) podão normalmente não atinge a altura, escalar é uma possibilidade onerosa e sujeita a riscos e o intricado das copas muitas vezes dificulta definir qual copa pertence à árvore em questão, mesmo com o auxílio de binóculos. Sendo a coleta de ramos reprodutivos a principal fonte de informações florísticas e diante das dificuldades já mencionadas, outra estratégia para reconhecimento das espécies de grande porte é aqui investigada. 
As partes mais facilmente acessíveis de árvores de dossel e emergentes estão na base da planta: o tronco, as raízes aparentes rentes ao tronco e as raízes superficiais, que içam paralelas ao solo. $\mathrm{O}$ formato de tais partes e a casca que as revestem pode variar entre espécies diferentes.

Comparada com outras estruturas vegetais, a casca tem sido relativamente pouco estudada, apesar de seu uso como critério de identificação de árvores (Yunus \& Yunus, 1990), bem como a forma do tronco e das raízes. Caracteres vegetativos variam muito mais que caracteres reprodutivos, principalmente no que se refere à formação da casca e das raízes. Indivíduos de uma mesma espécie frequentemente variam quanto à apresentação da casca e das raízes segundo a idade (Saa, 1967) e o clima (Yunus \& Yunus, 1990). As poucas descrições de casca publicadas muitas vezes adotam critérios subjetivos, dificultando o desenvolvimento dos estudos e o estabelecimento de uma nomenclatura uniforme. Apesar de tais problemas, características da casca combinadas a outros caracteres vegetativos são de grande valia na identificação das árvores (Saa, 1967; Yunus \& Yunus, 1990; Torres et al., 1994; Gartland et al., 2002) podendo, inclusive, acelerar o processo de identificação (Junikka, 1994).

A ilustração é muito importante para expressar os aspectos observados em troncos, raízes e cascas por fornecer, com maior fidelidade, a idéia expressa pela nomenclatura proposta, aproximando do que é visto em campo. Tais informações tornam-se ainda mais importantes no contexto de disponibilizar os resultados ao público não-especialista. Atualmente, tem-se tornado cada vez mais freqüente a confecção de guias de campo, que têm por objetivo facilitar o reconhecimento das espécies para pessoas interessadas no assunto, mas não necessariamente habituadas à terminologia técnica própria da botânica. Nesse contexto, e no âmbito do Projeto Parcelas Permanentes, já foi publicado o Guia de Identificação de Árvores da Restinga (Sapaio et al.,2005).

Com relação ao conhecimento florístico, na Parcela Permanente do Parque Estadual "Carlos Botelho" (PECB) houve um esforço anterior a este trabalho, que visou um levantamento florístico prévio. Tal trabalho, não publicado, resultou de um esforço conjunto de alguns pesquisadores e, nele foram incluídos indivíduos com DAP maior ou igual a 4,8cm e buscou-se a identificação das espécies por meio de ramos reprodutivos. Para isso, muitas árvores altas foram identificadas por meio de uso de binóculos, acarretando imprecisão e incerteza no reconhecimento das espécies. 
O presente trabalho, além de buscar contribuir para um maior conhecimento florístico da área, propondo correções no levantamento florístico anterior, tem por objetivo principal apresentar os padrões morfológicos observados a partir da base de árvores emergentes e de dossel em uma parcela permanente do PECB, região de Floresta Ombrófila Densa, utilizando uma nomenclatura específica e objetiva, proposta em outros trabalhos com adaptações para as peculiaridades dos padrões encontrados. Tem, também, o objetivo de prover um Guia Ilustrado para árvores emergentes e de dossel do PECB, utilizando, em sua identificação, características vegetativas do tronco e das raízes. 


\section{MATERIAL E MÉTODOS}

\section{1. Área de estudo}

O Parque Estadual “Carlos Botelho” (PECB) localiza-se a sul do Estado de São Paulo (Figura 1), nas coordenadas geográficas $24^{\circ} 00^{\prime}$ a $24^{\circ} 15^{\prime} \mathrm{S}$ e $47^{\circ} 55^{\prime}$ a $48^{\circ} 05^{\prime} \mathrm{W}$. Com área total de 37.793,63ha, engloba parte dos municípios de São Miguel Arcanjo, Capão Bonito e Sete Barras, com altitudes que variam de 30 a 1003 m (Domingues \& Silva, 1988; Negreiros et al., 1995). Preservado como Unidade de Conservação desde 1941 e como Parque Estadual desde 1982, possui a maior parte de sua cobertura vegetal representada por florestas não perturbadas ou com perturbações pouco significativas.

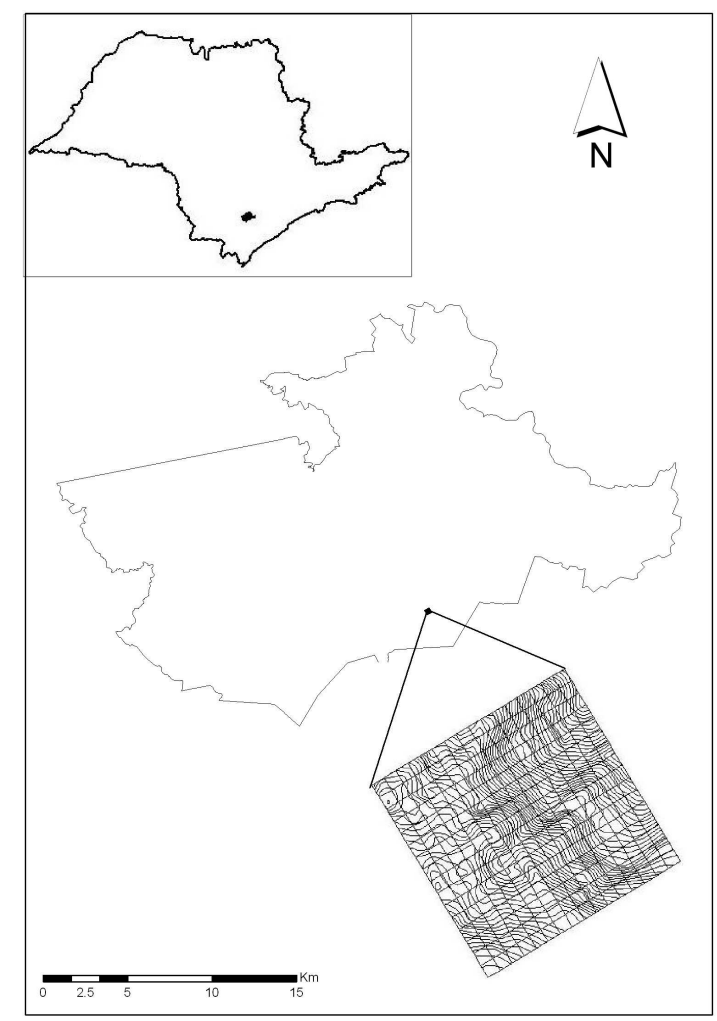

Figura 1. Mapa do Parque Estadual "Carlos Botelho" e localização da Parcela Permanente com indicação das subparcelas e curvas de nível. Fonte: Laboratório de Geoprocessamento e Sensoriamento Remoto, Centro de Métodos Quantitativos, LCF-ESALQ/USP

Nesta área há duas unidades geomorfológicas: o Planalto de Guapiara, drenado pelos rios que formam a bacia hidrográfica do Rio Paranapanema, e a Serra de 
Paranapiacaba, drenada pelos ribeirões Travessão, Temível e da Serra e pelos Rios Preto e Quilombo, que são formadores da bacia do Rio Ribeira de Iguape. Predominam no Parque as rochas graníticas, configurando um relevo altamente acidentado, associado aos elevados índices pluviométricos e definem morfogênese acelerada nas médias e altas vertentes, acumulando material nos sopés e canais fluviais (Domingues \& Silva, 1988).

Este relevo encontra-se associado a dois tipos climáticos diferentes, segundo a classificação de Köeppen (1948): a) clima quente úmido sem estiagem (Cfa), que ocupa áreas do Planalto de Guapiara com altitudes inferiores a $800 \mathrm{~m}$, a média e a baixa escarpa da Serra de Paranapiacaba, possuindo temperaturas inferiores a $18^{\circ} \mathrm{C}$ no mês mais frio e superiores a $22^{\circ} \mathrm{C}$ no mês mais quente, sendo o total pluviométrico do mês mais seco superior a $30 \mathrm{~mm}$; b) clima temperado úmido sem estiagem $(\mathrm{Cfb})$, nas partes mais elevadas da Serra de Paranapiacaba, diferindo do anterior apenas pela temperatura média do mês mais quente, que não ultrapassa $22^{\circ} \mathrm{C}$ (Setzer, 1946).

No Parque, foi descrita a ocorrência de solos Hidromórficos e Podzólicos Vermelho-Amarelo “intergrade” Latossolo Vermelho-Amarelo (Camargo et al., 1987). Eles se caracterizam por possuir elevados teores de matéria orgânica e de alumínio, baixos teores de bases trocáveis e acidez elevada como a maioria dos solos da região serrana do litoral do Estado (Negreiros, 1982).

No PECB ocorre a floresta atlântica de encosta (Veloso \& Góes Filho, 1982), onde foram realizados levantamentos por Custódio Filho et al. (1992) e Moraes (1992, 1993) e trabalhos fitossociológicos por Dias (1993), Negreiros (1982) e Negreiros et al. (1995). Para este estudo, foi escolhido um trecho no núcleo Sete Barras, com altitude em torno de 300m, na vertente atlântica da Serra de Paranapiacaba, tendo o ponto A00 nas coordenadas 202.827,9263 e 7.322.585,2885 em UTM no datum SAD69 (Fig. 1).

\subsection{Instalacão da Parcela Permanente}

A Parcela Permanente, onde foi desenvolvido o presente estudo, foi alocada pelo projeto temático "Diversidade, Dinâmica e Conservação em Florestas do Estado de São Paulo: 40ha de Parcelas Permanentes". Tal projeto abrange quatro áreas: Floresta Ombrófila Densa, Floresta de Restinga, Floresta Estacional Semidecidual e Cerradão, situadas respectivamente no Parque Estadual "Carlos Botelho", Parque Estadual da Ilha do Cardoso, Estação Ecológica de Caetetus e Estação Ecológica de Assis. Nestas áreas, 
parcelas de 10,24ha foram divididas em 256 sub-parcelas de 20x20m, nas quais foram plaqueados todos os indivíduos arbóreos com DAP (diâmetro a altura do peito) igual ou superior a $4,8 \mathrm{~cm}$.

A alocação da parcela maior e das sub-parcelas em cada área foi feita por equipe especializada em topografia, usando teodolito de alta precisão. Tanto a parcela como as sub-parcelas foram delimitadas com estacas permanentes. Em cada um dos quatro vértices da parcela permanente foram construídas marcações de $1,5 \mathrm{~m}$ de altura (3/4" de diâmetro), havendo também marcações internas nas sub-parcelas. Esta mesma equipe topográfica foi responsável pela marcação, numeração e mapeamento dos indivíduos.

\subsection{Levantamento das espécies}

Foram incluídas árvores com DAP igual ou superior a $48 \mathrm{~cm}$. São indivíduos de grande porte que atingem ou ultrapassam o dossel, cujos ramos foram coletados por escaladores com esporão ou com estilingue. Registros fotográficos da base do tronco, raízes e detalhes da casca externa foram feitos para facilitar a interpretação dos formatos e estruturas analisados utilizando uma câmera fotográfica digital Nikon Coolpix 995.

\subsection{Caracteres observados}

Entre os caracteres utilizados para descrição e diferenciação dos indivíduos emergentes e de dossel estão:

- formato do tronco à altura do peito;

- formato da base do tronco;

- formato das raízes, aquelas que são aparentes e rentes ao tronco;

- presença de raízes superficiais, aquelas que içam paralelas ao solo;

- textura da casca externa (ou ritidoma) das regiões acima mencionadas.

Apesar de a casca poder ser diferenciada em a) externa, que dá a aparência superficial, e b) interna, visível com um corte no caule, como apontado por Rizzini (1971), neste trabalho, foram abordadas exclusivamente características da casca externa, uma vez que o estudo da casca interna requer que sejam feitos cortes na planta, o que pode aumentar a probabilidade de infecção por patógenos.

A inclusão de árvores com DAP igual ou superior a $48 \mathrm{~cm}$ direciona o estudo a árvores mais velhas, diminuindo a variação no padrão da casca de indivíduos de uma 
mesma espécie pelas diferenças de idade. Sendo árvores de uma mesma área, as diferenças segundo o clima e o ambiente também diminuem.

Não existindo uma nomenclatura padrão para descrição de casca externa, foram utilizados termos propostos em diversos trabalhos, principalmente de Torres et al. (1994) e Ribeiro et al. (1999), com adaptações para as variações observadas no local de estudo, como será detalhado em Resultados e Discussão, além da proposta de novos conceitos.

\subsection{Descrição das espécies}

As descrições baseam-se exclusivamente em caracteres vegetativos, mais especificamente do tronco, da raiz e da casca.

A descrição inicia-se pelas características do tronco: DAP, coloração, formato do tronco à altura do peito, formato da base.

Segue-se a descrição da raiz: digitada ou sapopema, simples ou ramificada, formato da aresta, relação e dimensão dos comprimentos "a" e "b", espessura da raiz.

Foi medido o comprimento da raiz rente ao tronco, denominado comprimento "a", o comprimento rente ao solo, comprimento "b" (Fig. 2). A relação entre comprimento "a" e comprimento " $b$ " foi observada como: $a=b, a>b$ ou $a<b$. Quando o comprimento "b" não ultrapassa $30 \mathrm{~cm}$, o tronco é descrito como levemente digitado. Em alguns casos, os dígitos projetam-se suavemente do tronco, não apresentando nitidamente um comprimento "a", sendo dispensada esta medida (ex: Hymenaea courbaril, Fig. 23A). A espessura da raiz foi medida na metade da aresta a $5 \mathrm{~cm}$ de profundidade.

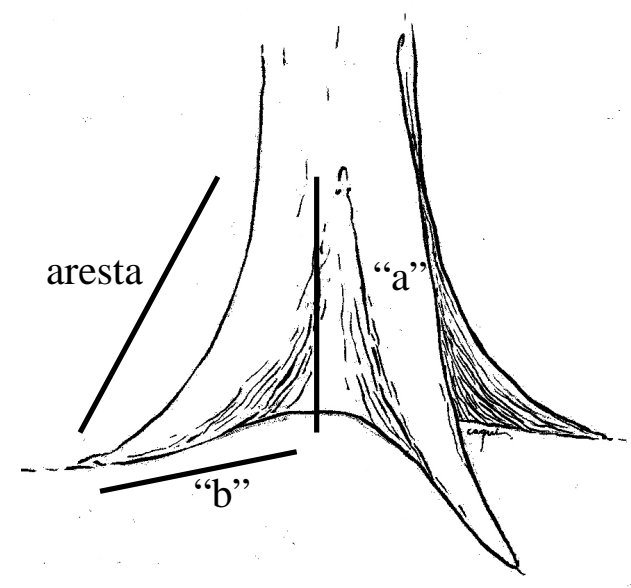

Figura 2. Diagrama demonstrando a aresta e os comprimentos "a" e "b" da raiz. 
Se a raiz superficial é numericamente abundante, muito grossa ou apresenta alguma característica importante para sua identificação, tal característica é referida depois da descrição da raiz.

Para a casca externa, foi elaborada uma descrição de cada região e diferenciada sua textura. Inicialmente é referida a nomenclatura específica do padrão encontrado, seguida das especificações das estruturas, como medidas de comprimento, largura, espessura ou profundidade, distância entre as estruturas e sua disposição na casca. Quando elementos de desprendimento (placas e lâminas) estão presentes, são descritas a superfície e a impressão deixada.

Quando em uma mesma região são observados diferentes padrões, eles são numerados. Havendo um padrão mais característico para a espécie, cobrindo maior parte da superfície e/ou presente em todos os indivíduos, é denominado padrão principal.

Nos comentários, encontra-se detalhada a relação entre os diferentes padrões de casca, se são encontrados isoladamente, isto é, em diferentes áreas de um mesmo indivíduo para a região descrita, ou em sobreposição, podendo também estar presentes em indivíduos diferentes de uma mesma espécie.

Também constam, nos comentários, peculiaridades observadas no tronco, nas raízes, folhas, frutos ou flores presentes no solo. São também mencionadas as características que facilitam a identificação, como diferenciar a espécie descrita de espécies semelhantes.

\subsection{Producão do Guia Ilustrado de Identificacão}

Entre as espécies incluídas no estudo, foram selecionadas, para inclusão no Guia, apenas árvores que apresentaram um padrão típico dos caracteres analisados para a espécie. Foi elaborada uma breve diagnose, intitulada "Dica de Campo", com ênfase nas características capazes de auxiliar no seu reconhecimento prático. Também foram feitas chaves dicotômicas de identificação, baseadas exclusivamente nas características analisadas do tronco, raízes e casca externa e uma descrição simplificada para cada espécie.

Partindo destas informações e dos registros fotográficos foi elaborado o Guia Ilustrado de Identificação para Árvores de Dossel e Emergentes amostradas na Parcela 
Permanente do PECB (ANEXO I). Eventualmente ilustrações de folhas e frutos encontrados no solo foram adicionadas por mostrarem-se úteis na confirmação da identificação. 


\section{RESULTADOS E DISCUSSÃO}

\subsection{Levantamento florístico}

O levantamento florístico revelou a existência de 64 espécies arbóreas com indivíduos com DAP igual ou superior a $48 \mathrm{~cm}$, pertencentes a 36 famílias. A lista das espécies levantadas, em ordem alfabética por família, acompanhada pelo número de indivíduos de dossel são apresentados na Tabela 1. Das 324 árvores analisadas, certa de $16 \%$ foram incorretamente identificadas no levantamento florístico anterior.

Tabela 1. Lista de espécies emergentes e de dossel (DAP igual ou superior a $48 \mathrm{~cm}$ ) encontradas em uma Parcela Permanente de 10,24ha de floresta ombrófila densa baixo montana no Parque Estadual "Carlos Botelho", município de Sete Barras - SP; n.d. = número de indivíduos emergentes e dossel; DAP = diâmetro à altura do peito, em centímetros.

\begin{tabular}{|c|c|c|}
\hline Família/Espécie & n.d. & $\mathbf{D A P}(\mathbf{c m})$ \\
\hline \multicolumn{3}{|l|}{ ANACARDIACEAE } \\
\hline Tapirira guianensis Aubl. & 3 & $50-66$ \\
\hline \multicolumn{3}{|l|}{ APOCYNACEAE } \\
\hline Aspidosperma parvifolium A. DC. & 4 & $52-76$ \\
\hline Malouetia arborea (Vell.) Miers. & 2 & $48-70$ \\
\hline \multicolumn{3}{|l|}{ ARALIACEAE } \\
\hline Oreopanax capitatus (Jacq.) Decne. \& Planch. & 1 & 58 \\
\hline \multicolumn{3}{|l|}{ BIGNONIACEAE } \\
\hline Tabebuia serratifolia (Vahl) G. Nicholson & 2 & $56-76$ \\
\hline \multicolumn{3}{|l|}{ BURSERACEAE } \\
\hline Protium widgrenii Engl. & 1 & 70 \\
\hline \multicolumn{3}{|l|}{ CANELLACEAE } \\
\hline Capsicodendron dinisii (Schw.) Occh. & 5 & $48-63$ \\
\hline \multicolumn{3}{|l|}{ CARICACEAE } \\
\hline Jacaratia spinosa (Aubl.) A. DC. & 1 & 80 \\
\hline \multicolumn{3}{|l|}{ CELASTRACEAE } \\
\hline Maytenus robusta Reiss. & 1 & 53 \\
\hline \multicolumn{3}{|l|}{ CHRYSOBALANACEAE } \\
\hline Parinari brasiliensis (Schott) Hook. f. & 7 & $49-88$ \\
\hline \multicolumn{3}{|l|}{ COMBRETACEAE } \\
\hline Buchenavia kleinii Exell & 6 & $52-120$ \\
\hline \multicolumn{3}{|l|}{ ELAEOCARPACEAE } \\
\hline Sloanea guianensis (Aubl.) Benth. & 23 & $50-143$ \\
\hline \multicolumn{3}{|l|}{ EUPHORBIACEAE } \\
\hline Alchornea triplinervia (Spreng.) Müll. Arg. & 5 & $52-105$ \\
\hline Croton macrobothrys Baill. & 2 & $54-67$ \\
\hline Pera glabrata (Schott) Poepp. ex Baill. & 1 & 50 \\
\hline Tetrorchidium rubrivenium Poepp. & 3 & $54-74$ \\
\hline \multicolumn{3}{|l|}{ FABACEAE (Caesalpinioideae) } \\
\hline Copaifera trapezifolia Hayne & 6 & $65-91$ \\
\hline Hymenaea courbaril $\mathrm{L}$. & 11 & $61-110$ \\
\hline
\end{tabular}

FABACEAE (Faboideae) 


\section{Família/Espécie}

Centrolobium robustum (Vell.)Mart. ex Benth.

Platymiscium floribundum Vogel

Pterocarpus rohrii Vahl

Swartzia acutifolia Vogel

Zollernia ilicifolia (Brongn.) Vogel

FABACEAE (Mimosoideae)

Pseudopiptadenia warmingii (Benth.) G.P. Lewis \& M.P. Lima

HUMIRIACEAE

Vantanea compacta (Schnizl.) Cuatrec.

LAURACEAE

Cryptocarya moschata Nees. \& C. Mart.

Nectandra membranacea (Sw.) Griseb.

Ocotea catharinensis $\mathrm{Mez}$

Ocotea mosenii Mez

LECYTHIDACEAE

Cariniana estrellensis (Raddi) Kuntze

MAGNOLIACEAE

Magnolia ovata (A. St.-Hil.) Spreng.

MALVACEAE

Quararibea turbinata (Sw.) Poir.

MELIACEAE

Cabralea canjerana (Vell.) Mart.

Cedrela fissilis Vell.

MORACEAE

Brosimum lactescens (S. Moore) C.C. Berg.

Ficus luschnathiana (Miq.) Miq.

MYRISTICACEAE

Virola bicuhyba (Schott ex Spreng.) Warb.

MYRTACEAE

Campomanesia guaviroba (DC.) Kiaersk.

Eugenia cambucarana Kiaersk.

Eugenia capitulifera $\mathrm{O}$. Berg

Eugenia cereja D. Legrand

Eugenia cf. burkartiana (D. Legrand) D. Legrand

Eugenia multicostata D. Legrand

Eugenia subavenia O. Berg

Marlierea suaveolens Cambess.

Myrcia pubipetala Miq.

NYCTAGINACEAE

Pisonia ambigua Heimerl

OLACACEAE

Heisteria silvianii Schw.

Tetrastylidium grandifolium (Baill.) Sleumer.

PHYLLANTHACEAE

Hyeronima alchorneoides Fr. Allem.

PHYTOLACCACEAE

Phytolacca dioica $\mathrm{L}$.

POLYGONACEAE

Coccoloba fastigiata Meisn.

PROTEACEAE

Roupala brasiliensis $\mathrm{Kl}$.

RUBIACEAE

Simira corumbensis (Standl.) Steyerm. n.d.

\section{DAP(cm)}

52-65

$49-116$

49-73

66-72

55-68

7

60-135

2

52-73

23

48-110

56-105

73

117-141

49-61

50-60

53

53-155

53-56

62-74

55

31

48-105

2

51-66

50-70

49

58

62

53

48

50-53

50-64

50-72

54-62

52-74

40

48-140

3

100-117

1

62

67

13 


\section{SABIACEAE}

n.d.

Meliosma sellowii Urb.

SALICACEAE

Casearia obliqua Spreng.

SAPINDACEAE

Matayba guianensis Aubl.

SAPOTACEAE

Chrysophyllum inornatum Mart.

Chrysophyllum viride Mart. \& Eichl.

Ecclinusa ramiflora Mart.

Pouteria caimito (Ruiz \& Pav.) Radlk.

Pouteria psammophila (Mart.) Radlk.

Pradosia lactescens (Vell.) Radlk.

URTICACEAE

Coussapoa microcarpa (Schott) Rizzini
DAP(cm)

55

$52-60$

58

53-57

51-96

66

$65-68$

60

$52-62$

As espécies mais representativas em número de indivíduos foram Hyeronima alchorneoides (12,35\%), Virola bicuhyba (9,57\%), Sloanea guianensis e Cryptocarya moschata $(7,10 \%)$ e Chrysophyllum viride (6,79\%). Vinte espécies apresentaram apenas um indivíduo de grande porte.

As famílias com maior riqueza foram Myrtaceae (14,06\%), Sapotaceae (9,37\%), Fabaceae (Faboideae) (7,81\%), Euphorbiaceae e Lauraceae (6,25\%). Apesar da maior riqueza, Myrtaceae apresentou poucos indivíduos por espécie no dossel com DAP, em geral, não muito grande.

\subsection{Analise dos padrões morfológicos}

A partir da observação e análise morfológica de todos os indivíduos em campo, foram detectados padrões para os caracteres encontrados. Tais padrões são descritos e agrupados da seguinte maneira:

\subsubsection{Tronco}

Os formatos do tronco à altura do peito foram classificados segundo o desenho formado pelo corte transversal. Quando as sapopemas atingem comprimento acima da altura do peito, o formato do tronco é analisado logo acima das sapopemas.

Cilíndrico (Ribeiro et al., 1999) - quando o tronco tende a um formato arredondado (Fig. 3A; Pranchas 1A; 2A; 5A; 6A; 8A; 9A; 10A; 15A; 12A; 17A; 18A; 
19A; 21A; 24A; 25C; 27A; 29A; 30A; 35A; 33A; 34A; 35A; 36A; 37A; 42A; 43A; 46A; 47A; 48A; 50A; 56A; 62A; 64A).

Acanalado (Ribeiro et al., 1999) - com depressões longitudinais formando canais ou sulcos, acompanhando o diâmetro do tronco, formando cristas e vales (Fig 3B; Pranchas 3A; 4A; 7A; 13A; 14A; 15A; 16A; 20A; 22A; 23A; 25A; 26A; 28A; 32A; 33C; 38A; 39A; 40A; 41A; 44A; 45A; 49A; 51A; 52A; 53A; 54A; 55A; 57A; 58A; 59A; 60A; 61A; 63A). Os sulcos podem ser rasos ou profundos. É denominado levemente acanalado quando os sulcos são muito rasos ou quando presentes apenas $1 \mathrm{ou}$ 2 sulcos. Quando o formato do tronco acanalado estende-se além da altura do peito, é denominado inteiramente acanalado.
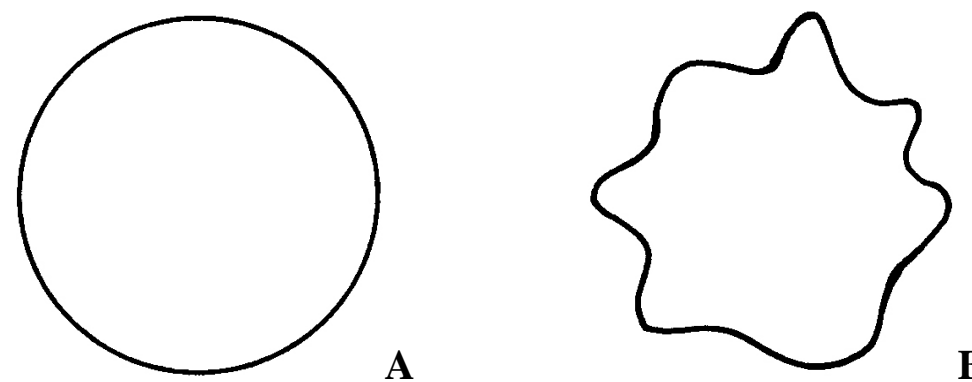

Figura 3. Formato do tronco: A. cilíndrico; B. acanalado.

Trinta e três espécies apresentaram tronco cilíndrico, sendo que, destes, cinco apresentaram também tronco levemente acanalado, foram elas: Copaifera trapezifolia, Hymenaea courbaril, Vantanea compacta, Tetrastylidium grandifolium e Phytolacca dioica. Em Copaifera trapezifolia e Hymenaea courbaril esta diferença variou segundo o porte: tronco cilíndrico em indivíduos de menor porte $(<75 \mathrm{~cm}$ DAP) e tronco levemente acanalado, com sulcos rasos, em indivíduos de maior porte (>75cm DAP).

Base do tronco acanalado foi encontrada em 17 espécies. Destes, cinco apresentaram o tronco levemente acanalado Croton macrobothrys, Ocotea catharinensis, Coccoloba fastigiata, Roupala brasiliensis e Matayba guianensis.

Tronco inteiramente acanalado foi encontrado em 9 espécies: Oreopanax capitatus, Pera glabrata, Tetrorchidium rubrivenium, Simira corumbensis e Chrysophyllum inornatum e 4 espécies de Myrtaceae (Campomanesia guaviroba, Eugenia cambucarana, E. capitulifera e Marlierea suaveolens).

Os dois tipos de tronco (cilíndrico e acanalado) foram observados em cinco espécies: Aspidosperma parvifolium, Malouetia arborea, Cryptocarya moschata, 
Cabralea canjerana e Pradosia lactescens. Em Cabralea canjerana, o tronco apresentou formato cilíndrico em indivíduos que estiveram sujeitos, aparentemente, a alguma doença, pois tinham o tronco coberto por cicatrizes proeminentes, cilíndricas, justapostas, o centro estava oco e apresentavam muitos rebrotos.

Com relação à forma de sua base, os troncos foram classificados em:

Reto (Ribeiro et al., 1999) - quando não há diferença na largura do tronco à altura do peito até a base (Fig. 4A; Pranchas 3A; 7A; 8A; 14A; 15A; 17A; 25A; 25C; 30A; 34A; 48A; 58A; 60A).

Dilatado (Ribeiro et al., 1999) - o tronco é mais largo rente ao solo (Figs. 4B; 52A; 56A).

O formato da base pode ser definido também pela presença de raízes aparentes (vide item 3.2.2.).

$$
\mid
$$
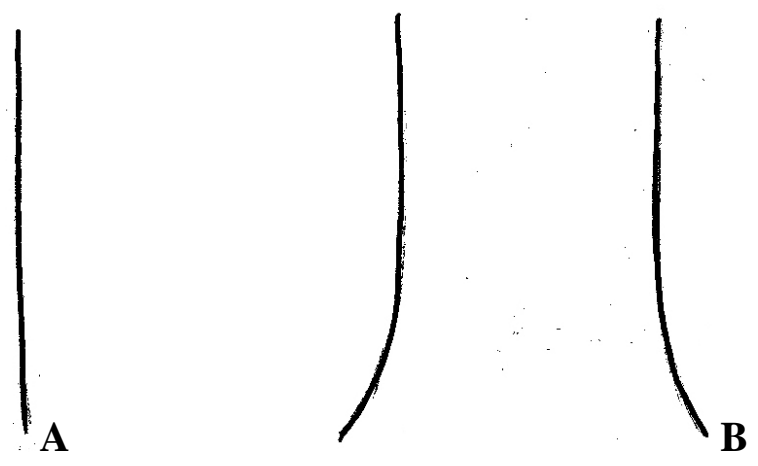

Figura 4. Diagrama da base do tronco: A. reta; B. dilatada.

A base do tronco reta foi encontrada em 14 espécies. Destas, cinco apresentaram também outro tipo de forma de base. Capsicodendron dinisii e Pera glabrata apresentaram também base levemente digitada. Ao atingir maior porte ( $>75 \mathrm{~cm}$ DAP), Copaifera trapezifolia e Hymenaea courbaril apresentaram raízes digitadas. Myrcia pubipetala apresentou também base levemente digitada, raízes digitadas e sapopemas.

Apenas 2 espécies apresentaram base do tronco dilatada, Pisonia ambigua e Phytolacca dioica (Prancha. 57A, 51A), sendo que, nesta última, a dilatação pode atingir grandes proporções.

Outros elementos observados no tronco, importantes para a identificação foram:

Rebrotos - nascem do tronco, como em Cabralea canjerana (Prancha. 33C) ou da raiz, como em Sloanea guianensis. São comuns em Sloanea guianensis, Vantanea 
compacta, Nectandra membranacea, Ocotea mosenii, Cabralea canjerana, Campomanesia guaviroba, Eugenia cereja, E. multicostata, Marlierea suaveolens, Chrysophyllum inornatum e Pradosia lactescens. Foi medido o diâmetro a $20 \mathrm{~cm}$ da base do rebroto. Os rebrotos com maior diâmetro foram encontrados em Sloanea guianensis e Nectandra membranacea.

Cicatrizes - marcas proeminentes (geralmente acima de $3 \mathrm{~cm}$ de espessura) com base cilíndrica ou elíptica, superfície arredondada configurando formato quase esférico (Figs.). Essas cicatrizes proeminentes são encontradas com freqüência em troncos com rebrotos. Somente Hyeronima alchorneoides e Alchornea triplinervea não apresentaram nenhum indivíduo com rebroto, apesar das freqüentes cicatrizes proeminentes. Existem também cicatrizes lineares, com cerca de $3 \mathrm{~cm}$ de espessura encontradas em Parinari brasiliensis, muito características para a espécie, estando presentes em todos os indivíduos estudados (Prancha. 10A).

\subsubsection{Raízes}

Os formatos das raízes aparentes localizadas rente ao tronco variaram entre:

Digitadas (Ribeiro et al., 1999) - pequenas projeções digitiformes onde as raízes superficiais unem-se ao tronco (Prancha. 5A; 9A; 10A; 13A; 18A; 19A; 20A; 22A; 26A; 27A; 28A; 31A; 32A; 33A; 35A; 38A; 40A; 41A; 43A; 44A; 45A; 49A; 52A; 53A; 54A; 55A; 57A; 59A; 61A; 63A).

Sapopemas (Ribeiro et al., 1999) - extensões achatadas, tabulares, da parte superior das raízes superficiais (do tupi-guarani, "raiz chata") (Pranchas. 1A; 4A; 6A; 11A; 12A; 16A; 21A; 23A; 24A; 29A; 36A; 37A; 39A; 42A; 46A; 50A; 56A).

As sapopemas e dígitos podem ser simples (Pranchas. 1A; 4A; 6A; 12A; 16A; 23A; 24A; 36A; 37A; 39A; 46A; 56A) ou ramificados (Pranchas. 11A; 21A; 29A; 42A) (Ribeiro et al., 1999), com ramificações proximais ou distais em relação ao tronco. Entre as raízes digitadas, são mais comuns raízes não-ramificadas (simples).

A aresta da sapopema pode ser reta (Figs. 9A; 11A; 16A; 17A; 26A; 34A; 42A; 47A), côncava (Figs. 6A; 21A; 28A; 41A; 44A; 61A) ou convexa (Ribeiro et al., 1999). Em alguns casos, apenas a região distal apresentou-se côncava e foi classificada como reta por assim se apresentar na maior extensão da raiz. O mesmo é feito quando a concavidade é muito suave. Dezenove espécies apresentaram raízes com aresta reta, 17 com aresta côncava e 7 apresentaram estes dois formatos de aresta. Raízes com arestas 
convexas foram observadas em casos isolados, em alguns indivíduos de Buchenavia kleinii e Ocotea mosenii, não caracterizando as espécies como um todo.

Algumas árvores digitadas eventualmente apresentam sapopemas, o que ocorreu principalmente em Cryptocarya moschata. Além disso, não é raro que um mesmo indivíduo apresente raízes digitadas e sapopemas. Nestes casos, a descrição refere a forma mais frequiente das raízes na árvore.

\subsubsection{Raízes superficiais}

Em algumas espécies, as raízes superficiais (Ribeiro et al., 1999), que içam paralelas ao solo (Fig. 5H), foram numericamente abundantes e/ou de importante auxílio na identificação devido à sua forma e à textura da casca (Jacaratia spinosa, Maytenus robusta, Pseudopiptadenia warmingii, Cariniana estrellensis, Hyeronima alchorneoides e Chrysophyllum viride, Figs. 13C; 14C; 29C; 35C; 55C; 64D).

\subsubsection{Casca externa}

\subsubsection{1 $\underline{\text { Regiões da casca externa }}$}

As descrições da casca externa foram feitas em diferentes regiões da superfície da árvore (Fig. 5):

Tronco - superfície ao redor do tronco à altura do peito. Em alguns indivíduos as sapopemas ultrapassam a altura do peito em todas as faces do tronco (comum em Sloanea guianensis). Não sendo possível observar a casca nesta região, foi muito importante, nestes casos, a observação da casca da raiz. Em geral, a casca do tronco foi o caráter de maior importância para a identificação das árvores.

Crista do tronco - porção mais externa do tronco acanalado.

Vale do tronco - região do sulco do tronco acanalado.

Base - porção mais próxima ao solo, em caso de troncos dilatados.

Raiz - superfície lateral das sapopemas e raízes digitadas.

Crista da raiz - porção mais externa da raiz.

Vale da raiz - região de encontro, no tronco, entre duas raízes.

Raízes superficiais - raízes que içam sobre o solo a certa distância do tronco. 

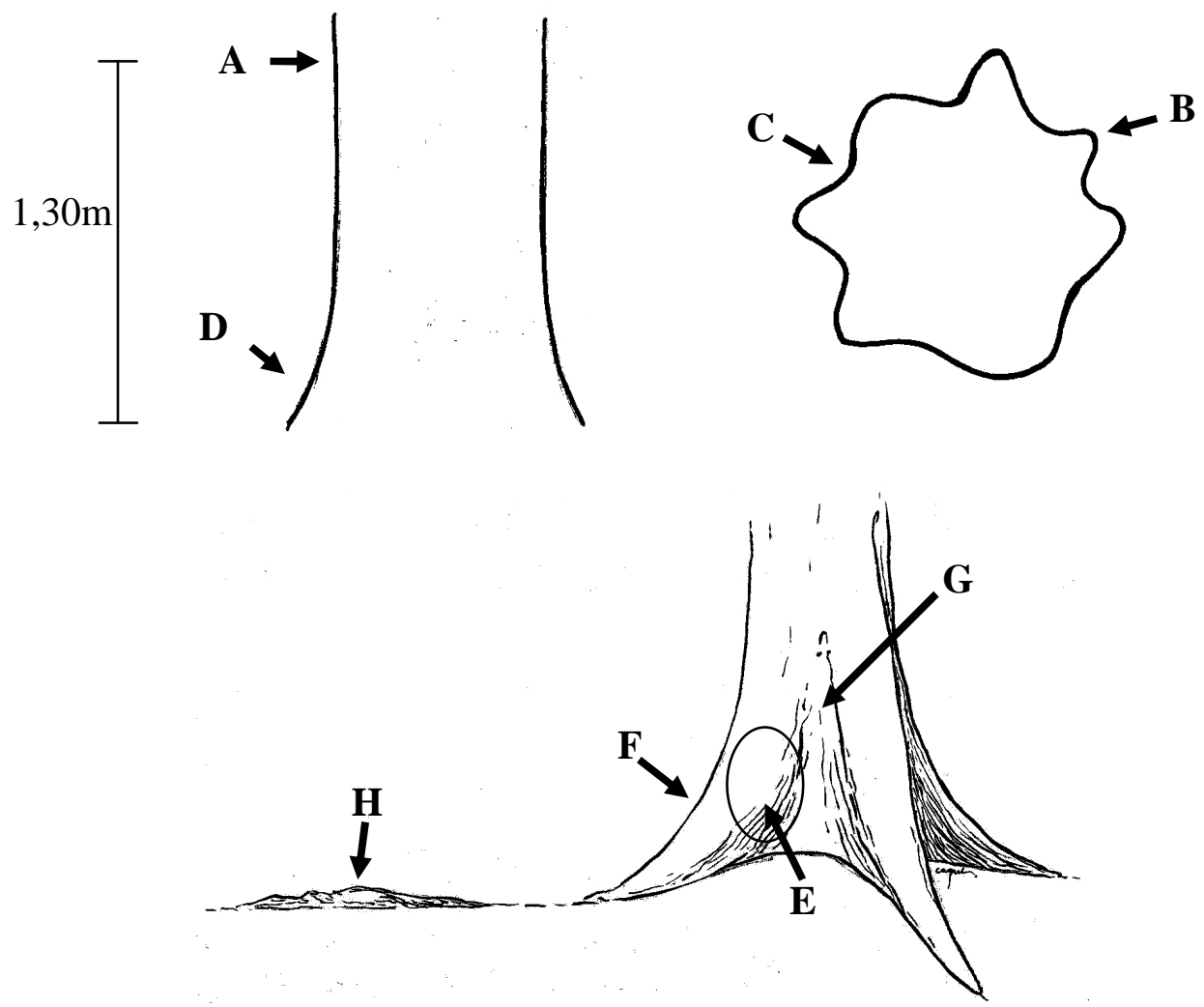

Figura 5. Regiões onde foram observadas as cascas externas. A. casca do tronco; B. casca da crista do tronco; C. casca do vale do tronco; D. casca da base; E. casca da raiz; F. casca da crista da raiz; G. casca do vale da raiz; $H$. casca da raiz superficial.

\subsubsection{Caracteres observados na casca externa}

Os caracteres encontrados na casca foram:

Fissuras (Ribeiro et al., 1999) - sulcos alongados, em "V" no corte transversal (Pranchas. 1B; 10D; 11B; 30B; 31C; 33D; 34B; 37B; 48B; 52C; 63B).

Fendas (Ribeiro et al., 1999) - fissuras com fundo plano (Pranchas. 1C; 5B; 10C; 16B; 16C; 19C; 22C; 30C; 32B; 32C; 37C; 51B).

Domos (Gartland et al., 2002) - é a porção da casca delimitada por fissuras e fendas.

Microfissuras - fissuras que possuem largura e profundidade igual ou inferior a 1mm (Pranchas. 2C; 3C; 10E; 15C; 19B; 28B; 38C; 41C; 48B; 50C; 58B).

Ranhuras - fissuras justapostas com largura e profundidade de 1-2mm (Pranchas.11C). 
Estrias (Ribeiro et al., 1999) - fissuras com fundo discolor (Pranchas. 12C). Podem ser formadas também por lenticelas discolores, associadas a fissuras (Ribeiro et al., 1999) (ex: Jacaratia spinosa, Pranchas. 8B; 8C).

Depressões (Junikka, 1994) - sulcos formados por bordas circulares ou elípticas (Pranchas. 6B; 25D; 59B).

Ondulações - projeções alongadas que acompanhando o perímetro do tronco ou da raiz (Pranchas. 21B; 22B; 22C; 24B; 59C).

Calos - projeções de superfície arredondada, com base cilíndrica ou linear, que não acompanham todo o perímetro (Jacaratia spinosa, Prancha. 8B).

Acúleos (Ribeiro et al., 1999) - órgãos cilíndricos ou elípticos, pontiagudos, lenhosos, que se originam superficialmente, isto é, do córtex (Jacaratia spinosa, Prancha. 8B).

Lenticelas (Ribeiro et al., 1999) - aberturas que aparecem como pequenos pontos em relevo (Pranchas. 3B; 5B; 5C; 7B; 7C; 9C; 10B; 12B; 16B; 16C; 17B; 17C; 18B; 18C; 19B; 20B; 21B; 21C; 23B; 24C; 26B; 28C; 31B; 32B; 33B; 35B; 36B; 36C; 47B; 47C; 50B; 51C; 52B, 53C; 54B; 54C; 55B; 57B; 58C; 59D; 63B; 64B; 64C).

Placas (Ribeiro et al., 1999) - elemento de desprendimento lenhoso (Pranchas. $6 \mathrm{~B} ; 61 \mathrm{~B})$.

Lâminas (Ribeiro et al., 1999) - elemento de desprendimento com espessura inferior a 1mm (Prancha. 4B; 38B; 39B; 39C; 40B; 41B; 42C; 43B; 44B; 45B).

\subsubsection{Estados dos caracteres observados na casca externa}

Fissuras, fendas e microfissuras - são longitudinais ou transversais. Podem ser retas (paralelas entre si) (Pranchas. 1B; 5B; 10C; 10D; 10E; 11B; 19C; 33D; 34B; 38C; 41C; 48B; 50C; 51B; 52C; 63B) ou sinuosas (Pranchas. 15B; 22C; 37B) (podendo formar alvéolos (Pranchas. 30C; 32B; 37C)), as microfissuras podem, ainda, ser estreladas (quando se originam 3 de um ponto comum) (Pranchas. 2C; 28B). Muitas vezes, sulcos muito longos não apresentam limites nítidos, sendo denominados contínuos (Prancha. 38C). Quando não é possível observar se o fundo é plano ou em "V", neste caso, foi descrito como fissura. A textura do fundo é descrita quando visualizada. Muitas vezes abrem-se fendas muito largas de onde irradiam as raízes do tronco. 
Domos - geralmente são fixos. Sua superfície pode ser plana, côncava, convexa ou aguda.

Ranhuras - podem ser retas ou formar conjuntos sinuosos (Prancha. 11C). É possível observar o fundo, mas como são muito estreitas, não chegam a apresentar uma textura, embora sua coloração possa ser distinta do aspecto geral da casca.

Estrias - estão sempre dispostas longitudinalmente.

Depressões - quando de formato elíptico, podem ser longitudinais ou transversais.

Ondulações - geralmente transversais e retas, justapostas e de superfície convexa (Prancha. 59C). Podem ser longitudinais, principalmente nos vales entre sapopemas (ex: Eugenia cf. burkartiana, Prancha. 42A). A superfície pode ser aguda, como em Pterocarpus rorhii, Swartzia acutifolia e Pseudopiptadenia warmingii (Pranchas. 21B; 22B; 24B) e, neste caso, não são retas e formam arcos irregulares.

Calos e acúleos - são especificados quanto ao: formato da base, disposição transversal ou longitudinal (Prancha. 8B).

Lenticelas - sua coloração pode ser diferente da cor da matriz, sendo então denominadas discolores (Prancha. 6C; 7B; 7C; 17C; 18B; 18C; 21B; 28C; 29B; 29C; 32B; 47B; 47C; 59D; 64C). Se forem vistas apenas depois de uma observação muito atenta, são denominadas inconspícuas. Quando são proeminentes na casca, são tidas como verrucosas (termo adaptado de Torres et al., 1994) (Pranchas. 3B; 7B; 9C; 10B; 16B; 16C; 17C; 18B; 18C; 19C; 20B; 23B; 24C; 27B; 28C; 29B; 29C; 31B; 32B; 33B; 35B; 47B; 47C; 50C; 51C; 52B; 53C; 54B; 54C; 55B; 57B; 58C; 59D; 63C; 64C) e quando o rompimento da casca não é completo e as lenticelas permanecem cobertas por parte da casca, são denominadas não-verrucosas (Pranchas. 17B; 17C). Podem ser fixas, quando dificilmente destacáveis, ou descamantes, quando caem ao toque da mão. A abertura pode ser circular (Ribeiro et al., 1999), estrelada (Pranchas. 10B; 17B; 23B), em espocação (Ribeiro et al., 1999) (Pranchas. 18B; 20B; 24C; 27B; 28C; 29B; 29C; 47B; 47C; 51C; 55B), linear (Ribeiro et al., 1999) (Pranchas. 9C; 14B; 16B; 16C; 18C; 21C; 31B; 33B; 50C; 53C; 63C) ou não evidente (Ribeiro et al., 1999) (Pranchas. 3B; 7C; 17C; 21B; 35B; 52B). A abertura linear pode ser formada a partir de sucessivas camadas, sendo denominada estratificada, observada em Capsicodendron dinisii (Prancha. 7B). Quanto ao formato, podem ser arredondadas (Pranchas. 3B; 7B; 7C; 10B; 12B; 20B; 21B; 23B; 24C; 27B; 28C; 29B; 29C; 32C; 35B; 47B; 47C; 51C; 52B; 54B; 54C; 55C; 57B), elípticas (Pranchas. 18B; 24C; 28C; 50C; 55C; 58C; 59D; 64C) 
ou lineares (Pranchas. 9C; 14B; 16B; 16C; 19C; 21C; 31B; 33B; 58C; 63C) (Ribeiro et $a l .$, 1999). Quanto à distribuição, podem ser homogêneas (Pranchas. 3B; 6B; 6C; 24C; 27B), irregulares (Pranchas. 7B; 7C; 17C; 18B; 18C; 20B; 18C; 19C; 47B; 47C; 51C; 57B), em agrupamentos (Pranchas. 24B), em linhas longitudinais (Pranchas. 6C; 21B; 32B; 52C; 59D) ou transversais (Prancha. 9C) ou associadas a microfissuras (Pranchas. 14B; 16B; 19B; 21C; 31B) (Ribeiro et al., 1999). Em relação à quantidade, podem ser numerosas (Pranchas. 3B; 6B; 6C; 7B; 7C; 9C; 10B; 17B; 17C; 18B; 18C; 20B; 27B; 28C; 31B; 32B; 33B; 55B; 58C) ou esparsas (Pranchas. 23B; 47B; 47C), como proposto por Torres et al. (1994) e Junikka (1994). Quanto ao tamanho as lenticelas variam segundo o maior comprimento, podem ser pequenas (menos de 3mm), médias (3-5mm) ou grandes (mais de 5mm) (Junikka, 1994).

Placas - possuem formato retangular, arredondado, alongado ou irregular. A espessura pode diminuir do centro em direção às bordas, geralmente formando uma depressão ao descamar, como ocorre em Simira corumbensis. A superfície das placas pode ser plana, côncava, convexa, aguda ou ondulada. $\mathrm{Na}$ casca onde existem placas descamantes, muitas vezes é possível observar uma diferenciação na textura decorrente desta descamação, sendo denominada impressão da placa.

Lâminas - são placas muito finas e podem ser papiráceas (Pranchas. 4B; 38B; 39B; 39C; 40B; 41B; 44B) ou coriáceas (Pranchas. 42C; 43B; 45B) (Ribeiro et al., 1999). São consideradas esparsas quando a distância em geral é igual ou superior a $20 \mathrm{~cm}$.

Estratificada - quando os domos ou placas são formados a partir de sucessivas camadas de lâminas (Cedrela fissilis, Prancha. 34B) ou placas finas, sobrepostas, dando aparência de linhas justapostas a paredes de fissuras e fendas (Pranchas. 1B; 3C; 37C). Este termo também foi empregado para descrever a abertura de lenticelas características de Capsicodendron dinisii (Prancha. 7B).

\subsubsection{Padrões encontrados para a casca externa}

Alguns padrões da casca receberam nomenclatura específica, segundo a organização dos caracteres:

Lisa (Ribeiro et al., 1999) - quando não apresenta nenhuma forma de desprendimento, fissuras, lenticelas, rugosidades, cicatrizes ou outras características. 
Para árvores de grande porte da parcela estudada, foi encontrada apenas uma espécie com esta casca: Eugenia cf. burkartiana (Prancha. 42B). A impressão das lâminas coriáceas de E. multicostata é lisa (Prancha. 43B) e a casca do tronco, acima de $4 \mathrm{~m}$, é inteiramente lisa, de cor vermelha muito intensa.

Áspera (adaptado de Ribeiro et al., 1999) - apresenta algumas irregularidades em sua superfície, porém sem um padrão específico (Pranchas. 2C; 3C) ou pode ser formada por pequenas lenticelas inconspícuas (Pterocarpus rohrii, Pseudopiptadenia warmingii e Casearia obliqua, Figs. 21B; 24B; 56B). É freqüente em matriz, superfície, impressão e fundo de fendas. Geralmente é encontrada em associação com outros elementos, como em Campomanesia guaviroba e Eugenia capitulifera, que podem apresentar grande parte do tronco com esta textura, porém lâminas sempre estão presentes. Em Maytenus robusta, a casca do tronco, raiz e crista da raiz é áspera ou suja, porém sua identificação é possível por ser friável ao toque, além de as lenticelas da raiz superficial serem muito características. Em indivíduos de Virola bicuhyba com casca do tronco com esta textura, a identificação pode ser feita pela observação das fendas da casca da crista da raiz. É possível observar esta textura em raízes de Magnolia ovata, Campomanesia guaviroba, Eugenia cereja e em raízes superficiais de Sloanea guianensis, Alchornea triplinervea, Campomanesia guaviroba, Eugenia capitulifera, Eugenia multicostata, Chrysophyllum innornatum.

Suja (adaptado de Ribeiro et al., 1999) - neste padrão, as irregularidades são muito acentuadas e, embora possam apresentar estruturas como lenticelas, fendas ou alguma forma de desprendimento, essas não definem o padrão da casca, dando um aspecto de desorganização dificultando sua identificação (Pranchas. 9C; 25B; 49B). Embora Tetrastylidium grandifolium apresente esta textura, seu reconhecimento é fácil depois de algum tempo de campo.

Rugosa (Ribeiro et al., 1999) - formada por pequenas ondulações (1-3mm larg.) transversais, justapostas, normalmente envolvendo todo o perímetro do tronco ou da raiz (Pranchas. 12B; 12C; 29C; 47C; 53B; 54C; 56C; 57C). Em Matayba guianensis, a rugosidade da casca do tronco está organizada em faixas intercaladas com casca lenticelada (Prancha. 57B), porém é toda rugosa na crista da raiz e nas raízes superficiais.

Fissurada (Ribeiro et al., 1999) - quando as fissuras são mais conspícuas na definição do aspecto geral da casca e os domos são geralmente fixos (Pranchas. 10D; 11B; 30B; 33D; 52C; 63B). 
Fendida (Ribeiro et al., 1999) - quando as fendas são mais conspícuas no aspecto geral da casca e os domos são geralmente fixos (Pranchas. 1C; 4C; 5B; 10C; 30C; 32B; 32C; 51B).

Lenticelada (Ribeiro et al., 1999) - quando as lenticelas são mais importantes no aspecto geral da casca (Pranchas. 3B; 6B; 6C; 7B; 7C; 9C; 10B; 13B; 16B; 17C; 18B; 18C; 20B; 21B; 21C; 23B; 24C; 27B; 28C; 29B; 29C; 31B; 33D; 35B; 36B; 36C; 47B; 47C; 50C; 51C; 52B; 54B; 54C; 55B; 57B; 58C; 59D; 63C; 64B; 64C).

Reticulada (Ribeiro et al., 1999) - fissuras transversais e longitudinais delimitando pequenos quadrados ou retângulos, conferindo ao tronco um aspecto rendado (Centrolobium robustum e Heisteria silvianii, Pranchas. 19B; 48B). Há casos em que as lenticelas são numerosas, muito próximas e organizadas de modo a dar, no conjunto, este mesmo aspecto rendado (Copaifera trapezifolia, Prancha. 17B).

Escamosa (Ribeiro et al., 1999) - geralmente formada por domos retangulares longitudinais que sofrem desprendimento (Pranchas. 2B). O desprendimento pode ocorrer aos poucos e, nesse caso, o tronco apresenta elementos de descamação presentes na casca alternados a elementos já desprendidos; ou alguma face do tronco pode mostrar-se totalmente descamada. São delimitados por fissuras ou fendas, porém os domos têm maior importância no aspecto geral da casca. Na descrição, é especificada a delimitação longitudinal e transversal. A delimitação transversal nem sempre é evidente.

Com domos lineares - casca escamosa com domos estreitos (menos de $2 \mathrm{~cm}$ de larg.) e com comprimento muito maior que a largura (acima de 7cm) (Pranchas. 1B; $61 \mathrm{C} ; 62 \mathrm{~B})$.

Laminada (Ribeiro et al., 1999) - quando a presença de lâminas descamantes é mais importante na definição do aspecto geral da casca (Pranchas. 4B; 38B; 39B; 39C; 40B; 41B; 42C; 43B; 44B; 45B).

Variegada (Torres et al., 1994) - quando a casca desprende em placas lenhosas, irregulares, geralmente longitudinais, afinam nas bordas, com impressões de coloração contrastante (Crystocaria moschata e Myrcia pubipetala, Pranchas. 26B; 46B).

\subsection{Chave de identificacão para espécies emergentes e de dossel da Parcela Permanente}

1. Base do tronco dilatada...................................................................................... 2 1'. Base do tronco reta, digitada ou com sapopemas.................................................... 3 
2. Casca do tronco castanho-esbranquiçada, com lenticela discolores, castanho-escuras.

Pisonia ambigua

2'. Casca do tronco castanho-clara, fendida, fissurada e/ou lenticelada

Phytolacca dioica

3. Base do tronco com predominância de sapopemas................................................. 4

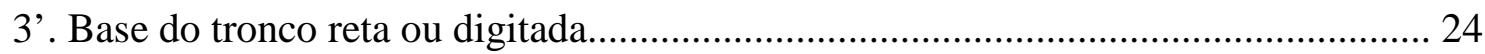

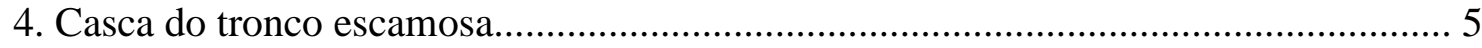

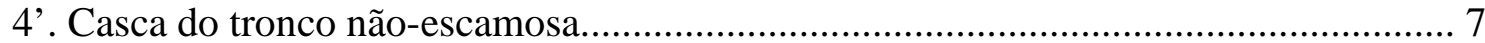

5. Casca do tronco sem lenticelas....................................................... Virola bicuhyba

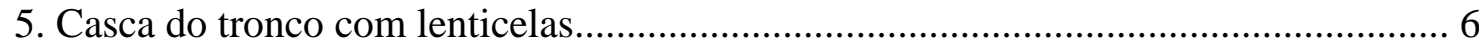

6. Casca do tronco com lenticelas arredondadas justapostas........... Parinari brasiliensis

6'. Casca do tronco com lenticelas lineares.................................... Pradosia lactescens

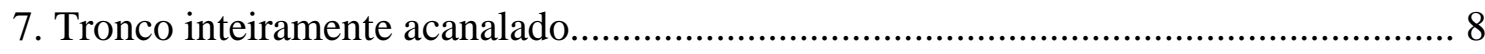

7'. Tronco cilíndrico ou acanalado apenas à altura do peito.......................................... 9

8. Casca do tronco com lâminas justapostas................................ Eugenia cambucarana

8'. Casca do tronco com lâminas dispersas.................................... Oreopanax capitatus

9. Casca do tronco lisa.......................................................... Eugenia cf. burkartiana

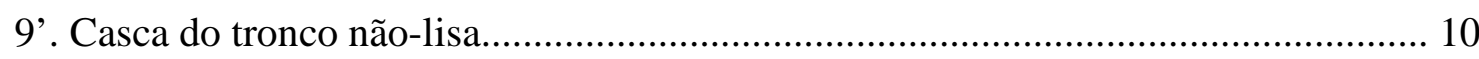

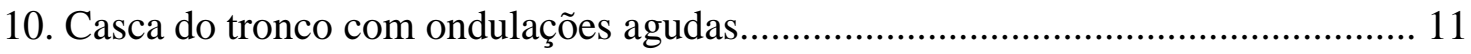

10'. Casca do tronco sem ondulações agudas................................................................. 12

11. Raízes com $6-13 \mathrm{~cm}$ de espessura.............................................. Pterocarpus rohrii

11'. Raízes com 17-25cm de espessura........................... Pseudopiptadenia warmingii

12. Casca do tronco com domos lineares...................................................................... 13

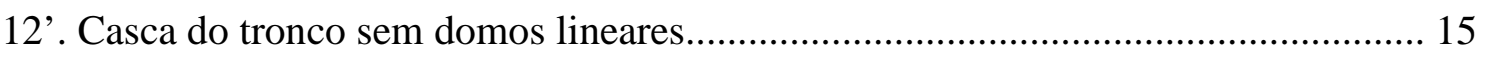

13. Casca da crista da raiz com fundo avermelhado........................ Tapirira guianensis

13'. Casca da crista da raiz com fundo da mesma cor da casca.................................. 14

14. Impressão dos domos fissurada.................................................... Pouteria caimito

14'. Impressão dos domos lenticelada......................................... Pouteria psammophila

15. Casca do tronco com placas lenhosas................................................................... 16

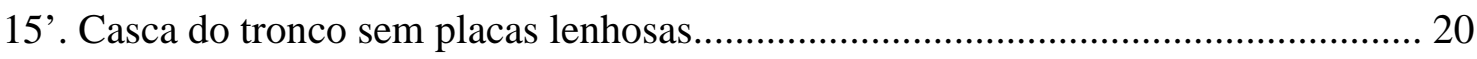

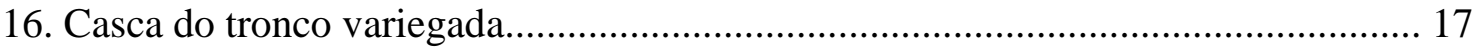

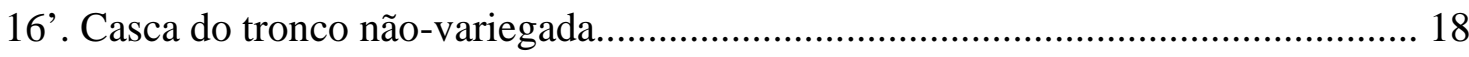

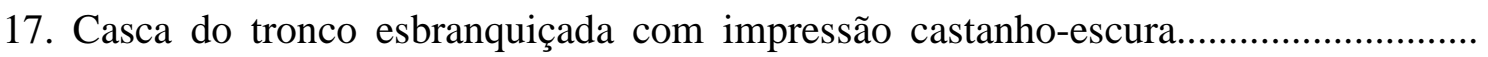


17'. Casca do tronco castanho-avermelhada com impressão avermelhada.

Cryptocarya moschata.

18. Casca do tronco com lenticelas pequenas e médias (1-4mm diâm.), da mesma cor da casca. 19

18'. Casca do tronco com lenticelas grandes (4-6mm diâm.), discolores.

Ocotea mosenii

19. Casca do tronco com lenticelas muito inconspícuas, $1 \mathrm{~mm}$ diâm., conferindo uma textura áspera.

Casearia obliqua

19'. Casca do tronco com lenticelas evidentes

Protium widgrenii

20. Casca do tronco sem lenticelas. Buchenavia kleinii

20'. Casca do tronco com lenticelas. 21

21. Casca do tronco com lenticelas dispersas ou em linhas longitudinais levemente sinuosas. Sloanea guianensis

21'. Casca do tronco com lenticelas em agrupamentos

22

22. Casca do tronco com regiões fissuradas Hyeronima alchorneoides

22'. Casca do tronco sem fissuras. 23

23. Tronco cilíndrico Ficus luschnathiana

23'. Tronco acanalado. Zollernia ilicifolia

24. Casca do tronco reticulada. 25

24' Casca do tronco não-reticulada. 27

25. Casca do tronco com delimitação longitudinal por microfissuras e com lenticelas não-verrucosas nos vértices Copaifera trapezifolia 25'. Casca do tronco com delimitação longitudinal por fissuras ou lenticelas associadas a fissuras. 26

26. Casca do tronco reticulada formada por retângulos longitudinais.

Heisteria silvianii

26'. Casca do tronco reticulada formada por quadrados ou retângulos transversais

Centrolobium robustum

27. Casca do tronco com acúleos Jacaratia spinosa

27'. Casca do tronco sem acúleos. 28

28. Casca do tronco com placas lenhosas. 29

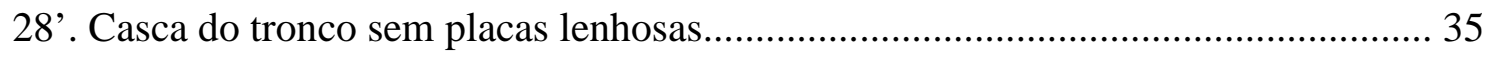

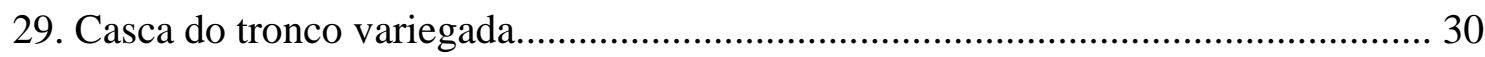

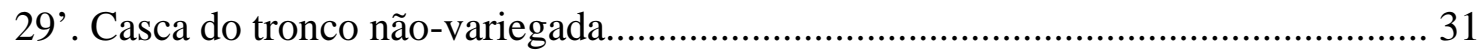


30. Casca do tronco esbranquiçada com impressão castanho-escura

Myrcia pubipetala

30'. Casca do tronco castanho-avermelhada com impressão avermelhada.

Cryptocarya moschata

31. Casca do tronco com depressões 32

31'. Casca do tronco sem depressões 33

32. Tronco inteiramente acanalado Simira corumbensis

32'. Tronco levemente acanalado apenas na base. Ocotea catharinensis

33. Casca do tronco com lenticelas arredondadas. Nectandra membranacea

33'. Casca do tronco com lenticelas lineares longitudinais. 34.

34. Base do tronco reto. Ecclinusa ramiflora

34'. Base do tronco digitado ou com sapopemas Pradosia lactescens

35. Casca do tronco com rugosidades. 36

35'. Casca do tronco sem rugosidades 37

36. Casca do tronco inteiramente rugosa Roupala brasiliensis

36'. Casca do tronco formada por faixas rugosas transversais intercaladas por casca lenticelada Matayba guianensis

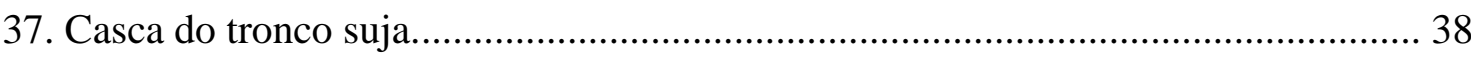

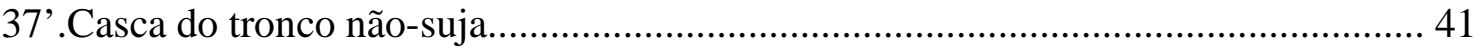

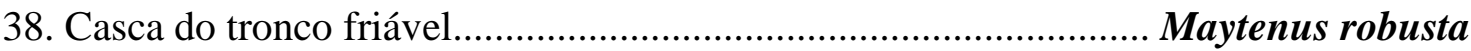

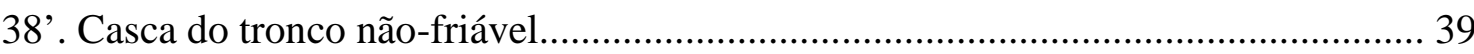

39. Tronco inteiramente acanalado.

Chrysophyllum inornatum

39'. Tronco cilíndrico ou levemente acanalado 40

40. Tronco com várias cicatrizes proeminentes (7-10 por indivíduo), de base cilíndrica, 3-5cm diâm., $5 \mathrm{~mm}$ de espessura Vantanea compacta

40'. Tronco sem cicatrizes proeminentes Tetrastylidium grandifolium

41. Casca do tronco com domos lineares Pouteria caimito

41'. Casca do tronco sem domos lineares......................................................................... 42

42. Casca do tronco escamosa............................................................................. 43

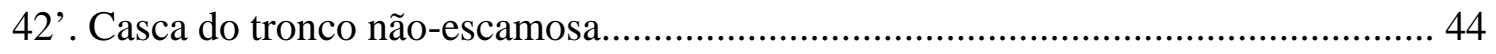

43. Casca do tronco com lenticelas evidentes, justapostas............... Parinari brasiliensis 43'. Casca do tronco com faixas de lenticelas inconspícuas

Aspidosperma parvifolium

44. Casca do tronco fendida. 45 
44'. Casca do tronco não-fendida.

45. Fundo das fendas da casca do tronco com lenticelas em linhas longitudinais

Quararibea turbinata

45'. Fundo das fendas da casca do tronco sem lenticelas 46

46. Tronco cilíndrico com casca com domos de 4-5mm larg.

Tabebuia serratifolia

46'. Tronco inteiramente acanalado com casca com domos de 2-3mm larg.

Pera glabrata

47. Casca do tronco com ondulações agudas Swartzia acutifolia

47'. Casca do tronco sem ondulações agudas. 48

48. Casca do tronco com lenticelas evidentes. 49

48'. Casca do tronco sem lenticelas ou com lenticelas inconspícuas. 63

49. Casca do tronco com lenticelas discolores muito mais escuras que a matriz. 50

49'. Casca do tronco com lenticelas da mesma cor da matriz, discolores, mais claras que a matriz ou pouco mais escuras 51

50. Casca do tronco com lenticelas castanhas a castanho-avermelhadas, a maioria estratificadas. Capsicodendron dinisii 50’. Casca do tronco com lenticelas não-estratificadas. Hymenaea courbaril

51. Casca do tronco com lenticelas em agrupamentos esparsos

Hyeronima alchorneoides

51'. Casca do tronco com lenticelas cobrindo a maior parte da superfície do tronco.... 52

52. Casca do tronco com maioria das lenticelas lineares longitudinais........................ 53

52'. Casca do tronco com maioria das lenticelas arredondadas ou elípticas.................. 56

53. Casca do tronco com maioria das lenticelas justapostas

Tetrorchidium rubrivenium

53'. Casca do tronco com maioria das lenticelas com mais de $3 \mathrm{~mm}$ de distância entre si. 54

54. Casca do tronco com lenticelas de formato semelhante a lábios.

Cabralea canjerana

54'. Casca do tronco com lenticelas e formato distinto do anterior. 55

55. Tronco reto. Croton macrobothrys

55'. Tronco digitado Magnolia ovata

56. Casca do tronco coberta apenas por lenticelas justapostas. Malouetia arborea

56'. Casca do tronco composta por lenticelas justapostas e não-justapostas. 57

57. Tronco cilíndrico 58 
57'. Tronco acanalado ou levemente acanalado.

58. Casca do tronco com algumas lenticelas organizadas em linhas longitudinais

Coussapoa microcarpa

58'. Casca do tronco com lenticelas com distribuição irregular.

Brosimum lactescens

59. Casca do tronco apresentando agrupamentos com fissuras delimitando domos quadrangulares.

Coccoloba fastigiata

59'. Casca do tronco sem fissuras.

60

60. Raízes superficiais abundantes, de casca cinza-escura com lenticelas discolores, castanho-claras

Chrysophyllum viride

60'. Raízes superficiais não-abundantes ou com padrão de casca distinto do anterior.. 61

61. Casca do tronco com lenticelas arredondadas, médias (3-5mm diâm.).....

Alchornea triplinervia

61'. Casca do tronco com lenticelas arredondadas pequenas (2-3mm diâm.), podendo apresentar regiões com lenticelas arredondadas grandes $(0,5-1,0 \mathrm{~cm}$ diâm.)..... 62

62. Casca do tronco com lenticelas arredondadas grandes $(0,5-1,0 \mathrm{~cm}$ diâm.) e pequenas (2-3mm diâm.) apresentadas isoladamente, sendo que as lenticelas pequenas organizamse em linhas longitudinais.

Platymiscium floribundum

62'. Casca do tronco com lenticelas arredondadas ou elípticas, pequenas (2-3mm compr.) em agrupamentos irregulares

Meliosma sellowii

63. Casca do tronco laminado. 64

63'. Casca do tronco não-laminado. 69

64. Casca do tronco com lâminas geralmente coriáceas. 65

64'. Casca do tronco com lâminas geralmente papiráceas. 66

65. Casca do tronco com impressão vermelha, lisa.... Eugenia multicostata

65'. Casca do tronco com impressão castanha bem clara ou castanho-escura, áspera.

Marlierea suaveolens

66. Casca do tronco com lâminas justapostas. 67

66'. Casca do tronco com lâminas esparsas. 68

67. Casca do tronco com impressão castanho-avermelhada.

Eugenia subavenia

67'. Casca do tronco com impressão castanho-esbranquiçada. Eugenia cereja 68. Casca do tronco fissurada. Eugenia capitulifera

68'. Casca do tronco áspera Campomanesia guaviroba

69. Casca do tronco fissurada. 70

69'. Casca do tronco não-fissurada. 71 
70. Casca do tronco com domos retangulares, longitudinais, $20-40 \mathrm{~cm}$ compr., $4-7 \mathrm{~cm}$ larg. Cedrela fissilis

70'. Casca do tronco com domos retangulares, longitudinais, $15-70 \mathrm{~cm}$ compr., 0,5$2,0 \mathrm{~cm}$ larg. Cariniana estrellensis

71. Casca do tronco áspera com microfissuras. Malouetia arborea 71'. Casca do tronco com depressões. Vantanea compacta

\subsection{Descricõoes das espécies}

\section{Anacardiaceae}

1. Tapirira guianensis Aubl., Hist. Pl. Guiane 1: 470, t. 188. 1775

Prancha 1.

Nome popular: peito-de-pombo.

Tronco 50-66cm DAP, castanho-escuro, cilíndrico. Raízes com sapopemas simples, aresta reta a levemente côncava, $a>b, a=120-230 \mathrm{~cm}, b=60-100 \mathrm{~cm}, 12-20 \mathrm{~cm}$ espessura. Casca do tronco com domos lineares, longitudinais, estratificados em placas, 1,56,0cm compr., 0,5-1,0cm larg., 3-6mm espessura; superfície côncava, áspera. Delimitação longitudinal com fissuras retas a levemente sinuosas, $8-15 \mathrm{~cm}$ compr., 0,21,0cm larg., 3-6mm profundidade. Delimitação transversal com fissuras retas, 0,51,0cm compr., $1 \mathrm{~mm}$ larg., 2-4mm profundidade. Fundo frequentemente castanhoavermelhado. Casca da crista da raiz fendida, com fendas sinuosas delimitando alvéolos, 5-8cm compr., 0,5-1,5cm larg., 2-4mm profundidade; fundo castanhoavermelhado. Domos longitudinais, 4-10cm compr., 0,5-1,0cm larg., 2-4mm espessura; superfície côncava, em placas estratificadas.

Diferencia-se das demais espécies com casca com domos lineares por serem estratificados e pela coloração castanho-avermelhada no fundo das fendas.

2. Aspidosperma parvifolium A. DC., Prodr. 8: 398. 1844.

Prancha 2.

Nome popular: guatambu. 
Tronco 52-76cm DAP, castanho bem claro, cilíndrico ou acanalado. Raízes digitadas, simples, aresta reta, $\mathrm{a}>\mathrm{b}, \mathrm{a}=40-70 \mathrm{~cm}, \mathrm{~b}=25-50 \mathrm{~cm}, 17-25 \mathrm{~cm}$ espessura. Casca do tronco escamosa, com domos retangulares, longitudinais, 9-20cm compr., 2-4cm larg., 0,4$1,0 \mathrm{~cm}$ espessura; superfície plana, com microfissuras, longitudinais, transversais ou estreladas, 0,6-1,5cm compr., 0,5-1,0cm distância, em matriz áspera, com lenticelas muito inconspícuas, verrucosas, fixas, abertura circular, arredondadas, 1-2mm diâm., justapostas em faixas longitudinais contínuas, 1,0-1,5(-2,0)cm larg. Delimitação longitudinal por fendas retas a levemente sinuosas, 15-30(-40)cm compr., 1,0-1,5(2,0)cm larg., (0,5-)0,8-1,0cm espessura; fundo com lenticelas muito inconspícuas, verrucosas, fixas, abertura circular, arredondadas, 1-2mm diâm., justapostas. Delimitação transversal não evidente. Impressão como a superfície. Algumas regiões totalmente descamadas. Casca da raiz padrão I: como a casca do tronco. Padrão II: lenticelado, com lenticelas verrucosas, descamantes, abertura em espocação ou linear, arredondadas, 4-7mm diâm., 2-4mm espessura, em linhas longitudinais, 0,5-2,0cm distância transversal. Matriz áspera. Padrão III: com ondulações transversais, contínuas, 1,5-3,0cm larg., justapostas.

Nesta espécie, o padrão I da raiz aparece isoladamente no mesmo indivíduo enquanto os padrões II e III podem apresentar-se isoladamente ou em sobreposição.

As faixas de lenticelas inconspícuas e justapostas na casca do tronco constituem um fator importante como auxílio na identificação.

3. Malouetia arborea (Vell.) Miers., Apocyn. S. Am.89. 1878.

Prancha 3.

Nome popular: guairana.

Tronco 48-70cm DAP, castanho, cilíndrico ou acanalado, reto. Casca do tronco padrão I: lenticelado, com lenticelas verrucosas, descamantes, castanho-claro ao descamar, com abertura não evidente, arredondadas, 2-3mm diâm., ou elípticas, longitudinais, 4-7mm compr., 2-4mm larg., 1mm espessura, 0-4mm distância, homogêneas, numerosas. Matriz áspera. Padrão II: áspero com microfissuras longitudinais, 1-3cm compr., 0,3$2,0 \mathrm{~cm}$ distância.

Os padrões I e II da casca do tronco são encontrados em indivíduos diferentes. 
4. Oreopanax capitatus (Jacq.) Decne. \& Planch., Rev. Hort. 16: 108. 1854

Prancha 4.

Tronco $58 \mathrm{~cm}$ DAP, castanho-esbranquiçado com regiões castanho-avermelhadas, inteiramente acanalado. Raízes com sapopemas simples, aresta reta, $a>b, a=80-90 \mathrm{~cm}$, b=50-70cm, $5-6 \mathrm{~cm}$ espessura. Casca do tronco laminado, com lâminas papiráceas retangulares, longitudinais, 3-8(-12)cm compr., 1-2cm larg., justapostas; superfície castanho-avermelhada ou castanho-esbranquiçada, plana, áspera. Delimitação longitudinal por fissuras 7-30cm compr., 2-3mm larg., 2-4mm profundidade. Impressãocastanho-avermelhada ou castanho-esbranquiçada, áspera. Algumas regiões totalmente descamadas e outras com lâminas em formação. Casca da raiz laminada como na casca do tronco, porém formada por lâminas irregulares, 3-20cm compr., 3$10 \mathrm{~cm}$ larg. Casca da crista da raiz fendida, castanho-acinzentada, com fendas longitudinais, sinuosas, formando alvéolos, 2-10cm compr., 0,5-2,0cm larg., 3-5mm profundidade, fundo estratificado. Domos 6-10cm compr., 5-8mm larg., 3-5mm espessura, superfície plana, áspera.

\section{Bignonicaceae}

5. Tabebuia serratifolia (Vahl) G. Nicholson, Ill. Dict. Gard. 4: 1. 1887.

Prancha 5.

Nome popular: pau-d'arco-amarelo, ipê-amarelo.

Tronco 56-76cm DAP, castanho-acinzentado, cilíndrico. Raízes digitadas, simples, aresta reta, $\mathrm{a}>\mathrm{b}, \mathrm{a}=75-100 \mathrm{~cm}, \mathrm{~b}=58-90 \mathrm{~cm}, 12-20 \mathrm{~cm}$ espessura. Casca do tronco fendida, com fendas retas, longitudinais, 7-13cm compr., 3-5mm larg., 2-4mm profundidade; fundo áspero. Domos 4-6mm larg.

\section{Burseraceae}

6. Protium widgrenii Engl., Fl. Bras. (Martius) 12(2): 272.

Prancha 6.

Nome popular: almecegueira, pau-de-breu.

Tronco $70 \mathrm{~cm}$ DAP, castanho-claro, cilíndrico. Raízes com sapopemas simples, aresta reta, $a<b, a=60-90 \mathrm{~cm}, b=70-110 \mathrm{~cm}, 5-13 \mathrm{~cm}$ espessura. Casca do tronco lenticelada 
com placas, com lenticelas verrucosas, fixas, abertura em espocação, linear ou não evidente, arredondadas a levemente elípticas, 1-4mm diâm., 0-1mm espessura, 0-5mm distância, numerosas. Placas lenhosas, irregulares tendendo a cilíndricas, $3-8 \mathrm{~cm}$ compr., 3-4mm espessura, afina nas bordas, $0-15 \mathrm{~cm}$ distância; superfície plana, com lenticelas como as descritas. Impressão em depressão com lenticelas como as descritas. Algumas regiões totalmente descamadas, com depressões justapostas. Casca da raiz padrão I: lenticelada, como no padrão I da casca do tronco, porém com lenticelas discolores, castanho mais claro ou castanho-esbranquiçado, na região proximal e rente ao solo. Padrão II: levemente rugosa com lenticelas arredondadas, $1 \mathrm{~mm}$ diâm., e lenticelas lineares, transversais, 3-5mm compr., 1 $\mathrm{mm}$ larg., <1 $\mathrm{mm}$ espessura. Casca da raiz superficial levemente rugosa com lenticelas discolores, esbranquiçadas, arredondadas e lineares como no padrão II da casca da raiz.

\section{Canellaceae}

\section{Capsicodendron dinisii (Schw.) Occh., Revista Brasil. Biol.3: 486. 1943.}

\section{Prancha 7.}

Nome popular: pimenteira.

Tronco 48-63cm DAP, castanho-esbranquiçado, acanalado, reto a levemente digitado.

Casca do tronco padrão I, principal: lenticelado, com lenticelas discolores, castanho a castanho-avermelhadas, verrucosas, descamantes, castanho-claro ao descamar, de formato arredondado, com abertura em espocação, ou quadrangular, estratificada, com abertura linear, transversal, raro longitudinal, 3-7mm diâm., 1-3mm espessura, 0-2,5cm distância, com distribuição irregular, numerosas. Matriz áspera ou com microfissuras longitudinais. Padrão II: lenticelado, com lenticelas discolores, castanho-avermelhadas, verrucosas, algumas descamantes, com abertura linear, algumas estratificadas, lineares transversais, 5-9cm compr., 4-8mm larg., 1-5mm espessura, numerosas. Matriz esbranquiçada, áspera, com microfissuras e fissuras, longitudinais ou estreladas, poucas transversais, 0,5-4,5cm compr., 3-8cm de distância, distribuídas em algumas faces do tronco, principalmente na crista do tronco. Padrão III: com depressões formadas por descamações irregulares, 5-8cm compr. Impressão castanha, quando a descamação é recente, com fissuras longitudinais, 2,5-5,0cm compr., 1-4mm larg., 3mm profundidade, 0,8-2,0cm distância, lenticelas arredondadas, $2 \mathrm{~mm}$ diâm., $1 \mathrm{~mm}$ espessura, ou elípticas, longitudinais, quando em matriz áspera. Casca da base como a casca do tronco, porém 
com as lenticelas descamadas, castanho-claras. Casca da raiz superficial lenticelada, com lenticelas castanho-claras, rasas a levemente verrucosas, fixas, abertura não evidente, arredondadas, 3-5mm de diâm., 0,8-2,0cm de distância, numerosas. Matriz áspera, com microfissuras longitudinais ou estreladas, 1,5-3,5cm compr., algumas com lenticelas associadas, $2 \mathrm{~cm}$ compr., $2 \mathrm{~mm}$ larg., $1 \mathrm{~mm}$ espessura, 1-3cm distância.

$\mathrm{Na}$ casca do tronco, os padrões I, II e III são encontrados sobrepostos ou isoladamente em um mesmo tronco. Alguns indivíduos não apresentam o padrão III.

Esta espécie diferencia-se de outras de casca castanho-esbranquiçada com lenticelas discolores mais escuras por apresentar abertura estratificada. $\mathrm{O}$ formato da base do tronco acanalado também auxilia em sua identificação.

Caricaceae

8. Jacaratia spinosa (Aubl.) A. DC., Prodr. 15(1): 419.1864.

Prancha 8 .

Nome popular: mamãozinho.

Tronco $80 \mathrm{~cm}$ DAP, castanho claro, cilíndrico, reto. Raízes superficiais surgem próximas ao tronco, $40-60 \mathrm{~cm}$ compr., 10-25cm larg., 10-25cm espessura. Casca do tronco estriada com acúleos em calos, 1 acúleo central por calo. Calos lineares transversais, por vezes não apresentam o acúleo, 5-11 cm compr., (0,3-)0,5-1,0cm larg, 1-4mm espessura. Acúleos elípticos, longitudinais, 0,4-1,0cm compr., 3-6mm larg., 0,51,2cm espessura, 1-8cm distância longitudinal. Estrias, lenticelas discolores associadas a fissuras, castanhas um pouco mais escuras que a matriz, verrucosas, as mais espessas descamam, associadas a microfissuras longitudinais, levemente sinuosas, $4-\underline{8}-12 \mathrm{~cm}$ compr., 3(-6)mm larg., 1(-3)mm espessura, 3-5mm distância transversal. Casca da raiz superficial padrão I: estriado, lenticelas discolores associadas a fissuras, castanhoescuras, verrucosas, descamantes, 6-8cm compr., 0,6-1,0 cm larg., 3-4mm espessura, 0,7-1,5cm distância. Matriz castanho-esbranquiçada. Padrão II: estriado como o padrão II da casca do tronco.

Na casca da raiz superficial, padrão I para raízes grossas (25cm larg.) e II para raízes estreitas (10-20cm larg.). 
A presença de acúleos é uma característica exclusiva desta espécie entre os indivíduos estudados na área analisada.

\section{Celastraceae}

9. Maytenus robusta Reiss., Fl. Bras. (Martius) 11(1): 15.

Prancha 9.

Tronco $53 \mathrm{~cm}$ DAP, branco, cilíndrico. Raízes digitadas, simples, aresta reta, a>b, $a=30-60 \mathrm{~cm}, b=20-35 \mathrm{~cm}, 7-11 \mathrm{~cm}$ espessura. Raiz superficial abundante, $7-13 \mathrm{~cm}$ diâm. Casca do tronco e da raiz áspera a suja, friável ao toque. Casca da crista da raiz padrão I: áspero, como a casca do tronco. Padrão II: com microfissuras longitudinais 1$3 \mathrm{~cm}$ compr., 3-6mm distância. Casca da raiz superficial padrão I, principal: lenticelado, com lenticelas verrucosas, fixas, abertura linear, lineares, transversais, 0,51,4cm compr., 1-2mm larg., 1mm espessura, 0-5mm distância longitudinal, em linhas transversais, numerosas. Padrão II: lenticelado, como as lenticelas do padrão I, porém longitudinais e 4-7mm compr. padrão III: sujo.

Entre as árvores estudadas a casca do tronco e da raiz friável ao toque foi observada apenas nesta espécie, sendo uma característica diagnóstica. Além disso, as raízes superficiais constituem um importante auxílio para a identificação através da observação do padrão principal.

Os padrões da casca da crista da raiz e da raiz superficial observados aparecem em raízes distintas.

\section{Chrysobalanaceae}

10. Parinari brasiliensis (Schott) Hook. f., Fl. Bras. 14(2): 51. 1867.

Prancha 10.

Tronco 49-88cm DAP, castanho-claro a castanho-escuro, podendo apresentar liquens esbranquiçados ou rosados, cilíndrico. Com cicatrizes, 1-3, lineares, transversais ou inclinadas, 15-20cm compr., 6-8cm larg, 3cm espessura. Raízes digitadas, simples, aresta reta, $a>b, a=43-80 \mathrm{~cm}, b=15-55 \mathrm{~cm}, 5-25 \mathrm{~cm}$ espessura ou sapopemas com ramificações distais, bifurcadas, aresta reta, $a>b, a=160-190 \mathrm{~cm}, b=60-75 \mathrm{~cm}$, espessura 13-20cm. Casca do tronco padrão I: castanho a castanho-escuro, lenticelado, com 
lenticelas verrucosas, descamantes, castanho bem claro ao descamar, arredondadas, com abertura estrelada, 2-4mm diâm., 2-4mm espessura, justapostas, numerosas. Padrão II: castanho, escamoso, com domos retangulares longitudinais, $2-5 \mathrm{~cm}$ compr., $1,0-1,5 \mathrm{~cm}$ larg., 2-3mm espessura, superfície côncava, com laterais levantadas. Delimitação longitudinal por fissuras 3-7cm compr., 2-5mm larg., 3-5mm profundidade. Delimitação transversal por fissuras 1,0-1,5cm compr., 1mm larg., o fundo contém fissuras com lenticelas arredondadas, $2 \mathrm{~mm}$ diâm., ou elípticas, 3-8mm compr., 2-4mm larg., ambas rasas. Padrão III: castanho-claro, fissurada, com fissuras retas, longitudinais, $2,5-5,0 \mathrm{~cm}$ compr., 1-2mm larg., 2-3mm profundidade, transversais, 3-5mm compr., 1mm larg., 2$5 \mathrm{~mm}$ espessura. Domos longitudinais, 1,0-2,5cm compr., 3-5mm larg., 2-3mm profundidade, superfície plana, áspera. Padrão IV: com microfissuras longitudinais, quase retas, contínuas, 2-4mm distância, com algumas microfissuras curtas transversais, 2-4mm compr., castanho-claro, coberto por liquens esbranquiçados e rosados. Casca da raiz lenticelada, com lenticelas não-verrucosas, fixas, arredondadas, 3-6mm diâm., 0$1 \mathrm{~mm}$ espessura, justapostas. Casca da crista da raiz padrão I: lenticelado, com lenticelas lineares, 1,0-1,5cm compr., 2-3mm larg., 0-1mm espessura, associadas a fissuras. Padrão II: fendido, com fendas longitudinais, sinuosas formando alvéolos, 3,06,5cm compr., 2-5mm larg., $1 \mathrm{~mm}$ espessura, 0,3-0,8(-1,0)cm distância, fundo levemente avermelhado, estratificado. Padrão III: lenticelado, com lenticelas longitudinais, inconspícuas, verrucosas, fixas, 4-6mm compr., $2 \mathrm{~mm}$ larg., rasas. Casca da raiz superficial lenticelada, com lenticelas pequenas e grandes, arredondadas, verrucosas, descamantes, 3-5mm diâm., rasas a 3mm espessura, podendo apresentar rugosidade. Matriz esbranquiçada, áspera.

Raiz digitada e com sapopemas em indivíduos de maior porte (DAP 60-88cm) e apenas digitado ou diltado em indivíduos de menor porte (DAP 49-60cm). São encontrados 3 a 4 padrões de casca de tronco isoladamente em um mesmo indivíduo. $\mathrm{O}$ padrão I sempre está presente. O padrão II pode ser encontrado em sobreposição ao padrão III. O padrão VI é apresentado geralmente na face onde a base do tronco é reta ou com raízes digitadas. Além disso, os padrões da casca da crista da raiz são encontrados em raízes diferentes de um mesmo indivíduo ou de indivíduos diferentes.

A presença de diferentes padrões em áreas grandes e bem delimitadas no tronco, sem sobreposição facilita sua identificação. 
11. Buchenavia kleinii Exell., Ann. Mag. Nat. Hist. 6: 400.1953.

Prancha 11.

Tronco 52-120cm DAP, castanho-escuro a cinza-escuro com porções esbranquiçadas, cilíndrico. Raízes com sapopemas geralmente simples, aresta reta, a=b ou "a" pouco maior que "b", a=70-270cm, 6-18cm espessura. Casca do tronco fissurada, com fissuras longitudinais, 3-6cm compr., 1-3mm larg., $1 \mathrm{~mm}$ profundidade. Descamando em lâminas papiráceas retangulares, longitudinais, 3-6cm compr., 0,5-1,0cm larg., com superfície plana e áspera. Impressão com microfissuras longitudinais, $1-4 \mathrm{~cm}$ compr., 0,5-1,0cm distância. Desprendem-se aos poucos. Casca da raiz com ranhuras longitudinais formando conjuntos sinuosos, com fundo castanho ou esbranquiçado. Pode apresentar descamações em lâminas irregulares, principalmente na porção proximal. Casca da crista da sapopema e casca da raiz superficial coloração mais clara com microfissuras ou ranhuras longitudinais.

Indivíduos de maior porte apresentam sapopemas ramificadas, de aresta levemente convexa, $a>b$.

Grandes sapopemas estreitas são observadas com frequiência nesta espécie e diferenciam-se de Sloanea guianensis pela ausência de lenticelas e rugosidade. A casca da raiz com ranhuras facilita sua identificação.

\section{Elaeocarpaceae}

12. Sloanea guianensis (Aubl.) Benth., J. Proc. Linn. Soc., Bot. 5(Suppl. 2): 69. 1861. Prancha 12.

Tronco 50-143cm DAP, castanho a castanho-escuro, cilíndrico. Com rebrotos, $3-13 \mathrm{~cm}$ diâm. Raízes com sapopemas ramificadas, aresta reta, a>b, a=120-390cm, b=50-310cm, 6-18cm espessura. É freqüente apresentar rebroto junto às raízes. Casca do tronco lenticelada, com lenticelas verrucosas, descamantes, arredondadas, 2-6mm diâm, 1$4 \mathrm{~mm}$ espessura, com distribuição irregular ou em linhas longitudinais levemente sinuosas, esparsas. Casca da raiz padrão I: lenticelado e rugoso, com lenticelas verrucosas, a maioria fixa, arredondadas, 2-4mm diâm. e 1-2mm espessura ou elípticas transversais com 4-6mm compr., 2-3mm larg., $1 \mathrm{~mm}$ de espessura, 0-2,5cm de distância, com distribuição irregular, numerosas a esparsas. Padrão II: com ondulações 
transversais, (3,0-)4,5-6,0 cm de larg., (0,5-)1,0-1,5cm de espessura, $13-17 \mathrm{~cm}$ de distância. Casca da crista da raiz padrão I: com fissuras longitudinais ou estreladas, $1 \mathrm{~cm}$ compr.; 1-2mm larg., 1mm profundidade, 3-4mm distância; podendo apresentar fundo avermelhado, estrias. Padrão II: lenticelado, com lenticelas arredondadas, 1-3mm de diâm., <1mm espessura, 5-10mm de distância, em quantidade menor que na casca da raiz. Padrão III: rugoso. Casca da raiz superficial áspera, podendo apresentar microfissuras longitudinais, 2-3mm de distância e lenticelas arredondadas, 2-3mm diâm., 3-10mm de distância.

Nos indivíduos com $50 \mathrm{~cm}$ de DAP, o tronco é cilíndrico à altura do peito, as sapopemas são menores, alcançando até $100 \mathrm{~cm}$, cateto "a"="b".

Para a casca da raiz, os padrões I e II sobrepõem-se em raízes com comprimento “a” superior a $200 \mathrm{~cm}$. Os três padrões da crista da raiz podem ser observados em sobreposição ou separadamente.

Esta espécie diferencia-se de Buchenavia kleinii devido à sua rugosidade e presença de lenticelas na casca, que também apresenta, com freqüência, grandes sapopemas estreitas. A presença de folhas e frutos no solo é freqüente e um importante auxílio na identificação.

\section{Euphorbiaceae}

\section{Alchornea triplinervia (Spreng.) Müll. Arg., Prodr. 15(2): 909. 1866.}

Prancha 13.

Nome popular: tapiá.

Tronco 52-105cm DAP, castanho, acanalado. Cicatrizes cilíndricas, $7 \mathrm{~cm}$ diâm., $4 \mathrm{~cm}$ espessura, ou elíptica, transversal, $18 \mathrm{~cm}$ compr., $9 \mathrm{~cm}$ larg., $2 \mathrm{~cm}$ espessura. Raízes digitadas, simples, aresta levemente côncava, a>b, a=40-100cm, b=20-90cm, $13-26 \mathrm{~cm}$ espessura. Casca do tronco lenticelada, com lenticelas verrucosas, muito descamantes, abertura em espocação, tendendo a arredondadas, 3-5(-6)mm diâm., 3-5mm espessura, 0-5mm distância, com distribuição irregular, numerosas. Casca da crista do tronco fendida, com fendas longitudinais, 5-10cm compr., 2-5mm larg., 4-5mm espessura, fundo áspero. Domos 1,0-1,5cm larg., superfície plana, áspera, com microfissuras longitudinais, 0,3-1,0cm compr., 2-5mm distância. Casca da crista da raiz padrão I: lenticelado, como a casca do tronco. Padrão II: fendido, como a casca da crista do 
tronco. Casca da raiz superficial com tom pouco esbranquiçado. Padrão I: áspero. Padrão II: fissurado, com fissuras longitudinais, 1-5cm compr., 1-2mm larg., 1-2mm espessura, 5-8mm distância. Padrão III: lenticelado, com lenticelas não verrucosas, fixas, abertura linear ou estrelada, arredondadas, 1-2mm diâm., 5-8mm distância, numerosas.

Na crista da raiz, o padrão I é encontrado nas raízes mais grossas $(20-23 \mathrm{~cm}$ espessura) e o padrão II é encontrado nas raízes mais estreitas (menos de $20 \mathrm{~cm}$ de espessura).

14. Croton macrobothrys Baill., Adansonia 4: 332. 1864.

Prancha 14.

Tronco 54-67cm DAP, castanho-escuro, levemente acanalado, reto. Casca do tronco lenticelada, com lenticelas verrucosas, fixas, abertura linear, lineares, longitudinais, 49cm compr., 3-5mm larg., 1-2mm espessura, 3-7mm distância, associadas a fissuras, numerosas.

15. Pera glabrata (Schott) Poepp. ex Baill., Étude Euphorb. : 434. 1858.

Prancha 15.

Tronco $50 \mathrm{~cm}$ DAP, castanho-acinzentado, inteiramente acanalado, reto, levemente digitado. Casca do tronco fendida, com fendas longitudinais, levemente sinuosas, com cerca de 5-10cm compr., 2-4mm larg., 2-3mm espessura. Domos longitudinais, 0,52,0cm compr., 2-3mm larg.; superfície plana, áspera, com fissuras transversais. Casca da crista do tronco com microfissuras longitudinais, 2-6cm compr., 3-8mm distância.

16. Tetrorchidium rubrivenium Poepp., Nov. Gen. Sp. Pl. 3: 23, t. 227. 1841. Prancha 16.

Tronco 54-74cm DAP, cinza-esbranquiçado, inteiramente acanalado. Raízes com sapopemas ramificadas, bifurcação distal, aresta reta a côncava, a>b, a=120-150cm, $\mathrm{b}=75-80 \mathrm{~cm}, 10-15 \mathrm{~cm}$ espessura ou digitadas, simples, aresta côncava, $\mathrm{a}>\mathrm{b}, \mathrm{a}=30-52 \mathrm{~cm}$, b=23-40 cm, $8-10 \mathrm{~cm}$ espessura. Raízes superficiais abundantes. Casca do tronco lenticelada, com lenticelas, verrucosas, descamantes, com abertura linear, lineares, longitudinais, 0,5-4,5cm compr., 5mm larg., 1-3mm espessura, maioria justaposta, podendo ter até $1 \mathrm{~cm}$ distância, associadas a fissuras, numerosas. Casca da crista da 
raiz padrão I: fendido, com fendas levemente sinuosas, $4-8 \mathrm{~cm}$ compr., $0,5-1,3 \mathrm{~cm}$ larg., 4-5mm espessura; fundo com lenticelas longitudinais, abertura linear, lineares, $1-4 \mathrm{~cm}$ compr., 2-3mm larg. Domos 1,5-4,0cm compr., 3-6mm larg., 4-5mm espessura. Padrão II: lenticelado, com lenticelas verrucosas, fixas, abertura linear, lineares, longitudinais, 0,3-1,5cm compr., 2mm larg., menos de $1 \mathrm{~mm}$ espessura, 2-5mm distância transversal, associadas a fissuras, numerosas. Padrão III: lenticelado: com lenticelas lineares, $1-6 \mathrm{~cm}$ compr., 3-4mm larg., menos de $1 \mathrm{~mm}$ espessura, justapostas. Casca do vale da raiz lenticelada, com lenticelas verrucosas, fixas, arredondadas, abertura não evidente, 23mm diâm., 0-2mm espessura, elípticas e lineares, abertura linear, longitudinais, 0,41,0cm compr., 2-3mm larg., 0-3mm espessura, justapostas, numerosas. Casca da raiz superficial lenticelada, com lenticelas verrucosas, descamantes ou fixas, abertura linear, elípticas ou lineares, longitudinais, 0,5-2,0cm compr., 3-4mm larg., 1mm espessura, justapostas.

Os indivíduos de $64 \mathrm{~cm}$ de DAP apresentaram raízes digitadas, enquanto o indivíduo com $74 \mathrm{~cm}$ de DAP apresentou raízes com sapopemas e uma raiz digitada.

Para a casca da crista da raiz, cada padrão é apresentado separadamente em diferentes raízes ou, na mesma raiz, em alturas diferentes.

No padrão I da casca da crista da raiz, as fendas com até $3 \mathrm{~mm}$ larg. apresentam uma lenticela ocupando todo o fundo; quando mais larga, apresenta 2 a 4 lenticelas justapostas no fundo.

Fabaceae

\section{Caesalpinioideae}

17. Copaifera trapezifolia Hayne, Getreue Darstell. Gew. : pl. 23. 1825.

Prancha 17.

Nome popular: pau-de-óleo.

Tronco $65-91 \mathrm{~cm}$ DAP, castanho-claro, cilíndrico, reto. Casca do tronco padrão I, principal: reticulado, com formas quadrangulares irregulares, 3-5mm compr., delimitados por microfissuras e lenticelas não-verrucosas, de abertura estrelada nos vértices dos quadrados. Padrão II: lenticelado, com lenticelas verrucosas, descamantes, discolores, castanho-escuro, arredondadas, 3-5mm diâm., 2mm espessura, 1-3cm 
distância ou mais, esparsas. Casca da raiz superficial lenticelada, com lenticelas discolores, castanho-escuras, verrucosas, fixas, abertura não evidente, arredondadas 24mm diâm., ou elípticas, geralmente longitudinal, 4-6mm compr., 2mm larg., 2mm espessura, 0-4mm distância, distribuição irregular. Matriz castanha ou castanhoesbranquiçada.

Indivíduos com DAP acima de $75 \mathrm{~cm}$ apresentaram raízes digitadas, simples, aresta reta, podendo, ainda, apresentar raízes superficiais abundantes. $\mathrm{Na}$ casca do tronco, o padrão II encontra-se apenas em alguns indivíduos e sobreposto ao padrão I.

Nesta espécie, a casca do tronco reticulada com lenticelas nos vértices é diagnóstica.

18. Hymenaea courbaril L., Sp. P1. 2: 1192. 1753.

Prancha 18.

Nome popular: jatobá.

Tronco 61-110cm DAP, esbranquiçado, cilíndrico ou levemente acanalado, reto a digitado. Raízes digitadas, simples, aresta reta, $a>>b, b=20-56 \mathrm{~cm}, 20-40 \mathrm{~cm}$ espessura. Casca do tronco padrão I, principal: lenticelado, com lenticelas discolores, castanhoescuras, verrucosas, fixas, abertura em espocação; arredondadas 2-6mm diâm., 1-3mm espessura, ou elípticas, transversais, 5-8mm compr., 3-5mm larg., 1-2mm espessura, 0$1 \mathrm{~cm}$ distância, distribuição irregular, numerosas. Matriz esbranquiçada ou rosada, com microfissuras e fissuras longitudinais, 0,5-2,5cm compr., $1-2 \mathrm{~mm}$ larg., $<1 \mathrm{~mm}$ profundidade, retas a sinuosas, 1-5mm distância; fundo castanho-escuro, áspero. Padrão II: lenticelado, com lenticelas, verrucosas, fixas, lineares, longitudinais, $2-5 \mathrm{~cm}$ compr., 4-6mm larg., 2mm espessura, 4-5mm distância transversal, associadas a fissuras retas a levemente sinuosas, numerosas. Matriz esbranquiçada ou rosada, áspera. Casca da crista do tronco rugosa com lenticelas como o padrão I da casca do tronco. Casca da raiz superficial lenticelada, com lenticelas discolores, castanho-escuras, verrucosas, fixas, abertura linear, elípticas a lineares, 0,6-2,8cm compr., 4-5mm larg., 2mm espessura, 0-4mm distância, numerosas. Matriz castanho-clara.

Os padrões I e II podem ser encontrados isoladamente em uma mesma planta, sendo que alguns indivíduos apresentam apenas o padrão I. 
A matriz da casca do tronco rosada é menos freqüente em relação a casca esbranquiçada.

Faboideae

19. Centrolobium robustum (Vell.) Mart. ex Benth., Comm. Legum. Gen. : 31. 1837.

Prancha 19.

Nome popular: araribá.

Tronco 52-95cm DAP, castanho, cilíndrico. Raízes digitadas, ramificadas, aresta reta a levemente côncava, $a>b, a=40-110 \mathrm{~cm}, b=30-55 \mathrm{~cm}, 10-20 \mathrm{~cm}$ espessura. Casca do tronco reticulada, formada por quadrados, $1 \mathrm{~cm}$ compr., e retângulos transversais, $1 \mathrm{~cm}$ compr., 5mm larg., superfície côncava ou plana, áspera. Delimitação longitudinal por lenticelas verrucosas, maioria fixa, lineares, 5-10(-15)cm compr., 4-7mm larg., 1-2(3)mm espessura, associadas a fissuras. Delimitação transversal por microfissuras, $1 \mathrm{~cm}$ compr. Casca da crista da raiz fendida, com fendas longitudinais, $15-20 \mathrm{~cm}$ compr., 1,5-2,5cm larg., 5-7mm profundidade; fundo com proeminências longitudinais. Domos 1-3cm larg. superfície plana, áspera, com microfissuras transversais. Casca da raiz superficial lenticelada, com lenticelas discolores, castanho-claras, arredondadas, 2$4 \mathrm{~mm}$ diâm., ou elípticas longitudinais e verticais, 4-6mm compr., 2-4mm larg., 1-2cm distância. Matriz castanho-escura.

No indivíduo com maior DAP $(95 \mathrm{~cm})$, o tronco é profundamente acanalado, a casca do tronco é lenticelada, com lenticelas verrucosas, fixas, elípticas, transversais, 0,5-2,0cm compr., 1-4mm larg., 1-2mm espessura, 1-8mm distância longitudinal ou arredondadas 4-6mm diâm.

20. Platymiscium floribundum Vogel, Linnaea 11: 199. 1837.

Prancha 20.

Nome popular: sacambu

Tronco 49-116cm DAP, castanho-claro, ereto, acanalado. Raízes digitadas, simples, aresta reta a levemente côncava, $a>b, a=50-65 \mathrm{~cm}, b=15-23 \mathrm{~cm}, 8-13 \mathrm{~cm}$ espessura. Casca do tronco padrão I: lenticelado, com lenticelas verrucosas, fixas, abertura em espocação, arredondadas, 0,5-1,0cm diâm., 2-3mm espessura, 1-5cm distância, com distribuição irregular, dispersas. Matriz áspera. Padrão II: lenticelada, com lenticelas 
verrucosas, fixas, abertura em espocação, arredondadas, 2-3mm diâm., $1 \mathrm{~mm}$ espessura, em linhas longitudinais, $1-3 \mathrm{~cm}$ compr., 1,0-1,5cm distância, numerosas. Casca da crista do tronco fendida, com fendas longitudinais, retas, $10-20 \mathrm{~cm}$ compr., $0,2-2,0 \mathrm{~cm}$ larg., 3-5mm profundidade; fundo com lenticelas verrucosas, fixas, abertura em espocação, arredondadas, 2-4mm diâm., ou elípticas transversais, 3-6mm compr., 23mm larg., 1mm espessura, 0-3mm distância. Domos 0,8-1,5cm larg.; superfície plana, áspera. Casca da raiz superficial lenticelada, com lenticelas verrucosas, descascadas, abertura estrelada ou em espocação, arredondadas, 2-4mm diâm., e elípticas transversais, 3-5mm compr., 2mm larg., rasas, com distribuição irregular.

Padrões I e II da casca do tronco são observadas isoladamente. As lenticelas do padrão I emergem liberando pequenas lâminas papiráceas descamantes.

21. Pterocarpus rohrii Vahl, Symb. Bot. 2: 79-80. 1791.

Prancha 21.

Nome popular: sangue-de-galo.

Tronco 49-73cm DAP, castanho-esbranquiçado, cilíndrico. Raízes com sapopemas geralmente simples, podendo ser ramificadas na região distal, aresta reta, $a>b, a=50$ $200 \mathrm{~cm}, \mathrm{~b}=30-140,6-13 \mathrm{~cm}$ espessura. Casca do tronco lenticelada com ondulações, lenticelas discolores, brancas, geralmente não-verrucosas, fixas, arredondadas, 1-2mm diâm., <1mm espessura, geralmente em linhas longitudinais, 1-2cm compr., 3-5mm distância, numerosas. Ondulações agudas formando arcos, 8-12cm compr., 2-5mm larg., 1-2mm espessura, $4-12 \mathrm{~cm}$ distância longitudinal. Matriz áspera por lenticelas inconspícuas, arredondadas, 1-2mm diâm., <1 mm espessura, justapostas. Casca da raiz e da crista da raiz rugosa com lenticelas não-verrucosas, fixas, arredondadas, $1 \mathrm{~mm}$ diâm., menos de $1 \mathrm{~mm}$ espessura, em linhas longitudinais 0,5-1,5cm compr., 3-8mm de distância e verrucosas, abertura linear longitudinal, lineares, 2-6cm compr., 2-3mm larg., 0,5-1,4cm distância transversal, associadas a fissuras. Casca da raiz superficial áspera e com lenticelas como na casca da raiz.

Apresentam também dígitos entre as sapopemas e, em indivíduos de menor porte (DAP $49-55 \mathrm{~cm}$ ), podem apresentar raiz apenas digitada ou sapopemas com a=b.

$\mathrm{Na}$ casca do tronco, a matriz áspera pela presença de lenticelas, é observada também em Pseudopiptadenia warmingii e Casearia obliqua, sendo diferenciada, nesta 
espécie, por apresentar linhas longitudinas formadas de lenticelas brancas e sapopemas estreitas.

\section{Swartzia acutifolia Vogel, Linnaea 11: 174. 1837.}

Prancha 22.

Tronco 66-72cm DAP, castanho-claro, acanalado, levemente digitado. Casca do tronco padrão I: áspero com ondulações agudas, em arco ou retas inclinadas, $2-4 \mathrm{~cm}$ compr., 2-3mm larg., 2mm espessura, 2-13cm distância a esparsas. Padrão II: com lâminas papiráceas, irregulares, longitudinais, 6-15cm compr., $4-10 \mathrm{~cm}$ larg., $4-9 \mathrm{~cm}$ distância; superfície e impressão ásperas. Casca da crista do tronco padrão I: áspero com ondulações como o padrão I da casca do tronco. Padrão II: fendido com ondulações, com fendas sinuosas, 0,5-2,0cm compr., 2-3mm larg., $1 \mathrm{~mm}$ profundidade. Domos ásperos, 1-2mm larg. Ondulações agudas, transversais a inclinadas, levemente curvas, 3-7cm compr., 2-3mm larg., dispersas.

Os padrões da casca do tronco e da crista do tronco aparecem em indivíduos diferentes.

\section{Zollernia ilicifolia (Brongn.) Vogel, Linnaea 11: 166. 1837.}

Prancha 23.

Tronco 55-68cm DAP, castanho ou castanho-escuro, acanalado. Raízes com sapopemas simples, aresta côncava, $\mathrm{a}=\mathrm{b}, 50-70 \mathrm{~cm}, 8-13 \mathrm{~cm}$ espessura. Casca do tronco e da raiz padrão I: lenticelado, com lenticelas discolores, castanho-claras, ou da mesma cor do tronco, verrucosas, fixas, arredondadas, 2-3mm diâm., <1mm espessura, abertura estrelada ou linear para todas as direções, e elíptica 3-4mm compr., 2mm larg., abertura linear para todas as direções, $0-5 \mathrm{~cm}$ distância, com distribuição irregular ou formando aglomerados de lenticelas justapostas, esparsas. Algumas faces descamam em lâminas quebradiças, impressão como a casca do tronco. Casca da crista da raiz como a casca do tronco, podendo ser rugosa.

\section{Mimosoideae}

24. Pseudopiptadenia warmingii (Benth.) G.P. Lewis \& M.P. Lima, Arch. Jard. Bot. Rio de Janeiro 30: 54 (1989-90 publ. 1991). 
Prancha 24.

Nome popular: caquerão ou calvi.

Tronco 60-135cm DAP, castanho-claro a castanho-esbranquiçado, cilíndrico. Raízes com sapopemas ramificadas, aresta côncava, $a>b, a=140-260 \mathrm{~cm}, b=120-160 \mathrm{~cm}, 17$ $25 \mathrm{~cm}$ espessura. Raízes superficiais grossas e abundantes. Casca do tronco e da raiz padrão I, principal: áspero com ondulações, com lenticelas inconspícuas verrucosas, com abertura estrelada ou linear para todas as direções, arredondadas 1-2mm diâm, $<1 \mathrm{~mm}$ espessura, justapostas, numerosas. Ondulações agudas, transversais ou formando arcos, 8-12cm compr., 2-5mm larg., 1-2mm espessura, 8-12cm de distância ou mais. Padrão II: fissurado, com fissuras longitudinais, (2-)9-45cm compr., (0,2-)0,5-3,0cm larg., (1,0-)1,5-3,0cm espessura, aglomerados em direção a crista da ramificação e na crista da raiz. Padrão III: descama em lâminas irregulares, esparsas. Casca da crista da raiz padrão I: como a casca do tronco e da raiz. Padrão II: áspero e rugoso, com lenticelas arredondadas, <1mm diâm., 0-1mm distância. Casca da raiz superficial padrão I: rugoso com lenticelas arredondadas, 2-4mm diâm., menos de $1 \mathrm{~mm}$ espessura, e elípticas, transversais, 5-8mm compr., 2-3mm larg., <1mm espessura, $0-1 \mathrm{~cm}$ de distância. Padrão II: áspero com lenticelas arredondadas, 0,5-1,0cm diâm., <1mm espessura, 0-3cm de distância.

Na casca do tronco e da raiz, o padrão I é distribuído por toda superfície sendo encontrado em todos os indivíduos, enquanto os padrões II e III apresentam-se em agrupamentos sobrepostos ao padrão I, ausentes em alguns indivíduos. Na casca da crista da raiz, o padrão II apresenta-se rente ao solo.

Raízes superficiais abundantes e grossas com grandes lenticelas diferenciam esta espécie de outras com casca áspera por pequenas lenticelas inconspícuas (Pterocarpus rohrii e Casearia obliqua).

Seus frutos são freqüentes no solo, o que auxilia em sua identificação.

\section{Humiriaceae}

25. Vantanea compacta (Schnizl.) Cuatrec., Contr. U.S. Natl. Herb. 35(2): 65. 1961. Prancha 25.

Nome popular: guarapari. 
Tronco 52-73cm DAP, castanho, cilíndrico ou levemente acanalado, reto. Com rebrotos com menos de 1cm diâm. Cicatrizes, 7-10 no indivíduo, cilíndricas, proeminentes, de base cilíndrica, $3-5 \mathrm{~cm}$ diâm., $5 \mathrm{~mm}$ espessura. Casca do tronco padrão I: sujo. Padrão II: com depressões alongadas, transversais, 1-2cm compr., 0,5-1,0cm larg., 3mm profundidade, justapostas a 5mm distância.

Os padrões I e II da casca do tronco são encontrados em indivíduos distintos, denotando a plasticidade desse caráter nesta espécie.

\section{Lauraceae}

26. Cryptocarya moschata Nees. \& C. Mart., Linnaea 8: 37. 1833.

Prancha 26.

Nome popular: nhutinga.

Tronco 48-110cm DAP, avermelhado, cilíndrico ou acanalado. Raízes digitadas, simples, de aresta reta a levemente côncava, $a>b, a=20-120 \mathrm{~cm}, b=14-33 \mathrm{~cm}, 11-22 \mathrm{~cm}$ espessura. Casca do tronco variegada, com placas irregulares, alongadas, longitudinais, (4-)8-15cm compr., 4-9cm larg., 1-2mm espessura, 2-10cm distância. Impressão áspera, com lenticelas verrucosas, descamantes, com abertura não evidente, arredondadas, 12mm diâm., 3-4mm espessura.

Podem apresentar uma ou duas sapopemas, aresta reta, a>b, raro b>a, a=50$90 \mathrm{~cm}, \mathrm{~b}=60-120 \mathrm{~cm}$.

A casca do tronco apresenta um padrão muito característico para a espécie, sendo diagnóstico.

27. Nectandra membranacea (Sw.) Griseb., Fl. Brit. W. I. : 282. 1860.

Prancha 27.

Nome popular: canela-cheirosa, canela-preta.

Tronco 56-105cm DAP, castanho, cilíndrico. Com muito rebrotos, 10-15 em um indivíduo, 2-10cm diâm. Raízes digitadas, simples, aresta reta, a>b, a=130-150cm, b=50-70cm, $10-20 \mathrm{~cm}$ espessura. Casca do tronco e raiz padrão I: lenticelado, com lenticelas verrucosas, fixas, abertura em espocação, arredondadas, 2-4mm diâm., 1$2 \mathrm{~mm}$ espessura, distribuídas em linhas longitudinais, $0,8-1,4 \mathrm{~cm}$ distância ou com 
distribuição irregular, numerosas. Matriz áspera ou descamante em lâminas papiráceas, com largura da distância entre as linhas de lenticelas, superfície côncava, impressão áspera. Padrão II: com placas coriáceas, irregulares, justapostas, 1-4cm compr., formadas por lâminas coriáceas estratificadas, superfície plana a côncava, áspera, 3$4 \mathrm{~mm}$ espessura.

Padrões do tronco e da raiz são apresentados isoladamente em um mesmo indivíduo.

28. Ocotea catharinensis Mez, Bot. Jahrb. Syst. 1xvii. 19. 1901.

Prancha 28.

Nome popular: canela-preta, canela-amarela.

Tronco $73 \mathrm{~cm}$ DAP, castanho, inclinado, levemente acanalado, levemente digitado. Com rebroto, $4 \mathrm{~cm}$ diâm. Casca do tronco padrão I: com microfissuras salientes geralmente estreladas, 3-5mm compr., 3-5mm distância. Padrão II: lenticelas discolores, castanho-escuras, verrucosas, fixas, abertura em espocação, arredondadas, 2-4mm diâm., e elípticas, 4-9mm compr., 2mm larg. e 1-2mm espessura, com distribuição irregular ou associadas as microfissuras como as do padrão I, numerosas. Padrão III: com placas lenhosas, irregulares, afina nas bordas, longitudinais, 7-20cm compr., 1,58,5cm larg, 5-8mm espessura; superfície e impressão com lenticelas como no padrão II, impressão em depressão.

Os padrões I e II aparecem isoladamente no mesmo indivíduo, sendo que o padrão I aparece em áreas menores que o padrão II. No padrão II, lenticelas pequenas (2mm) e médias (3-4mm) geralmente aparecem em áreas separadas, de forma que as médias têm menor distância entre si. O padrão III aparece em sobreposição ao padrão II.

Diferencia-se de Ocotea mosenii por apresentar base do tronco levemente digitado.

29. Ocotea mosenii Mez, Jahrb. Königl. Bot. Gart. Berlin 5: 373. 1889.

Prancha 29.

Tronco 117-141cm DAP, castanho-esbranquiçado, cilíndrico. Raízes com sapopemas simples ou ramificadas, aresta reta, $a>b, a=150-340 \mathrm{~cm}, b=115-175 \mathrm{~cm}, 8-20 \mathrm{~cm}$ espessura. Casca do tronco padrão I, principal: lenticelado, com lenticelas discolores, 
pretas, verrucosas, fixas, abertura em espocação, arredondadas, 4-6mm diâm., 3-4mm espessura, raro $2 \mathrm{~mm}$ diâm., $2 \mathrm{~mm}$ espessura, $0-2 \mathrm{~cm}$ distância, formando alguns agrupamentos de justapostas, numerosas. Padrão II: com placas lenhosas, irregulares, 10-20cm compr., 2-10cm larg., 0,5-1,0cm espessura, 5-10cm distância; superfície e impressão lenticelada como o padrão I, impressão em depressão. Casca da raiz padrão I: lenticelado com placas como a casca do tronco. Padrão II: mesmo padrão da casca do tronco, porém com mais descamações. Padrão III: rugosa e lenticelada, com lenticelas como a casca do tronco. Casca da crista da raiz padrão I: lenticelado e rugoso, com lenticelas pretas, verrucosas, descamantes, abertura em espocação, arredondada, $2 \mathrm{~mm}$ diâm., e elípticas, 3-5mm compr., 2mm larg., 1mm espessura, 0-3cm distância; distribuição irregular. Matriz com microfissuras longitudinais, $1 \mathrm{~mm}$ distância transversal. Padrão II: estriado e rugoso, com lenticelas discolores, pretas, $2-6 \mathrm{~cm}$ compr., 2-4mm larg., 0-2mm distância, associadas a fissuras. Padrão III: fendida, com fendas longitudinais, 12-16cm compr., 1,5-2cm larg., 4-6mm espessura; fundo com microfissuras longitudinais, $1 \mathrm{~mm}$ distância.

O padrão II da casca do tronco apresenta-se em algumas faces em sobreposição ao padrão I. Em algumas raízes, na crista da raiz, o padrão III apresenta-se em sobreposição com os demais padrões.

Diferencia-se de Ocotea catharinensis por apresentar sapopemas.

\section{Lecythidaceae}

30. Cariniana estrellensis (Raddi) Kuntze, Revis. Gen. P1. 3(2): 89. 1898.

Prancha 30.

Nome popular: jequitibá.

Tronco 49-61cm DAP, castanho, cilíndrico, reto. Raizes superficiais muito grossas, dispondo-se de maneira radiada à volta da base do tronco. Casca do tronco fissurada, com fissuras longitudinais, retas, $15-70 \mathrm{~cm}$ compr., 0,5-2,0cm larg., 4-8mm profundidade, fundo castanho-escuro. Domos fixos, retangulares, longitudinais, 1570cm compr., 1,5-2,5cm larg.; superfície plana, áspera ou estratificadas. Casca da raiz superficial fendida, com fendas longitudinais, sinuosas formando alvéolos, $1,5-5,0 \mathrm{~cm}$ compr., 3-5mm larg., 3-5mm profundidade, fundo castanho-avermelhado. Domos fixos, 
longitudinais, sinuosos, 4-12cm compr., 3-7mm larg., 3-5mm espessura, superfície áspera a estratificada.

As raízes superficiais radiais em conjunto com a casca fissurada são importantes para a identificação desta espécie.

\section{Magnoliaceae}

31. Magnolia ovata (A. St.-Hil.) Spreng., Syst. Veg., editio decima sexta 4(2): 217. 1827.

Prancha 31.

Nome popular: pinha-do-brejo.

Tronco 50-60cm DAP, castanho-claro, cilíndrico. Raízes digitadas, simples ou com ramificações proximais, aresta côncava, $a>b, a=40-73 \mathrm{~cm}, b=38-43 \mathrm{~cm}$. Casca do tronco padrão I, principal: lenticelado, com lenticelas verrucosas, maioria fixa, abertura linear, lineares, longitudinais, 0,5-8,0cm compr., 3-5mm larg., 1-2mm espessura, 0,5-1,0cm distância, associadas a microfissuras, numerosas. Matriz áspera. Padrão II: lenticelado, com lenticelas, elípticas longitudinais, 2-5cm compr., 1,0-1,5cm larg., 3-4mm espessura, associadas a fissuras, esparsas. Matriz áspera. Casca da raiz castanha, áspera. Casca da crista da raiz padrão I, principal: fissurada, castanho-escura, com fissuras longitudinais, 2-3cm compr., 3-5mm larg., 2-3mm profundidade, justapostas a $3 \mathrm{~mm}$ distância, fundo estratificado, culminando em linha pouco mais avermelhada. Padrão II: lenticelada, com lenticelas verrucosas, fixas, elípticas, 3-4mm compr., 2mm larg., $1 \mathrm{~mm}$ espessura.

$\mathrm{Na}$ casca do tronco, o padrão I pode se apresentar isoladamente ou em sobreposição ao padrão II e apresenta-se como bom caráter para a identificação da espécie.

O padrão II da casca da crista da raiz é pouco freqüente e aparece em sobreposição ao padrão I.

Malvaceae

32. Quararibea turbinata (Sw.) Poir., Encycl., Suppl. 4: 636. 1815.

Prancha 32. 
Tronco $53 \mathrm{~cm}$ DAP, castanho-esbranquiçado, muito acanalado, com dobras. Raízes digitadas, simples, aresta levemente côncava, $a>b, a=30-50, \quad b=15-30,8-10 \mathrm{~cm}$ espessura. Casca do troco e da raiz padrão I: lenticelado, com lenticelas discolores, castanho-escuras, verrucosas, fixas, abertura linear longitudinal, arredondada a levemente alongada longitudinal, 1mm diâm., associadas a microfissuras longitudinais 0,5-1,0(-1,5)cm compr., (0-)2-4mm distância, numerosas. Padrão II: fendido, com fendas sinuosas, formando alvéolos, 2-5cm compr., 0,8-1,5cm larg., 1mm espessura; fundo com lenticelas como no padrão I. Domos agudos, 1mm larg. Padrão III: fendido, com fendas retas, $1,5-4,0 \mathrm{~cm}$ compr., $2 \mathrm{~mm}$ larg., $2 \mathrm{~mm}$ profundidade; fundo com lenticelas como no padrão I. Domos 4-6mm larg., superfície plana, áspera.

Os padrões da casca do tronco e da raiz encontram-se isoladamente em um mesmo indivíduo.

Esta espécie diferencia-se de outras com lenticelas discolores mais escuras que a matriz por estarem ordenadas em linhas longitudinais.

Meliaceae

33. Cabralea canjerana (Vell.) Mart., Syst. Mat. Med. Veg. Bras. : 38.1843. Prancha 33.

Nome popular: cajarana.

Tronco 53-155cm DAP, castanho-avermelhado, acanalado pela continuação dos dígitos maiores. Raízes digitadas, simples, poucas raízes com ramificações distais, aresta côncava, $a<b, a=25-75 \mathrm{~cm}, \mathrm{~b}=40-90 \mathrm{~cm}, 20-22 \mathrm{~cm}$ espessura. Casca do tronco padrão I: lenticelado e rugoso, com lenticelas verrucosas, fixas, arredondadas, abertura em espocação, 2-4mm diâm., 0-2mm espessura, e alongadas, abertura linear ou em espocação, longitudinais ou transversais, 5-7mm compr., 2-3mm larg., <1mm espessura, 0,3-1,0cm distância, numerosas. Matriz áspera com microfissuras longitudinais $1-7 \mathrm{~cm}$ compr., 0,1-2,0cm distância. Padrão II: lenticelado, com lenticelas discolores, castanho um pouco mais escuro que a matriz, verrucosas, fixas ou descamantes, abertura linear, lineares, longitudinais, 1-4cm compr., 1-6mm larg., 0-3mm espessura, 0,5-1,5cm distância, numerosas. Matriz áspera. Padrão III: com microfissuras retas, longitudinais, 1,5-7,0cm compr., 1-7mm distância. Casca da crista do tronco lenticelada, como o padrão II da casca do tronco, porém com lenticelas mais espessas, 5mm, e mais largas, 
$5 \mathrm{~mm}$, formando fissuras na abertura, pouco mais próximas, 3-5mm distância. Matriz com microfissuras. Casca da crista da raiz lenticelada, como o padrão II da casca do tronco, porém lenticelas mais próximas, 3-5mm distância. Matriz com microfissuras.

Os padrões do tronco apresentam-se isoladamente. No padrão I, as lenticelas maiores (4mm espessura) são descamantes. No padrão II, as lenticelas mais espessas e largas são semelhantes a lábios. O padrão III encontra-se em região com poucas lenticelas. Alguns indivíduos apresentam cicatrizes proeminentes, cilíndricas, $6-15 \mathrm{~cm}$ diâm., justapostas, com vários rebrotos, $3-18 \mathrm{~cm}$ diâm. Nestes indivíduos, o tronco é cilíndrico e a base do tronco é reta. A casca do tronco apresenta fissuras delimitando domos de formato irregular a retangular nas regiões próximas às cicatrizes. Entre as cicatrizes existem algumas lenticelas como no padrão II da casca do tronco.

O formato das lenticelas é bem característico para a espécie.

34. Cedrela fissilis Vell., Fl. Flumin. : 75.1825 [1829].

Prancha 34.

Nome popular: cedro.

Tronco 53-56cm DAP, castanho-claro, cilíndrico, reto. Casca do tronco fissurada, com domos grandes, 20-40cm compr., 4-7cm larg., 0,6-1,0cm espessura; superfície plana a levemente côncava, formada por lâminas estratificadas. Delimitação longitudinal por fissuras 4-8mm profundidade. Delimitação transversal não evidente.

Os domos da casca do tronco são diagnósticos por serem os maiores entre as árvores estudadas.

Moraceae

35. Brosimum lactescens (S. Moore) C.C. Berg., Acta Bot. Neerl. 19: 326. 1970.

Prancha 35.

Tronco $62-74 \mathrm{~cm}$ DAP, castanho-claro, cilíndrico, levemente digitado. Casca do tronco padrão I: lenticelado, com lenticelas verrucosas, fixas, abertura não evidente ou lineartransversal, arredondadas, 1-2(-3)mm diâm., <1 mm espessura, 0-3mm distância, com distribuição irregular, numerosas. Padrão II: lenticelado, com lenticelas discolores, castanho-escuras, descamantes, arredondadas, 2-4mm diâm., 2-3mm distância, e elípticas, transversais, 4-6mm compr., 3mm larg., 1mm espessura, 0,3-1,0cm distância, 
com distribuição irregular, numerosas. Casca da base lenticelada e rugosa, com lenticelas como na casca do tronco, padrões I e II.

Os padrões da casca do tronco apresentam-se isoladamente em um mesmo indivíduo.

36. Ficus luschnathiana (Miq.) Miq., Ann. Mus. Bot. Lugduno-Batavum 3: 298. 1867. Prancha 36.

Nome popular: figueira.

Tronco 55cm DAP, castanho-escuro, cilíndrico. Raízes com sapopemas simples, aresta côncava, $a=b=92-108 \mathrm{~cm}, 16-21 \mathrm{~cm}$ espessura. Casca do tronco lenticelada, com lenticelas verrucosas, fixas, abertura em espocação, arredondadas, 3-6mm diâm., 1mm espessura, 0,5-2,0cm distância, com distribuição irregular ou em agrupamentos de lenticelas justapostas, numerosas. Descama em lâminas papiráceas, irregulares, de dimensões variadas. Casca da raiz superficial lenticelada, com lenticelas verrucosas, fixas, abertura não evidente, arredondadas, 2-4mm diâm., 0,3-1,5cm distância, com distribuição irregular.

\section{Myristicaceae}

37. Virola bicuhyba (Schott ex Spreng.) Warb., Ber. Deutsch. Bot. Ges. 13: 92. 1895. Prancha 37.

Nome popular: bucuva.

Tronco 48-105cm DAP, castanho-acinzentado a castanho-escuro, cilíndrico. Raízes com sapopemas, simples ou ramificadas, aresta reta, "a" pouco maior que "b" ou a=b, $\mathrm{a}=100-150 \mathrm{~cm}, \mathrm{~b}=80-130 \mathrm{~cm}, 6-16 \mathrm{~cm}$ espessura. Casca do tronco padrão I: escamoso, com domos retangulares longitudinais, $6-18 \mathrm{~cm}$ compr., $0,8-1,8 \mathrm{~cm}$ larg., $2-4 \mathrm{~mm}$ espessura; superfície plana, áspera, com microfissuras longitudinais, levemente sinuosas, 4-8mm distância. Delimitação longitudinal por fissuras, retas ou levemente sinuosas, 10-30cm compr., 2-8mm larg., 2-6mm profundidade. Delimitação transversal não evidente ou fissuras, 0,8-1,8cm compr., 1-2mm larg., 3-4mm profundidade. Impressão castanho-escura ou avermelhada com microfissuras longitudinais, $2-9 \mathrm{~cm}$ compr., 1,0-1,3cm distância. Padrão II: áspero, com microfissuras com distribuição irregular. Casca da raiz como o padrão II da casca do tronco; Casca da crista da raiz 
fendida, com fendas longitudinais, sinuosas formando alvéolos, 4-6cm compr., 1,01,5cm larg., 4-6mm profundidade; fundo castanho-avermelhado, estratificado. Domos 0,8-1,0cm larg.; superfície áspera.

A base é digitada em indivíduos de DAP inferior a $56 \mathrm{~cm}, \mathrm{a}>\mathrm{b}, \mathrm{a}=35-60 \mathrm{~cm}$, $\mathrm{b}=20-35 \mathrm{~cm}, 10-17 \mathrm{~cm}$ espessura. $\mathrm{Na}$ casca da crista da raiz, quanto mais estreitos os domos, mais largas as fendas que os delimitam.

A identificação é facilitada pela observação da forma das raízes e da casca da crista da raiz. A copa é diagnóstica por apresentar folhas alternas dísticas cujo formato característico é semelhante a uma pena, sendo possível observar mesmo sem binóculos.

\section{Myrtaceae}

38. Campomanesia guaviroba (DC.) Kiaersk., Enum. Myrt. Bras. : 8. 1893. Prancha 38.

Nome popular: guabirobeira.

Tronco 51-66cm DAP, esbranquiçado, profundamente acanalado. Cicatrizes proeminentes, cilíndricas, $13 \mathrm{~cm}$ diâm., $8 \mathrm{~cm}$ espessura. Raízes digitadas, geralmente simples, aresta reta ou côncava, $a>b, a=45-60, b=30-60 \mathrm{~cm}, 5-8 \mathrm{~cm}$ espessura. Casca do vale do tronco e casca da raiz padrão I, principal: áspera. Padrão II: laminado, com lâminas papiráceas irregulares, longitudinais, 6-20cm compr., 2-8cm larg., esparsas. Casca da crista do tronco e crista da raiz padrão I, principal: fissurado, com fissuras retas ou levemente sinuosas, contínuas, 1-2mm larg., 1mm profundidade. Domos 35mm larg.; superfície plana, com muitas microfissuras, $1 \mathrm{~mm}$ distância. Padrão II: laminado, com lâminas papiráceas irregulares, longitudinais, 6-14cm compr., 2-6cm larg., esparsas. Casca da raiz superficial padrão I: áspero. Padrão II: laminado, com lâminas papiráceas irregulares, longitudinais, 4-8cm compr., 2-4cm larg., esparsas. Padrão III: com microfissuras contínuas, 2-3mm distância.

Os padrões de cada região são encontrados em sobreposição.

$\mathrm{O}$ indivíduo de maior DAP apresenta rebrotos formando tufos na base. Na casca do tronco, o padrão áspero é apresentado em maior área, com poucas lâminas.

39. Eugenia cambucarana Kiaersk., Enum. Myrt. Bras. 151. 1893. 
Prancha 39.

Tronco 50-70cm DAP, cinza-esbranquiçado, inteiramente acanalado, com sulcos profundos, podendo formar dobras. Raízes com sapopemas simples, aresta côncava, $\mathrm{a}=\mathrm{b}=75-90 \mathrm{~cm}, 8-10 \mathrm{~cm}$ espessura. Casca do tronco laminada, com lâminas papiráceas, retangulares, longitudinais, 4-10cm compr., 1-6cm larg., justapostas; superfície plana, áspera. Impressão com microfissuras longitudinais. Casca da crista do tronco laminada, com lâminas como na casca do tronco, larg. 1-2cm.

40. Eugenia capitulifera O. Berg, Fl. Bras. (Martius) 14(1): 263.

Prancha 40.

Tronco $49 \mathrm{~cm}$ DAP, cinza-esbranquiçado, acanalado, com sulcos profundos, formando dobras. Raízes digitadas, simples, aresta côncava, a>b, a=40-65cm, b=25-45cm, 10$13 \mathrm{~cm}$ espessura. Casca do tronco padrão I: áspera. Padrão II: com lâminas papiráceas, irregulares ou retangulares, $3-5 \mathrm{~cm}$ compr., 1,0-1,5cm larg., esparsas. Padrão III: fissurado, com fissuras 2-4cm compr., 1-2mm larg., 2-3mm espessura, 0,5-1,0cm distância transversal. Padrão IV: com microfissuras 1-3cm compr., 2-4mm distância. Casca da crista do tronco padrão I: com lâminas papiráceas, irregulares ou retangulares, 3-5cm compr., 1-1,5cm larg., 5-8cm distância. Padrão II: fissurado, como o padrão III da casca do tronco. Casca da crista da raiz fissurada, como o padrão III da casca do tronco. Casca da raiz superficial áspera.

$\mathrm{Na}$ casca do tronco, o padrão I pode ocorrer em sobreposição ao II. O padrão II pode ocorrer em sobreposição ao III e ao IV. Na casca da crista do tronco, os padrões I e II podem ser apresentados em sobreposição.

\section{Eugenia cereja D. Legrand, Sellowia 13: 316. 1961.}

Prancha 41.

Tronco $58 \mathrm{~cm}$ DAP, castanho-esbranquiçado, inteiramente acanalado, com sulcos profundos. Com rebrotos, $10-15 \mathrm{~cm}$ diâm. Cicatrizes proeminentes, cilíndricas, $3,5 \mathrm{~cm}$ diâm., ou elípticas longitudinais, $10 \mathrm{~cm}$ compr., $6 \mathrm{~cm}$ larg. Raízes digitadas, simples, côncavas, $a=b=90-100 \mathrm{~cm}, 7-13 \mathrm{~cm}$ espessura. Raízes superficiais abundantes. Casca do tronco laminada, com lâminas papiráceas, retangulares, longitudinais, $4-7 \mathrm{~cm}$ compr., 1-2cm larg., justapostas, superfície plana a côncava, quando em desprendimento, áspera. Impressão áspera. Casca do vale com ondulações 
longitudinais, 3-5mm larg, 1-2mm espessura, contínuas, justapostas. Casca da crista do tronco laminada, como a casca do tronco, porém com lâminas mais estreitas, 5-8mm larg. Casca da crista da raiz padrão I: laminado, como a casca da crista do tronco. Padrão II: fissurada, com fissuras longitudinais, 2-4cm compr., 2-4mm larg., 2mm espessura, 0,5-1,0 cm distância. Casca da raiz padrão I: laminada, como a casca do tronco. Padrão II: áspera. Padrão III: com microfissuras longitudinais, 1-2cm compr., 0,5-1,0cm distância.

Os padrões de todas as cascas são encontrados isoladamente.

42. Eugenia cf. burkartiana (D. Legrand) D. Legrand, Sellowia 13: 321. 1961.

Prancha 42.

Nome popular: pau-brasil-branco.

Tronco 62cm DAP, creme-esbranquiçado, cilíndrico. Raízes com sapopemas simples ou com pequenas ramificações distais, aresta reta a levemente côncava, a>b, a=130$210 \mathrm{~cm}, b=60-90 \mathrm{~cm}, 15-20 \mathrm{~cm}$ espessura. Casca do tronco lisa. Casca do vale com ondulações longitudinais, $0,5-1,0 \mathrm{~cm}$, justapostas. Casca da raiz superficial laminada, esbranquiçada com lâminas coriáceas, castanho-escuras ou esverdeadas.

A casca do tronco é lisa devido à descamação que ocorreu no processo de crescimento, sendo possível observar as lâminas coriáceas acumuladas na base da árvore formando um amontoado. Observada a uma distância de 1,5-2,0m tem-se a impressão que a casca do tronco é levemente rugosa.

Única espécie da parcela com tronco inteiramente liso.

43. Eugenia multicostata D. Legrand, Sellowia 13: 309. 1961.

Prancha 43.

Nome popular: pau-brasil-vermelho.

Tronco $53 \mathrm{~cm}$ DAP, vermelho, cilíndrico. Com rebroto, $5 \mathrm{~cm}$ diâm. Cicatrizes proeminentes, cilíndricas, $10 \mathrm{~cm}$ diâm. Raízes digitadas, $a>b, a=35-50 \mathrm{~cm}, b=23-45 \mathrm{~cm}$, 5-6cm larg. Casca do tronco laminada, com lâminas coriáceas, irregulares, longitudinais, 7-20cm compr., 3-5cm larg.; superfície castanho-avermelhada, com muitos musgos e liquens esbranquiçados ou verdes. Impressão vermelha, lisa. Casca da raiz superficial castanha, áspera. 
Acima de 4m, o tronco é inteiramente vermelho e a textura é lisa.

44. Eugenia subavenia O. Berg, Fl. Bras. 14(1): 571. 1849.

Prancha 44.

Tronco $48 \mathrm{~cm}$ DAP, castanho bem claro, inteiramente acanalado. Cicatrizes proeminentes, cilíndricas, $4-15 \mathrm{~cm}$ diâm. Raízes digitadas, simples, aresta reta, a=b=30$43 \mathrm{~cm}, 5-7 \mathrm{~cm}$ espessura. Casca do tronco laminada, com lâminas papiráceas, retangulares, longitudinais, $3-8 \mathrm{~cm}$ compr., 1,5-4,0cm larg., justapostas Impressão castanho-avermelhada, áspera.

45. Marlierea suaveolens Cambess., Fl. Bras. Merid. (quarto ed.) 2: 374, t. 156. 1833. Prancha 45.

Tronco 50-53cm DAP, esbranquiçado, inteiramente acanalado, levemente digitado. Com rebroto, $4,5 \mathrm{~cm}$ diâm., com casca verde. Casca do tronco laminada, com lâminas geralmente coriáceas, algumas papiráceas, irregulares, longitudinais, 7-19cm compr., 5$7 \mathrm{~cm}$ larg., involutas ao descamar; superfície ondulada, com microfissuras longitudinais, 3-8mm compr, 2-5mm distância, em agrupamentos. Impressão castanha bem clara ou castanho-escura, áspera.

46. Myrcia pubipetala Miq., Linnaea 19: 441. 1845.

Prancha 46.

Nome popular: guamirim.

Tronco 50-64cm DAP, esbranquiçado, cilíndrico, reto a levemente digitado ou com raízes digitadas, simples, aresta reta, $a=b=20-30 \mathrm{~cm}$ e com sapopemas, simples, aresta reta, $\mathrm{a}=\mathrm{b}=50-120 \mathrm{~cm}$. Casca do tronco variegada, com placas involutas ao descamar, 15-20cm compr., 4-6cm larg., 5-8mm espessura, 4-20cm distância; superfície ondulada, suja; impressão castanho-escura, áspera, com lenticelas verrucosas, fixas, abertura circular ou não evidente, arredondadas, 1-2mm diâmetro, 2-5mm distância a esparsas, e elípticas, 4-5mm compr., $2 \mathrm{~mm}$ larg., <1mm espessura, esparsas.

Nyctaginaceae 
47. Pisonia ambigua Heimerl, Denkschr. Kaiserl. Akad. Wiss., Math.-Naturwiss. Kl. 79: 236.1983.

Prancha 47.

Nome popular: joão-mole.

Tronco 50-72cm DAP, esbranquiçado, cilíndrico, levemente dilatado. Casca do tronco lenticelada, com lenticelas discolores, castanho-escuro-avermelhado, verrucosas, descamantes, com abertura em espocação, arredondadas, 3-5mm diâm., 2mm espessura, 0,5-5,0cm distância, com distribuição irregular, esparsas. Matriz áspera com microfissuras. Casca da base do tronco lenticelada e rugosa, lenticelas como na casca do tronco. Casca da raiz superficial lenticelada, como na casca do tronco, porém com lenticelas menores, 2-4mm diâm., 1mm espessura, 3-10cm distância, esparsas. Matriz áspera.

A base do tronco dilatada a diferencia de outras espécies com lenticelas discolores mais escuras que a casca.

Olacaceae

48. Heisteria silvianii Schw., Pl. Nov. Mineir. 2: 3, t. 1. 1900.

Prancha 48.

Nome popular: brinco-de-mulata.

Tronco 54-62 cm DAP, castanho-avermelhado a castanho-claro, cilíndrico, reto. Casca do tronco padrão I: reticulado, castanho-avermelhado, com retângulos longitudinais, 1,0-1,8cm compr., 4-8mm larg.; superfície côncava, áspera. Delimitação longitudinal por fissuras, 2-5cm compr., 1-3mm larg., 1mm profundidade. Delimitação transversal por microfissuras, 3-7mm compr. Padrão II: estriado, lenticelas discolores associadas a fissuras, castanho-escuras, lineares longitudinais, verrucosas, fixas, 3-7cm compr., 35mm larg., 0-2mm espessura, 0,5-1,0cm distância transversal. Domos de superfície rugosa, côncava. Matriz castanho-clara.

Os padrões I e II estão presentes isoladamente em um mesmo indivíduo. No padrão I, ocorrem raras lenticelas arredondadas, verrucosas, fixas, abertura em espocação, nas delimitações do retículo, 5mm diâm., $2 \mathrm{~mm}$ espessura ou lenticelas longitudinais, verrucosas, associadas a fissuras, $1,5 \mathrm{~cm}$ compr., $4 \mathrm{~mm}$ larg., $3 \mathrm{~mm}$ 
espessura. Por vezes, o padrão II torna-se escamoso pela abertura das lenticelas em fendas 4-8mm larg., 0,2-1,0cm profundidade. Este padrão de retículo é encontrado apenas nesta espécie.

49. Tetrastylidium grandifolium (Baill.) Sleumer., Nat. Pflanzenfam. (ed. 2) 16b: 19, f. 9A-C. 1935.

Prancha 49.

Nome popular: mandegaú.

Tronco 52-74cm DAP, castanho-claro, cilíndrico a levemente acanalado. Raízes levemente digitadas ou digitadas, simples, aresta reta a levemente côncava, $a>b, a=30-$ $70 \mathrm{~cm}, \mathrm{~b}=17-60 \mathrm{~cm}, 10-14 \mathrm{~cm}$ espessura. Casca do tronco padrão I, principal: sujo, com lenticelas inconspícuas e placas de desprendimento irregulares. Padrão II: escamoso, com domos irregulares a retangulares, longitudinais, 5-8cm compr., 1-2(-3)cm larg., 1$4 \mathrm{~mm}$ espessura; superfície plana, suja. Delimitação longitudinal por fendas $5-8 \mathrm{~cm}$ compr., 1-4mm larg., 1-4mm espessura. Delimitação transversal não evidente. Impressão áspera com lenticelas verrucosas, descamantes, arredondadas, 2-4mm diâm, com abertura estrelada, 1-2mm espessura, 0,5-1,0 cm distância, ou associadas a fissuras longitudinais, com abertura linear, 0,5-1,0cm compr., 4-5mm larg., $1 \mathrm{~mm}$ espessura, $1 \mathrm{~cm}$ distância. Padrão III: lenticelado, com lenticelas discolores, castanho bem claro, ou mesma cor da casca, verrucosas, descamantes, arredondados, abertura não evidente ou estralada, 4-5mm diâm., 4-7mm espessura, ou elípticas, levemente retangular, abertura linear, em todas as direções, 0,7-1,2cm compr., 4-7mm larg., 4-7mm espessura, 1-8mm distância, numerosas.

Os padrões da casca do tronco são encontrados isoladamente na mesma planta e em algumas regiões se sobrepõem.

O padrão I da casca do tronco é diagnóstico, mesmo com a aparente desorganização da textura suja, que, após algumas experiências de campo, é facilmente reconhecida.

\section{Phyllanthaceae}

50. Hyeronima alchorneoides Fr. Allem., Diss. in Trab. Vell. Rio Janeiro ill. 1848. Prancha 50. 
Nome popular: urucurana.

Tronco 48-140cm DAP, castanho-avermelhado com regiões castanho-esbranquiçadas, cilíndricas. Frequentemente com cicatrizes proeminentes, cilíndricas ou elípticas, $5-8 \mathrm{~cm}$ compr., 4-5cm larg., 1-3cm espessura, $20 \mathrm{~cm}$ distância ou mais. Raízes digitadas e com sapopemas, simples a ramificadas, aresta reta ou côncava, com grande variação na relação dos comprimentos "a" e "b", variando de 30-220cm, 10-20cm espessura. Raízes superficiais frequentemente abundantes. Casca do tronco, da lateral raiz e da raiz superficial padrão I: áspero com microfissuras longitudinais ou estreladas, $1-4 \mathrm{~cm}$ compr., 0,4-2,0cm distância e fissuras longitudinais, 3-17cm compr., 2-4mm larg., 1$5 \mathrm{~cm}$ distância, em agrupamentos. Padrão II: lenticelado, com lenticelas da mesma cor da matriz ou discolores, castanho-claro, verrucosas, fixas ou descamantes, arredondadas, 1-4mm diâm., 0-3mm espessura, e lineares, associada a fissuras, 1-6cm compr., 2-5mm larg., <1 mm espessura, 0-1,5cm distância, em agrupamentos, esparsas. Padrão III: com lâminas papiráceas irregulares, alongadas, longitudinais, quebradiças, 3-10cm compr., 2-5cm larg., em agrupamentos, esparsas. Impressão com ranhuras longitudinais, geralmente avermelhadas.

Os padrões da casca do tronco apresentam-se isoladamente ou em sobreposição.

Existe uma grande variação nos estados dos caracteres apresentados por esta espécie. A identificação é mais facilmente confirmada pela copa. Como as folhas aglomeram-se na porção apical dos ramos em filotaxia alterna espiralada, observando de baixo aparenta ser palmada, formando um círculo de folhas com longos pecíolos. Além disso, as folhas tornam-se vermelhas e caem com freqüência.

\section{Phytolaccaceae}

51. Phytolacca dioica L., Sp. Pl. (ed. 2) 1: 632. 1762.

Prancha 51.

Nome popular: ceboleiro.

Tronco 100-117cm DAP, castanho bem claro, cilíndrico ou levemente acanalado, dilatado. Casca do tronco padrão I: fendido, com fendas longitudinais, retas a sinuosas, (2-)5-12cm compr., 0,4-3,0cm larg., 2-4mm espessura. Domos longitudinais, com extremidades afinadas, 0,8-2,0cm larg.; superfície áspera, côncava, laterais côncavas de modo que sobressai, por vezes, a fenda. Padrão II: fissurado, com fissuras longitudinais, 
retas a levemente sinuosas, 5-12cm compr., 2-7mm larg., 2-6mm espessura. Domos longitudinais, (0,5-)1,0-2,0cm larg.; superfície áspera e convexa. Padrão III: lenticelado, com lenticelas verrucosas, abertura em espocação, ou não-verrucosas com abertura estrelada ou linear, todas as direções, arredondadas, 0,1-1,0cm diâm., 2-3mm espessura, 0-2cm distância, com distribuição irregular. Casca da base do tronco lenticelada e com ondulações, com grandes lenticelas verrucosas, fixas, arredondadas, $1-3 \mathrm{~cm}$ diâm., 2$3 \mathrm{~mm}$ espessura ou elípticas, longitudinais, 1,0-1,5cm compr., 6-8mm larg., 2-3mm espessura, 0,3-2,0cm distância a esparsas, distribuição irregular. Ondulações transversais, 1,0-1,5cm larg., 3-5mm espessura, justapostas. Casca da raiz superficial lenticelada com microfissuras. Grandes lenticelas verrucosas, raro não-verrucosas, arredondadas, 0,5-1,0cm diâm., 0-2mm espessura, 2-5cm distância. Microfissuras estreladas, 0,4-1,0(-2,0)cm compr., 2-4cm distância, numerosas.

Os padrões da casca do tronco são apresentados isoladamente em um mesmo indivíduo.

Ocorre a formação de uma estrutura intumescida de grandes proporções na base do tronco, facilitando o reconhecimento da espécie.

Polygonaceae

52. Coccoloba fastigiata Meisn., Fl. Bras. (Martius) 5(1): 34.

Prancha 52.

Tronco com $62 \mathrm{~cm}$ de DAP, castanho, levemente acanalado, levemente digitado. Casca do tronco padrão I, principal: lenticelado, com lenticelas verrucosas, fixas, abertura não evidente, arredondadas, 2-3mm diâm., 1-2mm espessura, 0-5mm distância, distribuição irregular ou em linhas longitudinais, 3-5mm distância transversal. Padrão II: fissurado, com fissuras retas, longitudinais $0,4-2,0 \mathrm{~cm}$ compr., $1 \mathrm{~mm}$ larg., e transversais $0,4-1,0 \mathrm{~cm}$ compr., 1mm larg. Domos quadrangulares, 4-5mm compr., e retangulares geralmente transversais, 1,0-1,5cm compr., 4-6mm larg.

Os padrões da casca do tronco encontram-se isoladamente no mesmo indivíduo, sendo que o padrão II aparece em pequenos agrupamentos distribuídos pelo tronco. 
53. Roupala brasiliensis Kl., Linnaea 15: 55. 1841.

Prancha 53.

Nome popular: carne-de-vaca, carvalho.

Tronco 67cm DAP, castanho, levemente acanalado. Raízes digitadas, simples, aresta côncava, $a<b, a=30-50 \mathrm{~cm}, b=50-100 \mathrm{~cm}, 20-23 \mathrm{~cm}$ espessura. Casca do tronco padrão I, principal: rugoso, com lenticelas inconspícuas, não-verrucosas, fixas, com abertura circular, arredondada, 1-3mm diâm, <1 mm espessura, 0,5-1,5cm distância, numerosas, e elípticas transversais, 4-6mm compr., 2mm larg., esparsas. Padrão II: fissurado, com fissuras longitudinais, retas, 6-19cm compr., 0,8-1,0cm larg., 6-8mm espessura; fundo áspero. Domos (4,0-)5,5-8,0cm compr., 0,8-1,0cm larg., 2,0-2,5cm espessura; superfície áspera, mais ou menos plana. Casca da raiz padrão I: com ondulações transversais, 3$5 \mathrm{~cm}$ larg. Padrão II: lenticelada e com ondulações, semelhante a casca do tronco. Casca da raiz superficial padrão I: castanho, áspero a sujo, com lenticelas, arredondadas, (2)4-5mm diâm., elípticas, 6-7mm compr., 4-5mm larg., 3mm espessura; distribuição irregular, esparsas. Padrão II: com placas irregulares, $<1 \mathrm{~mm}$ espessura, domos de superfície áspera, côncava, 2,0-2,5cm compr., 0,8-1,0cm larg., 2-4mm profundidade. Padrão III: lenticelada, com lenticelas, verrucosas, abertura linear, lineares, transversais, 0,8-1,2cm compr., 2-4mm larg., <1mm espessura, e arredondadas, 0,2-0,4cm diâm., 0,51,0cm distância, em linhas transversais, numerosas. Matriz áspera.

Os diferentes padrões de casca do tronco aparecem isoladamente na mesma planta. Os padrões da casca da raiz superficial aparecem em raízes diferentes do mesmo indivíduo.

\section{Rubiaceae}

54. Simira corumbensis (Standl.) Steyerm., Mem. New York Bot. Gard. 23: 306. 1972.

Prancha 54.

Tronco 48-82cm DAP, castanho, castanho-avermelhado ou castanho-esbranquiçado, inteiramente acanalado. Raízes digitadas, geralmente simples, aresta côncava, a=b ou $a>b, a=30-70 \mathrm{~cm}, b=30-45 \mathrm{~cm}, 12-24 \mathrm{~cm}$ espessura. Casca do tronco padrão I, principal: lenticelado, com lenticelas discolores, castanho-escuro, verrucosas, descamantes, 
abertura linear em todas as direções ou estrelada, arredondadas, 1-4mm diâm., 1-2mm de espessura, 2-5mm distância, distribuição irregular. Matriz áspera, com microfissuras. Padrão II: com placas lenhosas, irregulares a arredondadas, afinam nas bordas, $3-5 \mathrm{~cm}$ diâm, justapostas; superfície plana, lenticelada como o padrão I; impressão com depressões justapostas. Casca da crista da raiz lenticelada, semelhante ao padrão I da casca do tronco, rugoso ou com ondulações justapostas, 0,5-1,0cm larg. Raiz superficial como o padrão I da casca do tronco.

No padrão I da casca do tronco, lenticelas pequenas e médias apresentam-se agrupadas separadamente. O padrão II está presente apenas em alguns indivíduos e é apresentado em sobreposição ao padrão I. No padrão I da casca da crista da raiz estão mescladas lenticelas pequenas e médias, podendo encontrar-se em sobreposição ao padrão II.

Esta espécie diferencia-se das outras com lenticelas mais escuras que a matriz por apresentar tronco acanalado. Além disso, os ramos baixos facilitam a identificação por binóculos.

\section{Sabiaceae}

55. Meliosma sellowii Urb., Ber. Deutsch. Bot. Ges. xiii. (1895) 212.

Prancha 55.

Tronco 55cm DAP, castanho bem escuro, acanalado. Raízes digitadas, simples, aresta levemente côncava, $a>b, a=37-115 \mathrm{~cm}, b=20-70 \mathrm{~cm}, 10-15 \mathrm{~cm}$ espessura. Casca do tronco lenticelada, com lenticelas discolores castanho-claras ou da mesma cor da casca, verrucosas, fixas, elípticas, 2-3mm compr., 1-2mm larg., <1mm espessura, justapostas, direção aleatória; e arredondadas, 2-3mm diâm., 1-2mm espessura, 0-4mm distância, em agrupamentos, numerosas. Descamam em lâminas irregulares, quebradiças, a impressão lenticelada como o padrão I. Casca da raiz como a casca do tronco, porém mais suja. Casca da raiz superficial lenticelada, com lenticelas, discolores, castanhoclaro, arredondadas, 2-3mm diâm., <1 mm espessura, 0-2(-3)cm distância, com distribuição irregular. 
56. Casearia obliqua Spreng., Syst. Veg., editio decima sexta 2: 355.1825.

Prancha 56.

Tronco 52-60cm DAP, castanho bem claro, bege, cilíndrico. Pode apresentar cicatrizes proeminentes, elípticas, transversais, $23-25 \mathrm{~cm}$ compr., 9-10 $\mathrm{cm}$ larg., 3-4cm espessura. Raízes com sapopemas simples, aresta côncava, a>b, a=68-140cm, b=44-130cm, 7$10 \mathrm{~cm}$ espessura. Casca do tronco padrão I, principal: áspero, com lenticelas muito inconspícuas, arredondadas, 1-2mm diâm., <1mm espessura, 0-2mm distância, numerosas. Padrão II: com microfissuras longitudinais, $1-3 \mathrm{~cm}$ compr., $0,4-1,0 \mathrm{~cm}$ distância, as vezes associadas a lenticelas. Padrão III: com placas lenhosas, irregulares, longitudinais, 2-10cm compr., 1,0-3,5cm larg., 1-3mm espessura; superfície e impressão como a textura do padrão I. Casca da raiz áspera, com pequenas lenticelas, inconspícuas, arredondadas, $1 \mathrm{~mm}$ diâm., justapostas. Cascas da crista da raiz rugosa e áspera como o padrão I da casca do tronco. Casca da raiz superficial esbranquiçada, com lenticelas discolores, castanhas, arredondadas, 1-2mm diâm., <1mm espessura, justapostas, em agrupamentos, e alongadas, 0,5-3,5cm compr., 1-2mm larg, rasas, 2$4 \mathrm{~mm}$ distância, numerosas.

Na casca do tronco, o padrão I geralmente é encontrado isoladamente. O padrão II, bem como o padrão III, sempre apresenta-se em sobreposição ao padrão I, em algumas áreas do tronco, podendo, ainda, estar ausente.

Diferencia-se das outras espécies que apresentam casca do tronco com textura áspera por lenticelas inconspícuas, justapostas por não apresentar ondulações agudas.

\section{Sapindaceae}

57. Matayba guianensis Aubl., Hist. Pl. Guiane: 331-332, t. 128. 1775.

Prancha 57.

Nome popular: miguel-pintado, cuvatã.

Tronco 58cm DAP, castanho-claro com liquens brancos, levemente acanalado. Raízes digitadas, simples, aresta côncava, $a>b, a=40-90 \mathrm{~cm}, \mathrm{~b}=25-60 \mathrm{~cm}, 6-15 \mathrm{~cm}$ espessura. Casca do tronco e da raiz padrão I: lenticelado, com lenticelas verrucosas, fixas, abertura circular ou linear, arredondadas a alongadas transversais, 2-4mm compr., $2 \mathrm{~mm}$ larg., <1mm espessura, 0-1cm distância, distribuição irregular. Em matriz áspera. Padrão II: rugoso, com faixas transversais rugosas que se estendem por todo o perímetro 
do tronco, 4-5cm larg., 5-13cm distância longitudinal. Casca da crista da raiz e da raiz superficial como a casca do tronco, porém toda a superfície é rugosa.

Os padrões I e II apareceram intercalados, sem sobreposição.

Sapotaceae

58. Chrysophyllum inornatum Mart., Flora 21(Beibl. 2): 96. 1838.

Prancha 58.

Tronco $53-57 \mathrm{~cm}$ DAP, castanho-esbranquiçado, inteiramente acanalado, reto. Com rebrotos, $2-8 \mathrm{~cm}$ diâm. Casca do tronco e da raiz superficial padrão I, principal: com microfissuras longitudinais, retas, $1-1,5 \mathrm{~cm}$ compr., 2-5mm distância transversal, podendo estar associadas a lenticelas verrucosas, fixas, abertura linear, lineares, longitudinais, 1,0-1,5cm compr., 1-2mm larg., <1mm espessura, 2-5mm distância transversal. Padrão II: áspero. Padrão III: lenticelado, com lenticelas, verrucosas, fixas, abertura estrelada, linear ou não evidente, arredondada, 1-2mm diâm., e alongadas, 24mm compr., 1-2mm larg., $1 \mathrm{~mm}$ espessura, 0-4mm distância, em pequenos agrupamentos.

Os padrões da casca do tronco são encontrados isoladamente em um mesmo tronco.

Um único indivíduo apresentou uma sapopema, com casca com dois padrões isolados. Padrão I: com estrias castanho-escuras, longitudinais, sinuosas, 3-6cm compr., 0,5-1,0cm larg., <1 mm espessura, 3-6mm distância, na região proximal. Padrão II: lenticelada, com lenticelas longitudinais, verrucosas, fixas, abertura linear, $0,5-2,0 \mathrm{~cm}$ compr., 2-4mm larg., 1-2mm espessura, 2-5mm distância, associadas a fissuras, na região distal. Matriz áspera.

59. Chrysophyllum viride Mart. \& Eichl., Fl. Bras. 7: 102. 1863.

Prancha 59.

Nome popular: guiné.

Tronco 51-96cm DAP, cinza-escuro a cinza-claro, acanalado. Raízes digitadas, simples ou ramificadas, aresta côncava, geralmente $a<b, a=60-75 \mathrm{~cm}, b=66-130 \mathrm{~cm}, 20-40 \mathrm{~cm}$ espessura. Raízes superficiais abundantes. Casca do tronco padrão I, principal: áspero, 
podendo apresentar lenticelas inconspícuas, arredondadas a elíptico-longitudinais, 0,22,5cm compr., 2-4mm larg., 0,3-1,0cm distância transversal, associadas a microfissuras, esparsas ou numerosas. Padrão II: com depressões circulares, 1-3cm diâm., 4-8mm profundidade, esparsas ou em aglomerações de $0-1,5 \mathrm{~cm}$ distância entre as depressões. Casca da crista da raiz com ondulações transversais, justapostas, 1,0-1,5cm larg., na região proximal. Casca da raiz superficial cinza-escuro, lenticelada, com lenticelas discolores, castanho-claras, verrucosas, fixas, arredondadas, 2-3mm diâm., elípticas e lineares longitudinais, 0,5-1,5cm compr., 2-3mm larg., $<1 \mathrm{~mm}$ espessura, 0,3-1,0cm distância transversal e 0-3cm distância longitudinal, em linhas longitudinais, numerosas. Matriz áspera.

Em algumas plantas as lenticelas do padrão I da casca do tronco são evidentes.

As ondulações da casca da crista da raiz são muito características, sendo muito importantes para a identificação desta espécie. A raiz superficial é abundante e sua casca também é muito característica para a espécie.

60. Ecclinusa ramiflora Mart., Flora 22(1); Beibl. 1: 2.1839.

Prancha 60.

Nome popular: pindaúva.

Tronco $66 \mathrm{~cm}$ DAP, cinza-escuro, acanalado, reto. Casca do tronco padrão I: com placas irregulares, 4-7cm compr., 1-2cm larg., 1-2mm espessura; superfície áspera; impressão castanha, com lenticelas lineares, verrucosas, fixas, associadas a microfissuras, longitudinais, 0,5-2cm compr., $1 \mathrm{~mm}$ larg., <1 $1 \mathrm{~mm}$ espessura, 2-4mm distância transversal. Padrão II: fissurada, com fissuras longitudinais, sinuosas, $2-10 \mathrm{~cm}$ compr., 2-4mm larg., 1-3mm espessura, 0,8-1,3cm distância transversal; superfície áspera.

Os padrões da casca do tronco encontram-se isoladamente.

61. Pouteria caimito (Ruiz \& Pav.) Radlk., Sitzungsber. Math.-Phys. Cl. Königl. Bayer. Akad. Wiss. München 12(3): 333. 1882.

Prancha 61.

Nome popular: embuia. 
Tronco 65-68cm DAP, castanho a castanho avermelhado, acanalado. Raízes digitadas, simples, aresta reta, $a>b, a>160 \mathrm{~cm}, b=30-40 \mathrm{~cm}$, ou com sapopemas, aresta reta ou côncava, $a=b=90-110 \mathrm{~cm}$. Casca do tronco com domos lineares, longitudinais, $13-27 \mathrm{~cm}$ compr., 1,3-2cm larg., 2-5mm espessura; superfície plana, áspera. Delimitação longitudinal por fendas, $16-40 \mathrm{~cm}$ compr., $3-4 \mathrm{~mm}$ larg., 2-5mm profundidade. Delimitação transversal por fissuras 1,3-2cm compr., 1-2mm larg., 1-3mm profundidade. Casca do vale do tronco com placas de desprendimento, irregulares, longitudinais, 15-30cm compr., 3-14cm larg., 1-2mm espessura, 0-5cm distância; superfície áspera; impressão com fissuras longitudinais 7-15cm compr., 1-2mm larg., 1$2 \mathrm{~mm}$ profundidade, $0,5-1,8 \mathrm{~cm}$ distância. Impressão áspera. Casca da crista do tronco com domos lineares, longitudinais, 10-20cm compr., 0,7-1,0cm larg., 3-5mm espessura; superfície plana, áspera. Delimitação longitudinal por fendas, 17-30cm compr., 0,41,0cm larg., 3-5mm profundidade; fundo áspero. Delimitação transversal não evidente.

Os padrões I e II da casca do tronco aparecem separadamente: o padrão I mais próximo da região da crista do tronco e o padrão II mais próximo do vale do tronco.

A casca com domos lineares é muito característica para identificar a espécie.

62. Pouteria psammophila (Mart.) Radlk., Sitzungsber. Math.-Phys. Cl. Königl. Bayer. Akad. Wiss. München 12: 333. 1882.

Prancha 62.

Tronco $60 \mathrm{~cm}$ DAP, castanho-acinzentado, cilíndrico. Raiz com sapopemas, simples, levemente côncava, $a>b, a=80-110 \mathrm{~cm}, b=37-60 \mathrm{~cm}, 11-18 \mathrm{~cm}$ espessura. Casca do tronco com domos lineares, com placas irregulares a retangulares longitudinais, geralmente com adesão na região lateral da placa, quebradiças, $2-5 \mathrm{~cm}$ compr., $1,5-2 \mathrm{~cm}$ larg., <1mm espessura. Delimitação longitudinal por fendas paralelas. Impressão castanho levemente avermelhado e alguns locais esbranquiçado, com lenticelas discolores, castanho levemente avermelhado, verrucosas, fixas, abertura linear, lineares, associadas a microfissuras longitudinais, pararelas, 0,5-2,0(-3,0) cm compr., $1 \mathrm{~mm}$ larg., $<1 \mathrm{~mm}$ espessura, 0-2mm distância. Casca da crista do tronco fendida, com fendas paralelas 4-6cm compr., 1-2mm larg., 1-2mm espessura, 0,7-1 cm distância, domos com superfície áspera, com lenticelas, verrucosa, fixa arredondadas, $2-5 \mathrm{~cm}$ diâm., $1 \mathrm{~mm}$ espessura, 0,5-1 cm distância. 
63. Pradosia lactescens (Vell.) Radlk., Sitzungsber. Math.-Phys. Cl. Königl. Bayer. Akad. Wiss. München 18: 407. 1888.

Prancha 63.

Tronco 52-63cm DAP, cinza-avermelhado, cilíndrico a acanalado. Pode apresentar rebrotos, até 5 em um indivíduo, $20 \mathrm{~cm}$ diâm. Raízes digitadas, simples, levemente côncavas, $a>b, a=20-80 \mathrm{~cm}, b=15-30 \mathrm{~cm}, 10-17 \mathrm{~cm}$ espessura ou, menos freqüente, com sapopemas, $a>b, a=50-145 \mathrm{~cm}, b=28-70 \mathrm{~cm}, 15-23 \mathrm{~cm}$ espessura. Casca do tronco fissurada, com fissuras longitudinais, retas, 3-7cm compr., 1-2mm larg., 1-2mm profundidade, 0,5-1,5cm distância. Descama em placas irregulares, longitudinais, $4-9 \mathrm{~cm}$ compr., 1,5-4,0cm larg., 1-2mm espessura. Impressão lenticelada com microfissuras, com lenticelas verrucosas, fixas, abertura linear, lineares, longitudinais, $0,5-3,0 \mathrm{~cm}$ compr., 2-3mm larg., <1 $\mathrm{mm}$ espessura, 2-8mm distância, e microfissuras retas, longitudinais, cerca de $5 \mathrm{~cm}$ compr., $1-5 \mathrm{~mm}$ distância. Casca da crista da raiz fissurada, com fissuras longitudinais, retas, 1-5cm compr., 2-3mm larg., 1-2mm profundidade, 5-9mm distância. Casca da raiz superficial da mesma cor do tronco ou mais avermelhada, padrão I: fissurado, fissuras longitudinais, retas, 1,5-2cm compr., 12mm larg., 1mm espessura, 0,5-1cm distância. Padrão II: lenticelado, com lenticelas verrucosas, fixas, abertura linear, lineares, longitudinais, 0,5-1 cm compr., $2 \mathrm{~mm}$ larg., $1 \mathrm{~mm}$ espessura, $1 \mathrm{~mm}$ distância transversal.

$\mathrm{Na}$ casca da raiz superficial, os dois padrões encontram-se isoladamente na mesma raiz ou em raízes diferentes de um mesmo indivíduo.

\section{Urticaceae}

\section{Coussapoa microcarpa (Schott) Rizzini, Dusenia 1(5): 295. 1950.}

Prancha 64.

Tronco 54-140cm DAP, castanho, cilíndrico, levemente digitado. Envolvendo hospedeira. Casca do tronco lenticelada, com lenticelas verrucosas, descamantes, abertura em espocação, arredondadas, 1-2mm diâm., <1mm espessura, e elípticas, geralmente longitudinais, 4-8mm, compr., 3-4mm larg., 1mm espessura, 1-5mm distância, com distribuição irregular ou em linhas longitudinais, numerosas. Casca da raiz superficial lenticelada e rugosa, com lenticelas discolores, castanho-claras, ou da cor da casca, verrucosas, fixas, abertura em espocação para lenticelas arredondadas, 2- 
3mm diâm., e abertura linear para lenticelas elípticas e lineares longitudinais, 0,5-1,2cm compr., 2-3mm larg., $1 \mathrm{~mm}$ espessura, 0-8mm distância.

A coloração das lenticelas da casca da raiz aparece isoladamente em raízes diferentes da mesma planta ou de plantas diferentes. 


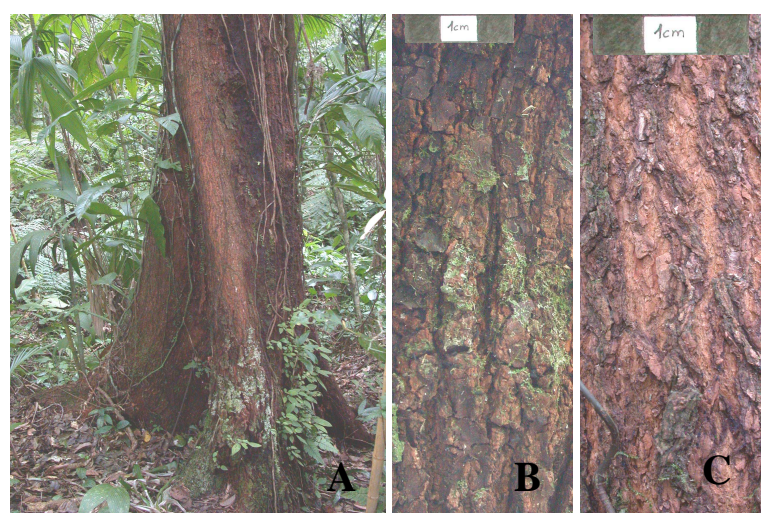

Prancha 1. Tapirira guianensis. A. tronco; B. casca do tronco; C. casca da crista do tronco.

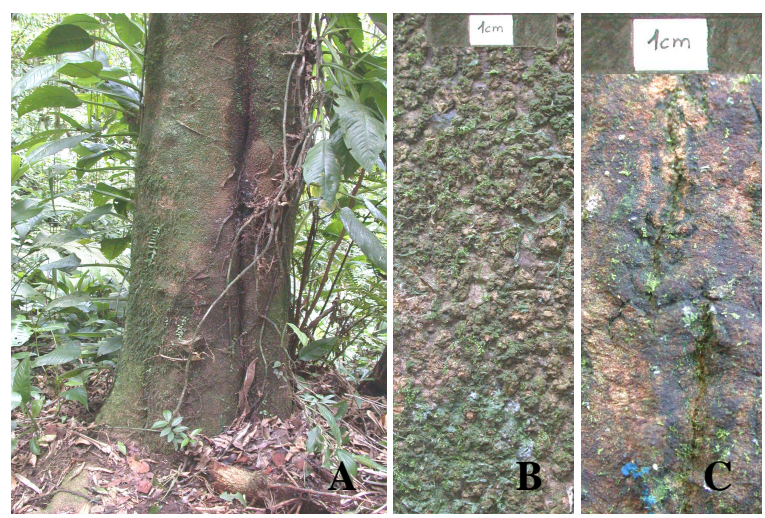

Prancha 3. Malouetia arborea. A. tronco; B e C. casca do tronco, padrões I e II, respectivamente.

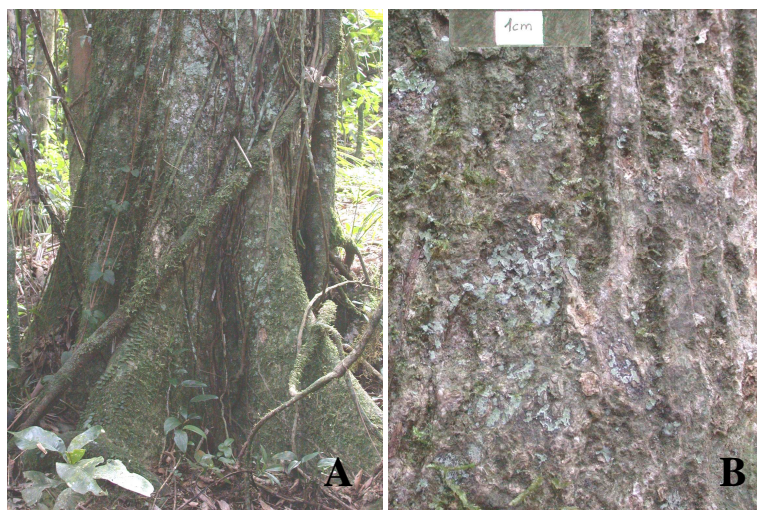

Prancha 5. Tabebuia serratifolia. A. tronco; B. casca do tronco.
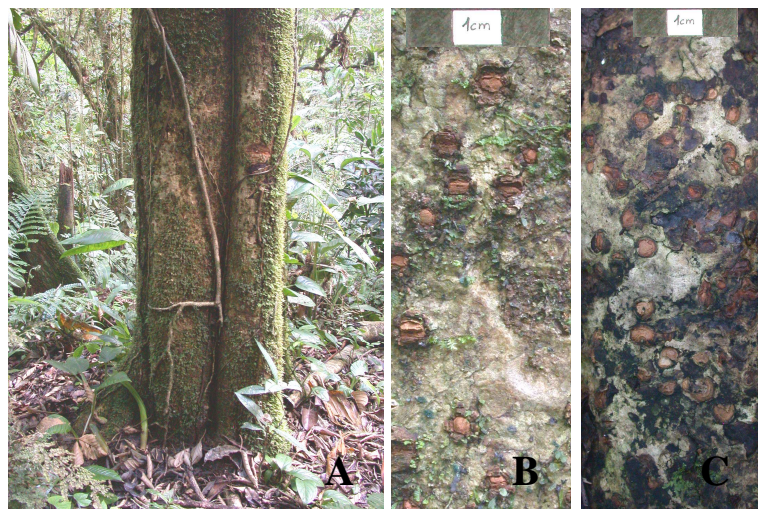

Prancha 7. Capsicodendron dinisii. A. tronco; B. casca do tronco, padrão I; C. casca da raiz superficial. do tronco; C. casca da raiz superficial. casca do tronco; C. casca do tronco descamada.

Prancha 4. Oreopanax capitatus. A. tronco; B. casca do tronco; C. casca da crista da raiz. tronco; C. casca da raiz superficial.

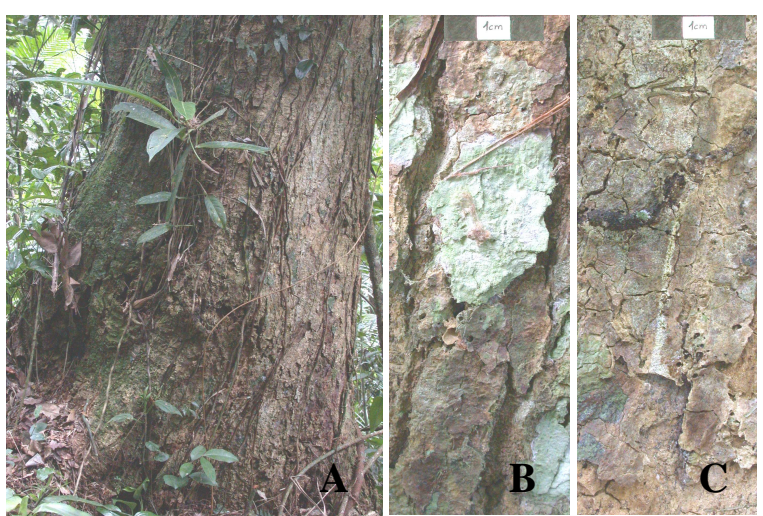

Prancha 2. Aspidosperma parvifolium. A. tronco; B.
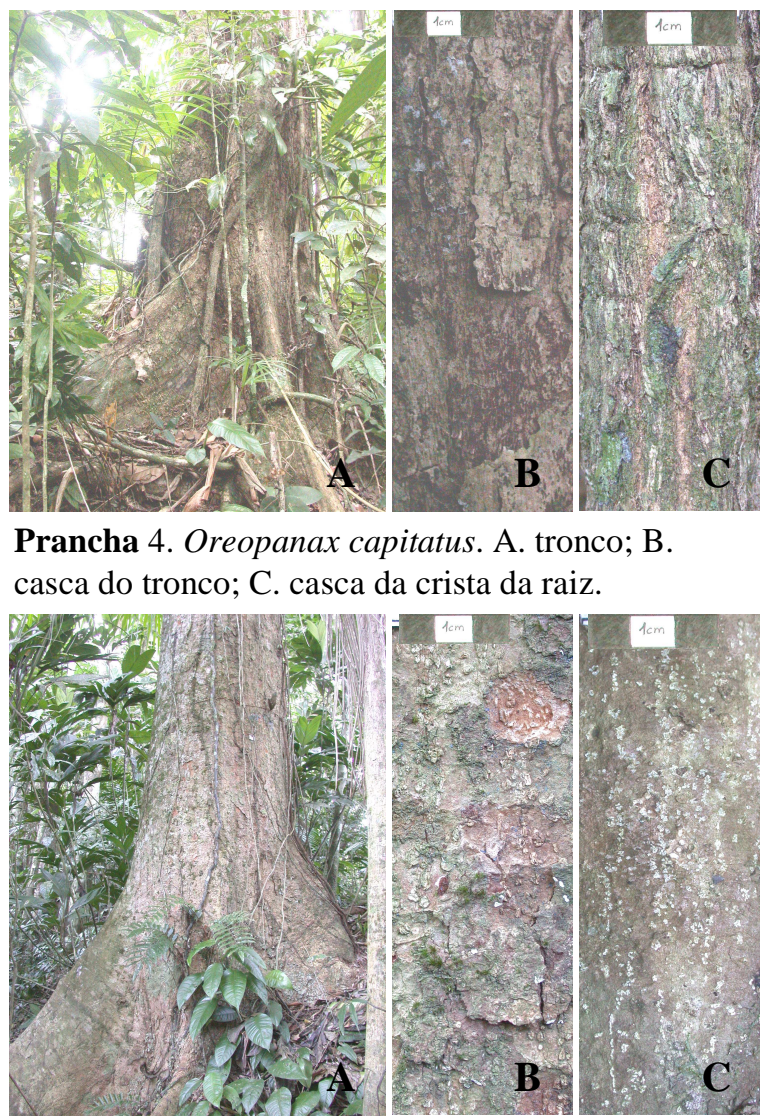

Prancha 6. Protium widgrenii. A. tronco; B. casca do

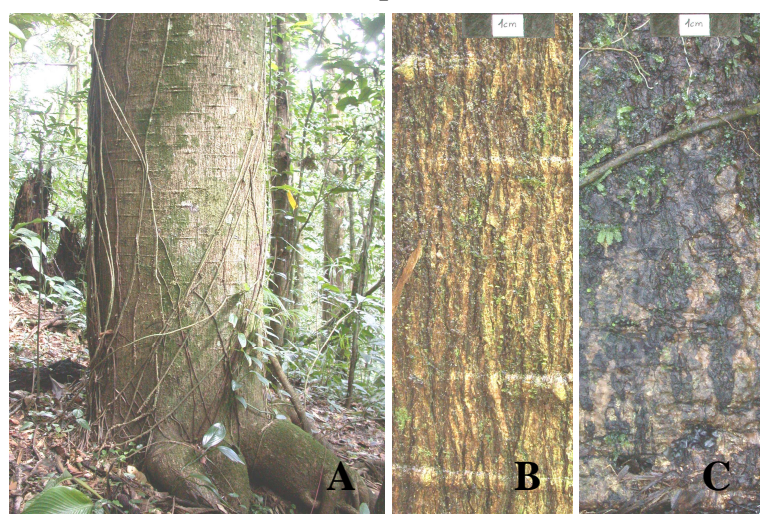

Prancha 8. Jacaratia spinosa. A. tronco; B. casca 


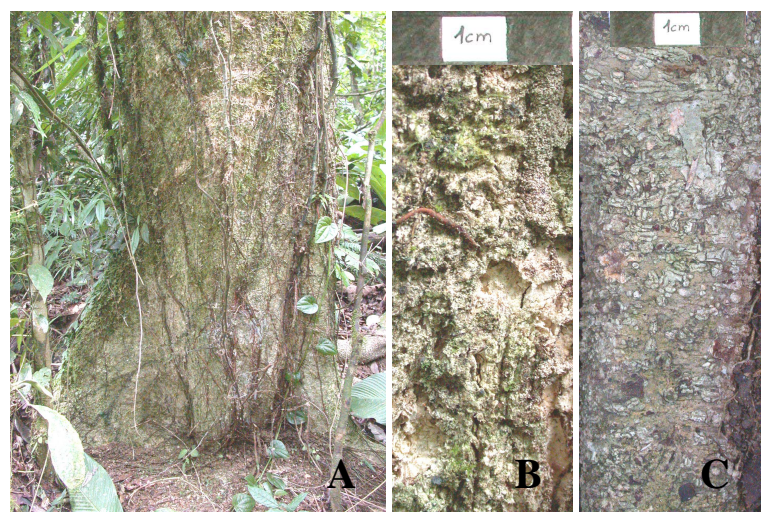

Prancha 9. Maytenus robusta. A. tronco; B. casca do tronco; C. casca da crista do tronco.

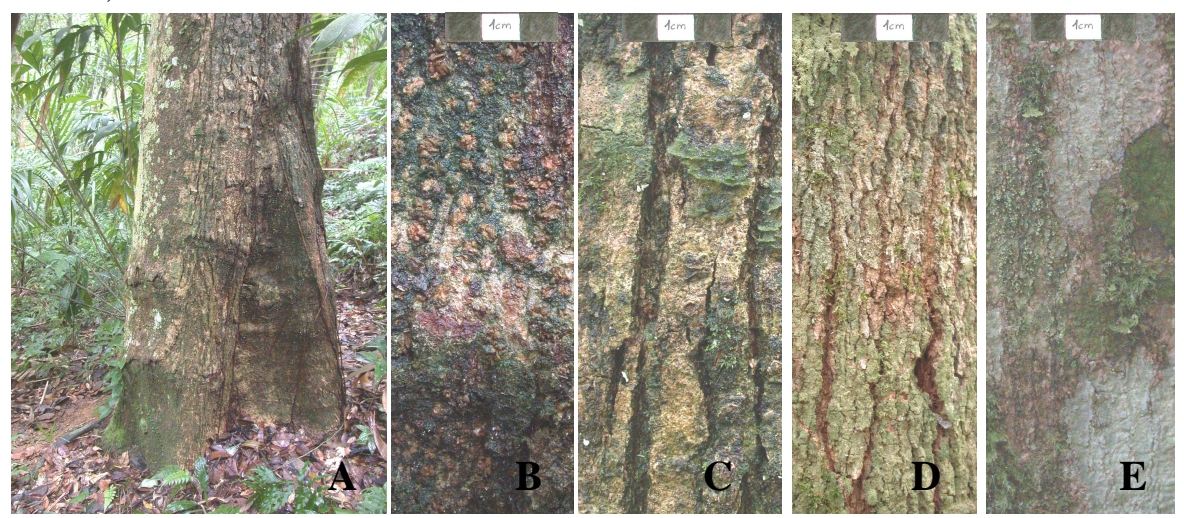

Prancha 10. Parinari brasiliensis. A. tronco; B, C, D e E. cascas do tronco, padrões I, II, III e IV.
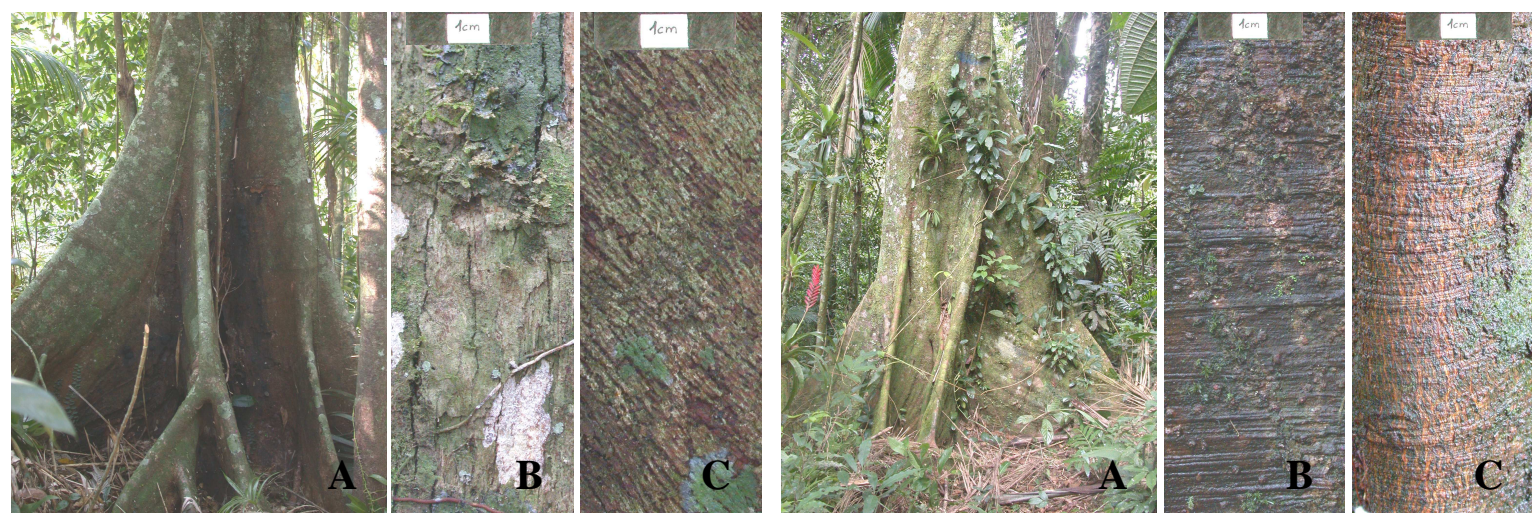

Prancha 11. Buchenavia kleinii. A. tronco; B. casca do tronco; C. casca da raiz.
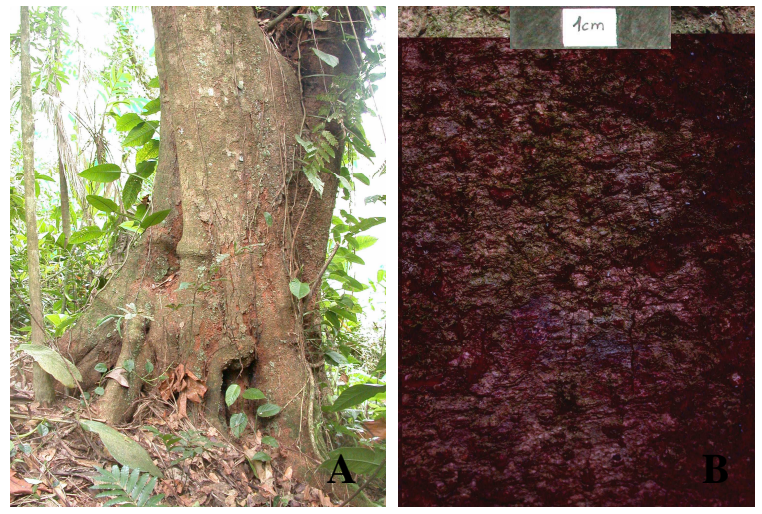

Prancha 13. Alchornea triplinervea. A. tronco; B. casca do tronco.

Prancha 12. Sloanea guianensis. A. tronco; B. casca do tronco; C. casca da crista da raiz, padrão I.

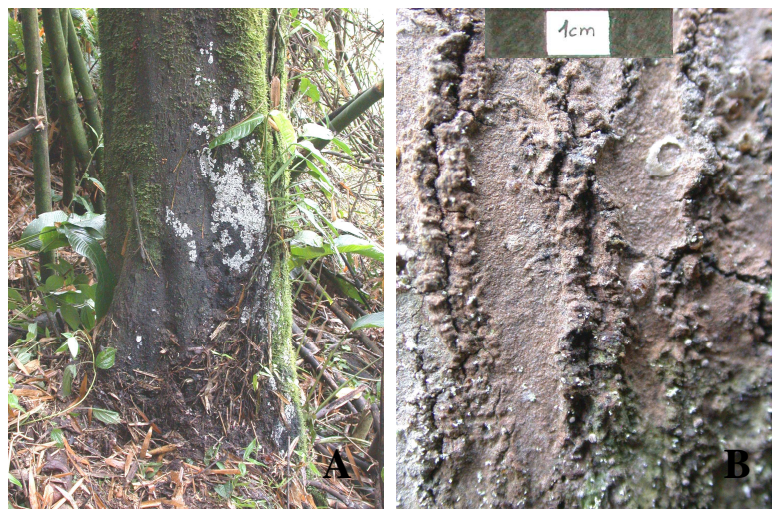

Prancha 14. Croton macrobothrys. A. tronco; B. casca do tronco. 


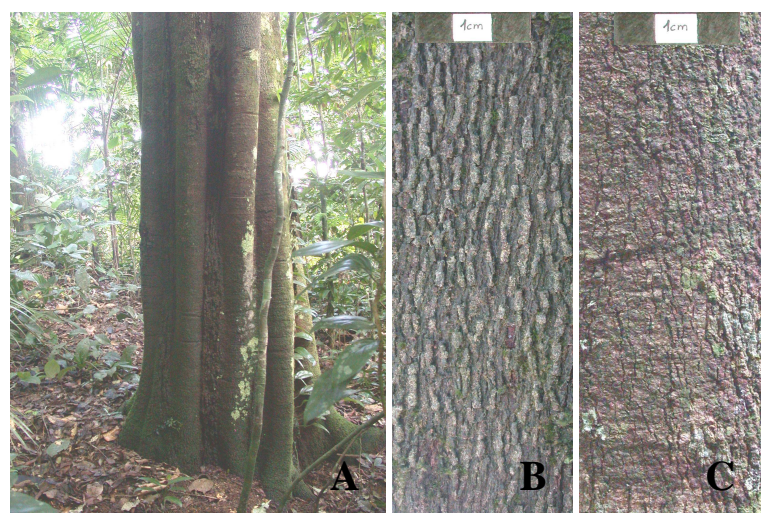

Prancha 15. Pera glabrata. A. tronco; B. casca do tronco; C. casca da crista do tronco.

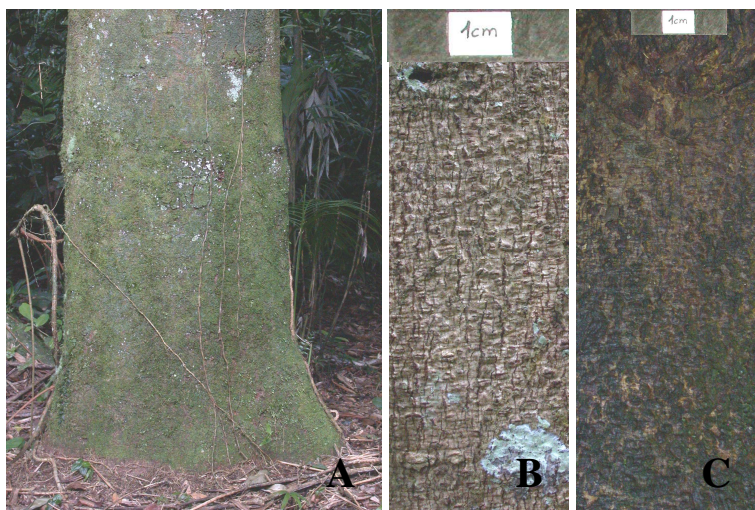

Prancha 17. Copaifera trapezifolia. A. tronco; B. casca do tronco; C. casca da raiz superficial.

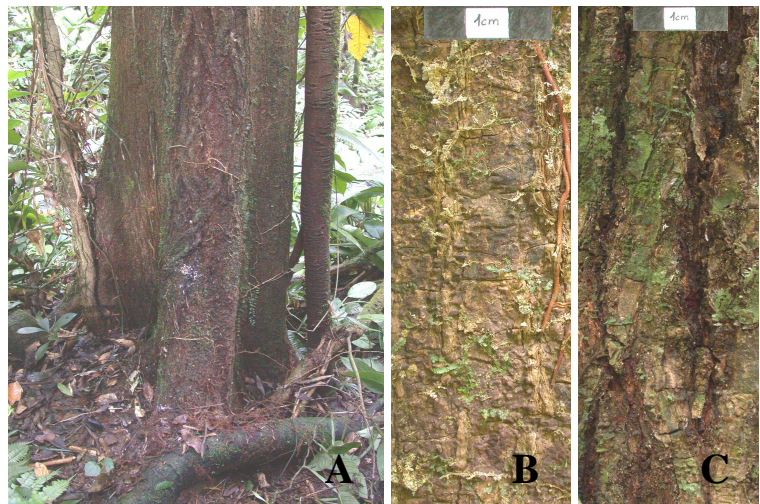

Prancha 19. Centrolobium robustum. A. tronco; B. casca do tronco.
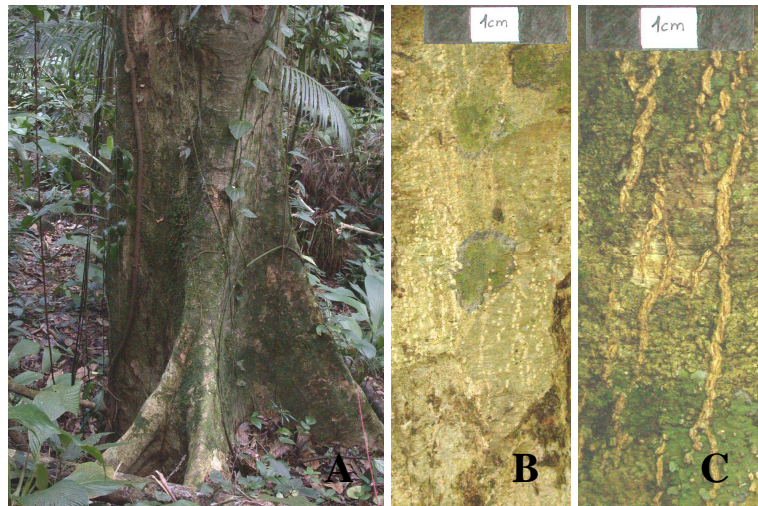

Prancha 21. Pterocarpus rohrii. A. tronco; B. casca do tronco, padrão I; C. casca da crista da raiz.

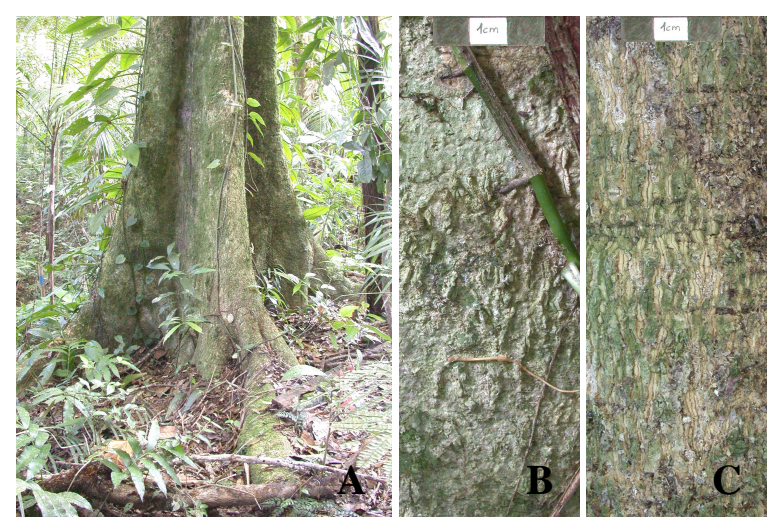

Prancha 16. Tetrorchidium rubrivenium. A. tronco;

B. casca do tronco; C. casca da crista da raiz.

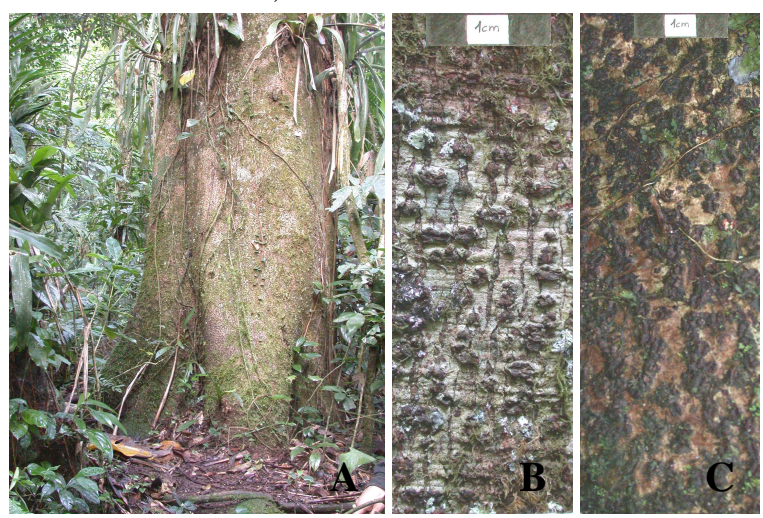

Prancha 18. Hymenaea courbaril. A. tronco; B. casca do tronco; C. casca da raiz superficial.

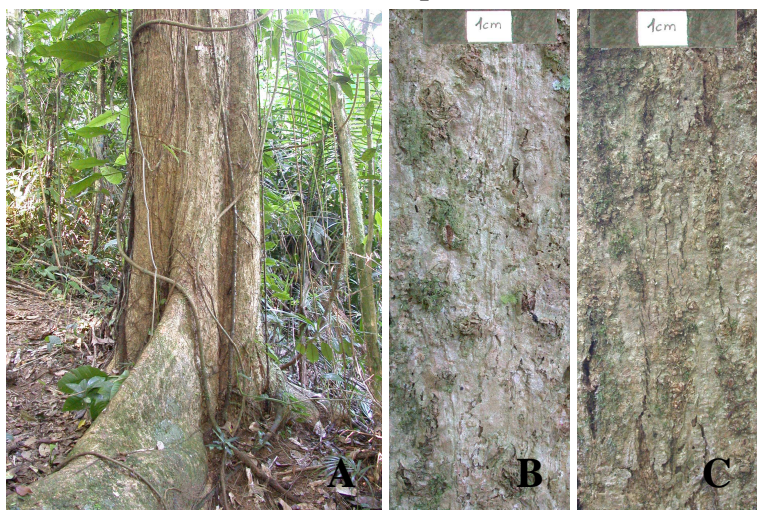

Prancha 20. Platymiscium floribundum. A. tronco; B casca do tronco, padrão I; C. casca da crista do tronco.

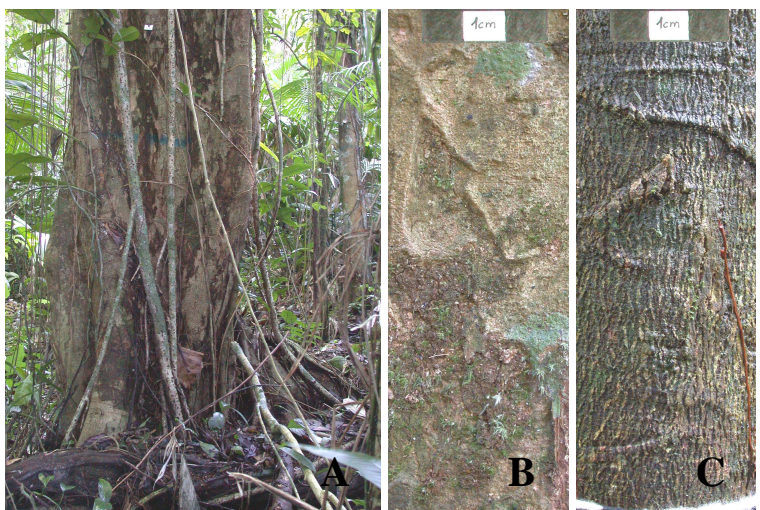

Prancha 22. Swartzia acutifolia. A. tronco; B. casca do tronco, padrão I; C. casca da crista do tronco, padrão II. 


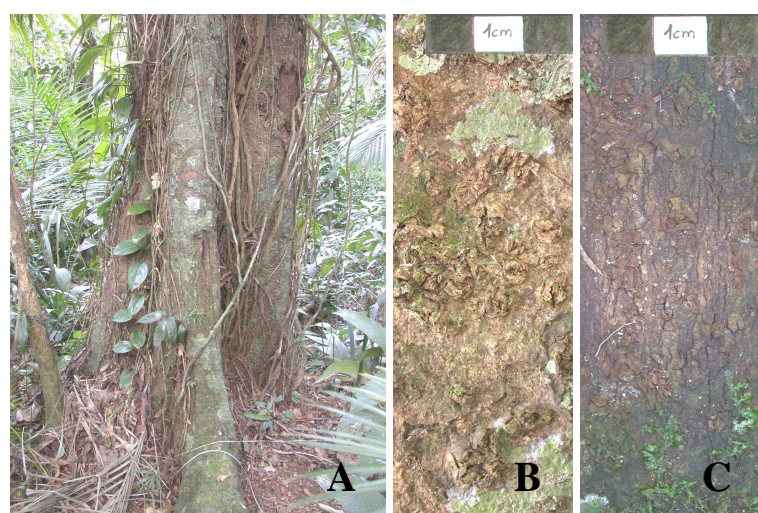

Prancha 23. Zollernia ilicifolia. A. tronco; B. casca do tronco; C. casca da raiz superficial.

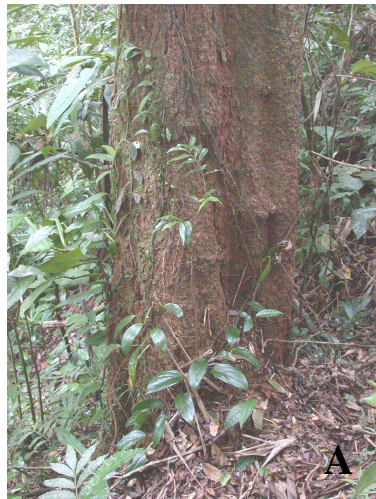

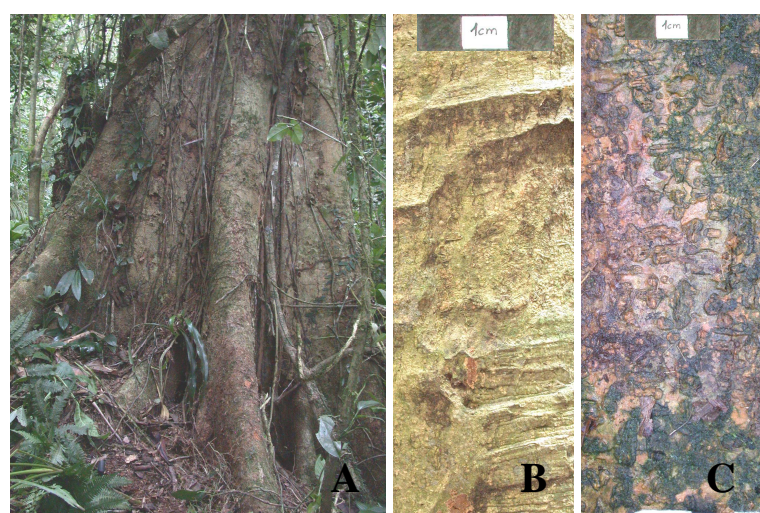

Prancha 24. Pseudopiptadenia warmingii. A. tronco; B. casca do tronco, padrão I; C. casca da raiz superficial.

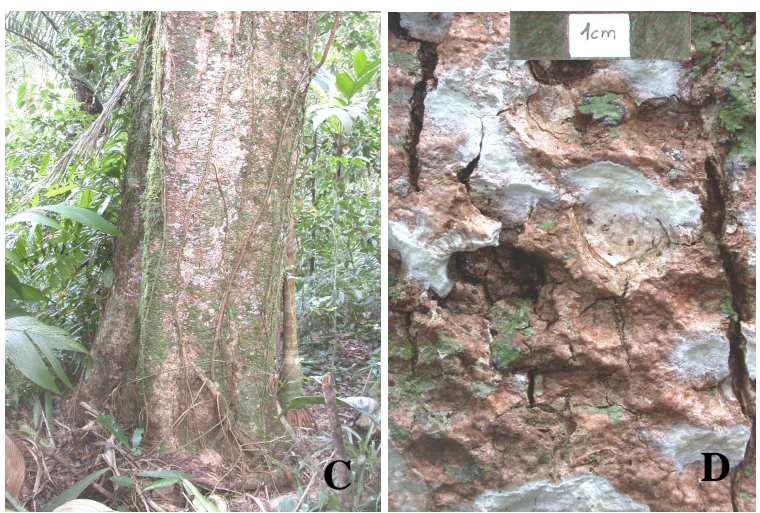

Prancha 25. Vantanea compacta. A. tronco; B. casca do tronco A, padrão I; C. tronco; D. casca do tronco C, padrão II.

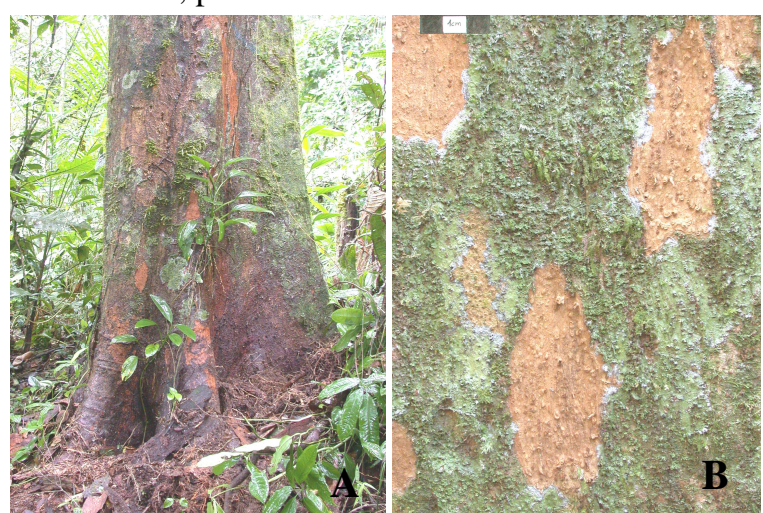

Prancha 26. Cryptocarya moschata. A. tronco; B. casca do tronco.
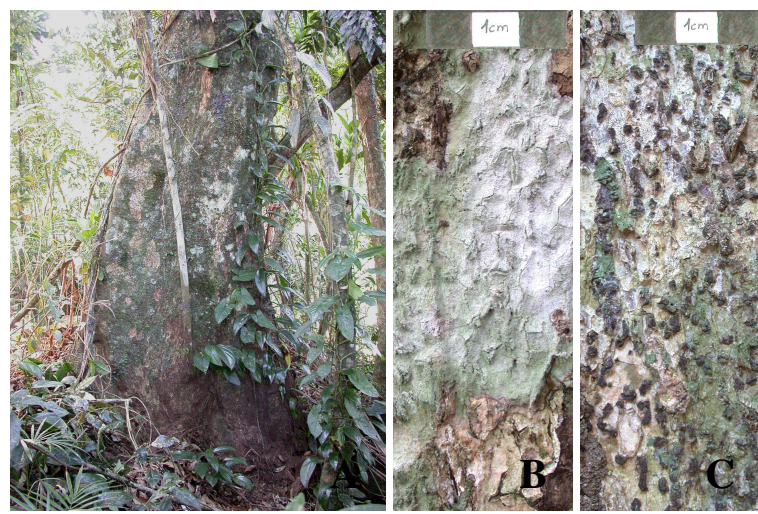

Prancha 28. Ocotea catharinensis. A. tronco; B e C. casca do tronco, padrões I e II.

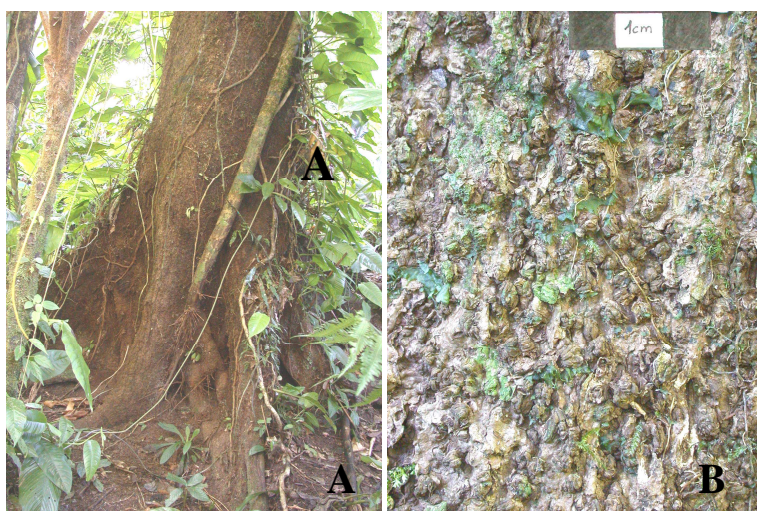

Prancha 27. Nectandra membranaceae. A. tronco; B. casca do tronco, padrão I.

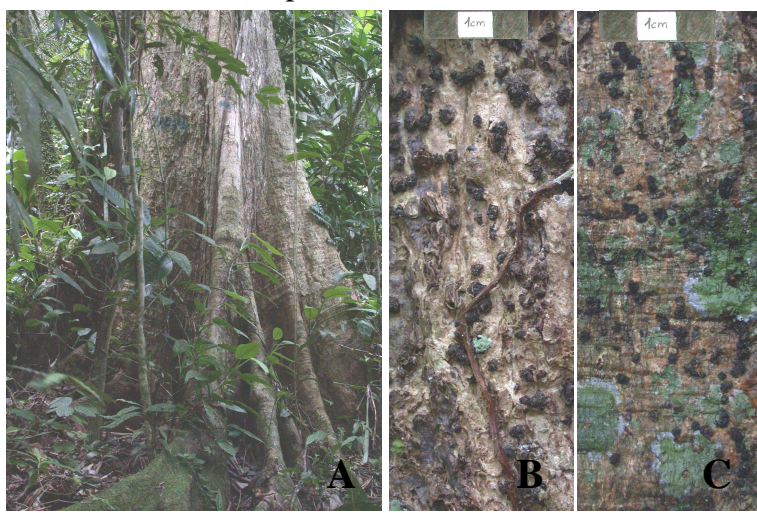

Prancha 29. Ocotea mosenii. A. tronco; B. casca do tronco, padrão I; C. casca da crista da raiz, padrão I. 


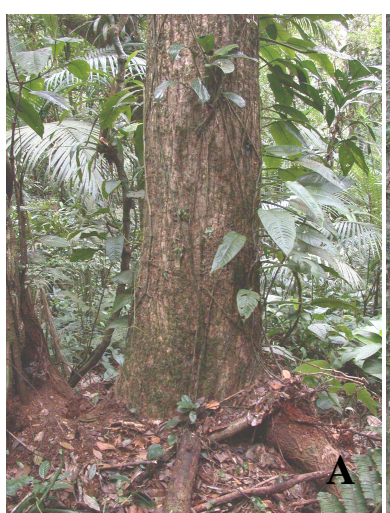

Prancha 30. Cariniana estrellensis. A. tronco; B. casca do tronco; C. casca da raiz superficial.

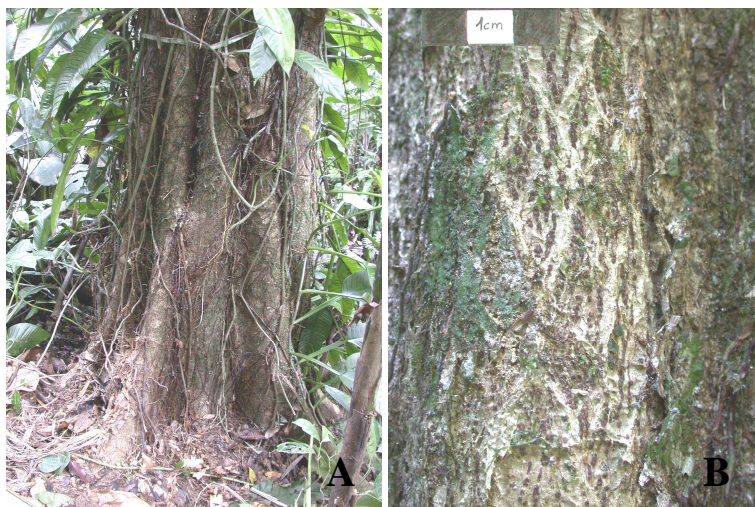

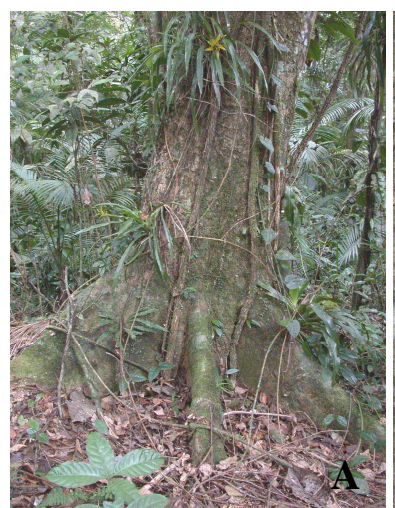
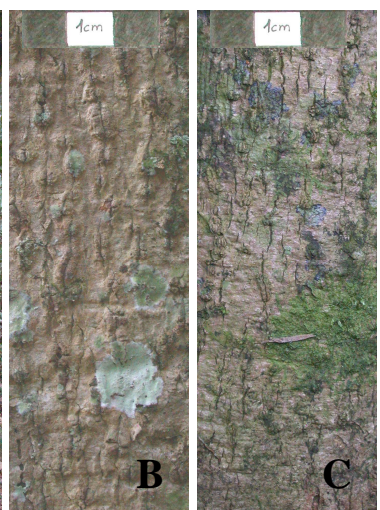

Prancha 31. Magnolia ovata. A. tronco; B. casca do tronco, padrão I; C. casca da crista da raiz.

Prancha 32. Quararibea turbinata. A. tronco; B e C. casca do tronco, padrões II e III.
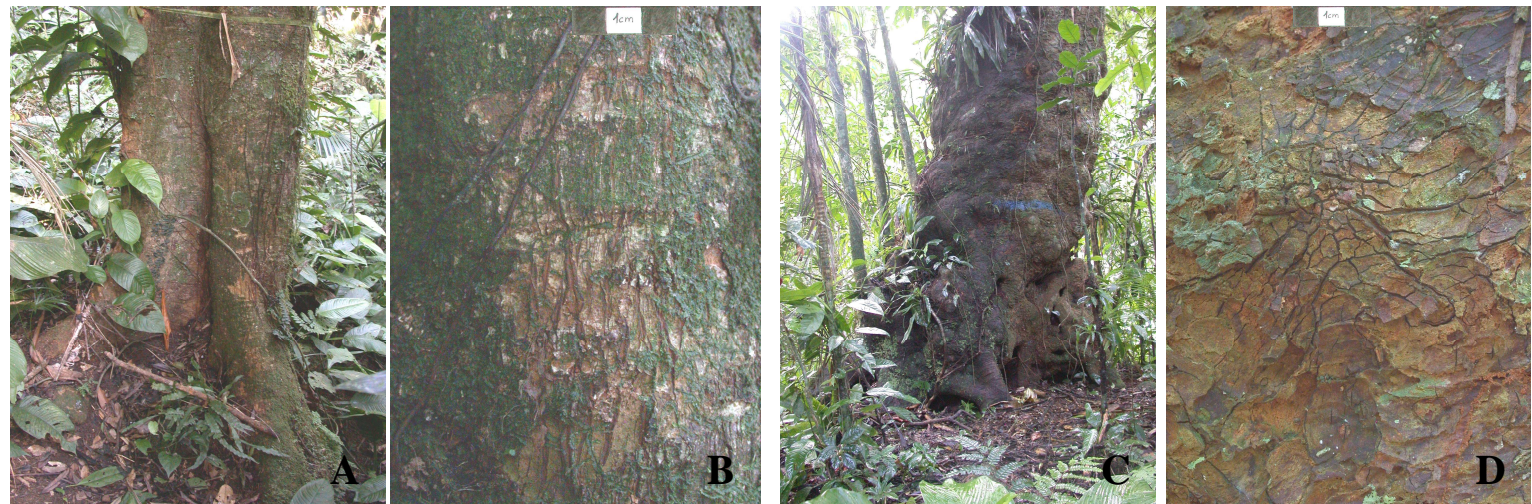

Prancha 33. Cabralea canjerana. A tronco; B. casca do tronco; C. tronco coberto por cicatrizes; D. casca do tronco ao sobre a cicatriz.

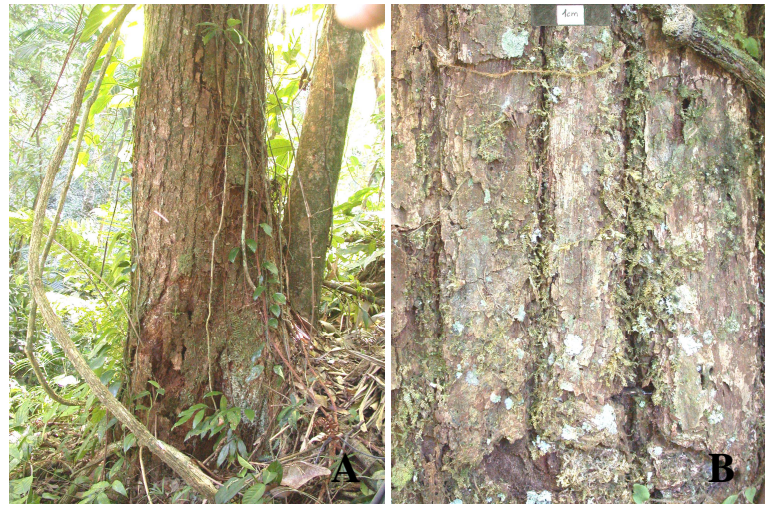

Prancha 34. Cedrela fissilis. A. tronco; B. casca do tronco; C. casca da raiz superficial.
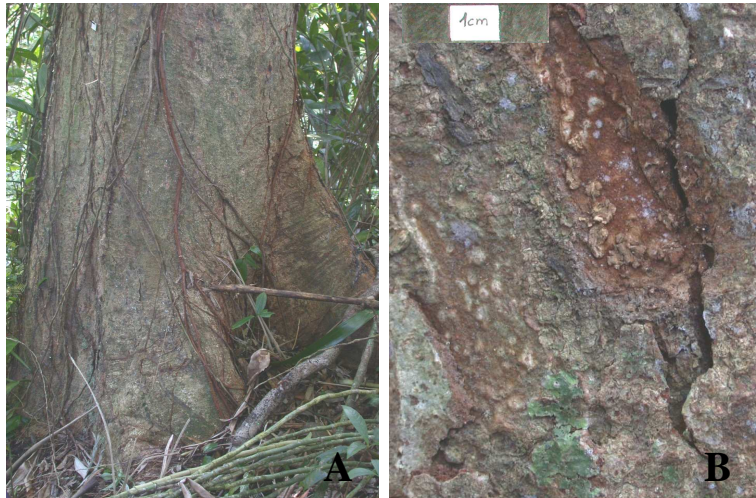

Prancha 35. Brosimum lactescens. A. tronco; B. casca do tronco, padrão I. 

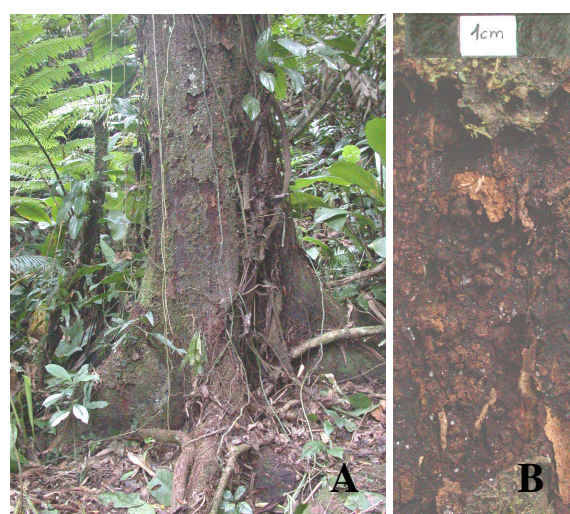

Prancha 36. Ficus luschnathiana. A. tronco; B. casca do tronco; C. casca da raiz superficial.

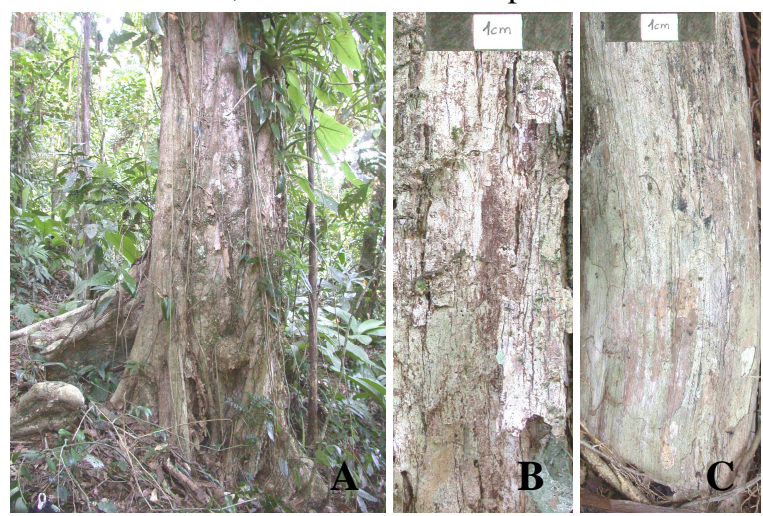

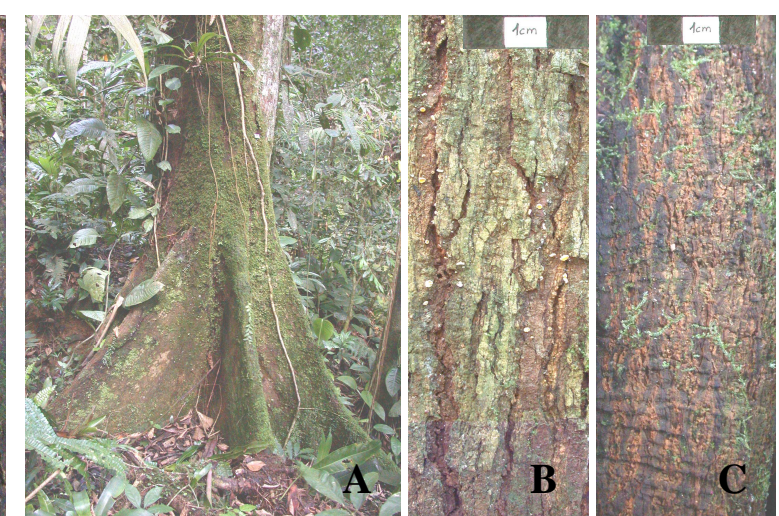

Prancha 37. Virola bicuhyba. A. tronco; B. casca do tronco, padrão I; C. casca da crista da raiz.

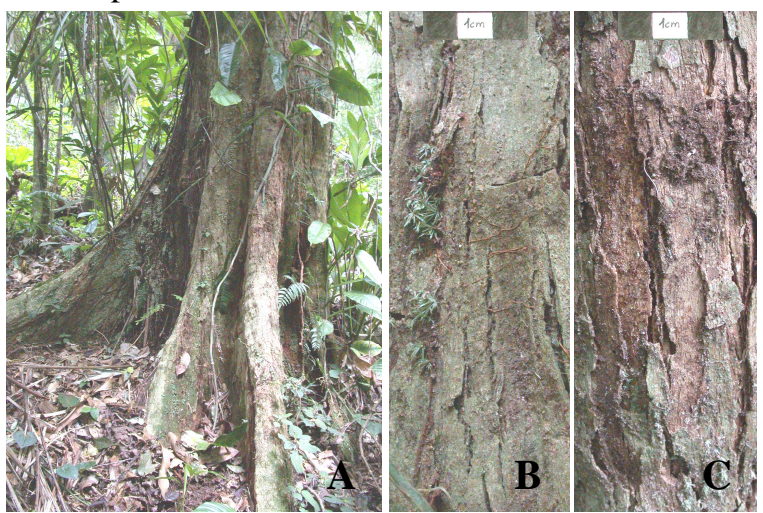

Prancha 38. Campomanesia guaviroba. A. tronco; B. Prancha 39. Eugenia cambucarana. A. tronco; B. casca do tronco, padrão II; C. casca da raiz superficial. casca do tronco; C. casca da crista da raiz.

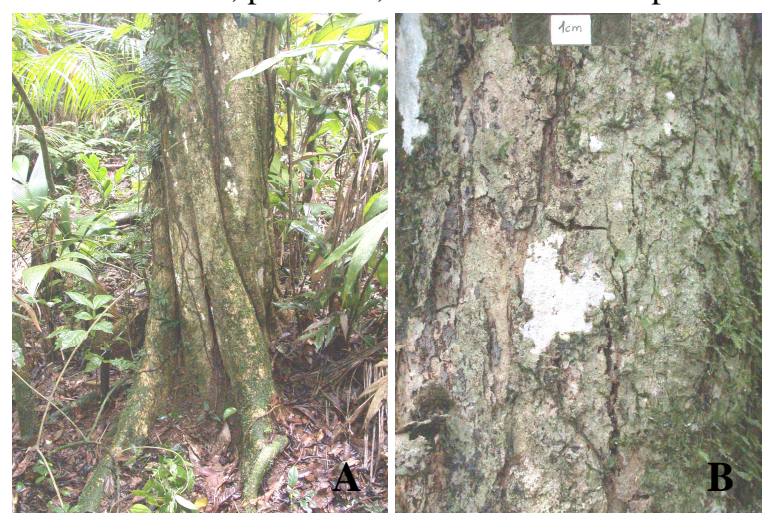

Prancha 40. Eugenia capitulifera. A tronco; B. casca do tronco, padrão II.
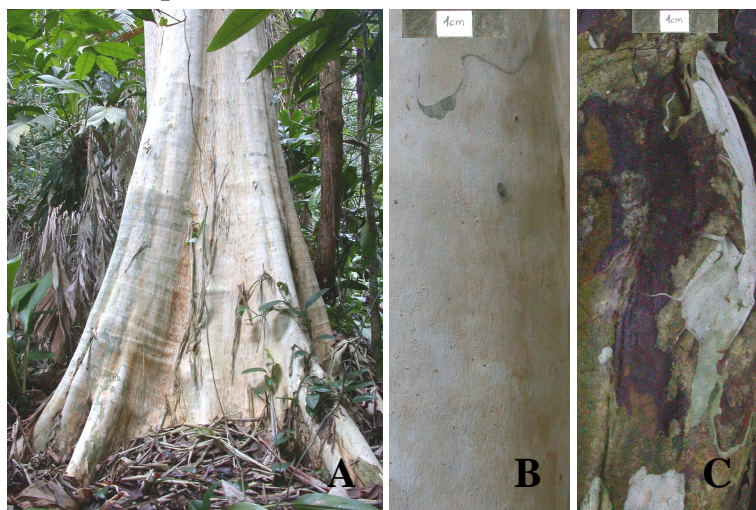

Prancha 42. Eugenia cf burkartiana. A. tronco; B. casca do tronco; C. casca da raiz superficial.

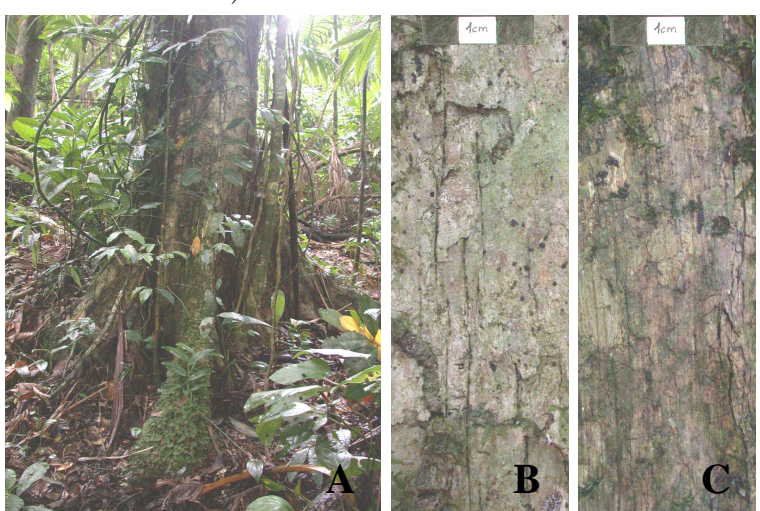

Prancha 41. Eugenia cereja. A. tronco; B. casca do tronco; C. casca da raiz superficial.

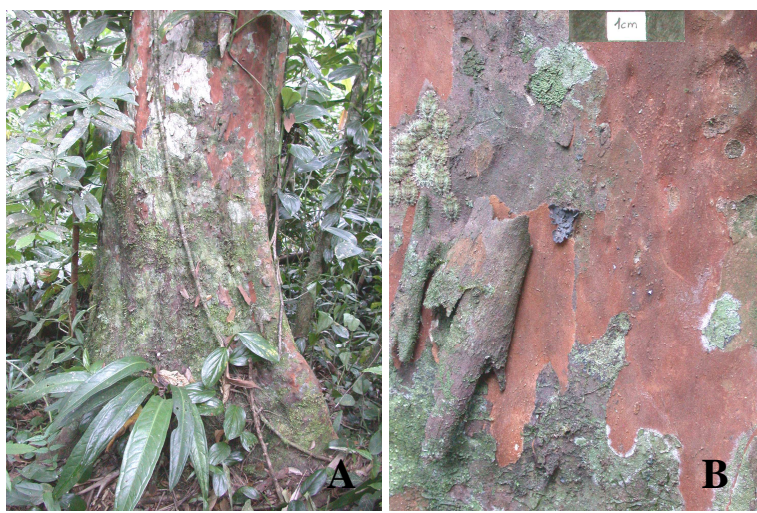

Prancha 43. Eugenia multicostata. A. tronco; B. casca do tronco. 


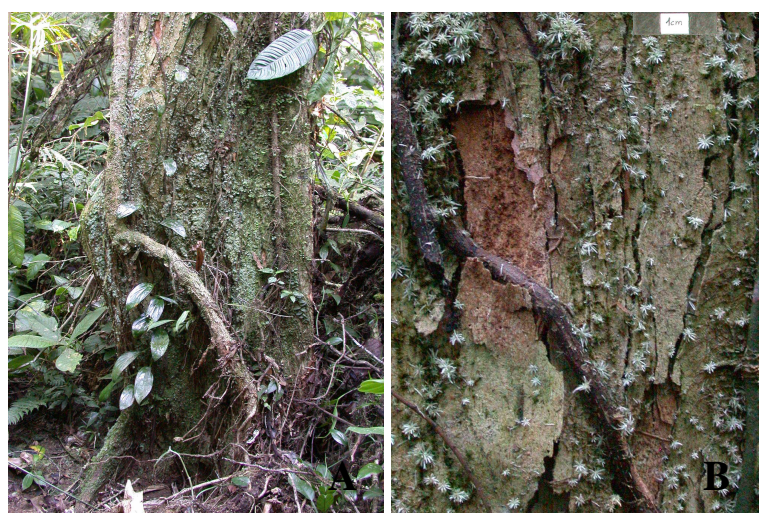

Prancha 44. Eugenia subavenia. A. tronco; B. casca do tronco.
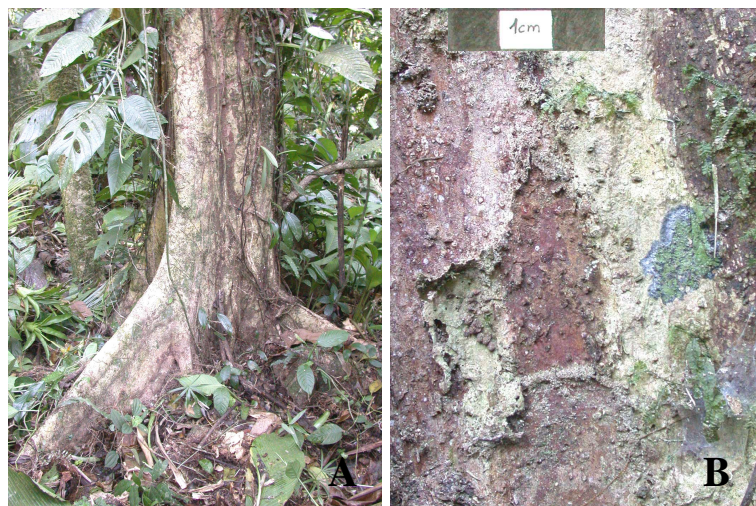

Prancha 46. Myrcia pubipetala. A. tronco; B. casca do tronco.

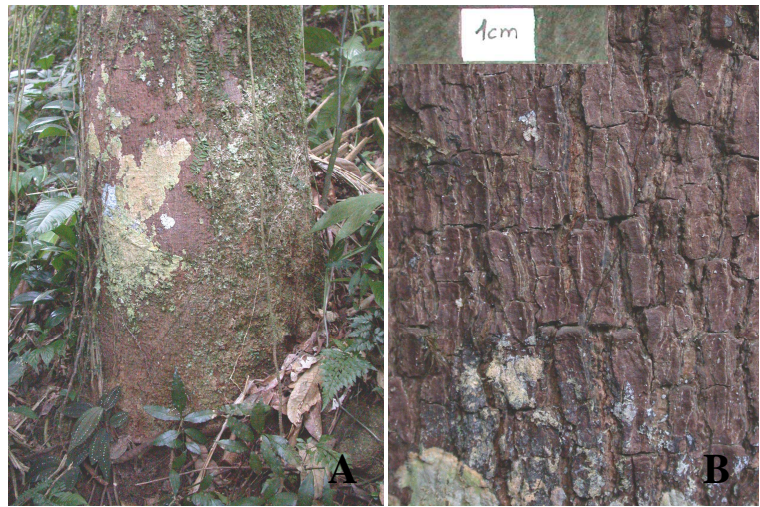

Prancha 48. Heisteria silvianii. A tronco; B. casca do tronco, padrão I.
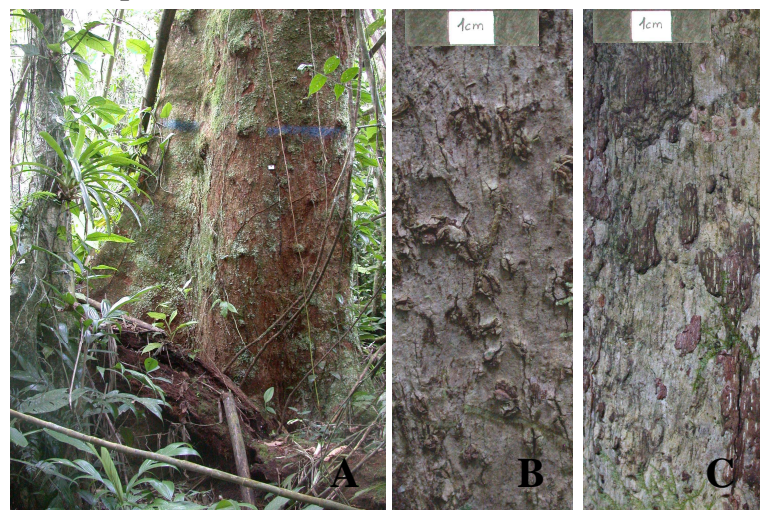

Prancha 50. Hyeronima alchorneoides. A. tronco; B. Prancha 51. Phytolacca dioica. A. tronco; B. casca casca do tronco, padrão II; C. casca da raiz superficial. do tronco, padrão I; C. casca da base do tronco. 

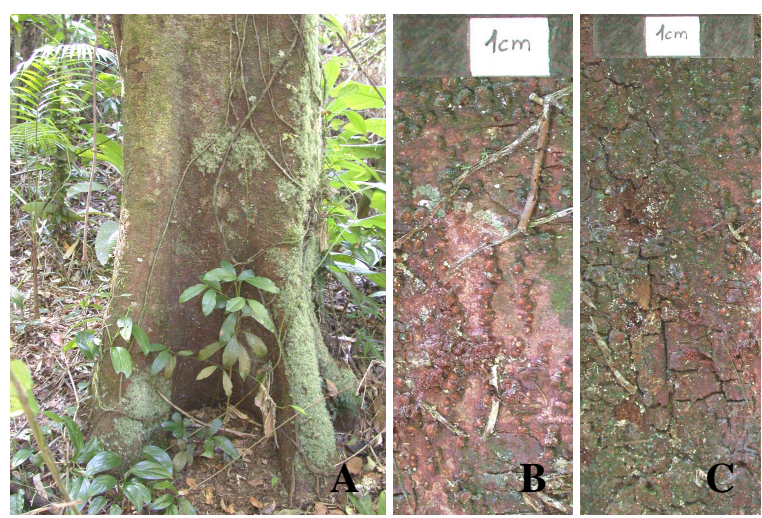

Prancha 52. Coccoloba fastigiata. A. tronco; B e C. casca do tronco, padrões I e II.
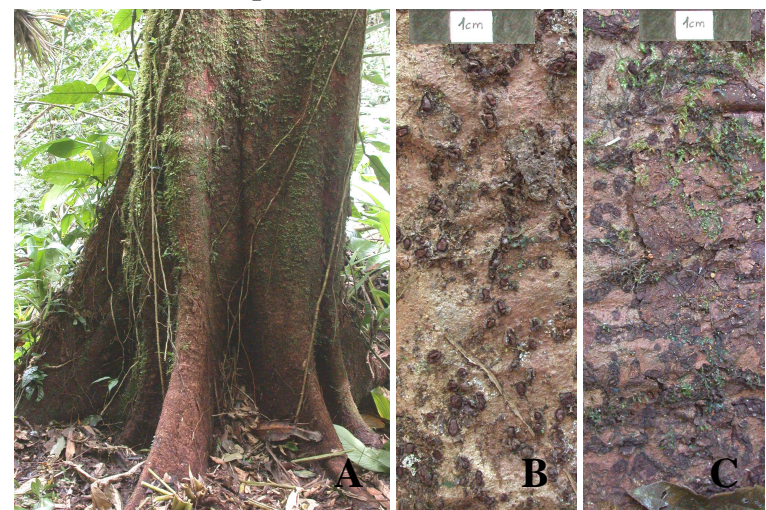

Prancha 54. Simira corumbensis. A. tronco; B.

casca do tronco, padrão I; C. casca da crista da raiz.
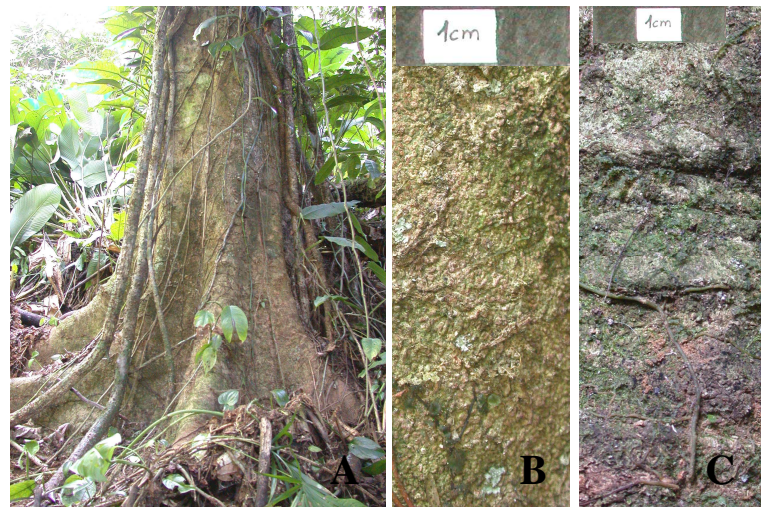

Prancha 56. Casearia obliqua. A tronco; B. casca do tronco, padrão I; C. casca da crista da raiz.

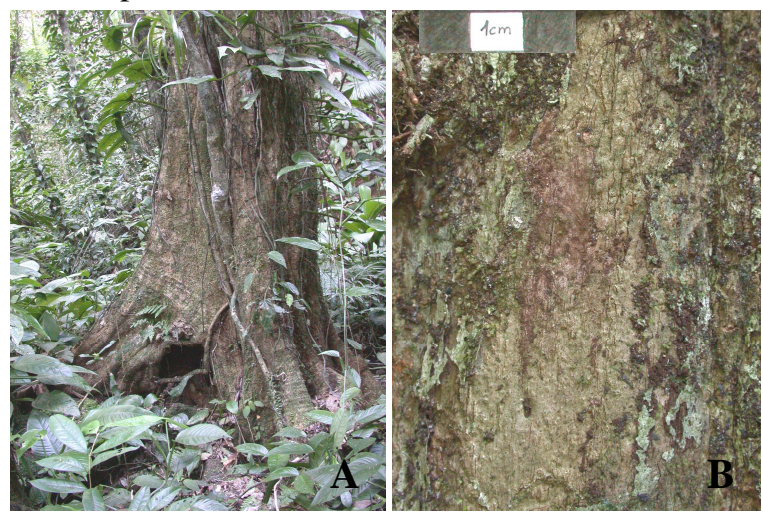

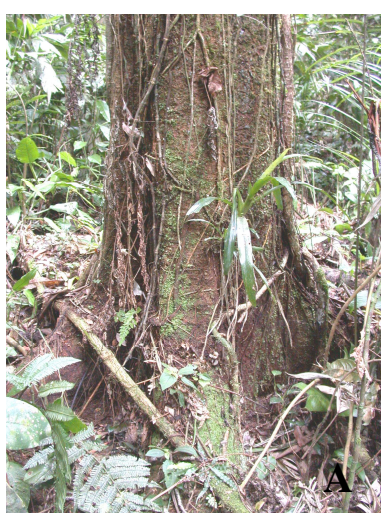

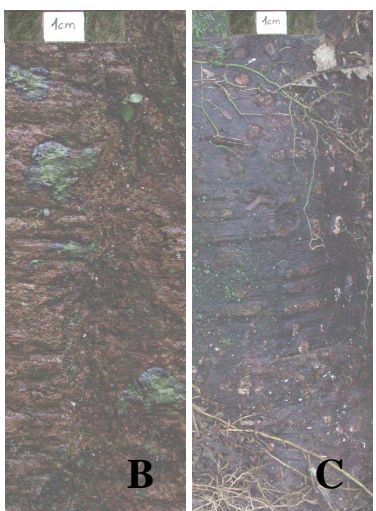

Prancha 53. Roupala brasiliensis. A. tronco; B. casca do tronco, padrão I; C. casca da raiz superficial.

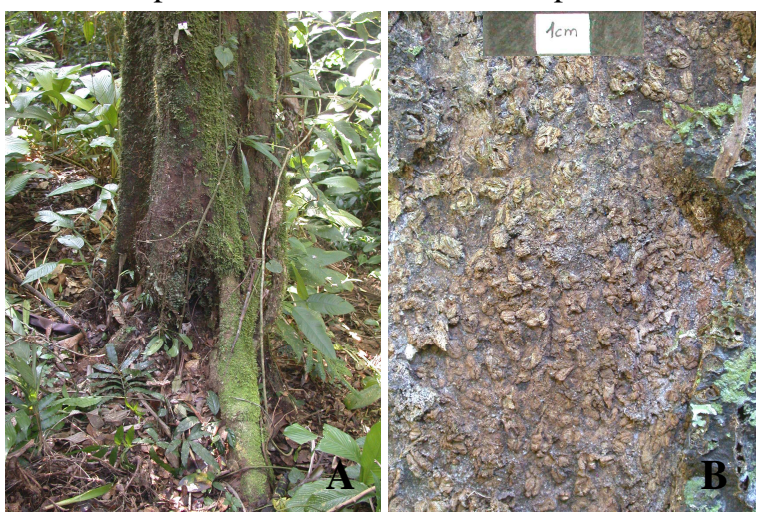

Prancha 55. Meliosma sellowii. A. tronco; B. casca do tronco.

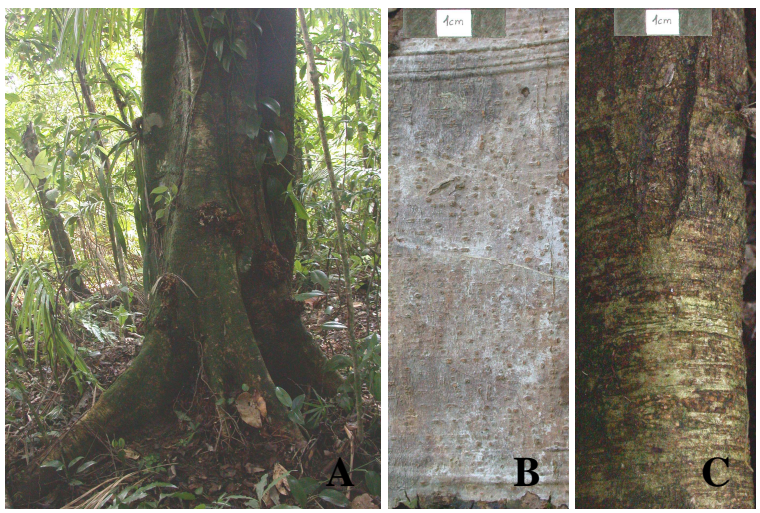

Prancha 57. Matayba guianensis. A. tronco; B. casca do tronco; C. casca da raiz superficial.

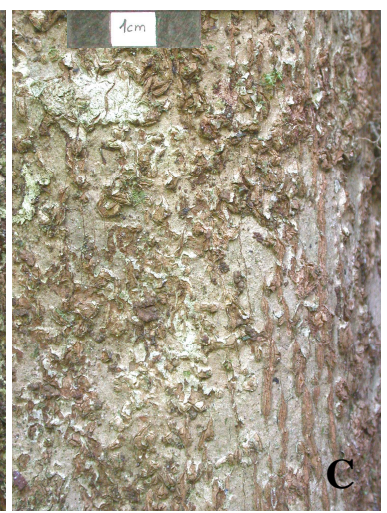

Prancha 58. Chrysophyllum inornatum. A. tronco; B e C. casca do tronco, padrões I e III. 


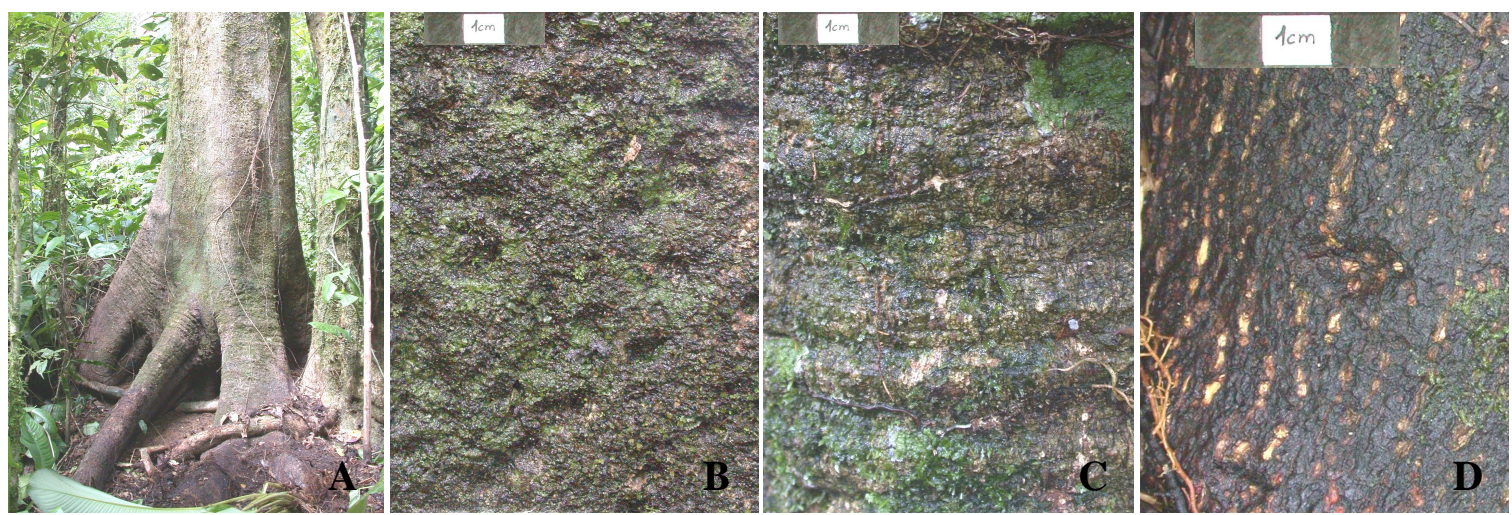

Prancha 59. Chrysophyllum viride. A. tronco; B. casca do tronco, padrão II; C. casca da crista da raiz; D. casca da raiz superficial.
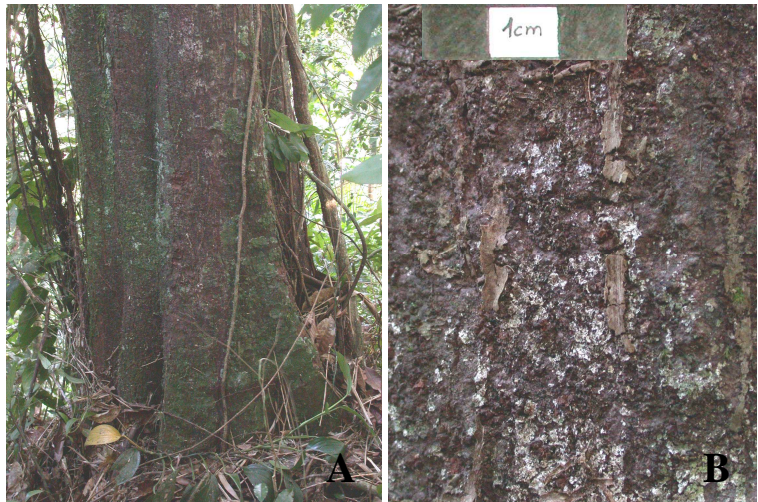

Prancha 60. Ecclinusa ramiflora. A. tronco; B. casca do tronco, impressão do padrão I.

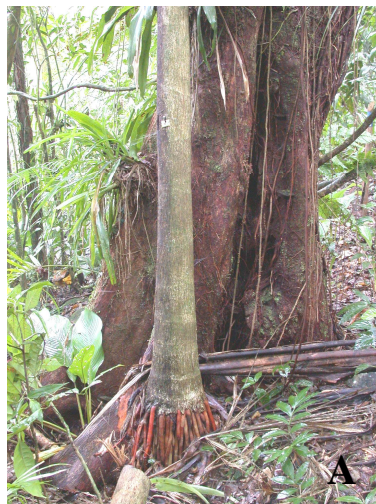

Prancha 62. Pouteria psammophila. A tronco; B. casca do tronco.

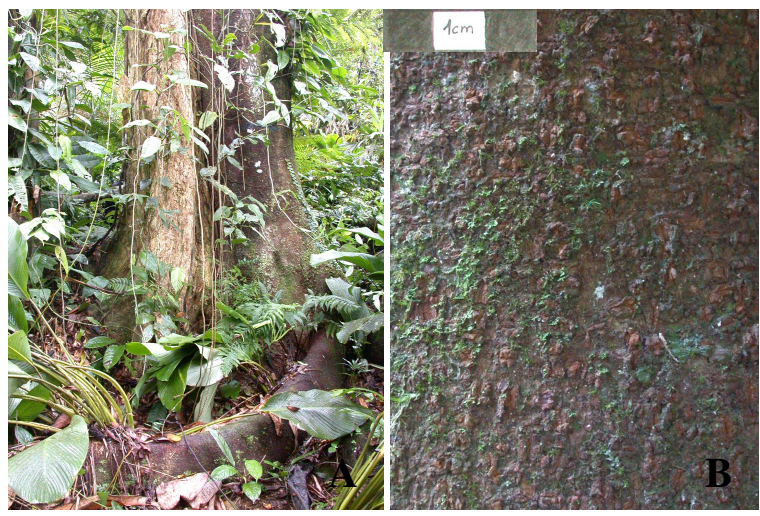

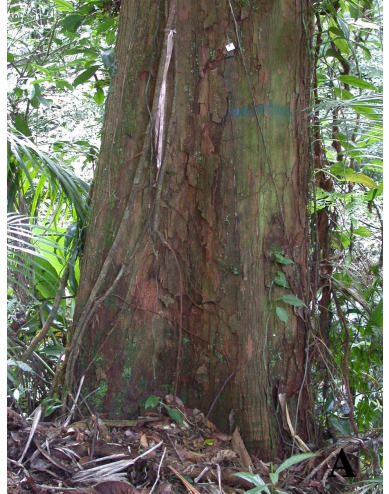

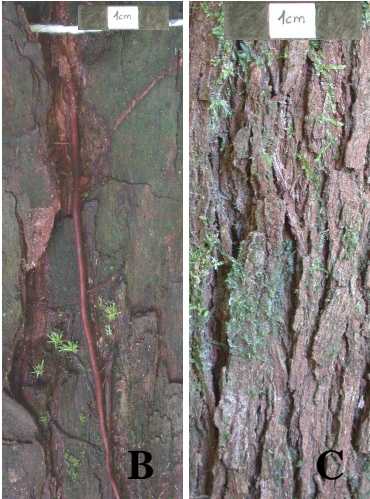

Prancha 61. Pouteria caimito. A. tronco; B. casca do vale do tronco; C. casca da crista do tronco.

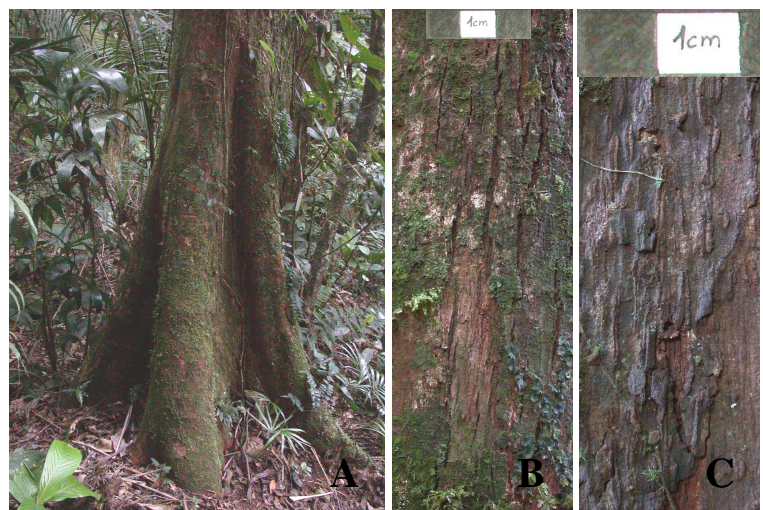

Prancha 63. Pradosia lactescens. A. tronco; B. casca do tronco; C. casca do tronco descamada.

Prancha 64. Coussapoa microcarpa. A. tronco (à direita sobre hospedeira); B. casca do tronco; C. casca da raiz superficial. 


\subsection{Comparações com outras áreas}

A seguir são realizadas algumas comparações com trabalhos semelhantes em áreas diferentes. São relacionadas características descritas entre espécies do mesmo gênero ou família, em alguns casos sendo possível até uma comparação dentro da mesma espécie. As comparações foram feitas principalmente com os trabalhos de Ribeiro et al. (1999) na Reserva Ducke e de Torres et al. (1994) na Estação Ecológica de Angatuba.

\subsubsection{Tronco}

- A base do tronco acanalada mostrou-se, na Reserva Ducke, como uma característica mais freqüente do que o tronco inteiramente acanalado, mas menos importante na identificação. No entanto, no presente estudo este fator facilitou a identificação de algumas espécies: Capsicodendron dinisii e Simira corumbensis.

- Swartzia acutifolia apresentou base do tronco profundamente acanalado no PECB. Na Reserva Ducke, o tronco inteiramente acanalado facilitou o reconhecimento do gênero.

- Oreopanax capitatus (Araliaceae), Pera glabrata e Tetrorchidium rubrivenium (Euphorbiaceae), Chrysophyllum innornatum (Sapotaceae), Campomanesia guaviroba, Eugenia cambucarana, E. capitulifera e Marlierea suaveolens (Myrtaceae) foram as espécies que apresentaram tronco inteiramente acanalado no PECB. Na Reserva Ducke algumas espécies de Euphorbiaceae, Sapotaceae e Myrtaceae, entre outras, tiveram seu reconhecimento facilitado pela presença deste tipo de tronco.

\subsubsection{Raízes}

- Parinari brasiliensis apresentou raízes digitadas ou pequenas sapopemas. Na Reserva Ducke, foi observado que, em Chrysobalanaceae, as sapopemas são em geral pequenas ou a base é apenas dilatada.

- As sapopemas de Sloanea guianensis apresentaram-se como um caráter diagnóstico para sua identificação. Na Reserva Ducke, Eleocarpaceae está entre as famílias que comumente apresentam grandes sapopemas. 
- Tapirira guianensis possui sapopemas. Na Reserva Ducke, este tipo de raiz foi comum em Anacardiaceae.

- Aspidosperma parvifolium apresentou raízes digitadas e Malouetia arborea apresentou base do tronco reta. Na Reserva Ducke, Apocynaceae raramente apresentou sapopemas.

- Das 8 espécies de Fabaceae encontradas no dossel do PECB, 3 apresentaram sapopemas. Na Reserva Ducke, este tipo de raiz foi comum para a família.

- As duas espécies de Olacaceae observadas no dossel do PECB não apresentaram sapopemas. Na Reserva Ducke, raramente foram encontradas sapopemas para a família.

- Das duas espécies de Moraceae observadas no PECB, uma apresentou sapopema. Na Reserva Ducke, sapopemas foram raras para a família.

- Vantanea compacta (Humiriaceae) e Cariniana estrellensis (Lecythidaceae) possuem tronco reto no PECB, enquanto na Reserva Ducke, tais famílias comumente apresentaram grandes sapopemas.

- Entre as 6 espécies de Sapotaceae presentes no dossel do PECB, 3 apresentaram alguns indivíduos com pequenas sapopemas. Já na Reserva Ducke, foi comum a presença de grandes sapopemas para a família.

- Em algumas espécies, as raízes superficiais foram abundantes e de importante auxílio na identificação devido à sua forma e à textura da casca (Jacaratia spinosa, Maytenus robusta, Pseudopiptadenia warmingii, Cariniana estrellensis, Hyeronima alchorneoides e Chrysophyllum viride). Na Reserva Ducke, raízes superficiais ocorreram principalmente em Lecythidaceae (Cariniana), Moraceae (Clarisia), Leguminoseae e Caryocaraceae.

\subsubsection{Casca externa do tronco}

Nos trabalhos comparados, as observações da casca externa foram feitas apenas à altura no peito, desta forma as comparações aqui apresentadas foram baseadas somente nesta região.

\section{$\underline{\text { Lisa }}$}

- Eugenia cf. burkartiana foi a única espécie a apresentar casca lisa, textura também observada na impressão das lâminas coriáceas de E. multicostata. Ribeiro et al. (1999) só citam a ocorrência desta textura em espécies de 
Myrtaceae, embora apresenta-se assim em geral sob as lâminas de desprendimento, como observada, neste trabalho, em E. multicostata.

\section{$\underline{\text { Aspera }}$}

- Em Maytenus robusta a casca é áspera ou suja no PECB. Na Reserva Ducke, $M$. guianensis apresentou casca do tronco escamosa.

\section{Fissurada e fendida}

- Buchenavia kleinii, no PECB, e B. guianensis, na Reserva Ducke, apresentaram fissuras e sem desprendimento evidente, sendo que, na primeira espécie, as fissuras são mais rasas que na segunda.

- Cariniana estrellensis, no PECB, e C. micrantha, na Reserva Ducke, apresentaram casca do tronco com fissuras profundas e sem desprendimento evidente.

- Cedrela fissilis apresentou padrão fissurado no PECB e em Misiones, Argentina (Gartland, 2002), com domos largos, 4-7cm e 3-5cm, respectivamente, formados por lâminas sobrepostas.

- Pera glabrata apresentou fendas sinuosas no PECB. Na Reserva Ducke, P. bicolor possui padrão de casca reticulado.

\section{Lenticelada}

- Na maioria dos casos, a distribuição das lenticelas é irregular. Assim também foi encontrado na Estação Ecológica de Angatuba, porém Roupala brasiliensis aparece entre os casos em que a distribuição é ordenada. No PECB, o único indivíduo desta espécie encontrado no dossel apresentou apenas lenticelas esparsas, inconspícuas e de distribuição irregular.

- Entre os indivíduos de Sloanea guianensis lenticelas caracterizam sua casca sem formar um agrupamento nítido. Na Reserva Ducke, S. rufa apresentou lenticelas organizadas em linhas verticais, enquanto em S. pubescens o padrão é reticulado.

- Croton macrobothrys apresentou casca do tronco com lenticelas associadas a fissuras, mas, em Angatuba, C. floribundus apresentou-se reticulada e na Reserva Ducke C. lanjouwensis possui sulcos rasos, sem desprendimento evidente. 
- Pterocarpus rohrii apresentou lenticelas organizadas em linhas verticais tanto no PECB como na Reserva Ducke, onde esta textura ocorreu principalmente em Fabaceae.

- Nectancra membranaceae apresentou casca do tronco lenticelada no PECB. Em Angatuba, N. grandiflora apresentou casca do tronco escamosa delimitado por fissuras transversais e longitudinais.

- As duas espécies de Ocotea encontradas no PECB, O. catharinensis e $O$. mosenii, apresentaram casca do tronco com lenticelas discolores. Na Reserva Ducke, o padrão lenticelado, com lenticelas dispersas ou com distribuição irregular, foi a textura mais comum em Lauraceae. O. aciphylla, O. cujumari e O. guianensis apresentaram esta textura na casca do tronco. O. ceanothifolia e O. tabacifolia apresentaram lenticelas em linhas horizontais. O. immersa apresentou lenticelas em linhas verticais. O. floribunda apresentou fissuras rasas, sem desprendimento evidente.

- Cabralea canjerana apresentou lenticelas lineares longitudinais no PECB. Em Misiones, Argentina (Gartland, 2002), a mesma espécie possui escamas quadrangulares na casca do tronco.

- Brosimum lactescens apresentou lenticelas arredondadas e elípticas no PECB. Na Reserva Ducke, B. rubescens e B. potabile apresentaram lenticelas em linhas horizontais.

- Pradosia lactescens apresentou lenticelas lineares longitudinais, além de padrão fissurado. Duas espécies deste gênero, $P$. cochlearia e $P$. decipiens, apresentaram textura variegada na Reserva Ducke.

\section{$\underline{\text { Escamosa }}$}

- Aspidosperma parvifolium apresentou como padrão principal textura escamosa. Na Reserva Ducke, A. schultesii apresentou placas lenhosas grandes.

- Virola bicuhyba tem, como padrão principal da casca do tronco, a textura escamosa. Virola venosa apresentou fissuras rasas sem desprendimento evidente na casca do tronco na Reserva Ducke.

\section{Domos lineares}

- As duas espécies de Pouteria analisadas no PECB apresentaram textura com domos lineares na casca do tronco ( $P$. caimito e P. psammophila). Já na Reserva 
Ducke $P$. caimito apresentou casca do tronco não muito diferente, com sulcos profundos e sem desprendimento, textura também encontrada em $P$. virescens e $P$. aff. gardneri. $P$. freitasii e $P$. reticulata apresentaram casca escamosa no tronco. Outras duas espécies do mesmo gênero, $P$. erythrochrysa e $P$. peruviensis, apresentaram lâminas coriáceas, enquanto $P$. laevigata apresentou fissuras rasas, $P$. minima com sulcos profundos, as duas últimas sem desprendimento evidente e $P$. vernicosa com placas lenhosas grandes.

- Tapirira guianensis apresentou domos lineares, estratificados com fundo castanho-avermelhado. Na reserva Ducke, a mesma espécie apresentou sulcos rasos, com domos estreitos, sem desprendimento evidente.

- Na parcela permanente do PECB, entre as Myrtaceae, apenas Eugenia multicostata e Marlierea suaveolens apresentaram lâminas coriáceas, enquanto a maior parte das espécies apresentou lâminas papiráceas (Campomanesia guaviroba, E. cambucarana, E. capitulifera, E. cereja e E. subavenia). Na Reserva Ducke, lâminas coriáceas ocorreram principalmente em Myrtaceae, como Eugenia cf. longiracemosa, Marlierea umbraticola e Myrcia gigas.

- No PECB, Campomanesia guaviroba apresentou lâminas papiráceas, textura observada em outra espécie do mesmo gênero, C. guazumifolia, na Estação Ecológica de Angatuba.

- Crystocaria moschata e Myrcia pubipetala apresentaram textura variegada no PECB. Na Estação Ecológica de Angatuba, Torres et al. (1994) observaram esta textura em Myrcia tomentosa. Ribeiro et al. (1999) denominaram esta textura como "com depressões", ocorrendo especialmente em Lecythidaceae e Sapotaceae.

Obviamente, as comparações possuem um alcance limitado, posto que os dados decorrem de metodologias diferentes e, mais importante, aplicadas em plantas ocorrendo em ambientes distintos. Contudo, ainda assim tais comparações são válidas por permitirem, por um lado a aplicação da nomenclatura morfológica aqui proposta, e, por outro, a compreensão dos limites de sua aplicabilidade.

\subsection{Guia de identificacãão}


Das 64 espécies analisadas, 33 apresentaram padrões que possibilitam sua identificação observando tronco, raízes e casca externa em uma comparação entre árvores de grande porte da parcela estudada. 


\section{CONCLUSÕES E CONSIDERAÇÕES FINAIS}

A casca externa pode apresentar caracteres macroscópicos diagnósticos que constituem elementos valiosos para o reconhecimento de espécies em campo, constituindo-se em importante ferramenta para a identificação dessas espécies em estágio vegetativo. Alguns caracteres mostram-se tão diagnósticos que constituem, por si mesmos, um excelente instrumento para uma fiel identificação. Deve-se sublinhar, contudo, que, para a maioria das espécies, esta ferramenta deve ser usada em conjunto com outras características. Freqüentemente é difícil expressar com fidelidade o aspecto que apresentam algumas cascas, sendo, por isso, de grande importância sua ilustração.

O formato do tronco e da raiz também pode auxiliar na identificação. Porém, quando as espécies apresentam tronco cilíndrico ou acanalado apenas na base, esse caráter demonstra um alcance limitado para a identificação. Em contrapartida, tronco inteiramente acanalado apresentou-se como fator que facilitou o reconhecimento de algumas espécies, como foi observado também na Reserva Ducke (Ribeiro et al. 1999).

Frutos, folhas e flores no solo, podem representar elementos para a confirmação da identificação. Porém devem ser utilizados com muita cautela, já que muitos desses órgãos, quando encontrados no chão não permitem a averiguação precisa de sua origem. Apenas depois de realizadas todas as observações possíveis no indivíduo em si, estes elementos podem apresentar-se como um indício confirmando a identificação.

Como os caracteres estudados tiveram valores relativos para cada espécie, tornase difícil propor um protocolo fixo para a descrição. Inicialmente deve ser feita uma observação geral para, então, aplicar a metodologia adequada em cada caso, selecionando aqueles aspectos de maior relevância para a identificação. No decorrer deste processo, é necessária uma grande permanência e acurada observação em campo. As diferenças e semelhanças de uma mesma espécie são percebidas após um aprendizado que avança gradualmente, observando o valor relativo que é dado a cada caráter estudado. Inclusive porque a comparação inicial deve ser feita preferencialmente in loco, já que fotos não revelam peculiaridades observadas em campo e, muitas vezes, os indivíduos da mesma espécie encontram-se distantes.

O uso de terminologia padronizada na descrição de características de tronco, raízes e casca permitem sua aplicação e comparação com dados de estudos desenvolvidos em diferentes regiões, sendo importante ressaltar sua utilização aliada a outros caracteres da planta para uma identificação eficiente. 
A chave para diferenciação apresentada neste trabalho não pode ser usada sem ressalvas. O estabelecimento de um critério de inclusão a partir de $48 \mathrm{~cm}$ de DAP não aborda características observadas em indivíduos de menor porte. Deve-se ter em mente também que caracteres vegetativos são muito mais variáveis que caracteres reprodutivos, principalmente em se tratando da expressão da casca. 


\section{IMPRESSÕES FINAIS: Términos e novos começos}

Para crescer sobre um alicerce seguro, com profundas e firmes raízes, é necessário um tempo. O desenvolvimento gra...du...al... permite o crescimento de raízes robustas, capazes de sustentar exuberantes troncos e copas. A busca inferior pela firmeza e pela nutrição no interior da terra. A busca superior pela luz do Sol, a iluminação vinda do céu que também nutre. Forças que se mesclam e promovem o crescimento e a expansão.

No processo deste crescimento é preciso flexibilidade para desviar de obstáculos no caminho anteriormente traçado, como as raízes ao depara-se com sólida rocha. Ou seria melhor não construir caminho algum com antecedência, e sim permitir conhecê-lo, senti-lo ao caminhar?! Desta forma obstáculos transformam-se em pontos de checagem e direcionamento para abrir portais. O equilíbrio trás a harmonia. É estar aberta às oportunidades oferecidas, mesmo quando distantes do que desenhava como ideal. Não deixar o tempo passar por mim, mas estar presente no tempo PRESENTE! Onde reside a potencialidade da construção. Estar receptiva para o presente, a dádiva da vida. É expandir minhas raízes superficiais influenciando o ambiente que me cerca e recebendo suas influências na construção do meu espaço sagrado.

Se algum cupim conseguir penetrar minha fortaleza e me consumir, mesmo raízes profundas serão impotentes contra rajadas de vento. Mas ainda é possível rebrotar! A base permaneceu. Agora é reconstruir. Formando cascas, que fazem a interface dentro-fora, segundo as relações de troca que pretendo estabelecer com o meio onde vivo, me protegendo de agressões externas e conservando a água que circula em mim, porém sempre mantendo as trocas gasosas.

Meu objetivo é o crescimento, e os mais variados caminhos podem ser percorridos. Se existem algumas pedras sobre as quais desejo firmar meu passo a sede pelo crescimento deve superar o desejo pelas pedras, do contrário minha visão pode turvar-se. As ambições promovem e impulsionam sim, mas o cuidado é para não permitir que se transforme em obsessões, que me fecha às oportunidades. Desejo o impossível, vejo as realizações do inatingível para anseios do meu coração.

As forças do inferior e superior, terra e céu, canalizadas pela busca da firmeza e iluminação se mesclam no centro, são sorvidas pelo coração de onde brotam e irradiam desejos e ambições que incitam, invariavelmente, para a construção do caminho do meu crescimento. Quero estar no dossel, ou melhor, ser uma árvore emergente! Quanta luz! 
O que não deixa de causar certo receio, já que a incidência direta pode ressecar. Porém, no decorrer do processo de crescimento diferentes estratégias são desenvolvidas, fortalecendo-me para seguir íntegra. Fechar olhos e ouvidos ao meu coração e lançarme em uma busca incessante por algo determinado pode levar-me ao desperdício de energia, fazendo que não saiba distinguir a real necessidade dos meus desejos, colocando como prioridade o que é secundário. Mas o crescimento secundário não trás a robustez necessária para a ascensão?!

Gostoso é como meu caminho, ao mesmo tempo em que solitário, recebe tantas influências dos caminhos que o cruzam. São astros que modificam minha órbita. Acompanham-me por um tempo. Os mais próximos exercem influência mais direta naquele momento. Mas minha trajetória já tinha sido influenciada anteriormente por outros planetas e estrelas! Apesar de agora distantes, me trouxeram para cá. E ainda existem astros tão grandes que agem sobre o presente mesmo a distância. Essa distância não é necessariamente eterna. Acontece de órbitas se reaproximarem, mais perto ou mais distante que da última vez. E tornam a influenciar minha trajetória!

Agradeço ao universo, por aprender que o mundo que vejo, que sinto, é simplesmente o que eu sou. Conhecer o mundo é conhecer a mim. Não experimento o mundo de outro ser. Para seguir tranqüila em meu caminho devo conhecer e respeitar minha natureza. Assim, sinto-me mais capaz de respeitar a natureza dos outros ao meu redor. Como é lindo viver! 


\section{REFERÊNCIAS BIBLIOGRÁFICAS}

CAMARGO, M.N.; KLAMT, E.; KAUFTMAN, J.H. Classificação de solos usada em levantamentos pedológicos no Brasil. Boletim Informativo da Sociedade Brasileira de Ciência do Solo, v.12, p.11-33, 1987.

CUSTÓDIO-FILHO, A.; FRANCO, G.A.D.C.; DIAS, A.C.; NEGREIROS, O.C. Composição florística do estrato arbóreo do Parque Estadual de Carlos Botelho, SP. Revista do Instituto Florestal, v.4, p.184-191, 1992.

DIAS, A.C. Estrutura e diversidade do componente arbóreo e a regeneração natural do Palmito (Euterpe edulis Mart.) em um trecho da mata secundária, no Parque Estadual de Carlos Botelho, SP. Piracicaba, 1993. 126p. Dissertação (Mestrado) Escola Superior de Agricultura "Luiz de Queiroz”, Universidade de São Paulo.

DOMINGUES, E.N.; SILVA, D.A. Geomorfologia do Parque Estadual de Carlos Botelho (SP). Boletim Técnico do Instituto Florestal, v.42, p.71-105, 1988

GARTLAND, H.M.; MIRANDA, D.; GRACE, L.; BOHREN, A. Estructura anatómica de la corteza y diseño del ritidoma de Cedrela fissilis Vell. y Cabralea canjerana subsp. canjerana (Vell.) Mart. (Meliaceae), Misiones, Argentina. Revista de Ciências Forestales, Quebracho $N^{\circ}$ 9, 2002: 43-53.

JUNIKKA, L. Survay of english macroscopic bark terminology. IAWA Journal, Vol. 15 (1), 1994: 3-45.

KÖEPPEN, W. Climatologia. Fondo de cultura econômica, México, 1948.

MORAES, P.R.L. de. Caracterização morfológica de frutos, sementes e plântulas de espécies da família Lauraceae, no Parque Estadual de Carlos Botelho, São Paulo. Rio Claro, 1993. 234p. Dissertação (Mestrado) - Universidade Estadual Paulista "Júlio de Mesquita Filho"

MORAES, P.R.L. de. Espécies utilizadas na alimentação do mono-carvoeiro (Brachyteles arachnoides E. Geofrey, 1806) no Parque Estadual de Carlos Botelho. Revista do Instituto Florestal, v.4, p.1208-1206, 1992.

NEGREIROS, O.C. Características fitossociológicas de uma floresta latifoliada pluviosa tropical visando ao manejo do palmito, Euterpe edulis Mart. Piracicaba. Dissertação (Mestrado) - Escola Superior de Agricultura ("Luiz de Queiroz", Universidade de São Paulo,1982.

NEGREIROS, O.C.; CUSTÓDIO-FILHO, A.; DIAS, A.C.; FRANCO, G.A.D.C.; COUTO, H.T.Z.; VIEIRA, M.G.L.; MOURA NETTO, B.V. Análise estrutural de 
um trecho de Floresta Pluvial Tropical, Parque Estadual Carlos Botelho, Núcleo Sete Barras (SP-Brasil). Revista do Instituto Florestal, v.7, n.1, p.1-33, 1995.

PAGANO, S.N.; LEITÃO FILHO, H.F. Composição florística do estrato arbóreo de mata mesófila semidecídua, no município de Rio Claro (Estado de São Paulo). Revista Brasileira de Botânica, v.10, p.37-47, 1987.

RIBEIRO, J.E.L.S. et. al. Flora da Reserva Ducke, guia de identificação das plantas vasculares de uma floresta de terra-firme na Amazônia Central. Manaus. INPA. 1999.

RIZZINI, C.T. 1971. Árvores e madeiras úteis do Brasil. Manual de dendrologia brasileira. Edgard Blücher Ltda, São Paulo. (ver biblio usp)

ROSAYRO, R.A. Field characters in the identification of tropical forest trees. Emp. For. Rev. 32:124-141. 1953.

SAA, J.H.J. La identificacion de los arboles tropicales por medio del tronco y la corteza. Tesis de Magister Scientiae. Instituto interamericano de Ciencias Agrícolas de la O.E.A. Turrialba, Costa Rica. 1967.

SAMPAIO, D.; SOUZA, V.C.; OLIVEIRA, A.A.; PAULA-SOUZA, J.; RODRIGUES, R.R. Árvores de Restinga: guia de identificação. Ed. Neotrópica. 2005.

SETZER, J. Contribuição para o estudo do clima do Estado de São Paulo. Escolas Profissionais Salesianas. São Paulo, 200p, s ed.1946.

TORRES, R.B.; KINOSHITA, L.S.; :MARTINS, F.R. 1994. Aplicação de padrões de casca na identificação de árvores da Estação Ecológica de Angatubo, SP. Revta. Brasil. Bot., São Paulo, V.17, n.2, p. 119-127.

VELOSO, H.P.; GÓES-FILHO, L. Fitogeografia brasileira: classificação fisionômicoecológica da vegetação Neotropical. Salvador, 1982. 86p.

YUNUS, M., YUNUS, D. \& IQBAL, M. 1990. Systematic bark of some tropical trees.

Bot. J. Linn. Soc. 103:367-377. 


\section{Árvores Emergentes e de Dossel da Mata Atlântica}

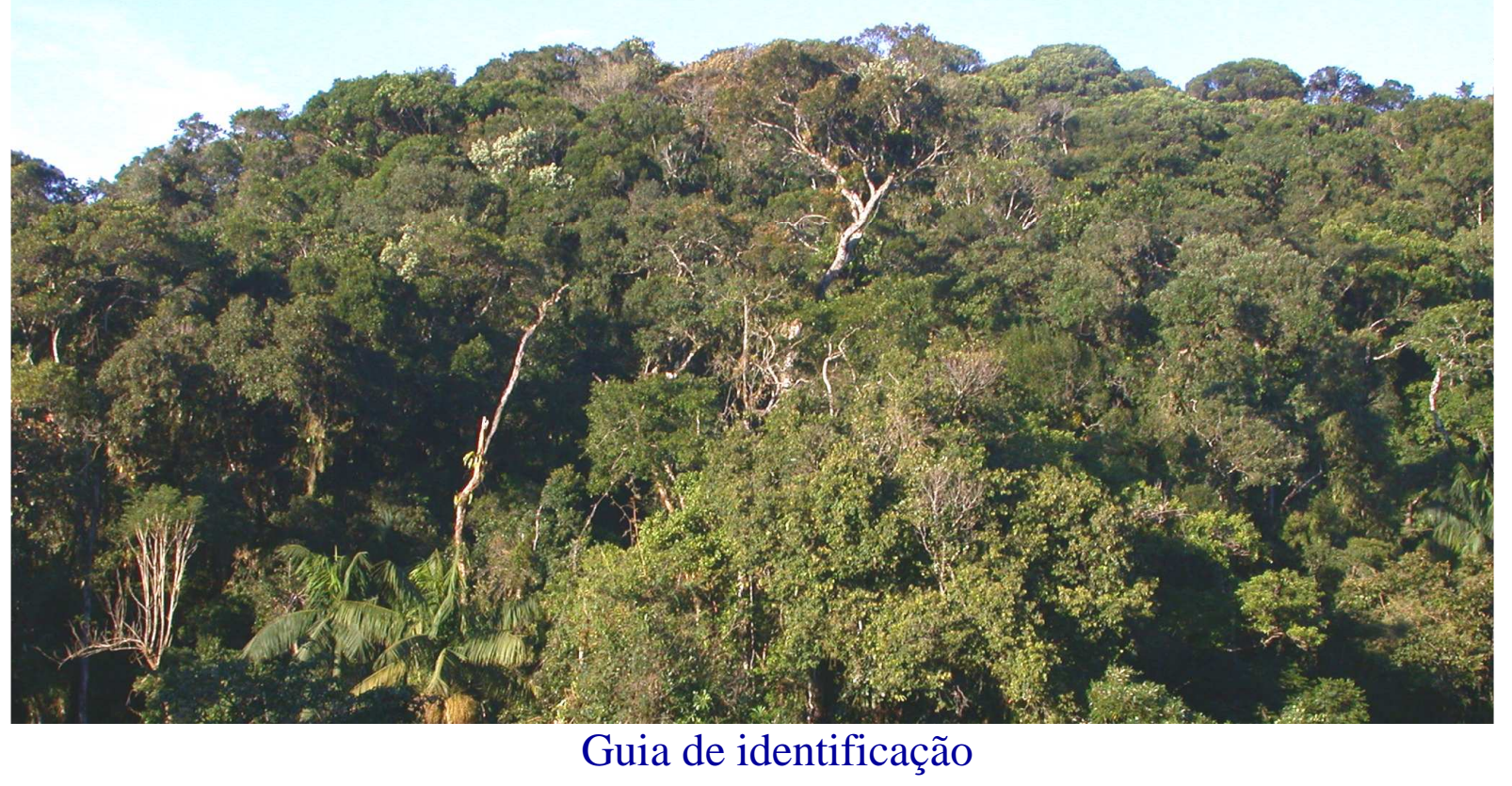




\section{Chave de identificacão}

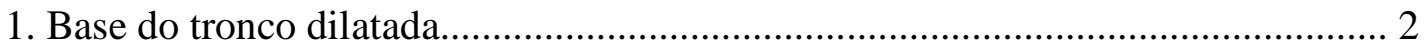

1'. Base do tronco reta, digitada ou com sapopemas................................................ 3

2. Casca do tronco castanho-esbranquiçada, com lenticela discolores, castanho escuras. Pisonia ambigua

2'. Casca do tronco castanho-clara, fendida, fissurada e/ou lenticelada.

. Base do tronco com predominância de sapopemas................................................ 4

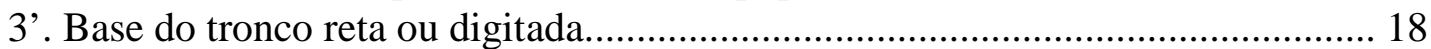

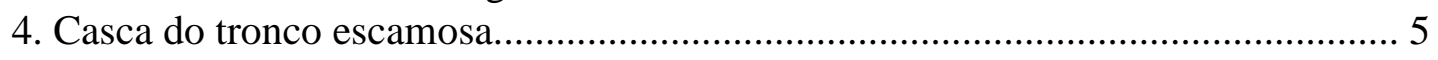

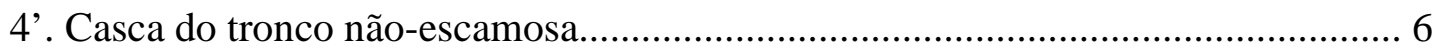

5. Casca do tronco sem lenticelas................................................... Virola bicuhyba

5. Casca do tronco com lenticelas arredondadas justapostas....... Parinari brasiliensis

6. Casca do tronco lisa ou com lâminas coriáceas com impressão lisa....................... 7

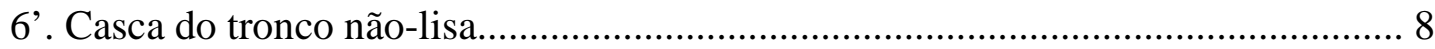

7. Casca do tronco branca.................................................. Eugenia cf. burkartiana

7'. Casca do tronco vermelha................................................... Eugenia multicostata

8. Casca do tronco com ondulações agudas.............................................................. 9

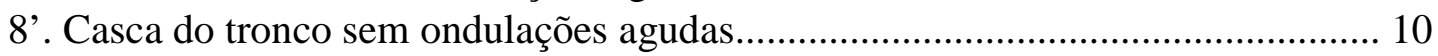




\section{Chave de identificacão}

9. Raízes com 6-13cm de espessura.............................................Pterocarpus rohrii

9'. Raízes com 17-25cm de espessura.......................... Pseudopiptadenia warmingii

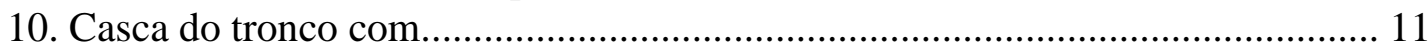

10'. Casca do tronco sem domos lineares............................................................... 12

11. Casca da crista da raiz com fundo avermelhado.................... Tapirira guianensis

11'. Casca da crista da raiz com fundo da mesma cor da casca........ Pouteria caimito

12. Casca do tronco com placas lenhosas................................................................. 13

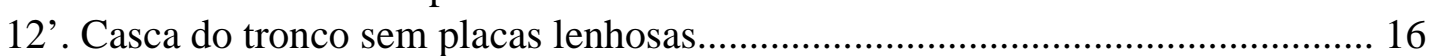

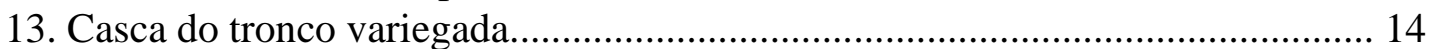

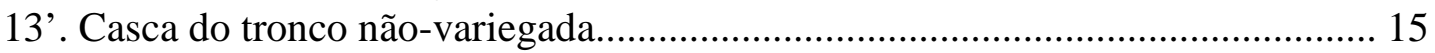

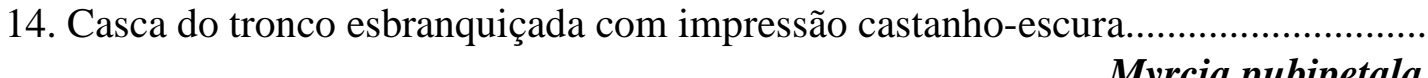

14'. Casca do tronco castanho-avermelhada com impressão

avermelhada......................................................................... Cryptocarya moschata

15. Casca do tronco com lenticelas, pouco aparentes, pequenas ( $1 \mathrm{~mm}$ diâm.),

conferindo uma textura áspera.

Casearia obliqua

15'. Casca do tronco com lenticelas grandes (4-6mm diâm.),

discolores

Ocotea mosenii 


\section{Chave de identificacão}

16. Casca do tronco sem lenticelas.

Buchenavia kleinii

16'. Casca do tronco com lenticelas....

17. Casca do tronco com lenticelas dispersas ou em linhas longitudinais levemente sinuosas.

Sloanea guianensis

17'. Casca do tronco com lenticelas em agrupamentos...... Hyeronima alchorneoides

18. Casca do tronco reticulada

18'. Casca do tronco não-reticulada. 21

19. Casca do tronco com delimitação longitudinal por microfissuras e com lenticelas não-verrucosas nos vértices. Copaifera trapezifolia

19'. Casca do tronco com delimitação longitudinal por fissuras ou lenticelas associadas a fissuras

20. Casca do tronco reticulada formada por retângulos longitudinais

Heisteria silvianii

20'. Casca do tronco reticulada formada por quadrados ou retângulos transversais

Centrolobium robustum

21. Casca do tronco com acúleos Jacaratia spinosa

21 '. Casca do tronco sem acúleos 


\section{Chave de identificacão}

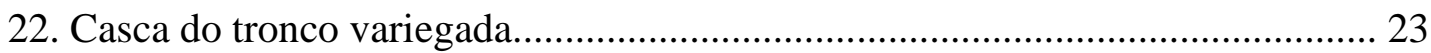

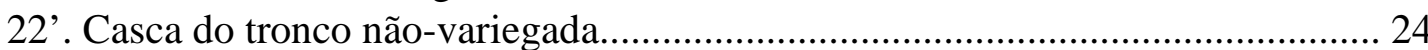

23. Casca do tronco esbranquiçada com impressão castanho-escura.

Myrcia pubipetala

23'. Casca do tronco castanho-avermelhada com impressão avermelhada.....

Cryptocarya moschata

24. Tronco inteiramente acanalado

Simira corumbensis

24. Tronco cilíndrico ou levemente acanalado....

25. Casca do tronco com domos lineares

Pouteria caimito

25'. Casca do tronco sem domos lineares.

26. Casca do tronco suja.

26'. Casca do tronco não-suja

27. Tronco branco, com casca friável.

Maytenus robusta

27'. Tronco castanho-claro, com casca não-friável........ Tetrastylidium grandifolium

28. Casca do tronco escamosa.....

29

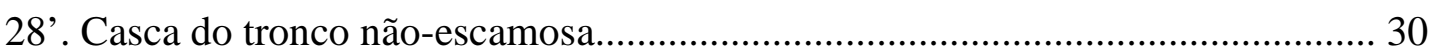




\section{Chave de identificação}

29. Casca do tronco com lenticelas evidentes, justapostas Parinari brasiliensis 29'. Casca do tronco com faixas de lenticelas pouco aparentes.

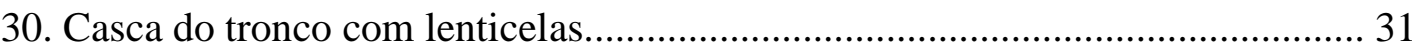
Aspidosperma parvifolium

30'. Casca do tronco sem lenticelas ou não aparentes........................................37

31. Casca do tronco com lenticelas discolores muito mais escuras que a matriz..... 32 31'. Casca do tronco com lenticelas da mesma cor da matriz, discolores, mais claras que a matriz ou pouco mais escuras

32. Casca do tronco com lenticelas castanhas a castanho-avermelhadas, a maioria estratificada...

.Capsicodendron dinisii

32'. Casca do tronco com lenticelas não-estratificadas. Hymenaea courbaril

33. Casca do tronco com lenticelas em agrupamentos esparsos..

Hyeronima alchorneoides

33'. Casca do tronco com lenticelas cobrindo a maior parte da superfície do tronco....

34. Casca do tronco com lenticelas lineares longitudinais de formato semelhante a lábios. 


\section{Chave de identificação}

35. Casca do tronco com lenticelas arredondadas

Coussapoa microcarpa

35'. Casca do tronco com lenticelas lineares longitudinais...

36. Raízes superficiais abundantes, de casca cinza-escura com lenticelas discolores, castanho-claras............................................................... Chrysophyllum viride 36'. Raízes superficiais não-abundantes ou com padrão de casca distinto do anterior.. Magnolia ovata

37. Casca do tronco com domos retangulares, longitudinais, $4-7 \mathrm{~cm}$ larg., $20-40 \mathrm{~cm}$ compr.

Cedrela fissilis 37'. Casca do tronco com domos retangulares, longitudinais, 0,5-2,0cm larg., 15-

$70 \mathrm{~cm}$ compr

Cariniana estrellensis 



\section{ANACARDIACEAE}

\section{Tapirira guianensis Aubl.}

peito-de-pombo

Tronco castanho-escuro, cilíndrico. Raízes com sapopemas simples, aresta reta a levemente côncava, $a>b, a=120-230 \mathrm{~cm}, b=60-100 \mathrm{~cm}, 12-20 \mathrm{~cm}$ espessura. Casca do tronco com domos lineares, estratificados em placas, 1,5-6,0cm compr., 0,51,0cm larg., 3-6mm espessura; superfície côncava, áspera. Delimitação longitudinal por fissuras retas a levemente sinuosas, $8-15 \mathrm{~cm}$ compr., $0,2-1,0 \mathrm{~cm}$ larg., 3-6mm profundidade. Fundo frequentemente castanho-avermelhado. Casca da crista da raiz fendida, com fendas sinuosas delimitando alvéolos, $5-8 \mathrm{~cm}$ compr., 0,5-1,5cm larg., 2-4mm profundidade; fundo castanho-avermelhado. Domos em placas estratificadas, de superfície côncava.

\section{DICAS DE CAMPO}

Casca do tronco com domos lineares, estratificados e fundo castanho-avermelhado (seta). 


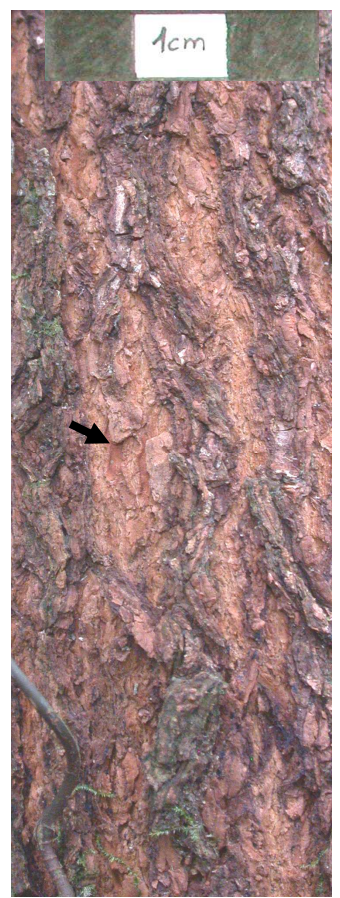

casca da crista da raiz

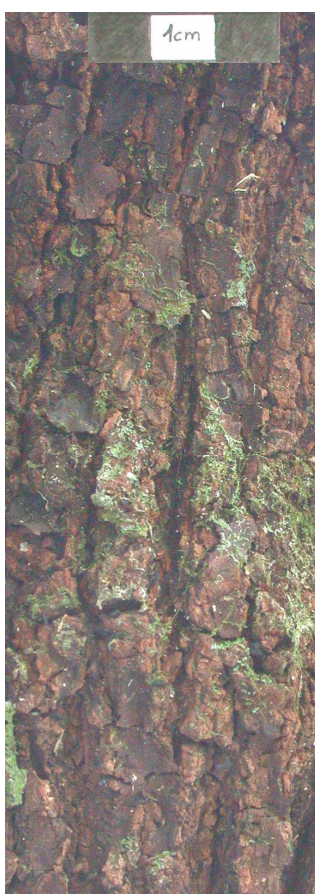

casca do tronco

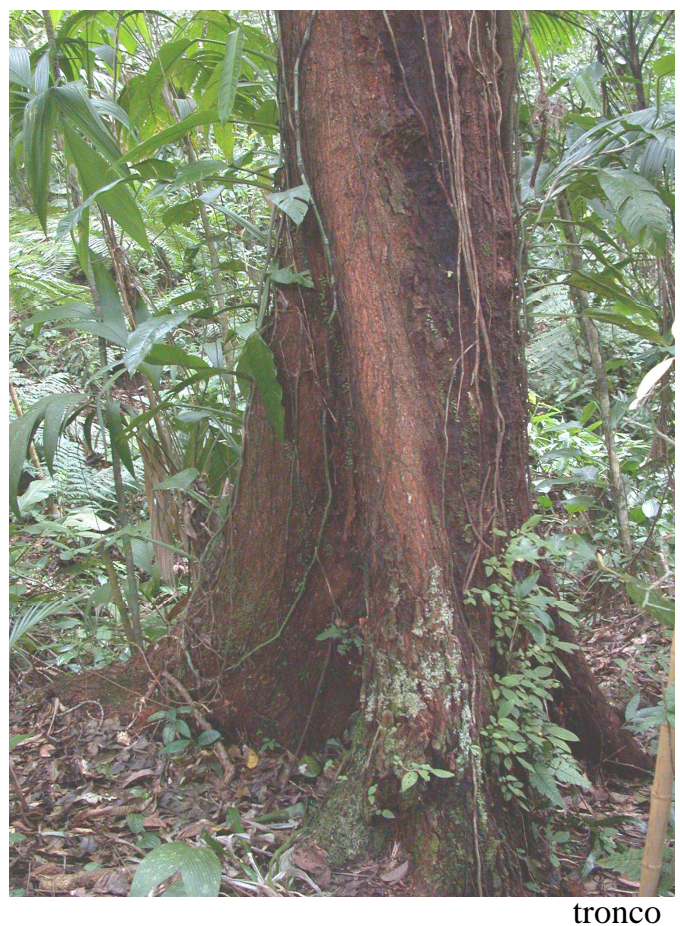

(peito-de-pombo) Tapirira guianensis 


\section{APOCYNACEAE \\ Aspidosperma parvifolium A. DC. \\ guatambu}

Tronco castanho bem claro, cilíndrico ou acanalado. Raízes digitadas, simples, aresta reta, $\mathrm{a}>\mathrm{b}, \mathrm{a}=40-70 \mathrm{~cm}, \mathrm{~b}=25-50 \mathrm{~cm}, 17-25 \mathrm{~cm}$ espessura. Casca do tronco escamosa, com domos retangulares, longitudinais, 9-20cm compr., 2-4cm larg., 0,4-1,0cm espessura; superfície plana, com microfissuras, longitudinais, transversais ou estreladas, com lenticelas pouco aparentes, verrucosas, fixas, abertura circular, arredondadas, pequenas, justapostas em faixas longitudinais contínuas, 1,0-1,5(-2,0)cm larg. Delimitação longitudinal por fendas retas a levemente sinuosas; fundo com lenticelas como as da superfície dos domos. Delimitação transversal não evidente. Impressão como a superfície. Algumas regiões totalmente descamadas. Casca da raiz como a casca do tronco ou lenticelado, com lenticelas verrucosas, descamantes, abertura em espocação ou linear, arredondadas, grandes, em linhas longitudinais, numerosas, podendo apresentar ondulações transversais, contínuas, justapostas.

\section{DICAS DE CAMPO}

Casca do tronco escamoso com faixa de lenticelas pouco aparentes e justapostas no fundo das fendas e na superfície das placas. 


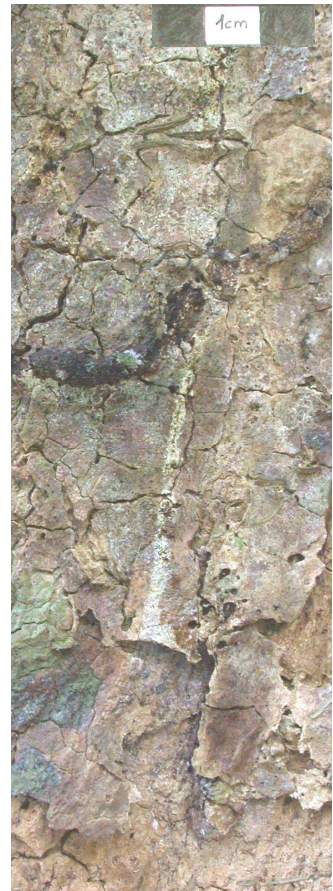

casca do tronco descascada

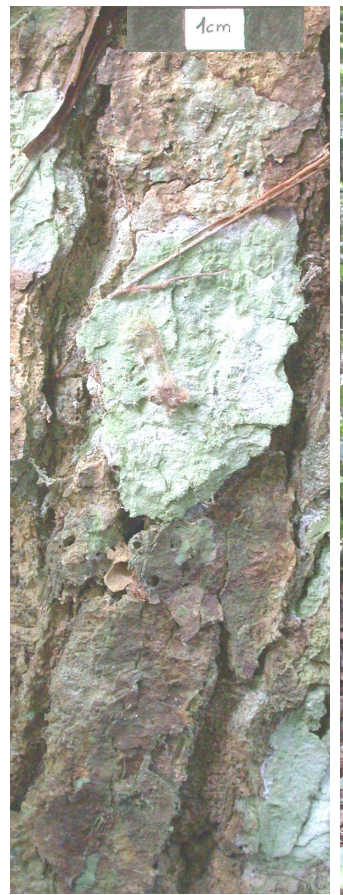

casca do tronco

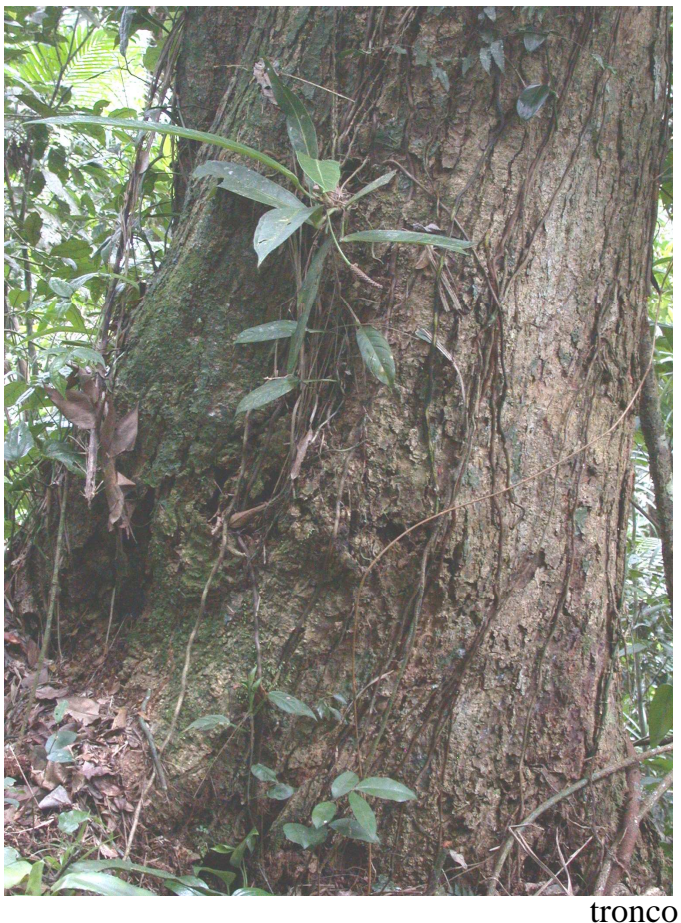

(guatambu) Aspidosperma parvifolium 


\section{CANELLACEAE}

\section{Capsicodendron dinisii (Schw.) Occh.}

pimenteira

Tronco castanho-esbranquiçado, acanalado, reto a levemente digitado. Casca do tronco lenticelado, com lenticelas discolores, castanho a castanho-avermelhadas, verrucosas, descamantes, castanho-claro ao descamar, de formato arredondado, com abertura em espocação, ou quadrangular, estratificada, com abertura linear,

transversal, raro longitudinal, grandes, com distribuição irregular, numerosas. Casca da raiz superficial lenticelada, com lenticelas castanho-claras, rasas a levemente verrucosas, fixas, abertura não evidente, arredondadas, grandes, numerosas.

\section{DICAS DE CAMPO}

Casca do tronco esbranquiçado, com lenticelas discolores, castanhas a castanhoavermelhadas, estratificadas (seta). $\mathrm{O}$ formato da base do tronco acanalado também auxilia em sua identificação. 


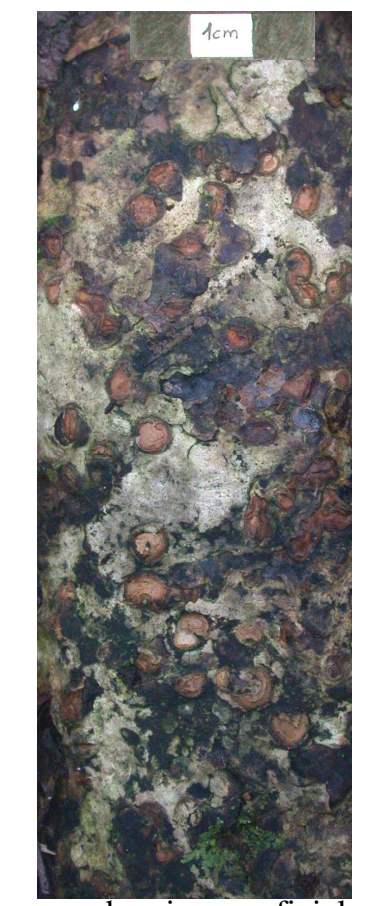

casca da raiz superficial

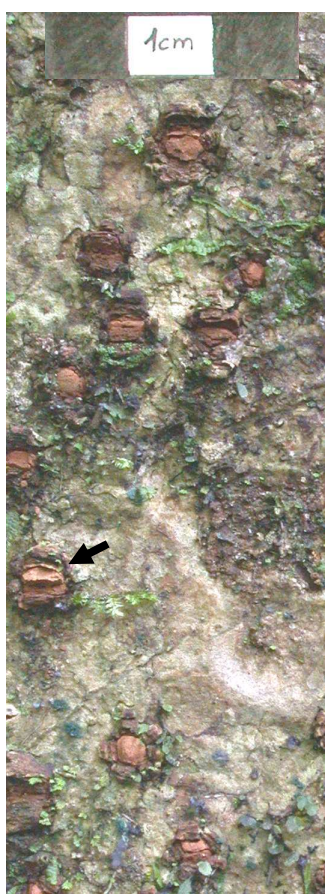

casca do tronco

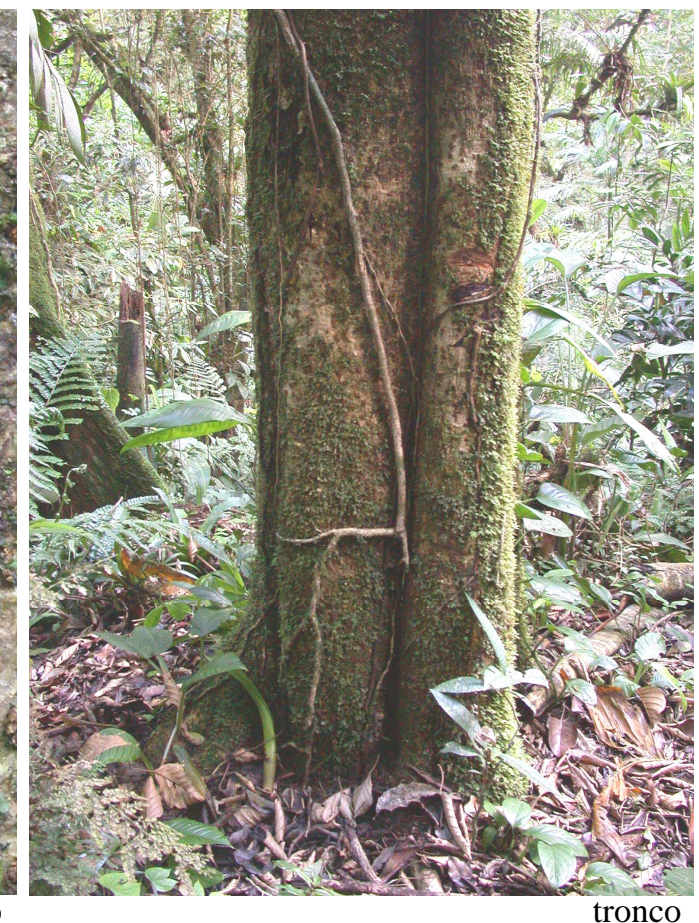

(pimenteira) Capsicodendron dinisii 


\section{CARICACEAE}

\section{Jacaratia spinosa (Aubl.) A. DC.}

mamãozinho

Tronco castanho claro, cilíndrico, reto. Raízes superficiais surgem próximas ao tronco, 40-60 cm compr., $10-25 \mathrm{~cm}$ larg., $10-25 \mathrm{~cm}$ espessura. Casca do tronco estriada com acúleos em calos, 1 acúleo central por calo. Calos lineares transversais, por vezes não apresentam o acúleo, $5-11 \mathrm{~cm}$ compr., (0,3-)0,5-1,0cm larg, 1-4mm espessura. Acúleos elípticos, longitudinais, 0,4-1,0cm compr., 3-6mm larg., 0,5$1,2 \mathrm{~cm}$ espessura,. Estrias, lenticelas discolores associadas a fissuras, castanhas um pouco mais escuras que a matriz, verrucosas, fixas, as mais espessas descamam, associadas a microfissuras longitudinais, levemente sinuosas, 4-ㅁ-12cm compr., 3(6)mm larg., 1(-3)mm espessura, 3-5mm distância transversal. Casca da raiz superficial estriada, lenticelas discolores associadas a fissuras, castanho-escuras, verrucosas, descamantes, 6-8cm compr., 0,3-1,0cm larg., 2-4mm espessura, 0,7$1,5 \mathrm{~cm}$ distância.

\section{DICAS DE CAMPO}

Única árvore de dossel na área com acúleos (seta) na casca do tronco. 

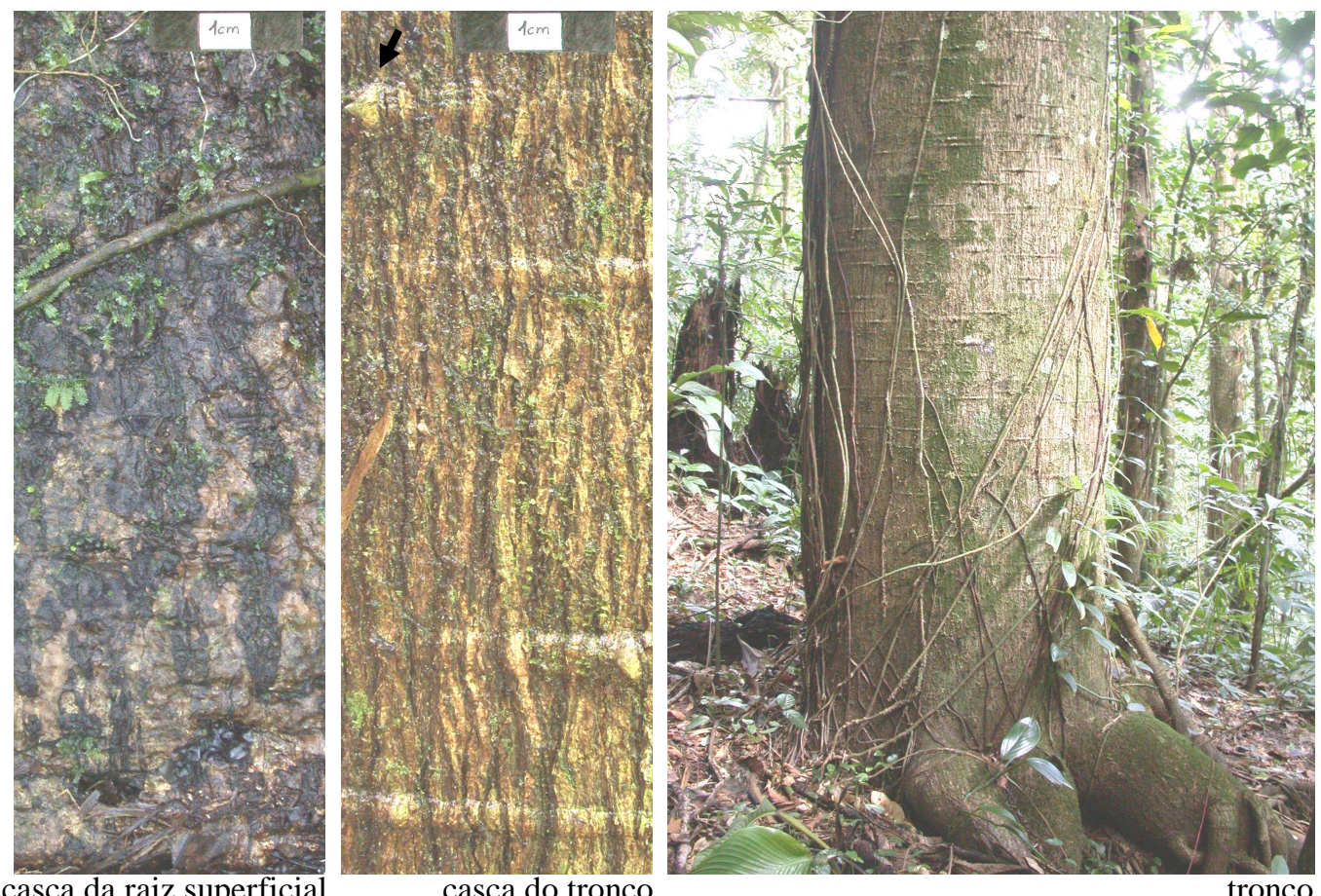

casca do tronco

(mamãozinho) Jacaratia spinosa 


\section{CELASTRACEAE}

\section{Maytenus robusta Reiss.}

Tronco branco, cilíndrico. Raízes digitadas, simples, aresta reta, a $>b, a=30-60 \mathrm{~cm}$, $b=20-35 \mathrm{~cm}, 7-11 \mathrm{~cm}$ espessura. Raiz superficial abundante, $7-13 \mathrm{~cm}$ diâm. Casca

do tronco e da raiz áspera a suja, friável ao toque. Casca da crista da raiz padrão I: áspero, como a casca do tronco. Padrão II: com microfissuras longitudinais 1$3 \mathrm{~cm}$ compr., 3-6mm distância. Casca da raiz superficial padrão I, principal: lenticelado, com lenticelas verrucosas, fixas, abertura linear, lineares, transversais e longitudinais, grandes, em linhas transversais, numerosas. padrão II: sujo.

\section{DICAS DE CAMPO}

Casca do tronco e da raiz esbranquiçada, friável ao toque. Casca da raiz superficial com lenticelas características verrucosas e lineares, padrão I (seta). 


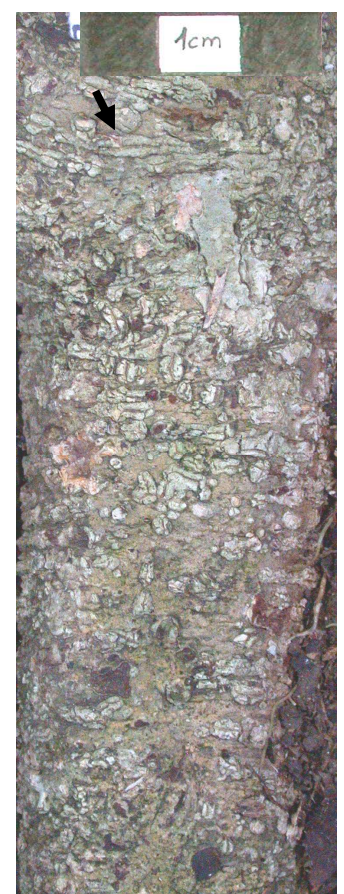

casca da raiz superficial

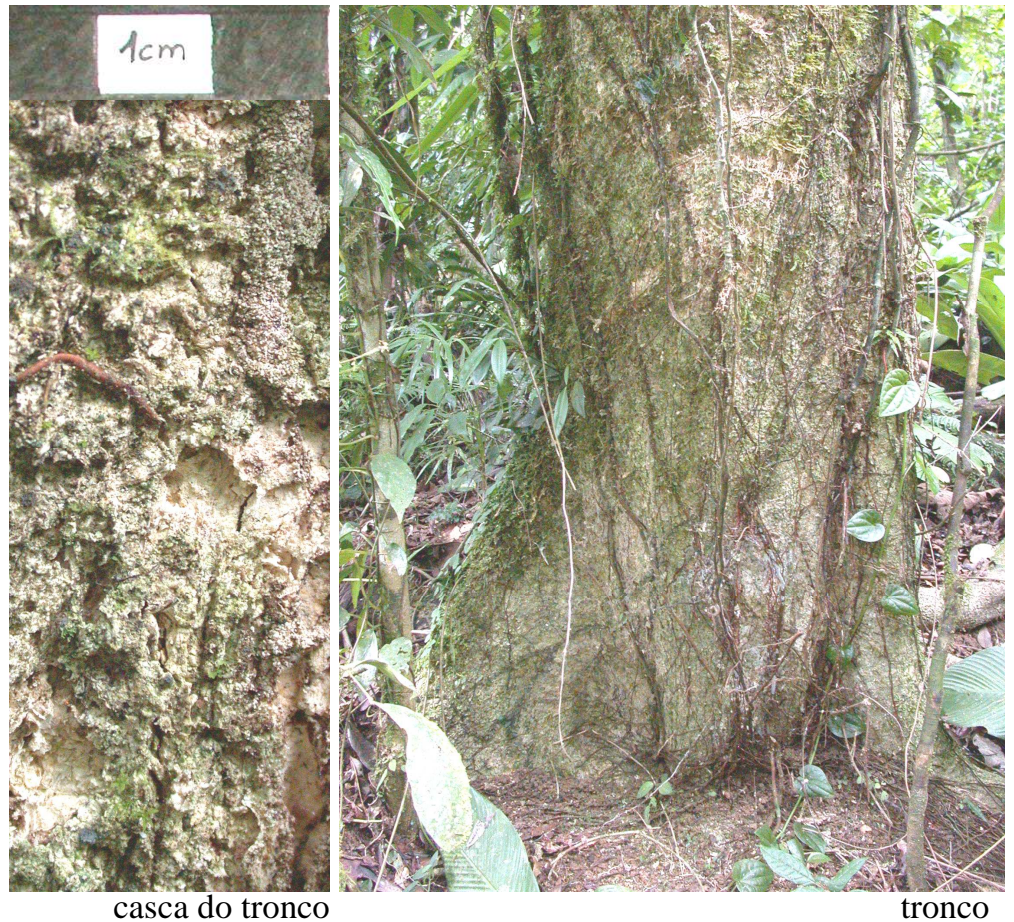

Maytenus robusta 


\section{CHRYSOBALANACEAE \\ Parinari brasiliensis (Schott) Hook. F.}

Tronco castanho-claro a castanho-escuro, podendo apresentar liquens esbranquiçados ou rosados, cilíndrico. Com cicatrizes, 1-3, lineares, transversais ou inclinadas, $15-20 \mathrm{~cm}$ compr., $6-8 \mathrm{~cm} l a r g, 3 \mathrm{~cm}$ espessura. Raízes digitadas, simples, aresta reta, $a>b, a=43-80 \mathrm{~cm}, b=15-55 \mathrm{~cm}, 5-25 \mathrm{~cm}$ espessura ou sapopemas, quando acima de $60 \mathrm{~cm}$ DAP, com ramificações distais, bifurcadas, aresta reta, a $>b$, $a=160-190 \mathrm{~cm}, b=60-75 \mathrm{~cm}$, espessura $13-20 \mathrm{~cm}$. Casca do tronco padrão I: castanho a castanhoescuro, lenticelado, com lenticelas verrucosas, descamantes, castanho bem claro ao descamar, arredondadas, com abertura estrelada, médias, justapostas, numerosas. Padrão II: castanho, escamoso, com domos retangulares longitudinais, 2-5cm compr., 1,0-1,5cm larg., 2-3mm espessura, superfície côncava. Delimitação longitudinal por fissuras 3-7cm compr., 2-5mm larg. Delimitação transversal por fissuras 1,0-1,5cm compr., $1 \mathrm{~mm}$ larg., o fundo contém fissuras com lenticelas arredondadas, pequenas, ou elípticas, grandes. Padrão III: castanho-claro, fissurada, com fissuras retas, longitudinais, 2,5-5,0 cm compr., 1-2mm larg., 2-3mm profundidade, transversais, $3-5 \mathrm{~mm}$ compr., $1 \mathrm{~mm}$ larg., 2-5mm espessura. Domos longitudinais, 1,0-2,5cm compr., 3-5mm larg., 2-3mm profundidade, superfície plana, áspera. Padrão IV: com microfissuras longitudinais, quase retas, contínuas, 2-4mm distância, com algumas microfissuras curtas transversais, castanho-claro, coberto por liquens esbranquiçados e rosados.

\section{DICAS DE CAMPO}

Casca do tronco com 3 a 4 padrões na mesma planta em áreas grandes e bem delimitadas: A. lenticelado; B. escamoso; C. fissurado; D. com microfissuras. 


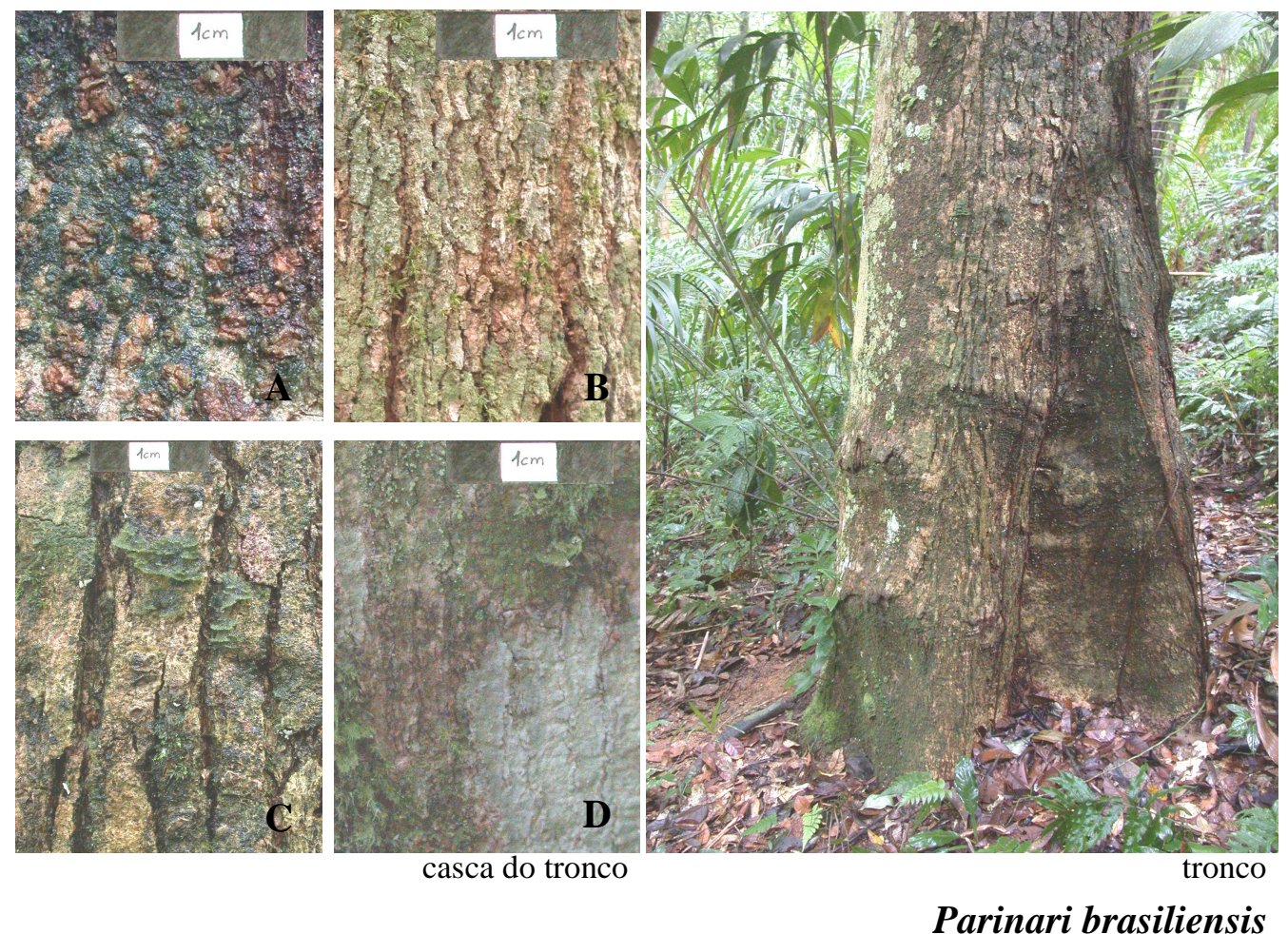




\section{COMBRETACEAE}

\section{Buchenavia kleinii Exell.}

Tronco castanho-escuro a cinza-escuro com porções esbranquiçadas, cilíndrico.

Raízes com sapopemas geralmente simples, aresta reta, $a=b$ ou "a" pouco maior que "b", $a=70-270 \mathrm{~cm}, 6-18 \mathrm{~cm}$ espessura. Casca do tronco fissurada, com fissuras longitudinais, 3-6cm compr., 1-3mm larg., $1 \mathrm{~mm}$ profundidade. Descamando em lâminas papiráceas retangulares, longitudinais, 3-6cm compr., 0,5-1,0cm larg., com superfície plana e áspera. Impressão com microfissuras longitudinais, $1-4 \mathrm{~cm}$ compr., 0,5-1,0cm distância. Desprendem-se aos poucos. Casca da raiz com ranhuras longitudinais formando conjuntos sinuosos, com fundo castanho ou esbranquiçado. Pode apresentar descamações em lâminas irregulares, principalmente na porção proximal. Casca da crista da raiz e da raiz superficial coloração mais clara com microfissuras ou ranhuras longitudinais.

Indivíduos de maior porte apresentam sapopemas ramificadas, de aresta levemente convexa, $a>b$.

\section{DICAS DE CAMPO}

Grandes sapopemas estreitas são observadas com freqüência nesta espécie e diferenciam-se de Sloanea guianensis pela ausência de lenticelas e rugosidade. A casca da porção lateral da raiz com ranhuras facilita sua identificação. 


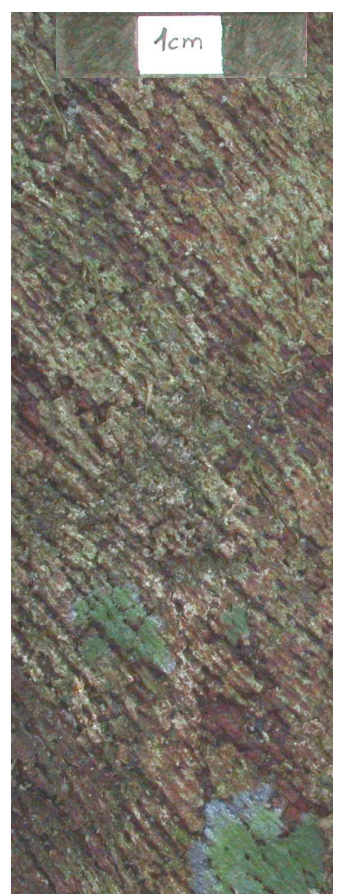

casca da raiz

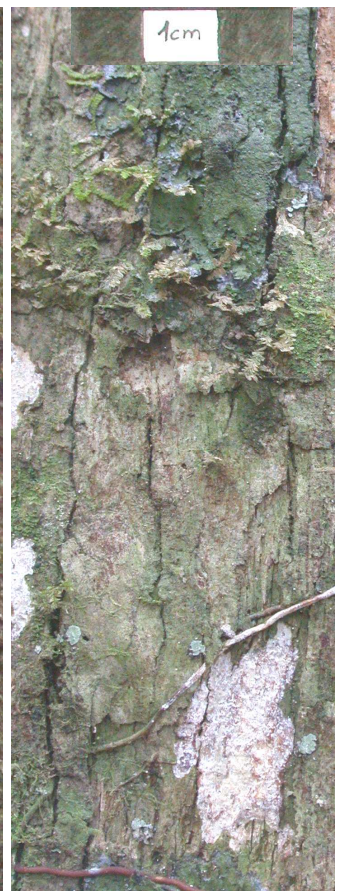

casca do tronco

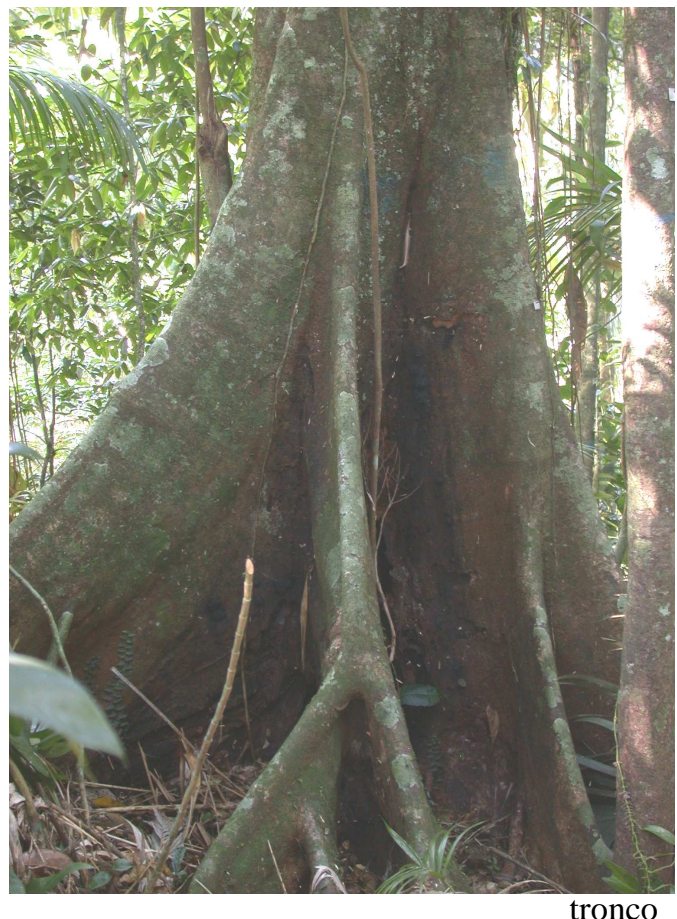

Buchenavia kleinii 


\section{ELAEOCARPACEAE}

\section{Sloanea guianensis (Aubl.) Benth.}

Tronco castanho a castanho-escuro, cilíndrico. Com rebrotos, $3-13 \mathrm{~cm}$ diâm. Raízes com sapopemas ramificadas, aresta reta, $a>b, a=120-390 \mathrm{~cm}, b=50-310 \mathrm{~cm}, 6-18 \mathrm{~cm}$ espessura. É freqüente apresentar rebroto junto às raízes. Casca do tronco lenticelada, com lenticelas verrucosas, descamantes, arredondadas, médias a grandes, com distribuição irregular ou em linhas longitudinais levemente sinuosas, esparsas. Casca da raiz padrão I: lenticelado e rugoso, com lenticelas verrucosas, a maioria fixa, arredondadas ou elípticas transversais, médias, com distribuição irregular, numerosas a esparsas. Padrão II: com ondulações transversais, (3,0-)4,56,0 cm de larg., (0,5-)1,0-1,5cm de espessura, 13-17 cm de distância. Casca da raiz superficial áspera, podendo apresentar microfissuras longitudinais, 2-3mm de distância e lenticelas arredondadas, pequenas, esparsas.

\section{DICAS DE CAMPO}

Com sapopemas grandes e estreitas, como em Buchenavia kleinii. Diferencia-se desta espécie devido à sua rugosidade e presença de lenticelas na casca. A presença de frutos no solo é freqüente e um importante auxílio na identificação. 

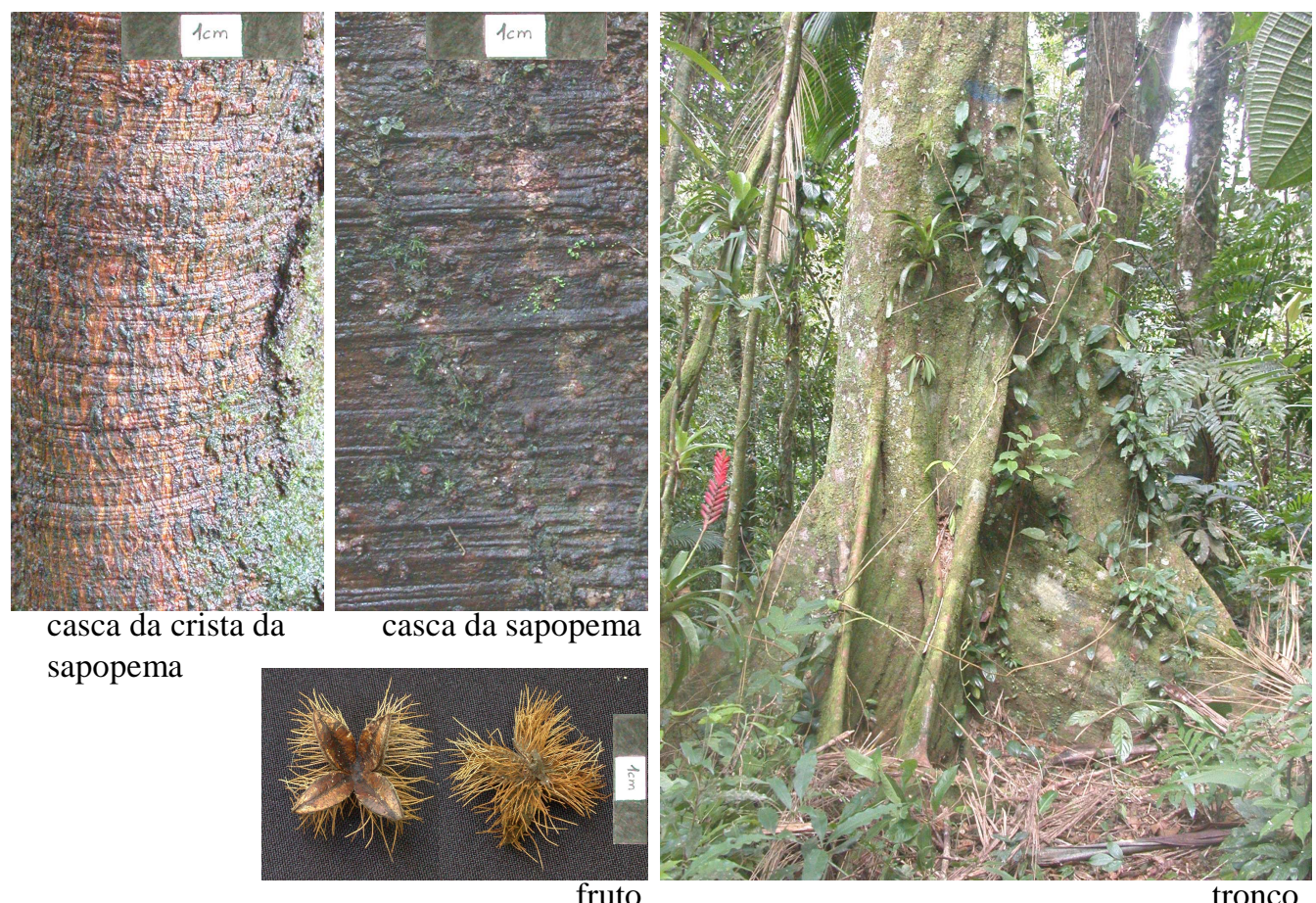

Sloanea guianensis 


\section{FABACEAE CAESALPINIOIDEAE}

\section{Copaifera trapezifolia Hayne}

pau-de-óleo

Tronco castanho-claro, cilíndrico, reto a digitado. Raízes digitadas, simples, aresta reta em indivíduos com DAP acima de $75 \mathrm{~cm}$ podendo, ainda, apresentar raízes superficiais abundantes. Casca do tronco reticulada, com formas quadrangulares irregulares, 3-5mm compr., delimitados por microfissuras e lenticelas não-verrucosas, de abertura estrelada nos vértices dos quadrados.

Casca da raiz superficial lenticelada, com lenticelas discolores, castanhoescuras, verrucosas, fixas, abertura não evidente, arredondadas, pequenas, ou elípticas, geralmente longitudinal, grandes, distribuição irregular, numerosas. Matriz castanha ou castanho-esbranquiçada.

\section{DICAS DE CAMPO}

Casca do tronco reticulada, formada por pequenos quadrados com lenticelas nos vértices. 


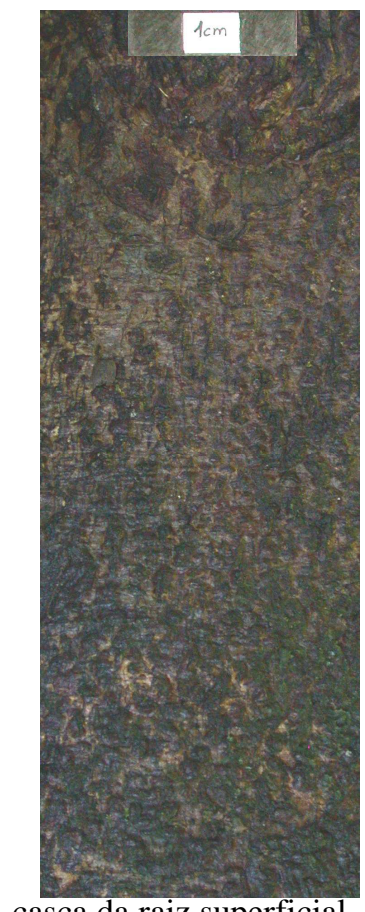

casca da raiz superficial

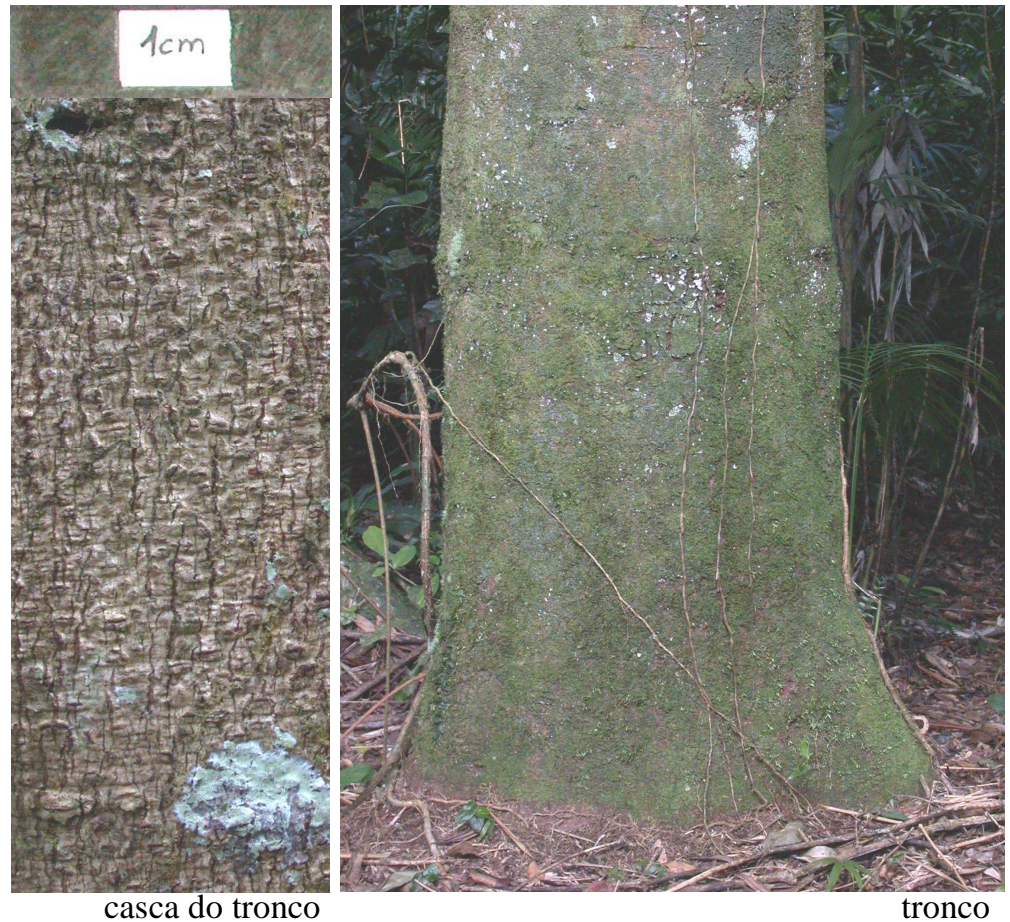

(pau-de-óleo) Copaifera trapezifolia 


\section{FABACEAE CAESALPINIOIDEAE}

\section{Hymenaea courbaril L.}

jatobá

Tronco esbranquiçado, cilíndrico ou levemente acanalado, reto a digitado. Raízes digitadas, simples, aresta reta, $a>>b, b=20-56 \mathrm{~cm}, 20-40 \mathrm{~cm}$ espessura. Casca do tronco lenticelado, com lenticelas discolores, castanho-escuras, verrucosas, fixas, abertura em espocação; arredondadas ou elípticas transversais, grandes, distribuição irregular, numerosas. Matriz esbranquiçada ou rosada, com microfissuras e fissuras longitudinais, 0,5-2,5cm compr., 1-2mm larg., <1mm profundidade, retas a sinuosas, 1-5mm distância; fundo castanho-escuro, áspero. Matriz esbranquiçada ou rosada, áspera. Casca da crista do tronco rugosa com lenticelas como o padrão I da casca do tronco. Casca da raiz superficial lenticelada, com lenticelas discolores, castanho-escuras, verrucosas, fixas, abertura linear, elípticas a lineares, grandes, numerosas. Matriz castanho-clara.

\section{DICAS DE CAMPO}

Casca do tronco esbranquiçada, com grandes lenticelas discolores, castanhoescuras, arredondadas. 

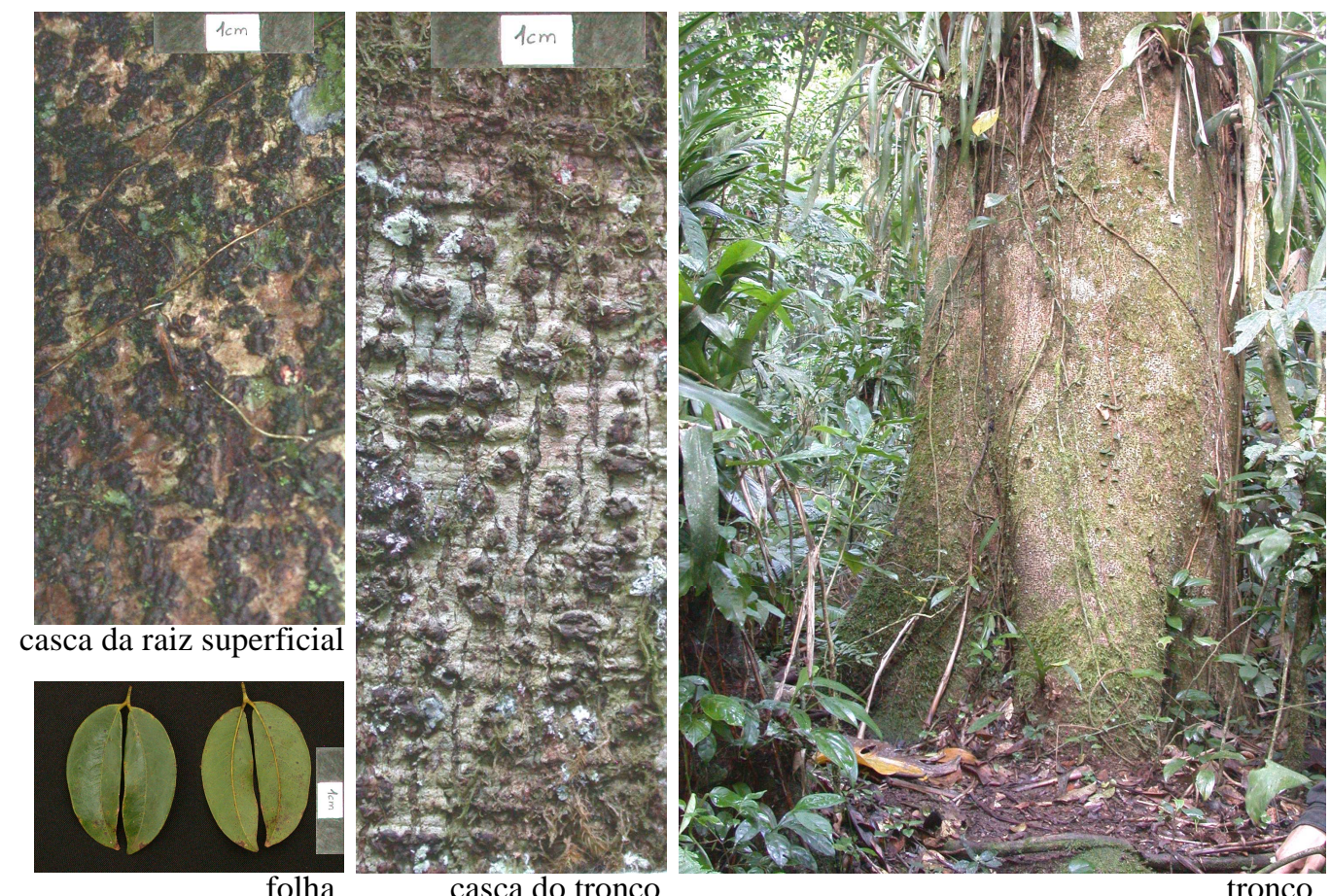

(jatobá) Hymenaea courbaril 
FABACEAE FABOIDEAE

Centrolobium robustum (Vell.) Mart. Ex Benth.

araribá

Tronco castanho, cilíndrico. Raízes digitadas, ramificadas, aresta reta a levemente côncava, $a>b, a=40-110 \mathrm{~cm}, b=30-55 \mathrm{~cm}, 10-20 \mathrm{~cm}$ espessura. Casca do tronco reticulada, formada por quadrados, $1 \mathrm{~cm}$ compr., e retângulos transversais, $1 \mathrm{~cm}$ compr., 5mm larg., superfície côncava ou plana, áspera. Delimitação longitudinal por lenticelas verrucosas, maioria fixa, lineares, grandes, associadas a fissuras. Delimitação transversal por microfissuras. Casca da crista da raiz fendida, com fendas longitudinais, $15-20 \mathrm{~cm}$ compr., $1,5-2,5 \mathrm{~cm}$ larg., 5-7 mm profundidade; fundo com proeminências longitudinais. Domos $1-3 \mathrm{~cm}$ larg. superfície plana, áspera, com microfissuras transversais. Casca da raiz superficial lenticelada, com lenticelas discolores, castanho-claras, arredondadas, médias, ou elípticas longitudinais e verticais, médias a grandes, esparsas. Matriz castanho-escura.

\section{DICAS DE CAMPO}

Casca do tronco reticulada, formada por quadrados ou retângulos transversais, delimitados por lenticelas associadas a fissuras longitudinais e por microfussuras transversais. 


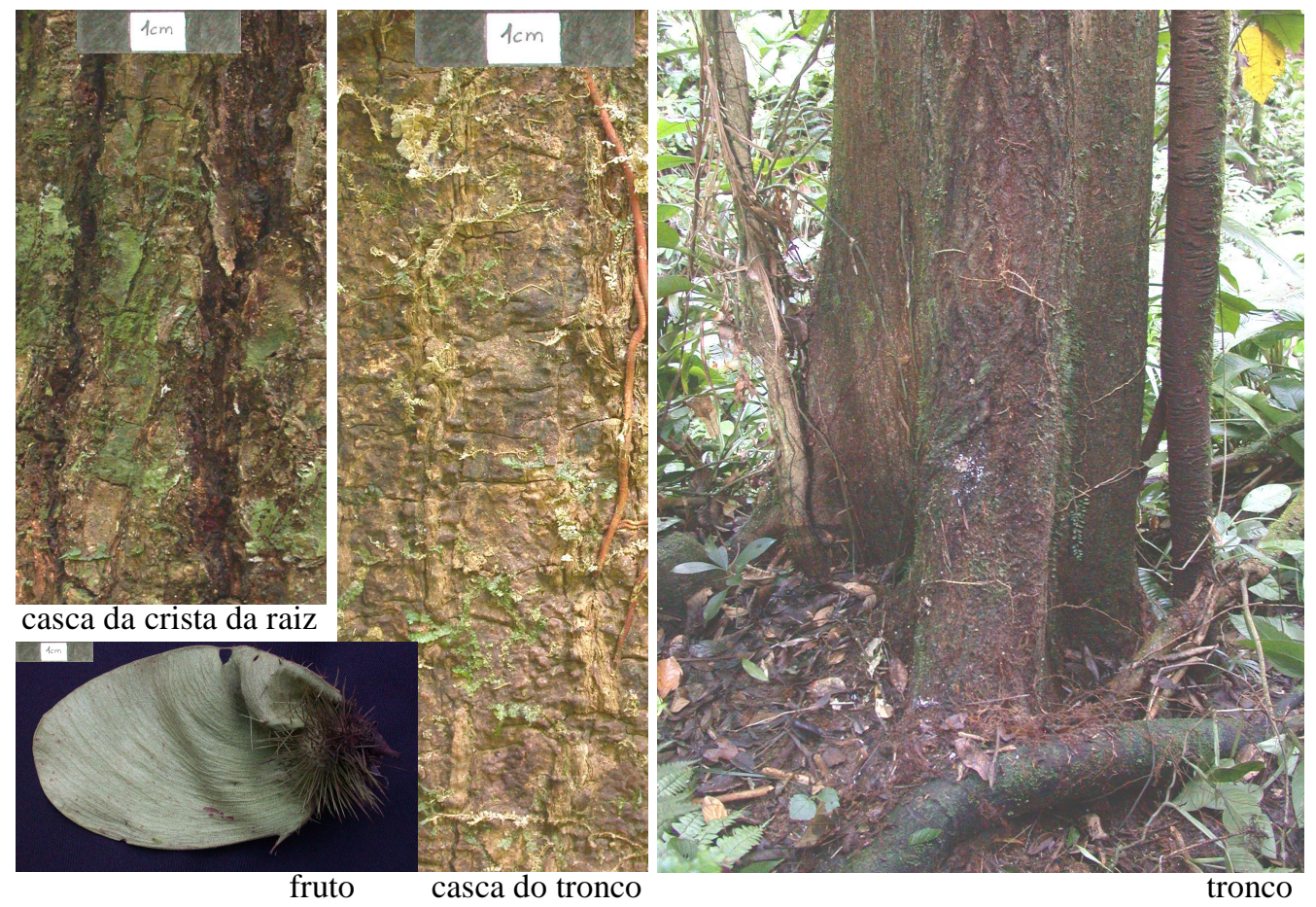

(araribá) Centrolobium robustum 


\section{FABACEAE FABOIDEAE}

\section{Pterocarpus rohrii Vahl.}

sangue-de-galo

Tronco castanho-esbranquiçado, cilíndrico. Raízes com sapopemas geralmente simples, podendo ser ramificadas na região distal, aresta reta, $a>b, a=50-200 \mathrm{~cm}$, $\mathrm{b}=30-140,6-13 \mathrm{~cm}$ espessura. Casca do tronco lenticelada com ondulações, lenticelas discolores, brancas, geralmente não-verrucosas, fixas, arredondadas, pequenas, em linhas longitudinais, $1-2 \mathrm{~cm}$ compr., numerosas. Ondulações agudas formando arcos, 8-12cm compr., 2-5mm larg., 1-2mm espessura, 4-12cm distância longitudinal. Matriz áspera por lenticelas pouco aparentes, arredondadas, pequenas, justapostas. Casca da raiz e da crista da raiz rugosa com lenticelas não-verrucosas, fixas, arredondadas, pequenas, em linhas longitudinais $0,5-1,5 \mathrm{~cm}$ compr., $3-8 \mathrm{~mm}$ de distância, e verrucosas, abertura linear longitudinal, lineares, médias a grandes, associadas a fissuras, numerosas. Casca da raiz superficial áspera e com lenticelas como na casca da raiz.

\section{DICAS DE CAMPO}

Casca do tronco castanho-esbranquiçado com ondulações agudas formando arcos e pequenas lenticelas brancas em linhas longitudinais (seta). 


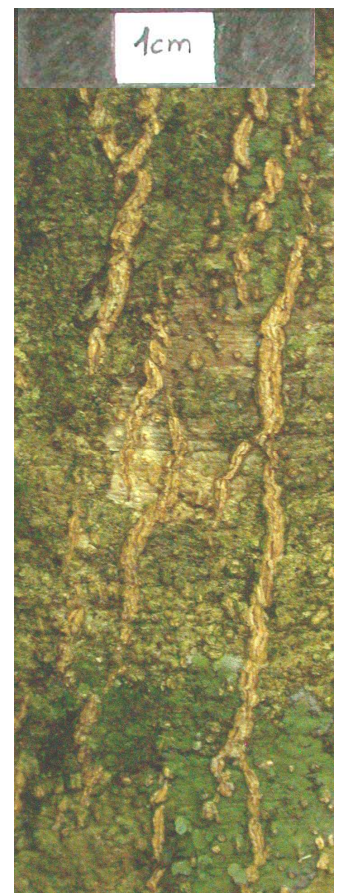

casca da crista da raiz

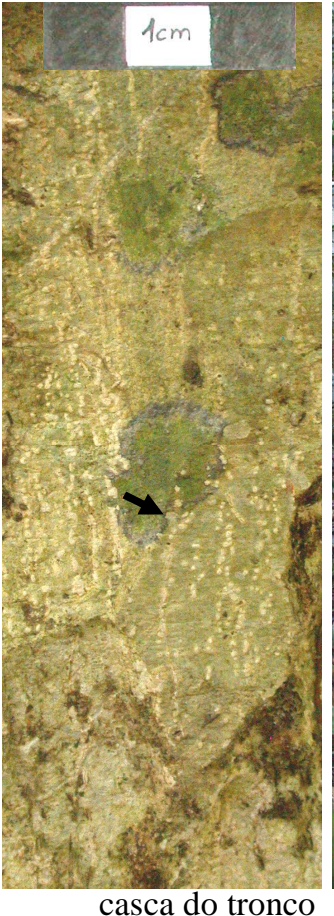

casca do tronco

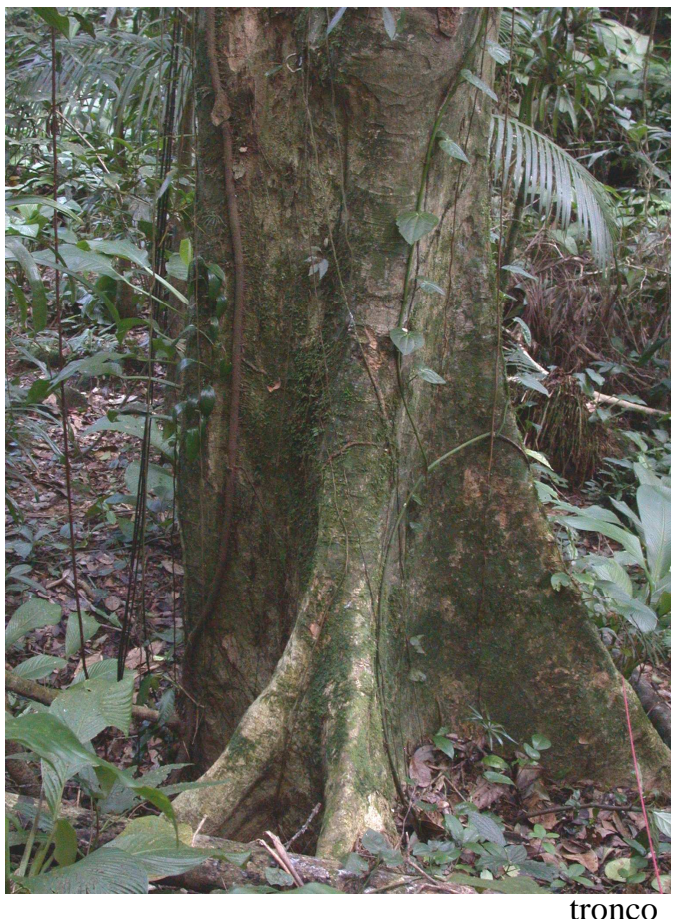

(sangue-de-galo) Pterocarpus rohrii 


\section{FABACEAE MIMOSOIDEAE}

\section{Pseudopiptadenia warmingii (Benth.) G.P. Lewis \& M.P. Lima}

caquerão ou calvi

Tronco castanho-claro a castanho-esbranquiçado, cilíndrico. Raízes com sapopemas ramificadas, aresta côncava, a>b, a=140-260cm, b=120-160cm, 17$25 \mathrm{~cm}$ espessura. Raízes superficiais grossas e abundantes. Casca do tronco e da raiz padrão I, principal: áspero com ondulações, com lenticelas pouco aparentes verrucosas, com abertura estrelada ou linear para todas as direções, arredondada, pequenas, justapostas, numerosas. Ondulações agudas, transversais ou formando arcos, 8-12cm compr., 2-5mm larg., 1-2mm espessura, 8-12cm de distância ou mais. Pode apresentar descamação por grandes placas lenhosas. Casca da raiz superficial padrão I: rugoso com lenticelas arredondadas e elípticas transversais, grandes, numerosas.

\section{DICAS DE CAMPO}

Casca do tronco com ondulações agudas formando arcos e raízes superficiais abundantes e grossas com casca com grandes lenticelas arredondadas (seta). 


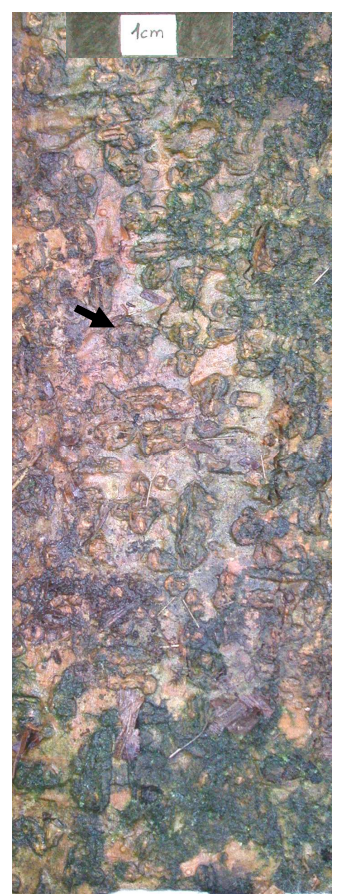

casca da raiz superficial

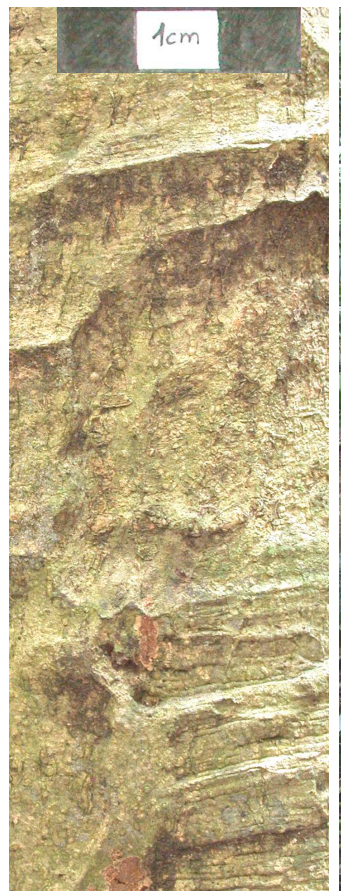

casca do tronco

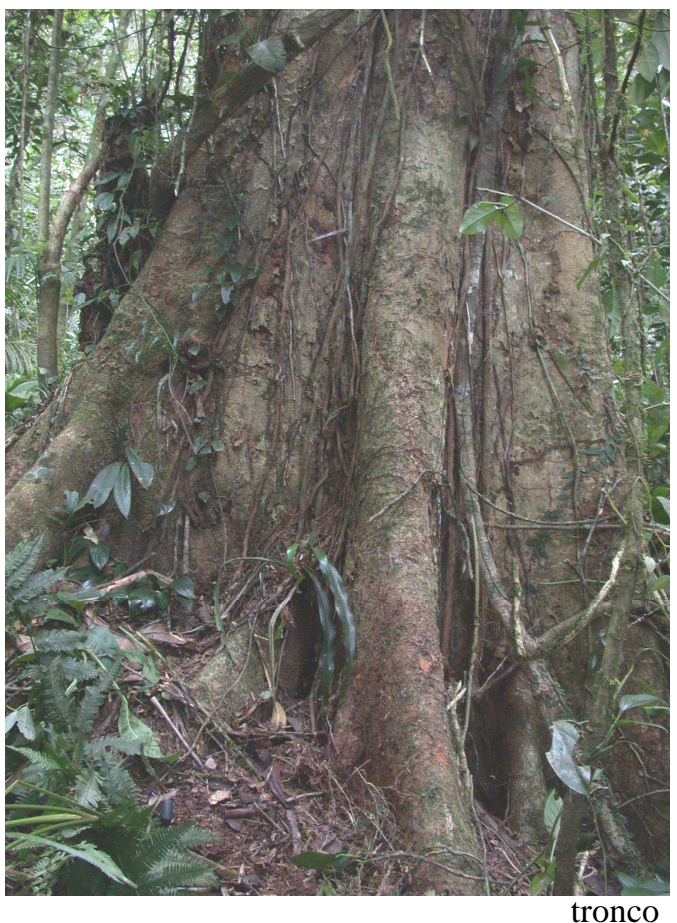

tronco

(caquerão ou calvi) Pseudopiptadenia warmingii 
LAURACEAE

Cryptocarya moschata Nees. \& C. Mart.

nhutinga

Tronco avermelhado, cilíndrico ou acanalado. Raízes digitadas, simples, de aresta reta a levemente côncava, $a>b, a=20-120 \mathrm{~cm}, b=14-33 \mathrm{~cm}, 11-22 \mathrm{~cm}$ espessura.

Casca do tronco variegada, com placas irregulares, alongadas, longitudinais, (4-)8$15 \mathrm{~cm}$ compr., 4-9cm larg., 1-2mm espessura, 2-10cm distância. Impressão áspera, com lenticelas verrucosas, descamantes, com abertura não evidente, arredondadas, pequenas, muito salientes.

Podem apresentar uma ou duas sapopemas, aresta reta, $a>b$, raro $b>a$, $a=50-90 \mathrm{~cm}, \mathrm{~b}=60-120 \mathrm{~cm}$.

\section{DICAS DE CAMPO}

Casca do tronco variegada com impressão avermelhada. 


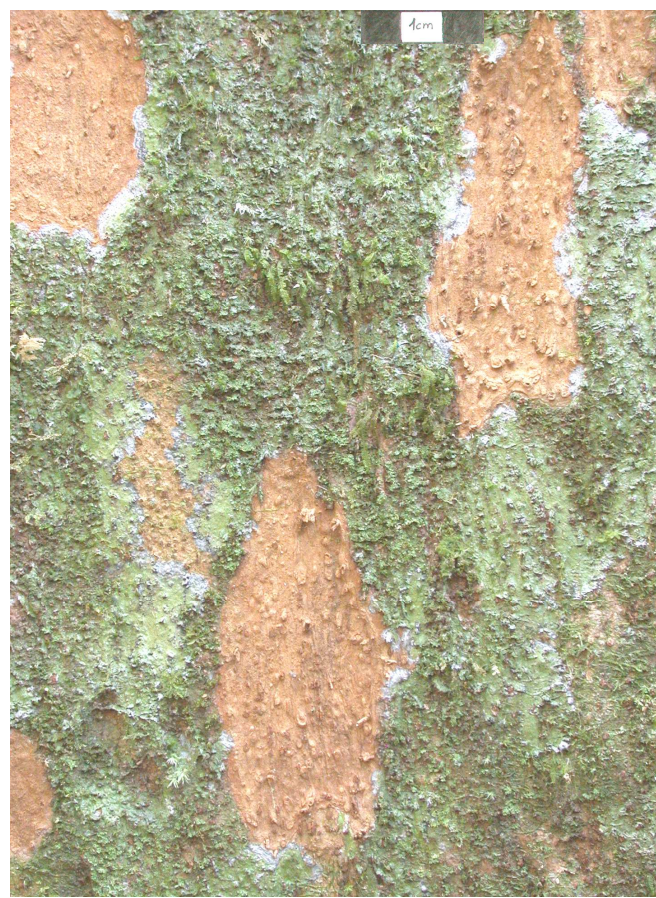

casca do tronco

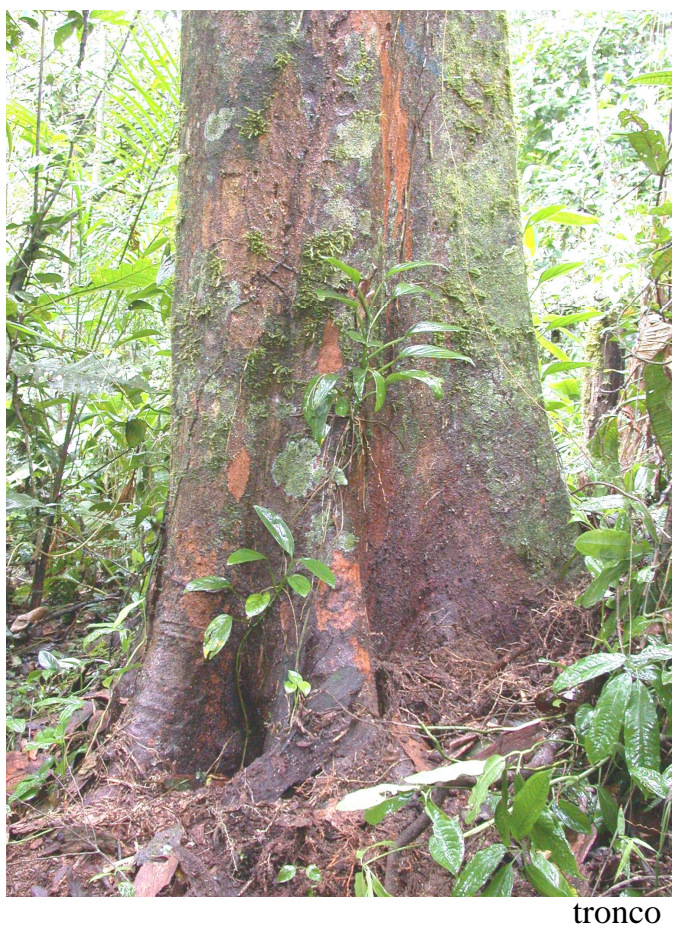

(nhutinga) Cryptocarya moschata 


\section{LAURACEAE}

\section{Ocotea mosenii Mez}

Tronco castanho-esbranquiçado, cilíndrico. Raízes com sapopemas simples ou ramificadas, aresta reta, $a>b, a=150-340 \mathrm{~cm}, b=115-175 \mathrm{~cm}, 8-20 \mathrm{~cm}$ espessura. Casca do tronco lenticelada, com lenticelas discolores, pretas, verrucosas, fixas, abertura em espocação, arredondadas, grandes, formando alguns agrupamentos de justapostas, numerosas. Pode descamar em placas lenhosas, irregulares, $10-20 \mathrm{~cm}$ compr., 2-10cm larg., 0,5-1,0cm espessura, $5-10 \mathrm{~cm}$ distância; superfície e impressão lenticelada, impressão em depressão.

\section{DICAS DE CAMPO}

Casca do tronco castanho-esbranquiçada com numerosas lenticelas discolores, pretas e placas lenhosas irregulares, com impressão em depressão. 


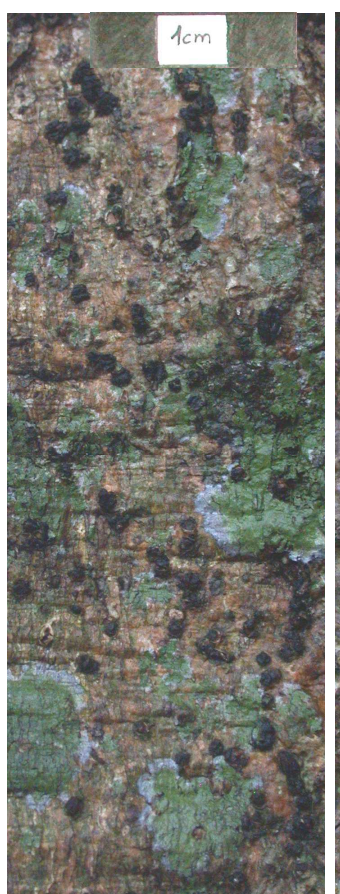

casca da crista da raiz

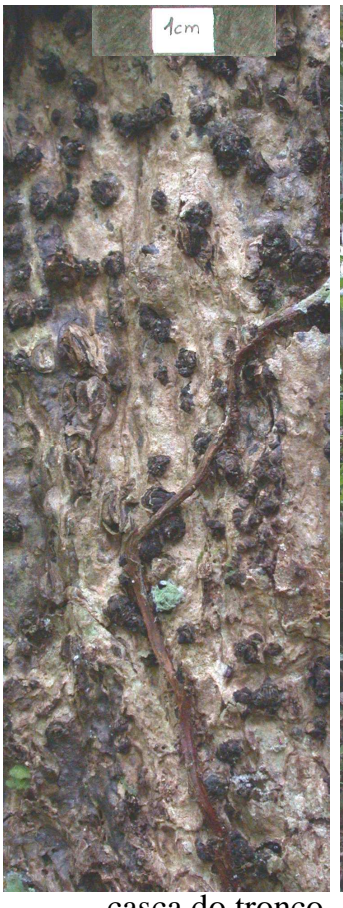

casca do tronco

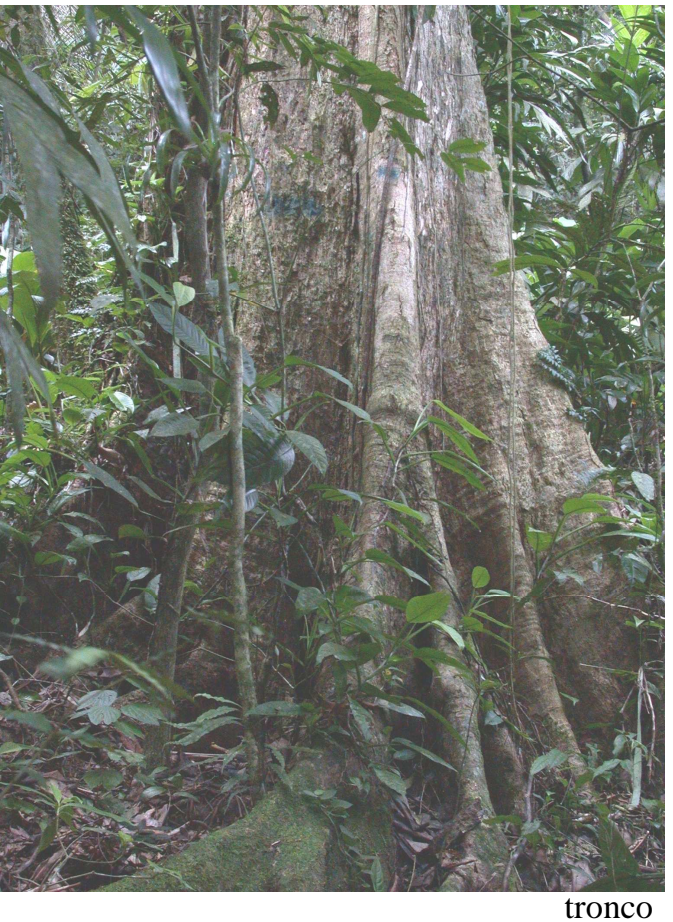

Ocotea mosenii 


\section{LECYTHIDACEAE}

\section{Cariniana estrellensis (Raddi) Kuntze}

jequitibá

Tronco castanho, cilíndrico, reto. Raizes superficiais muito grossas, dispondo-se de maneira radiada à volta da base do tronco. Casca do tronco fissurada, com fissuras longitudinais, retas, $15-70 \mathrm{~cm}$ compr., 0,5-2,0cm larg., $4-8 \mathrm{~mm}$ profundidade, fundo castanho-escuro. Domos fixos, retangulares, longitudinais, 15$70 \mathrm{~cm}$ compr., 1,5-2,5cm larg.; superfície plana, áspera ou estratificadas. Casca da raiz superficial fendida, com fendas longitudinais, sinuosas formando alvéolos, 1,5-5,0cm compr., 3-5mm larg., 3-5mm profundidade, fundo castanhoavermelhado. Domos fixos, longitudinais, sinuosos, 4-12cm compr., 3-7mm larg., 3-5mm espessura, superfície áspera a estratificada.

\section{DICAS DE CAMPO}

Tronco reto, castanho, com raízes superficiais radiais e casca do tronco fissurada com fundo castanho-escuro. 


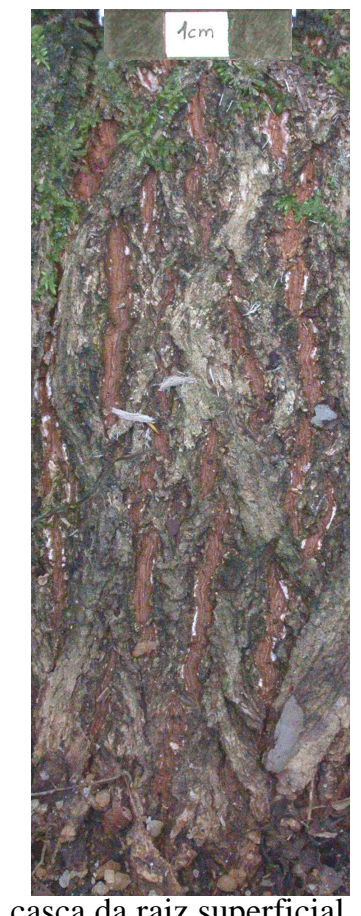

casca da raiz superficial

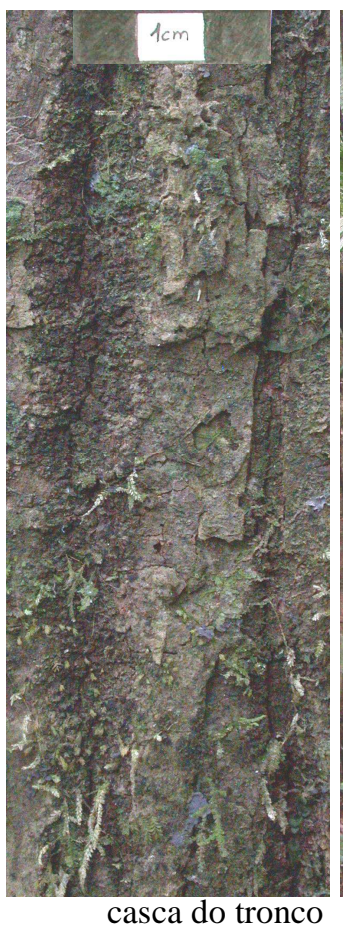

casca do tronco

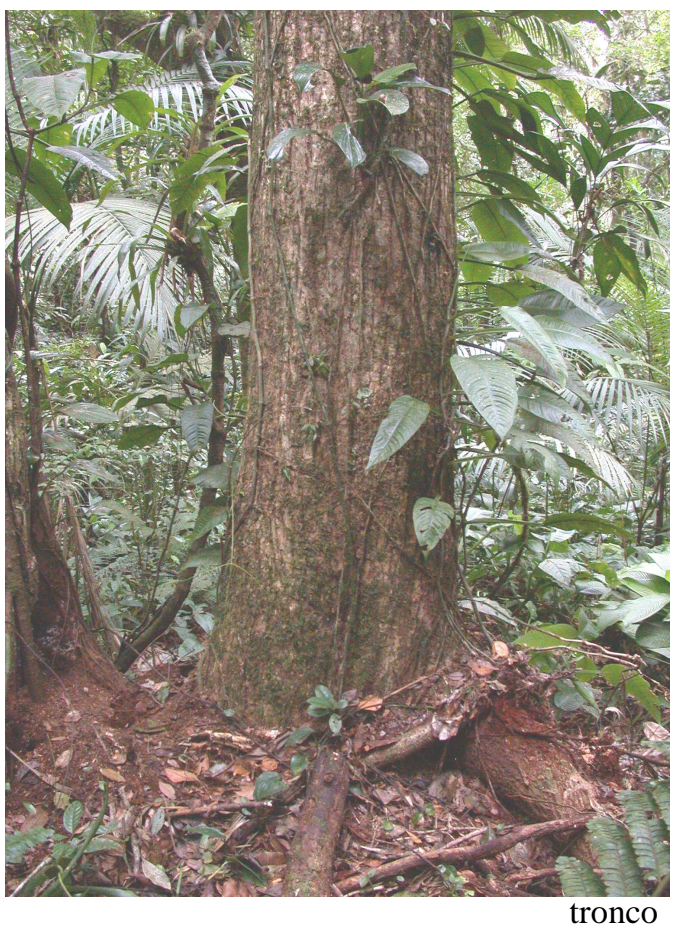

(jequitibá) Cariniana estrellensis 


\section{MAGNOLIACEAE}

Magnolia ovata (A. St.-Hil.) Spreng.

Tronco castanho-claro, cilíndrico. Raízes digitadas, simples ou com ramificações proximais, aresta côncava, $a>b, a=40-73 \mathrm{~cm}, b=38-43 \mathrm{~cm}$. Casca do tronco lenticelada, com lenticelas verrucosas, maioria fixa, abertura linear, lineares, longitudinais, grandes, associadas a microfissuras, numerosas. Matriz áspera. Casca da raiz castanha, áspera. Casca da crista da raiz fissurada, castanho-escura, com fissuras longitudinais, 2-3cm compr., 3-5mm larg., 2-3mm profundidade, 0-3mm distância, fundo estratificado, culminando em linha pouco mais avermelhada.

\section{DICAS DE CAMPO}

Casca do tronco com lenticelas lineares longitudinais, grandes, com 3-5mm de largura (seta). 


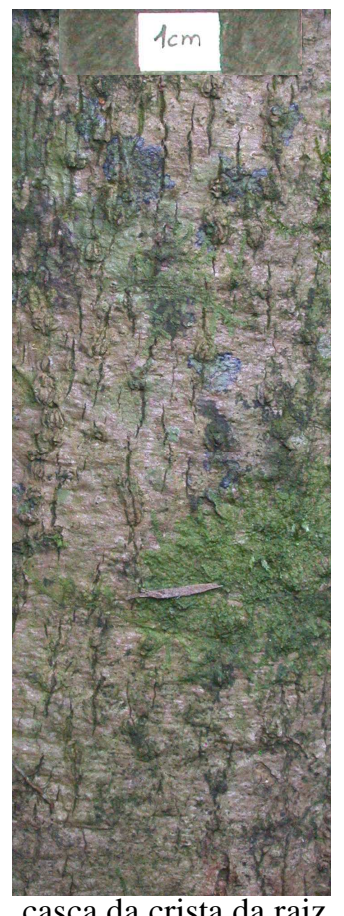

casca da crista da raiz

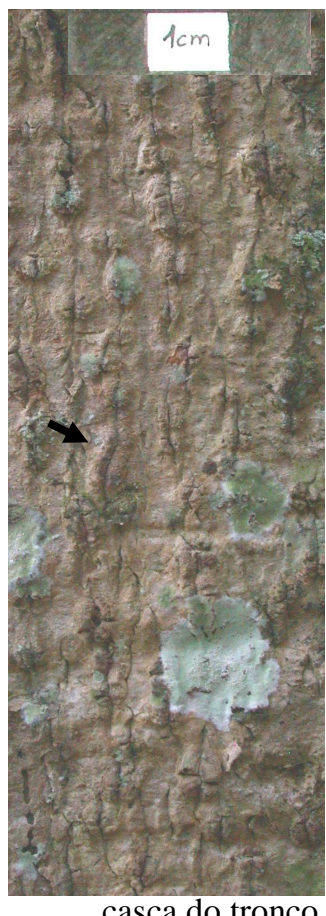

casca do tronco

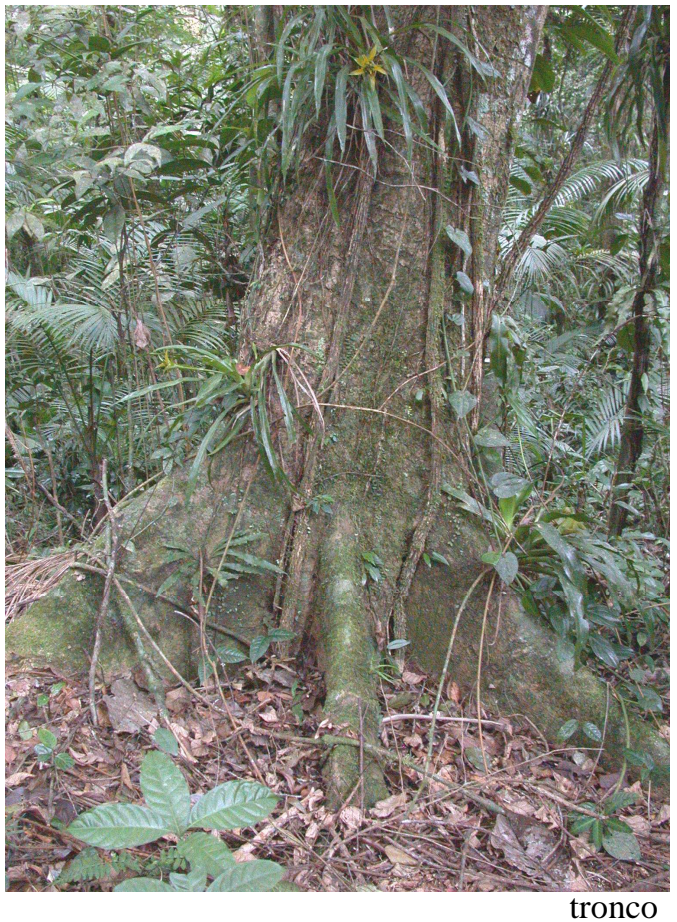

Magnolia ovata 


\section{MELIACEAE}

\section{Cabralea canjerana (Vell.) Mart.}

cajarana

Tronco castanho-avermelhado, acanalado. Raízes digitadas, simples, poucas raízes com ramificações distais, aresta côncava, $a<b, a=25-75 \mathrm{~cm}, b=40-90 \mathrm{~cm}, 20-22 \mathrm{~cm}$ espessura. Casca do tronco lenticelada, com lenticelas discolores, castanho um pouco mais escuras que a matriz, verrucosas, fixas ou descamantes, abertura linear, lineares, longitudinais, grandes, numerosas. Matriz áspera.

Alguns indivíduos apresentam cicatrizes proeminentes, cilíndricas, 6-15 cm diâm., justapostas, com vários rebrotos, $3-18 \mathrm{~cm}$ diâm. Nestes indivíduos, o tronco é cilíndrico e a base do tronco é reta. A casca do tronco apresenta fissuras delimitando domos de formato irregular a retangular nas regiões próximas às cicatrizes. Entre as cicatrizes existem algumas lenticelas como as descritas para a casca do tronco.

\section{DICAS DE CAMPO}

Casca do tronco castanho-avermelhada com lenticelas lineares longitudinais, um pouco mais escuras que a matriz, as mais largas com formato semelhante a lábios (seta). 


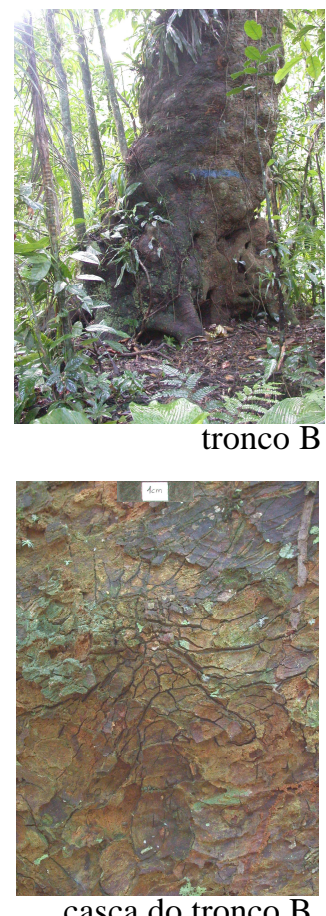

casca do tronco B

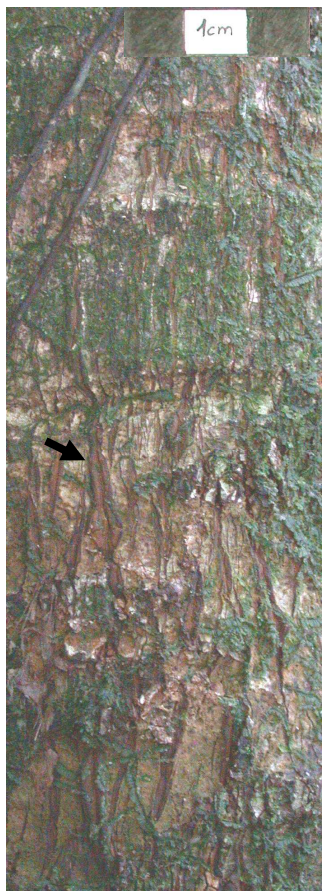

casca do tronco

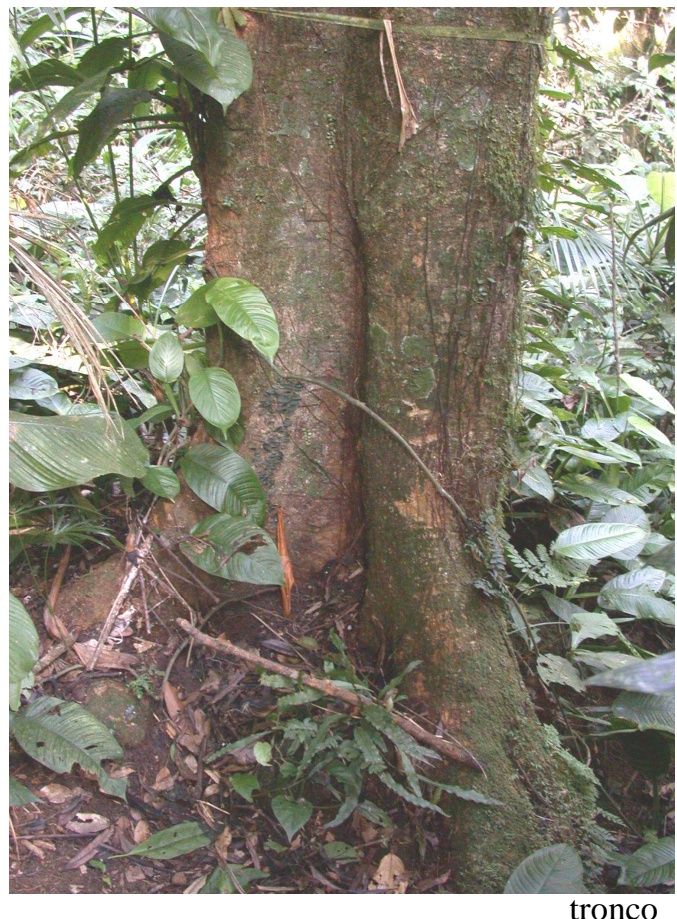

(cajarana) Cabralea canjerana 


\section{MELIACEAE}

\section{Cedrela fissilis Vell.}

cedro

Tronco castanho-claro, cilíndrico, reto. Casca do tronco fissurada, com domos grandes, 20-40cm compr., 4-7cm larg., 0,6-1,0cm espessura; superfície plana a levemente côncava, formada por lâminas estratificadas. Delimitação longitudinal por fissuras 4-8mm profundidade. Delimitação transversal não evidente.

\section{DICAS DE CAMPO}

Casca do tronco fissurada com grandes domos retangulares longitudinais $(20-40 \mathrm{~cm}$ compr. e $4-7 \mathrm{~cm}$ larg.). 

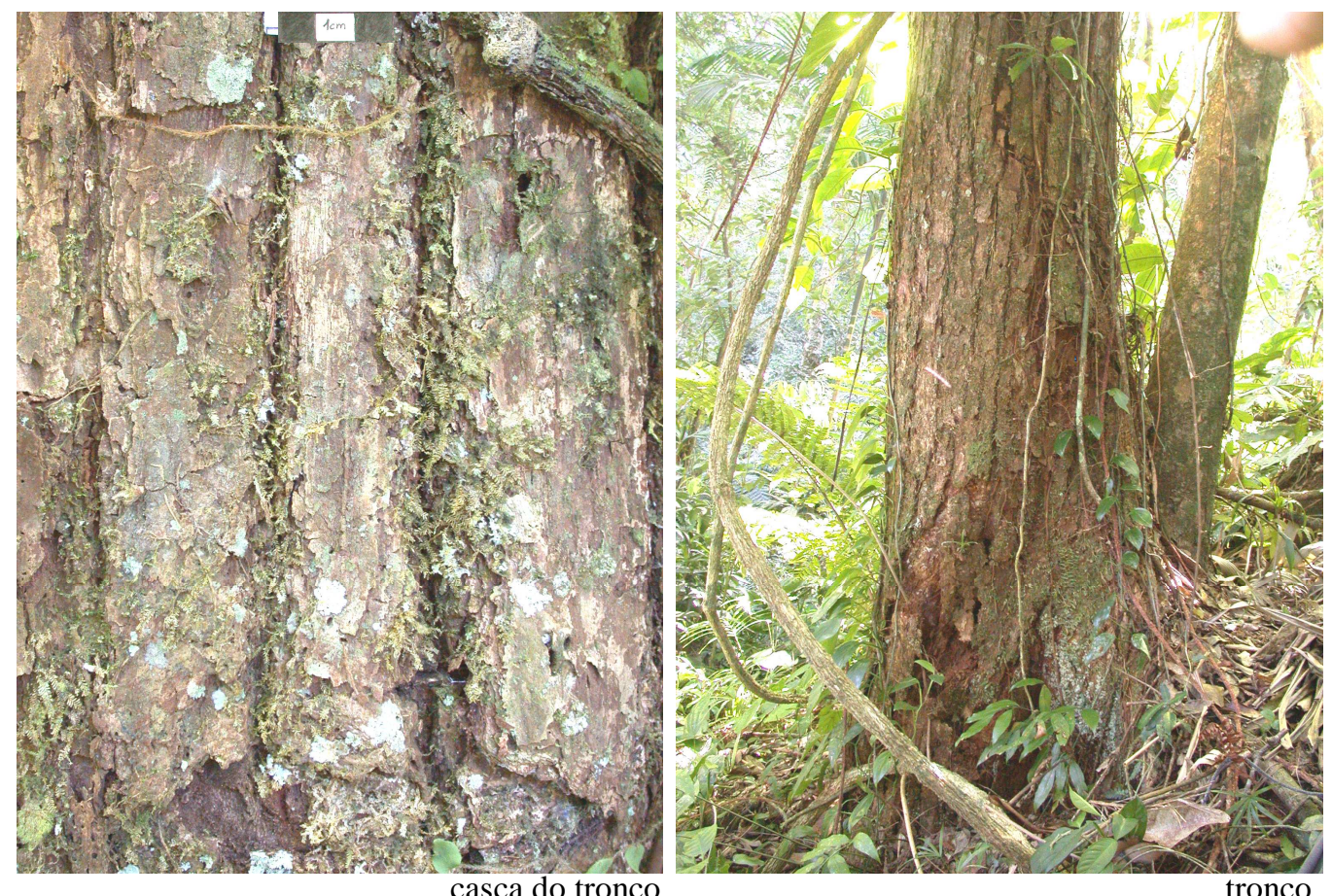

(cedro) Cedrela fissilis 


\section{MYRISTICACEAE}

\section{Virola bicuhyba (Schott ex Spreng.) Warb.}

bucuva

Tronco castanho-acinzentado a castanho-escuro, cilíndrico. Raízes com sapopemas, simples ou ramificadas, aresta reta, $a=b=80-150 \mathrm{~cm}, 6-16 \mathrm{~cm}$ espessura. Casca do tronco com microfissuras longitudinais ou escamosa, com domos retangulares longitudinais, 6-18cm compr., 0,8-1,8cm larg., 2-4mm espessura; superfície plana, áspera. Delimitação longitudinal por fissuras, retas ou levemente sinuosas, $10-30 \mathrm{~cm}$ compr., 2-8mm larg., 2-6mm profundidade. Delimitação transversal não evidente ou fissuras. Impressão castanho-escura ou avermelhada com microfissuras longitudinais. Casca da raiz com microfissuras longitudinais. Casca da crista da raiz fendida, com fendas longitudinais, sinuosas formando alvéolos, 4-6cm compr., 1,0-1,5cm larg., 4-6mm profundidade; fundo castanho-avermelhado, estratificado. Domos 0,8-1,0cm larg.; superfície áspera.

\section{DICAS DE CAMPO}

Geralmente com pequenas sapopemas de aresta reta com casca da crista fendida, com fundo castanho-avermelhado. Copa característica, com folhas semelhantes a penas (seta). 

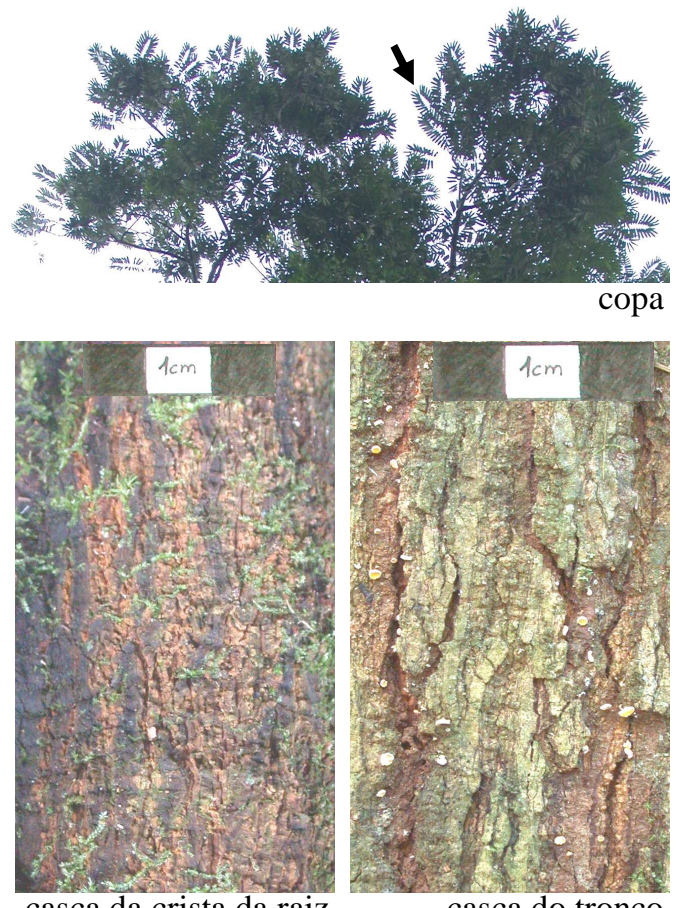

casca do tronco

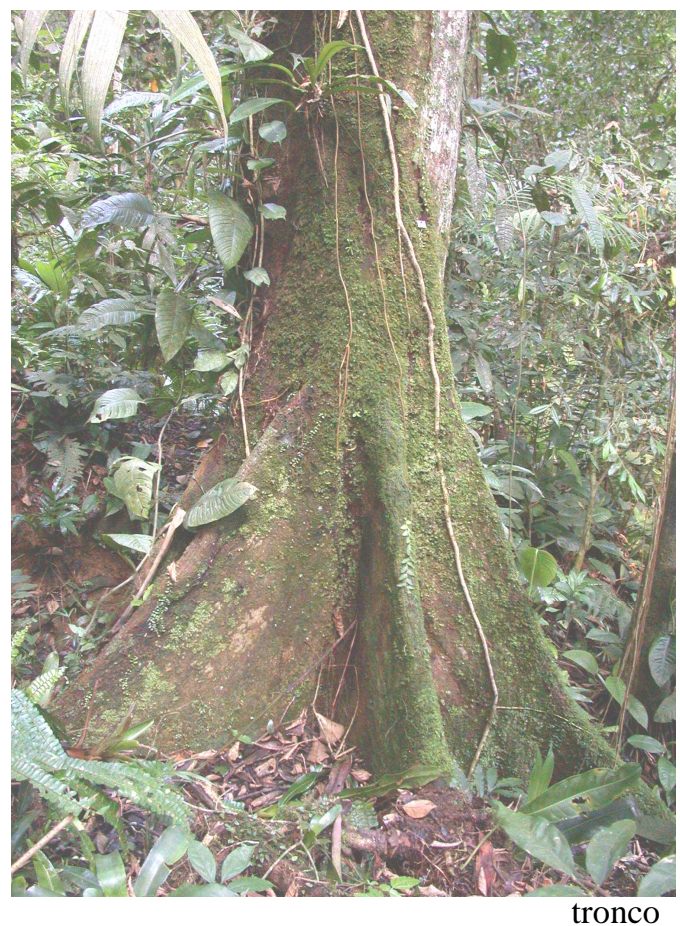

(bucuva) Virola bicuhyba 


\section{MYRTACEAE}

Eugenia cf. burkartiana (D. Legrand) D. Legrand

pau-brasil-branco

Tronco creme-esbranquiçado, cilíndrico. Raízes com sapopemas simples ou com pequenas ramificações distais, aresta reta a levemente côncava, $a>b, a=130-210 \mathrm{~cm}$, $\mathrm{b}=60-90 \mathrm{~cm}, 15-20 \mathrm{~cm}$ espessura. Casca do tronco lisa. Casca do vale com ondulações longitudinais, $0,5-1,0 \mathrm{~cm}$, justapostas. Casca da raiz superficial laminada, esbranquiçada com lâminas coriáceas, castanho-escuras ou esverdeadas.

\section{DICAS DE CAMPO}

Casca do tronco branca e lisa. Com lâminas coriáceas acumuladas ao redor da base do tronco. 


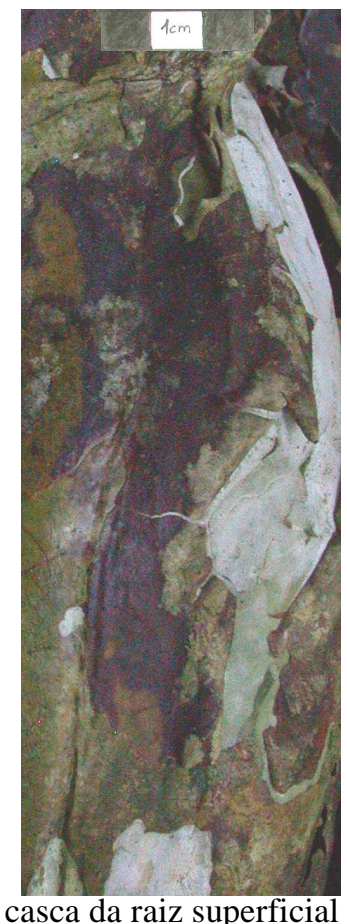

casca da raiz superficial

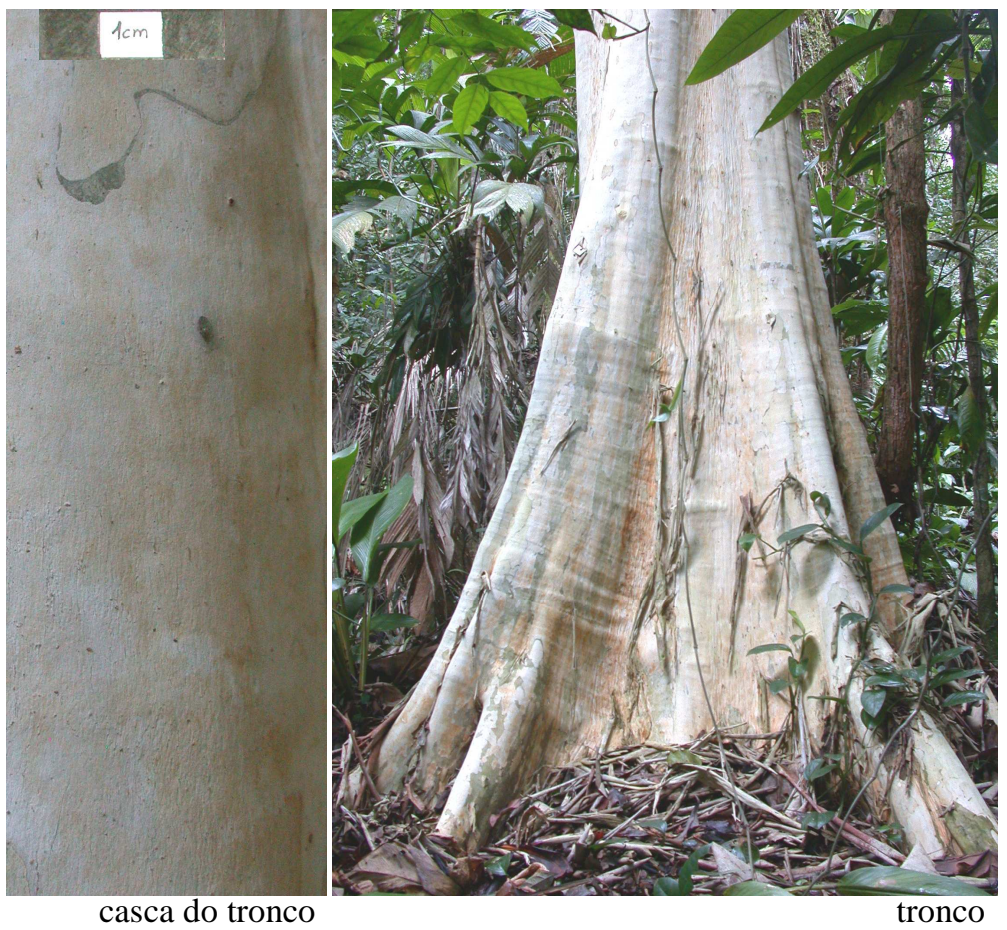

(pau-brasil-branco) Eugenia cf. burkartiana 
MYRTACEAE

Eugenia multicostata D. Legrand

pau-brasil-vermelho

Tronco vermelho, cilíndrico. Com rebroto, $5 \mathrm{~cm}$ diâm. Cicatrizes proeminentes, cilíndricas, $10 \mathrm{~cm}$ diâm. Raízes digitadas, a $>b$, a =35-50cm, b=23-45 cm, $5-6 \mathrm{~cm}$ larg. Casca do tronco laminada, com lâminas coriáceas, irregulares, longitudinais, 7-

20cm compr., 3-5cm larg.; superfície castanho-avermelhada, com muitos musgos e liquens esbranquiçados ou verdes. Impressão vermelha, lisa. Casca da raiz superficial castanha, áspera.

Acima de 4m, o tronco é inteiramente vermelho e a textura é lisa.

\section{DICAS DE CAMPO}

Casca do tronco avermelhada, com lâminas coriáceas e impressão lisa e vermelha. 

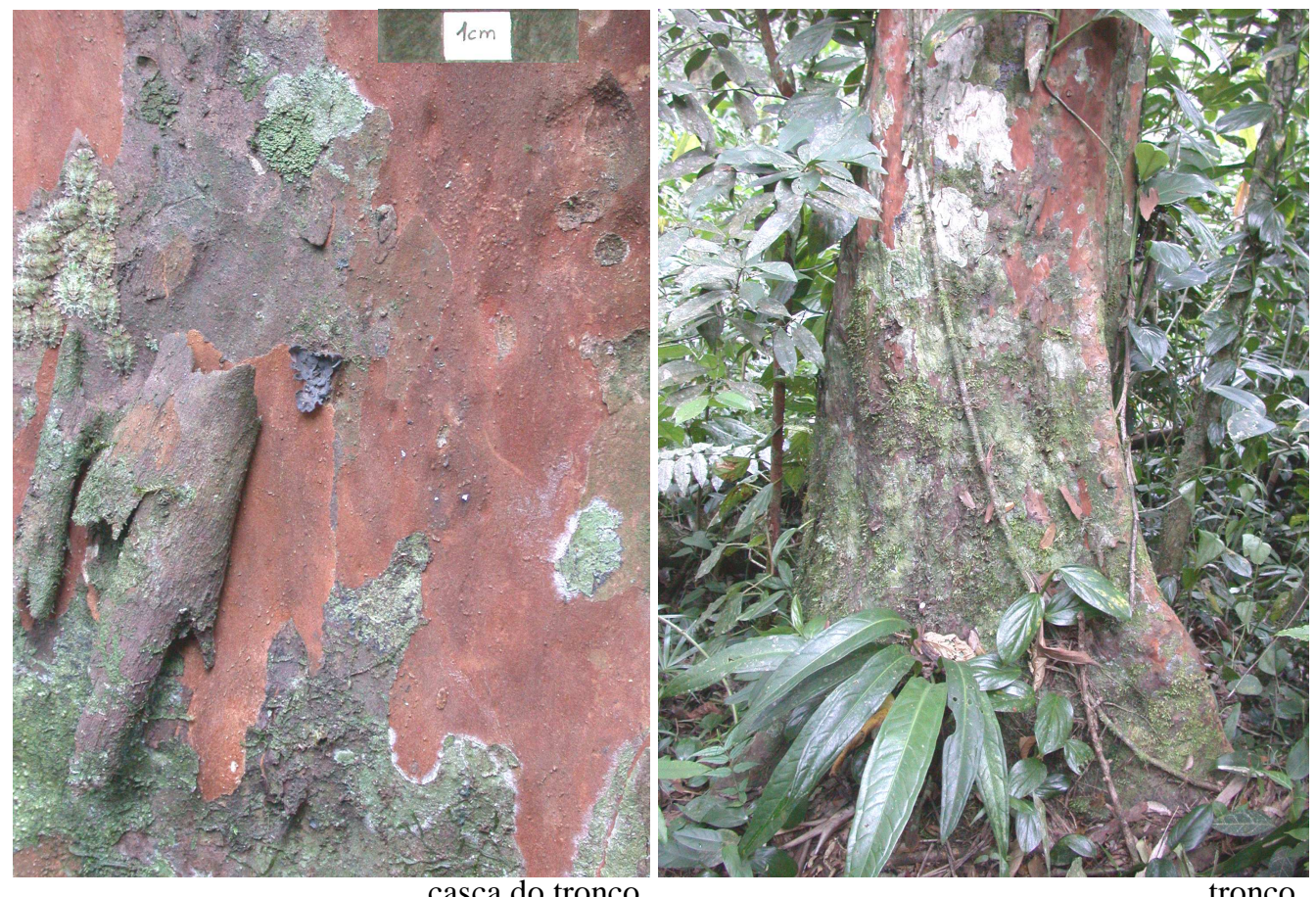

casca do tronco

tronco

(pau-brasil-vermelho) Eugenia multicostata 


\section{MYRTACEAE \\ Myrcia pubipetala Miq. \\ guamirim}

Tronco esbranquiçado, cilíndrico, reto a levemente digitado ou com raízes digitadas, simples, aresta reta, $a=b=20-30 \mathrm{~cm}$ e com sapopemas, simples, aresta reta, $\mathrm{a}=\mathrm{b}=50-120 \mathrm{~cm}$. Casca do tronco variegada, com placas que se dobram para dentro ao descamar, 15-20cm compr., 4-6cm larg., 5-8mm espessura, 4-20cm distância; superfície ondulada, suja; impressão castanho-escura, áspera, com lenticelas verrucosas, fixas, abertura circular ou não evidente, arredondadas, pequenas, e elípticas, médias, esparsas.

\section{DICAS DE CAMPO}

Casca do tronco esbranquiçada, variegada, com placas se dobram para dentro ao descamar, impressão castanho-escura. 


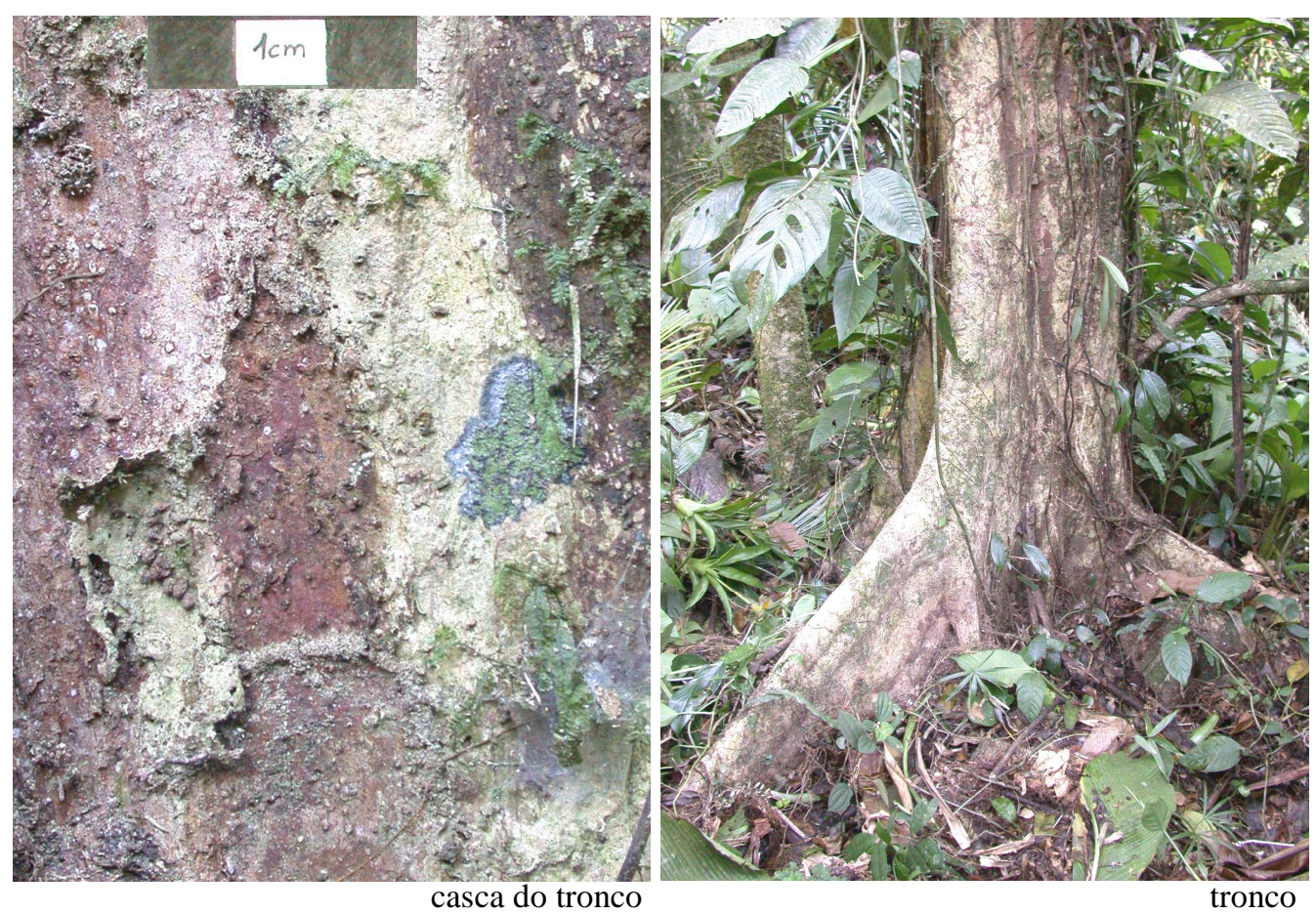

(guamirim) Myrcia pubipetala 


\section{NYCTAGINACEAE}

\section{Pisonia ambigua Heimerl}

joão-mole

Tronco esbranquiçado, cilíndrico, levemente dilatado. Casca do tronco lenticelada, com lenticelas discolores, castanho-escuras, verrucosas, descamantes, com abertura em espocação, arredondadas, médias, com distribuição irregular, esparsas. Matriz áspera com microfissuras. Casca da base do tronco lenticelada e rugosa, lenticelas como na casca do tronco. Casca da raiz superficial lenticelada, como na casca do tronco, porém com lenticelas pequenas, esparsas.

\section{DICAS DE CAMPO}

Tronco esbranquiçado com base do tronco levemente dilatada e casca com lenticelas esparsas, discolores, castanho-escuras (seta). Suas folhas, ao caírem, tornam-se negras. 


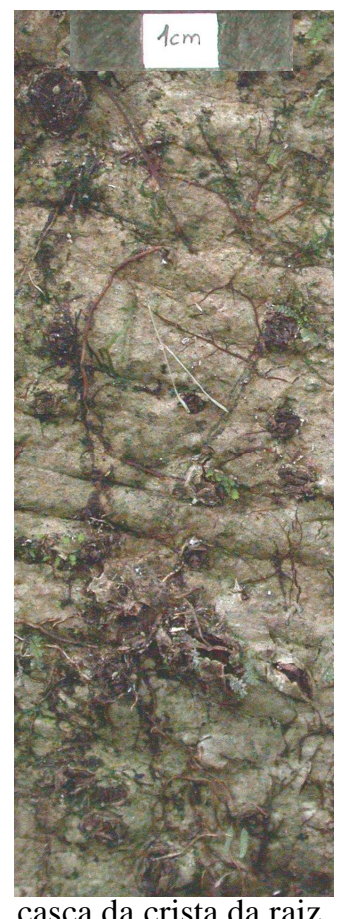

casca da crista da raiz

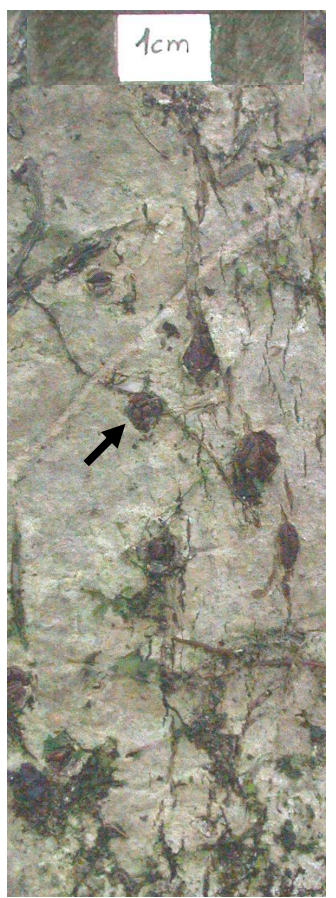

casca do tronco

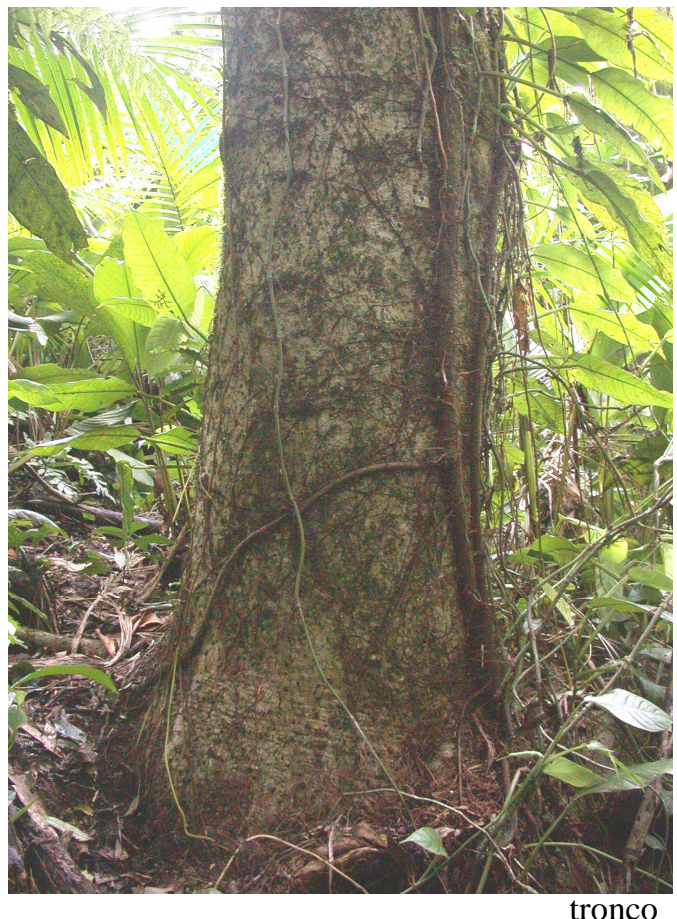

(joão-mole) Pisonia ambigua 


\section{OLACACEAE}

\section{Heisteria silvianii Schw.}

brinco-de-mulata

Tronco castanho-avermelhado a castanho-claro, cilíndrico, reto. Casca do tronco padrão I: reticulado, castanho-avermelhado, com retângulos longitudinais, 1,0-1,8cm compr., 4-8mm larg.; superfície côncava, áspera. Delimitação longitudinal por fissuras, 2-5cm compr., 1-3mm larg., $1 \mathrm{~mm}$ profundidade. Delimitação transversal por microfissuras, 3-7mm compr. Padrão II: estriado, lenticelas associadas a fissuras, com lenticelas castanho-escuras, lineares longitudinais, associadas a fissuras retas, verrucosas, fixas, grandes, 0,5-1,0cm distância transversal. Domos de superfície rugosa, côncava. Matriz castanho-clara. indivíduo.

Os padrões I e II estão presentes isoladamente em um mesmo

\section{DICAS DE CAMPO}

Casca do tronco reticulada (foto), formando retângulos longitudinais, delimitados por fissuras longitudinais e microfissuras transversais. 

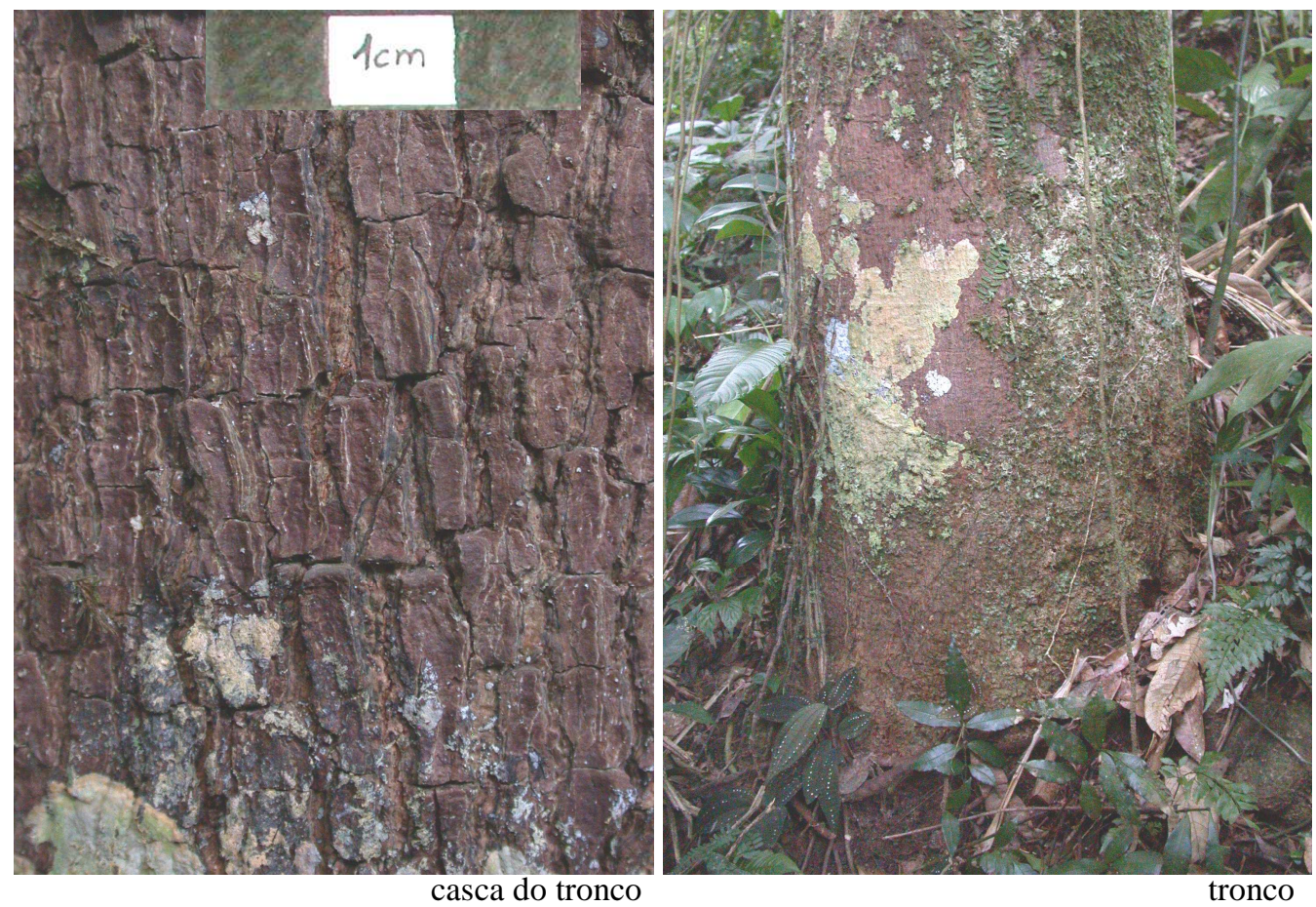

(brinco-de-mulata) Heisteria silvianii 


\section{OLACACEAE}

\section{Tetrastylidium grandifolium (Baill.) Sleumer.}

\section{mandegaú}

Tronco castanho-claro, cilíndrico a levemente acanalado. Raízes levemente digitadas ou digitadas, simples, aresta reta a levemente côncava, $a>b, a=30-70 \mathrm{~cm}$, $\mathrm{b}=17-60 \mathrm{~cm}, 10-14 \mathrm{~cm}$ espessura. Casca do tronco suja, podendo apresentar placas irregulares a retangulares, longitudinais, 5-8cm compr., 1-2(-3)cm larg., 1-4mm espessura; superfície plana, suja. Impressão áspera com lenticelas verrucosas, descamantes, arredondadas, médias, com abertura estrelada, ou associadas a fissuras longitudinais, com abertura linear, grandes. Pode ainda apresentar lenticelas discolores, castanho bem claro, ou mesma cor da casca, verrucosas, descamantes, arredondados, abertura não evidente ou estralada, médias, ou elípticas, levemente retangular, abertura linear, em todas as direções, grandes, distribuídas em agrupamentos, numerosas.

\section{DICAS DE CAMPO}

Casca do tronco castanho-clara, suja, com placas irregulares e lenticelas médias (24mm diâm.) 


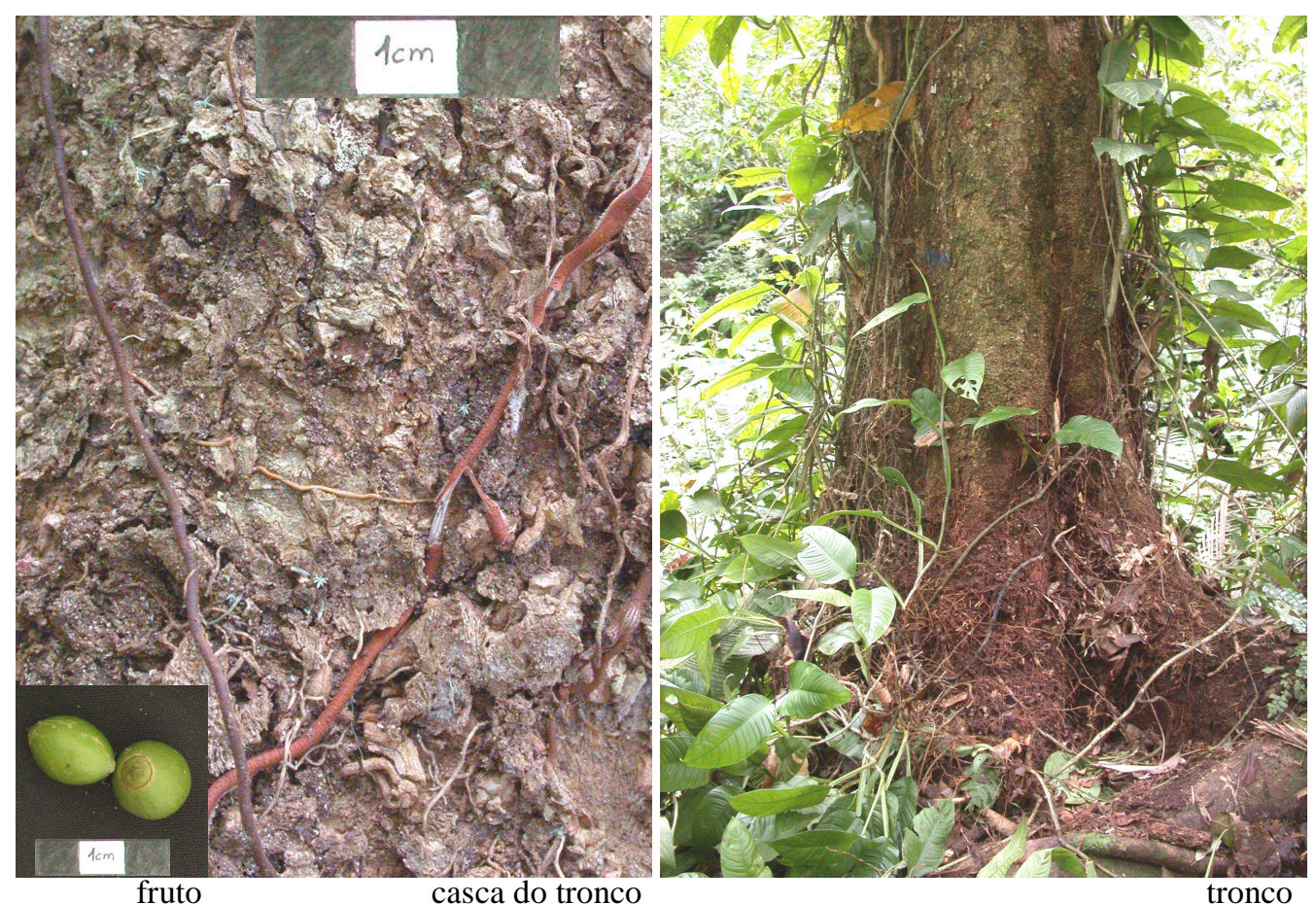

(mandegaú) Tetrastylidium grandifolium 


\section{PHYLLANTHACEAE}

Hyeronima alchorneoides Fr. Allem.

urucurana

Tronco castanho-avermelhado com regiões castanho-esbranquiçadas, cilíndricas. Frequentemente com cicatrizes proeminentes, cilíndricas ou elípticas, 5-8cm compr., 4-5cm larg., 1-3cm espessura. Raízes digitadas e com sapopemas, simples a ramificadas, aresta reta ou côncava, com grande variação na relação dos comprimentos "a" e "b", variando de 30-220cm, 10-20cm espessura. Raízes superficiais frequentemente abundantes. Casca do tronco, da lateral raiz e da raiz superficial áspera com microfissuras longitudinais ou estreladas, $1-4 \mathrm{~cm}$ compr., 0,42,0cm distância e fissuras longitudinais, 3-17cm compr., 2-4mm larg., $1-5 \mathrm{~cm}$ distância, em agrupamentos. Agrupamentos de lenticelas da mesma cor da matriz ou discolores, castanho-claro, verrucosas, fixas ou descamantes, arredondadas, pequenas, e lineares, grandes, associada a fissuras. Pode descamar em lâminas papiráceas irregulares, alongadas, longitudinais, quebradiças, esparsas. Impressão com ranhuras longitudinais, geralmente avermelhadas.

\section{DICAS DE CAMPO}

Copa com folhas e pecíolos grandes parecendo digitadas quando observadas do solo (círculo). No inverno, tornam-se vermelhas e caem com freqüência. 


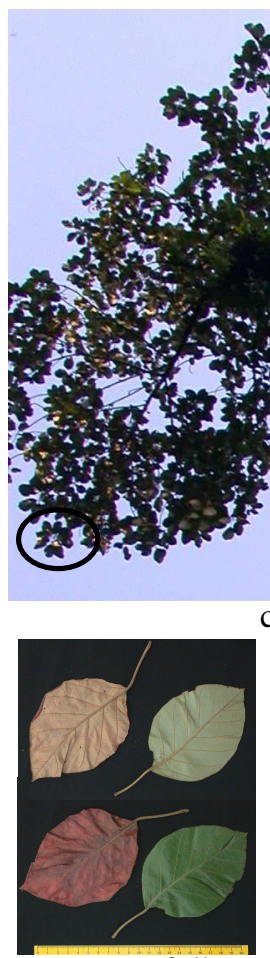

folhas

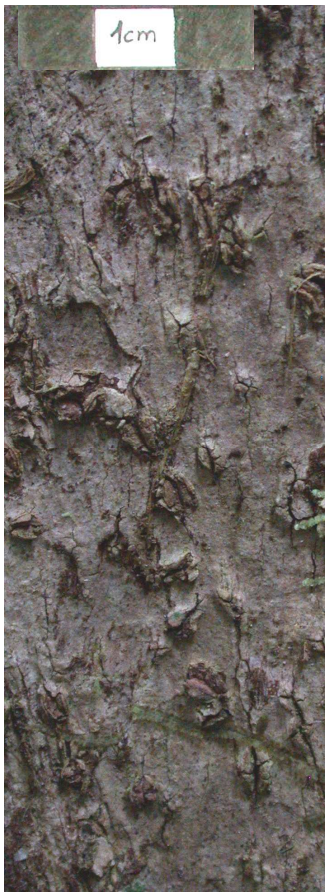

casca do tronco

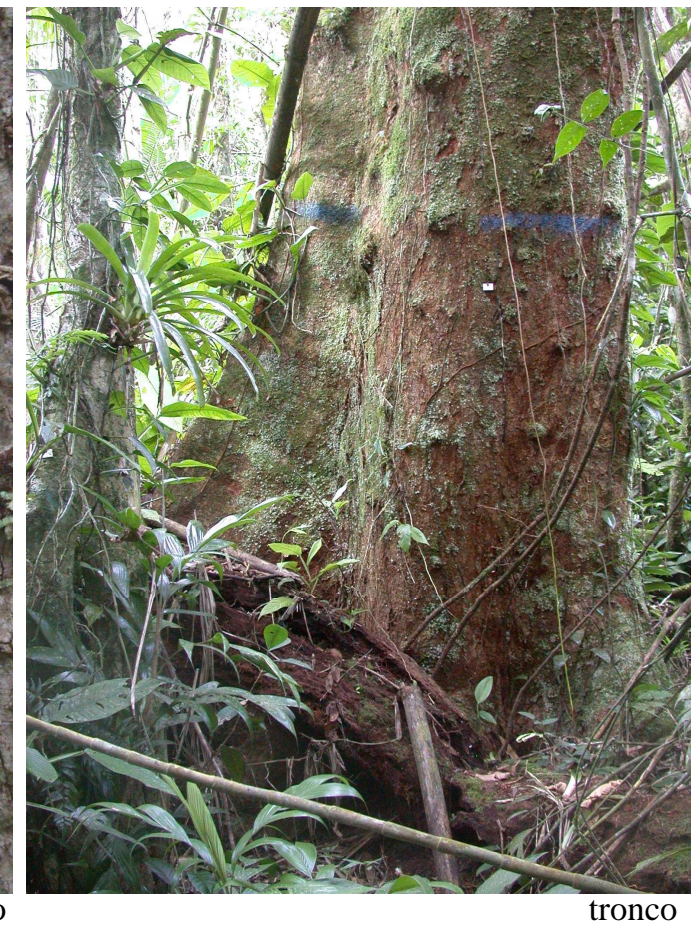

(urucurana) Hyeronima alchorneoides 
PHYTOLACCACEAE

Phytolacca dioica $\mathbf{L}$.

ceboleiro

Tronco castanho bem claro, cilíndrico ou levemente acanalado, dilatado. Casca do tronco padrão I: fendido, com fendas longitudinais, retas a sinuosas, (2-)5-12cm compr., 0,4-3,0cm larg., 2-4mm espessura. Domos longitudinais, com bordas afinadas, 0,8-2,0cm larg.; superfície áspera, côncava, laterais côncavas de modo que sobressai, por vezes, a fenda. Padrão II: fissurado, com fissuras longitudinais, retas a levemente sinuosas, 5-12cm compr., 2-7mm larg., 2-6mm espessura. Domos longitudinais; superfície áspera e convexa. Casca da base do tronco lenticelada e com ondulações, com lenticelas verrucosas, fixas, arredondadas, ou elípticas, longitudinais, grandes, distribuição irregular, esparsas. Ondulações transversais, 1,0-1,5cm larg., 3-5mm espessura, justapostas. Casca da raiz superficial lenticelada com microfissuras. Lenticelas verrucosas, raro não-verrucosas, arredondadas, grandes, numerosas.

Os padrões da casca do tronco são apresentados isoladamente em um mesmo indivíduo.

\section{DICAS DE CAMPO}

Base do tronco dilatada formando estrutura intumescida de grandes proporções. 


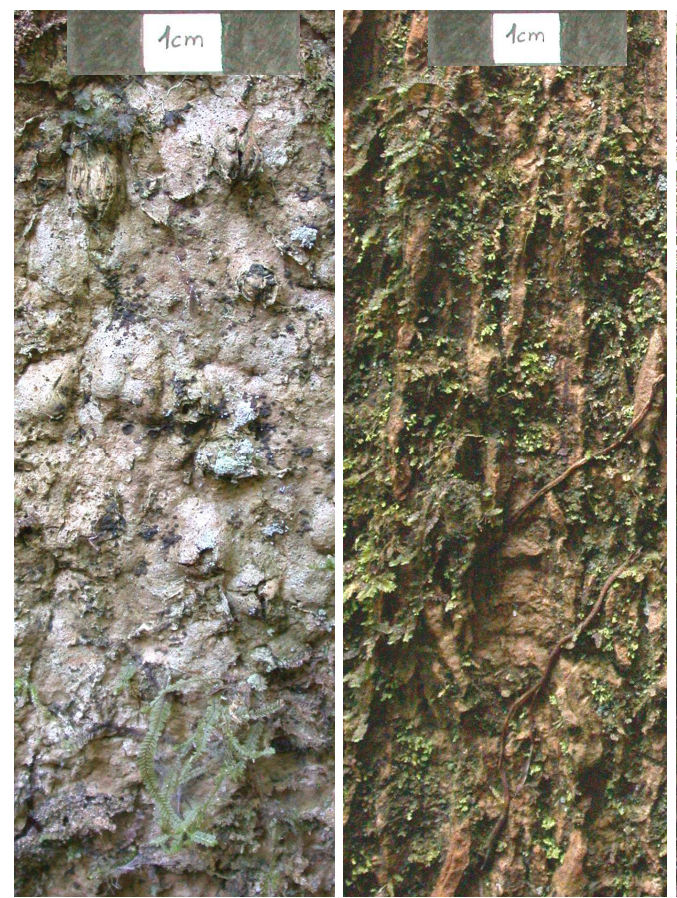

casca do tronco

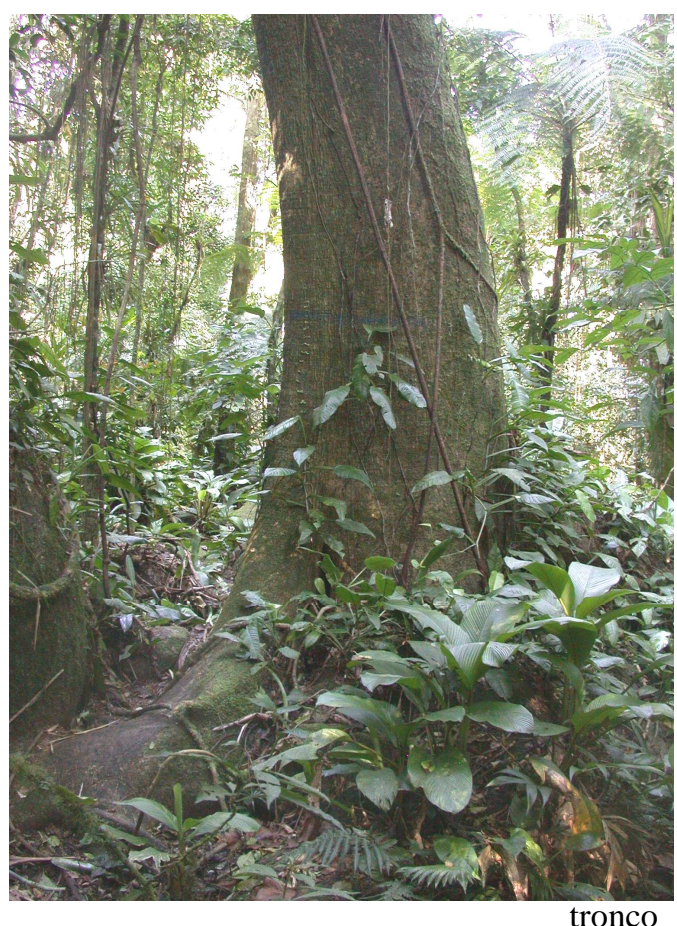

(ceboleiro) Phytolacca dioica 


\section{RUBIACEAE}

Simira corumbensis (Standl.) Steyerm.

Tronco castanho, castanho-avermelhado ou castanho-esbranquiçado, inteiramente acanalado. Raízes digitadas, geralmente simples, aresta côncava, a=b ou a>b, a=30$70 \mathrm{~cm}, \mathrm{~b}=30-45 \mathrm{~cm}, 12-24 \mathrm{~cm}$ espessura. Casca do tronco lenticelada, com lenticelas discolores, castanho-escuro, verrucosas, descamantes, abertura linear em todas as direções ou estrelada, arredondadas, pequenas e médias, distribuição irregular, numerosas. Matriz áspera, com microfissuras. Pode apresentar descamação em placas lenhosas, irregulares a arredondadas, afinadas nas bordas, 3 $5 \mathrm{~cm}$ diâm, justapostas; superfície plana, lenticelada, impressão em depressões justapostas. Casca da crista da raiz lenticelada, semelhante à casca do tronco, rugoso ou com ondulações justapostas, $0,5-1,0 \mathrm{~cm}$ larg. Raiz superficial lenticelada como a casca do tronco.

\section{DICAS DE CAMPO}

Tronco inteiramente acanalado com casca castanho-avermelhada ou castanhoesbranquiçada com lenticelas discolores, castanho-escuras. Com formações de ramos baixos. 


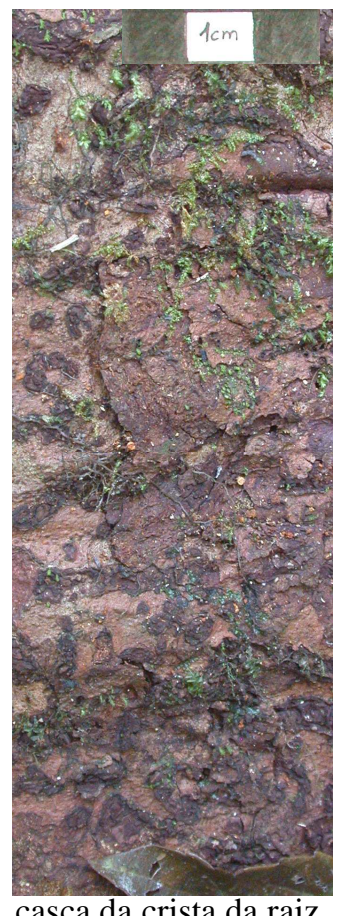

casca da crista da raiz

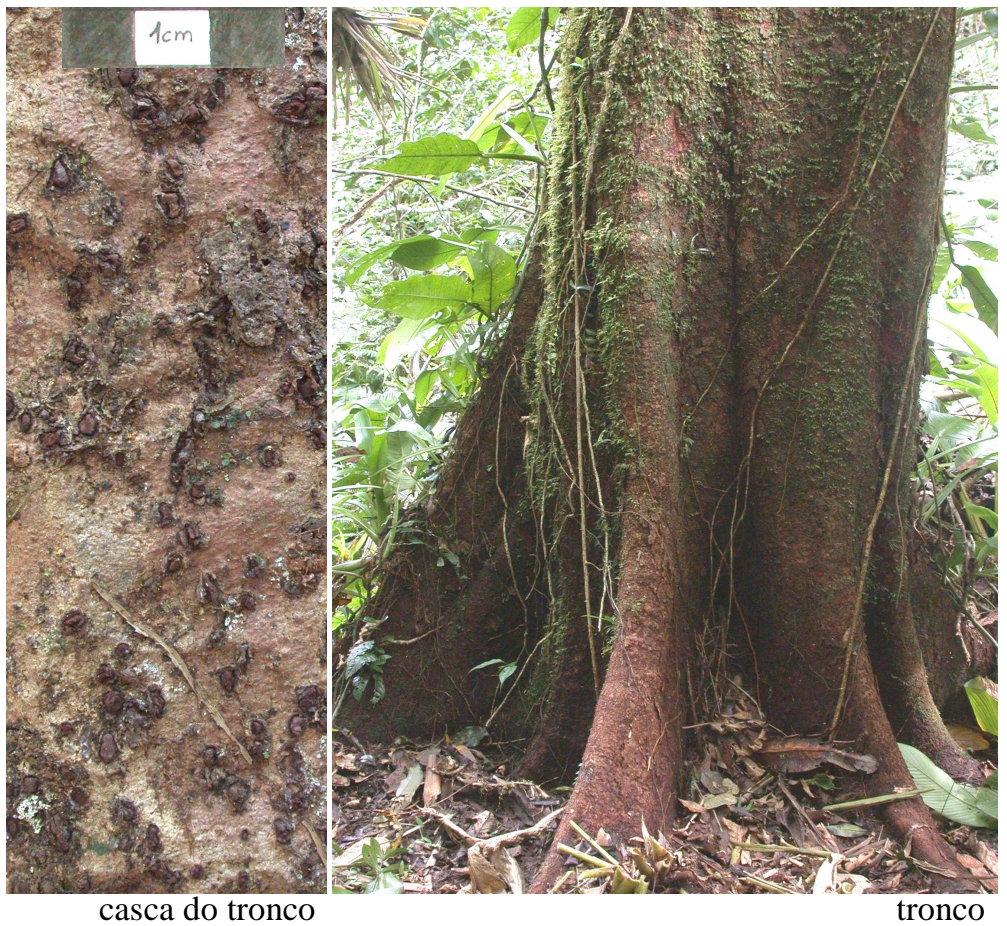

Simira corumbensis 


\section{SALICACEAE}

\section{Casearia obliqua Spreng.}

Tronco castanho bem claro (bege), cilíndrico. Pode apresentar cicatrizes proeminentes, elípticas, transversais, $23-25 \mathrm{~cm}$ compr., 9-10cm larg., 3-4cm espessura. Raízes com sapopemas simples, aresta côncava, a>b, a=68-140cm, $\mathrm{b}=44-130 \mathrm{~cm}, 7-10 \mathrm{~cm}$ espessura. Casca do tronco áspera, com lenticelas muito pouco evidentes, arredondadas, pequenas, justapostas, numerosas. Pode descamar em placas lenhosas, irregulares, longitudinais, $2-10 \mathrm{~cm}$ compr., 1,0-3,5cm larg., 1$3 \mathrm{~mm}$ espessura; superfície e impressão áspera. Casca da raiz áspera, com lenticelas, pouco evidentes, arredondadas, pequenas, justapostas, numerosas. Cascas da crista da raiz rugosa e áspera como a casca do tronco. Casca da raiz superficial esbranquiçada, com lenticelas discolores, castanhas, arredondadas, justapostas, em agrupamentos, e alongadas, pequenas, numerosas.

\section{DICAS DE CAMPO}

Diferencia-se das outras espécies que apresentam casca do tronco com textura áspera por lenticelas pouco evidentes, justapostas por não apresentar ondulações agudas. 


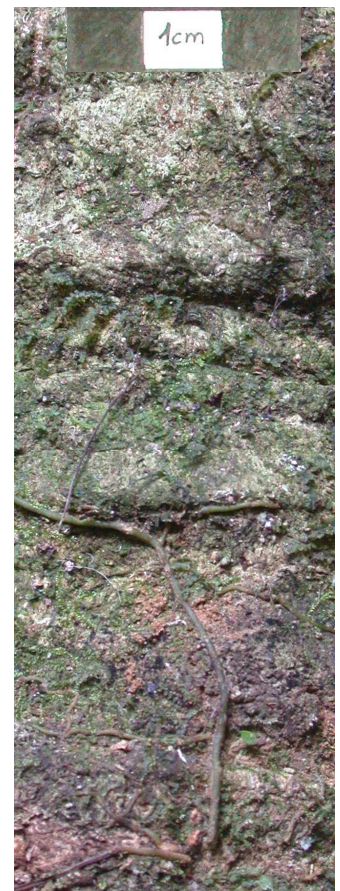

casca da crista da raiz

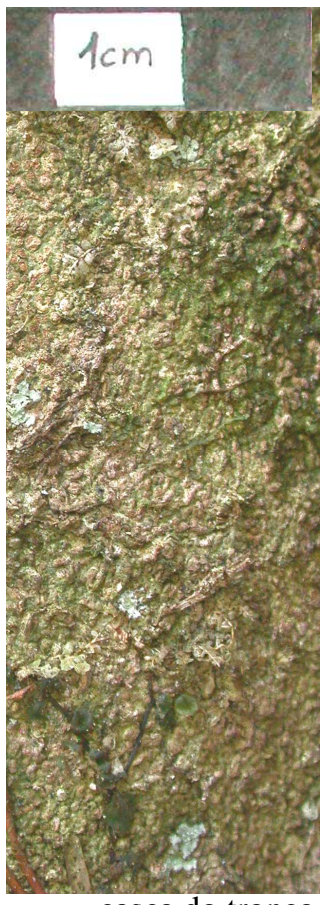

casca do tronco

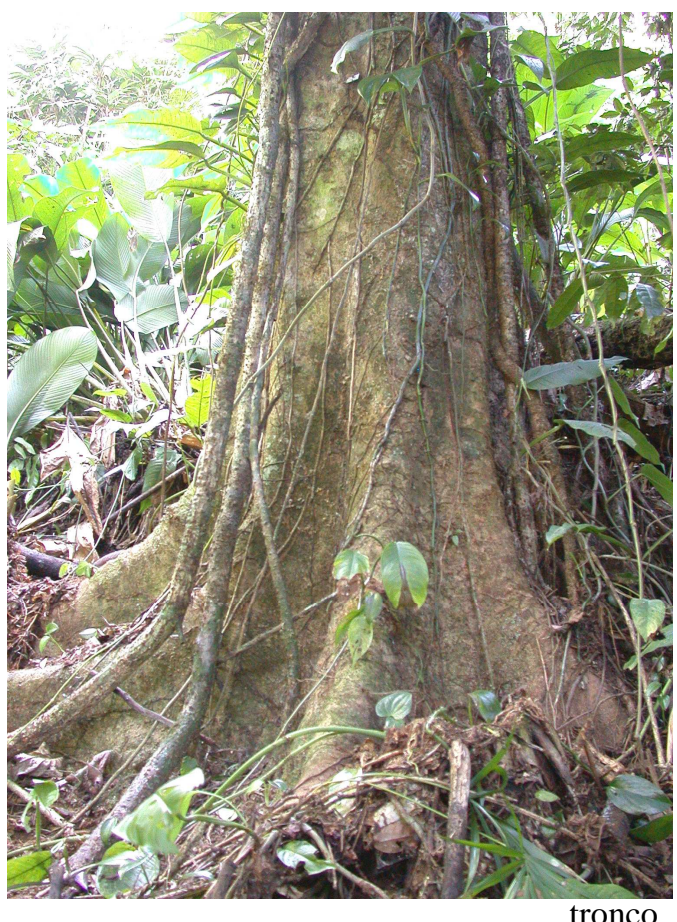

Casearia obliqua 


\section{SAPOTACEAE}

Chrysophyllum viride Mart. \& Eichl.

guiné

Tronco cinza-escuro a cinza-claro, acanalado. Raízes digitadas, simples ou ramificadas, aresta côncava, geralmente $a<b, a=60-75 \mathrm{~cm}, b=66-130 \mathrm{~cm}, 20-40 \mathrm{~cm}$ espessura. Raízes superficiais abundantes. Casca do tronco áspera, podendo apresentar lenticelas pouco evidentes, arredondadas a elíptico-longitudinais, pequenas, associadas a microfissuras, esparsas ou numerosas. Pode apresentar depressões circulares, 1-3cm diâm., 4-8mm profundidade, esparsas ou em aglomerações de $0-1,5 \mathrm{~cm}$ distância entre as depressões. Casca da crista da raiz com ondulações transversais, justapostas, $1,0-1,5 \mathrm{~cm}$ larg., na região proximal. Casca da raiz superficial cinza-escuro, lenticelada, com lenticelas discolores, castanho-claras, verrucosas, fixas, arredondadas, pequenas, elípticas e lineares longitudinais, grandes, em linhas longitudinais, numerosas.

\section{DICAS DE CAMPO}

Casca da crista da raiz proximal com grandes ondulações transversais. Casca das raízes superficiais cinza-escura com lenticelas castanho-claras (seta). 


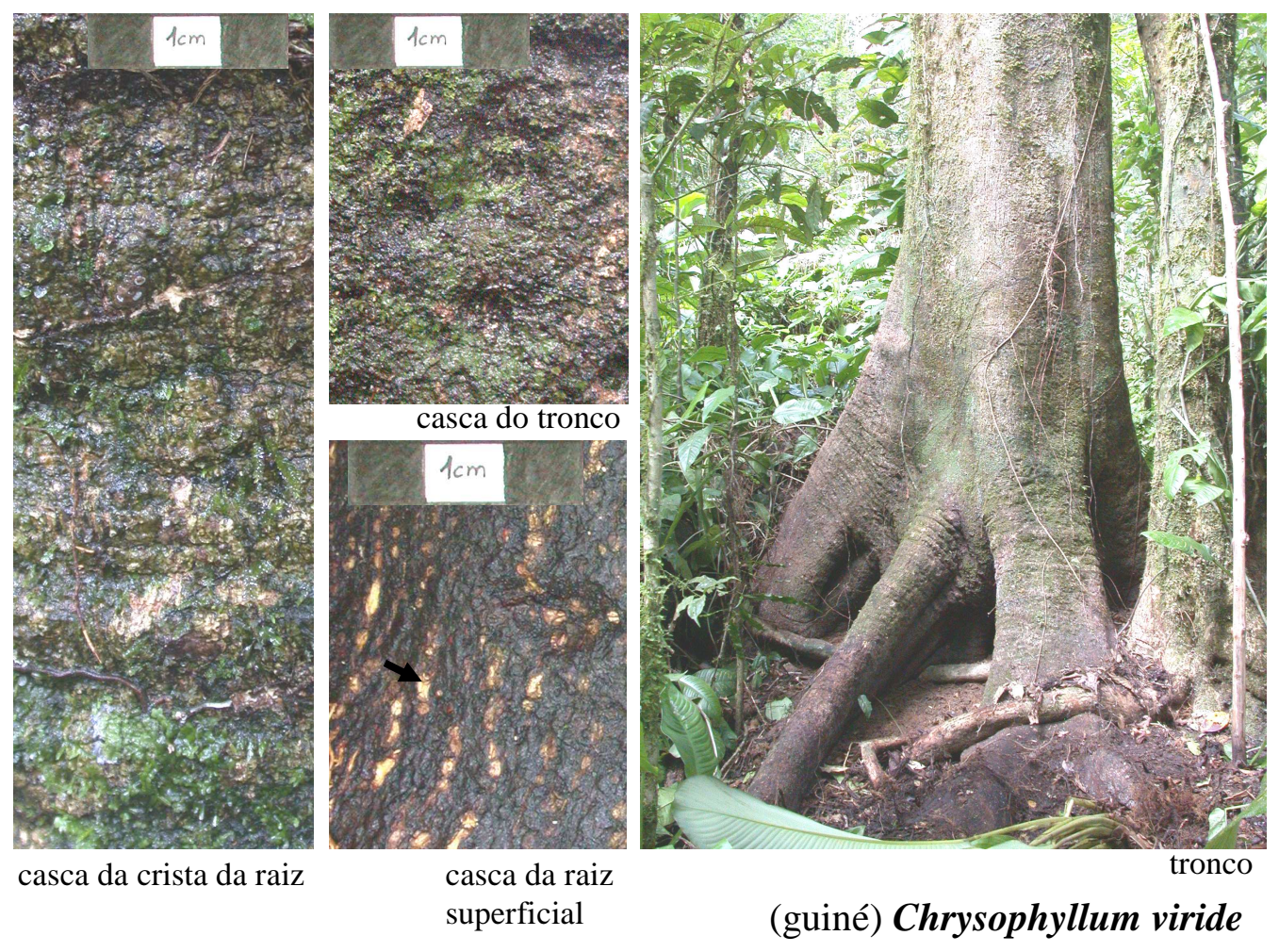




\section{SAPOTACEAE}

\section{Pouteria caimito (Ruiz \& Pav.) Radlk.}

embuia

Tronco castanho a castanho avermelhado, acanalado. Raízes digitadas, simples, aresta reta, $a>b, a>160 \mathrm{~cm}, b=30-40 \mathrm{~cm}$, ou com sapopemas, aresta reta ou côncava, $a=b=90-110 \mathrm{~cm}$. Casca do tronco com domos lineares, longitudinais, $13-27 \mathrm{~cm}$ compr., 1,3-2cm larg., 2-5mm espessura; superfície plana, áspera. Delimitação longitudinal por fendas, 16-40 cm compr., 3-4mm larg., 2-5mm profundidade. Delimitação transversal por fissuras 1,3-2cm compr., 1-2mm larg., 1-3mm profundidade. Casca do vale do tronco com placas de desprendimento, irregulares, longitudinais, 15-30cm compr., 3-14cm larg., 1-2mm espessura, 0-5cm distância; superfície áspera; impressão com fissuras longitudinais 7-15cm compr., 1-2mm larg., 1-2mm profundidade, 0,5-1,8cm distância. Impressão áspera. Casca da crista do tronco filete, com domos longitudinais, mais estreitos que na casca do tronco.

\section{DICAS DE CAMPO}

Casca do tronco com domos lineares, longitudinais que se tornam mais estreitos na crista do tronco. 


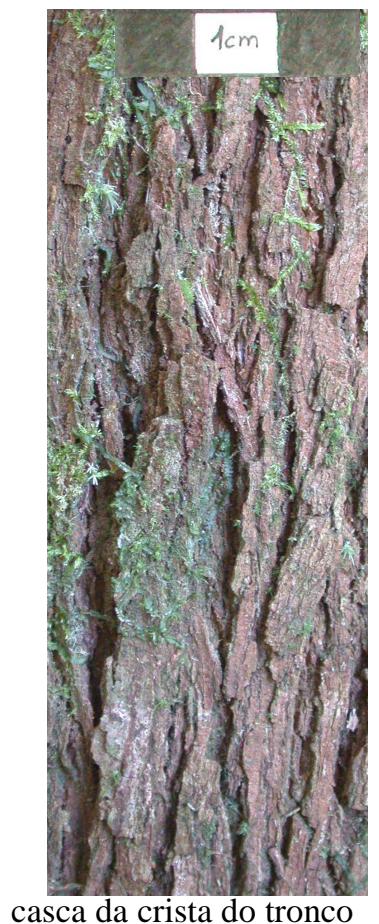

casca da crista do tronco

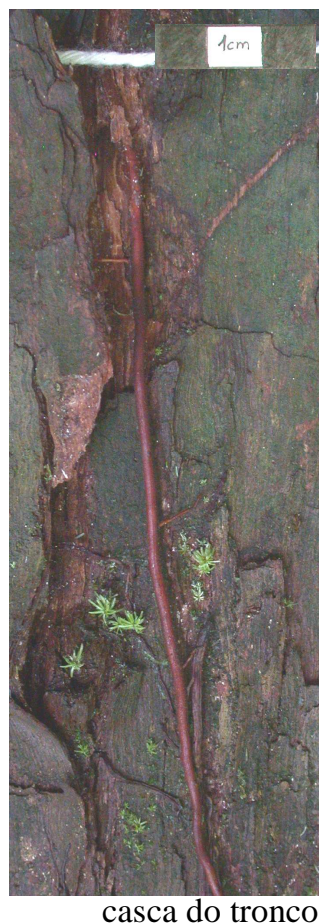

casca do tronco

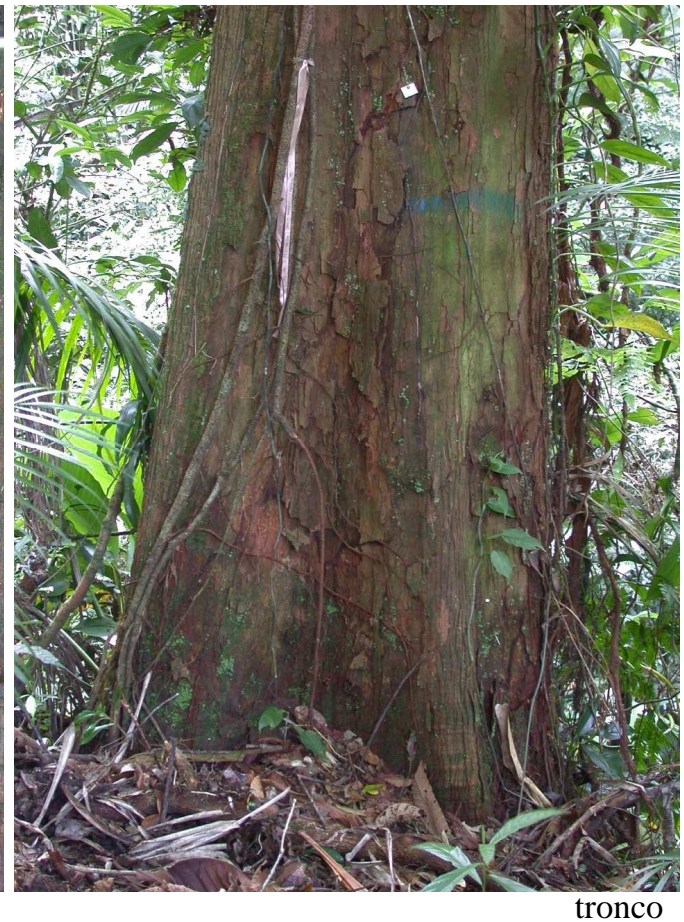

(embuia) Pouteria caimito 


\section{URTICACEAE}

Coussapoa microcarpa (Vell.) Radlk.

Tronco castanho, cilíndrico, levemente digitado. Envolvendo hospedeira. Casca do tronco lenticelada, com lenticelas verrucosas, descamantes, abertura em espocação, arredondadas, pequenas, e elípticas, geralmente longitudinais, grandes, com distribuição irregular ou em linhas longitudinais, numerosas. Casca da raiz superficial lenticelada e rugosa, com lenticelas discolores, castanho-claras, ou da cor da casca, verrucosas, fixas, abertura em espocação para lenticelas arredondadas, pequenas, e abertura linear para lenticelas elípticas e lineares longitudinais, grandes, numerosas.

\section{DICAS DE CAMPO}

Freqüentemente sobre hospedeira. Casca do tronco com numerosas lenticelas não nitidamente agrupadas ou em linhas longitudinais. Apresenta nervura em forma de "V" na base da folha (seta). 


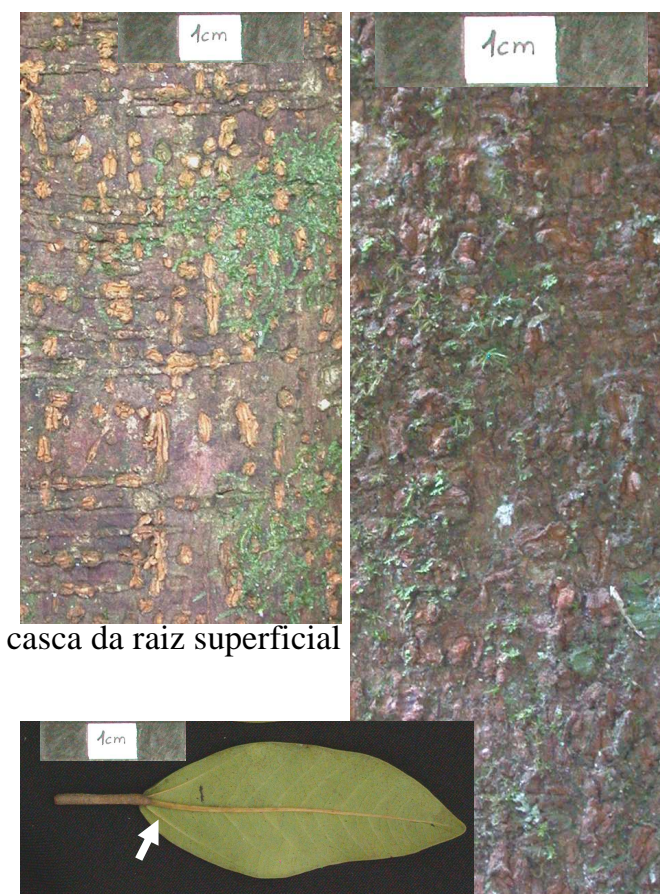

folha (face inferior) casca do tronco

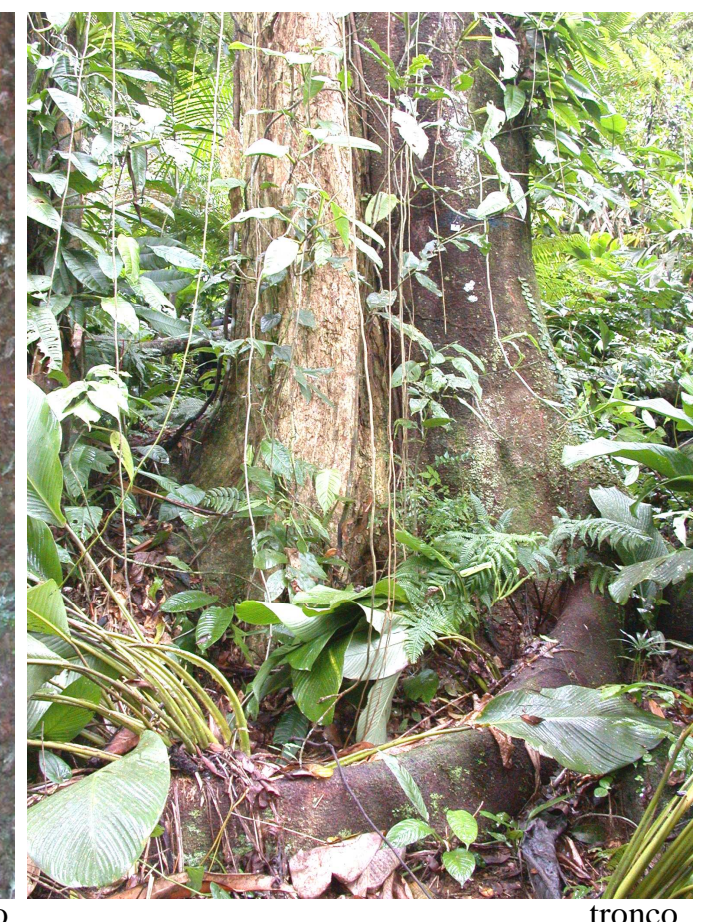

Coussapoa microcarpa 